

Assinatura:

\section{Caroline Viezel}

\section{Solução numérica do modelo Oldroyd-B para valores pequenos da razão de viscosidades: aplicação em escoamentos com superfícies livres}

\footnotetext{
Tese apresentada ao Instituto de Ciências Matemáticas e de Computação - ICMC-USP, como parte dos requisitos para obtenção do título de Doutora em Ciências - Ciências de Computação e Matemática Computacional. VERSÃO REVISADA

Área de Concentração: Ciências de Computação e Matemática Computacional

Orientador: Prof. Dr. Murilo Francisco Tomé
} 
Ficha catalográfica elaborada pela Biblioteca Prof. Achille Bassi e Seção Técnica de Informática, ICMC/USP, com os dados inseridos pelo(a) autor(a)

Viezel, Caroline Solução numérica do modelo oldroyd-B para valores pequenos da razão de viscosidades: aplicação em escoamentos com superfícies livres / Caroline Viezel; orientador Murilo Francisco Tomé. -- São Carlos, 2020 .

$129 \mathrm{p}$.

Tese (Doutorado - Programa de Pós-Graduação em Ciências de Computação e Matemática Computacional) -Instituto de Ciências Matemáticas e de Computação, Universidade de São Paulo, 2020.

1. Escoamentos viscoelásticos. 2. Superfície livre. 3. UCM. 4. Oldroyd-B. 5. Diferenças finitas. I. Tomé, Murilo Francisco, orient. II. Título. 


\section{Caroline Viezel}

\section{Numerical solution of the Oldroyd-B model for small values of the viscosity ratio: application to free surface flows}

Thesis submitted to the Institute of Mathematics and Computer Sciences - ICMC-USP - in accordance with the requirements of the Computer and Mathematical Sciences Graduate Program, for the degree of Doctor in Science. FINAL VERSION

Concentration Area: Computer Science and Computational Mathematics

Advisor: Prof. Dr. Murilo Francisco Tomé 

Esta tese é dedicada aos melhores e verdadeiros: minha família e amigos! 

Primeiramente quero agradecer todo apoio, compreensão e torcida da minha família que incentivaram e deram todo suporte possível para a concretização dessa meta. Obrigada pela confiânça!

Agradeço ao meu orientador Professor Dr. Murilo Francisco Tomé pelos ensinamentos, paciência, troca de experiências e direcionamento no desenvolvimento deste trabalho. Também sou grata a todos os professores que direta ou indiretamente participaram em todo o processo de minha formação em especial a Professora Dra. Gilcilene Sanchez de Paulo que me iniciou na área de matemática computacional.

Ao ICMC-USP agradeço todo apoio de funcionários e equipe técnica, além de toda infraestrutura proporcionada para a realização deste trabalho.

Agradeço também, a colaboração de amigos, em especial minhas amigas Crislaine e Franciane e ao futuro engenheiro Mateus, pelo suporte e conselhos nos momentos difíceis e pelo compartilhamento de muitos momentos alegres. A minha amiguinha Débora agradeço pelas conversas, momentos de descontração e dicas de vinhos. Agradeço a companhia de colegas e amigos do laboratório LMACC durante o período do meu doutorado.

Quero deixar meus agradecimentos, ao Coral da USP São Carlos, em especial ao maestro Sergio Alberto de Oliveira (USP - Ribeirão), monitores e as contraltos maravilhosas com os quais compartilhei momentos de descontração, muito aprendizado e cantoria.

O presente trabalho foi realizado com apoio da Coordenação de Aperfeiçoamento de Pessoal de Nível Superior - Brasil (CAPES) - Código de Financiamento 001 e o suporte do cluster Euler financiado pela Fundação de Amparo a Pesquisa do Estado de São Paulo (No. 2013/07375-0) (CEPID-CeMEAI). 

"Para nós os grandes homens não são aqueles que resolveram os problemas, mas aqueles que os descobriram." (Albert Schweitzer) 



\section{RESUMO}

VIEZEL, C. Solução numérica do modelo Oldroyd-B para valores pequenos da razão de viscosidades: aplicação em escoamentos com superfícies livres. 2020. 129 p. Tese (Doutorado em Ciências - Ciências de Computação e Matemática Computacional) - Instituto de Ciências Matemáticas e de Computação, Universidade de São Paulo, São Carlos - SP, 2020.

Esse trabalho trata do desenvolvimento de um método numérico para simular escoamentos axissimétricos com superfícies livres modelados pela equação constitutiva Oldroyd-B. Uma nova metodologia utilizando o método de diferenças finitas para resolver as equações governantes de escoamentos de fluidos Oldroyd-B em que o parâmetro $\beta$ pode assumir valores no intervalo $[0,1]$ é proposta. Assim, fazendo $\beta=0$, esta técnica permite simular escoamentos de fluidos puramente elásticos governados pela equação constitutiva Upper Convected-Maxwell (UCM). Nessa nova estratégia, o tensor tensão extra é calculado em função do tensor conformação que é aproximado implicitamente pelo método de diferenças finitas cujas equações são resolvidas analiticamente. Para obter a solução da equação de conservação de quantidade de movimento e as condições de contorno na superfície livre, emprega-se uma transformação Elastic Viscous Stress Splitting (EVSS) que evita instabilidades numéricas quando $\beta$ é pequeno. O código numérico é verificado utilizando uma solução analítica para escoamentos axissimétricos em um tubo e também, comparando resultados obtidos na literatura para os escoamentos "impacting drop", "inchamento do extrudado" e "inchamento retardado do extrudado" de fluidos Oldroyd-B. Novos resultados desses escoamentos são apresentados utilizando o modelo UCM e resultados originais obtidos da simulação dos escoamentos "bouncing drops" e "inchamento retardado do extrudado" de fluidos UCM são incluídos; os resultados existentes são decorrentes de modelos viscoelásticos com adição de solventes, como por exemplo, Oldroyd-B, Phan-Thien-Tanner (PTT), FENE-P (Finitely Extensibility Nonlinear Elastic), entre outros.

Palavras-chave: Escoamentos viscoelásticos, Superfície livre, UCM, Oldroyd-B, Diferenças finitas. 



\section{ABSTRACT}

VIEZEL, C. Numerical solution of the Oldroyd-B model for small values of the viscosity ratio: application to free surface flows. 2020. 129 p. Tese (Doutorado em Ciências - Ciências de Computação e Matemática Computacional) - Instituto de Ciências Matemáticas e de Computação, Universidade de São Paulo, São Carlos - SP, 2020.

This work deals with the development of a numerical method to simulate axisymmetric free surface flows governed by the constitutive equation Oldroyd-B. A methodology employing the finite difference method to solve the governing equations for axisymmetric free surface flows of Oldroyd-B fluids where the parameter $\beta$ covers the interval $[0,1]$ is proposed. Thus, this new methodology allows the numerical solutions of the Oldroyd-B model which involves a solvent viscosity $(\beta>0)$ and purely elastic flows described by the Upper Convected-Maxwell (UCM) $(\beta=0)$. Moreover, in this approach the extra-stress tensor is combined with the conformation tensor which is approximated implicitly by finite differences which are solved exactly. The momentum equations coupled with the free surface stress conditions are solved using an Elastic Viscous Stress Splitting (EVSS) transformation: this avoid numerical instabilities that can appear when $\beta$ is small. This new technique is verified by an analytic solution for tube flows and also by comparing results from the literature obtained for the flows "impacting drop", "dieswell" and "delayed dieswell" using the Oldroyd-B model. New results for "bouncing drops", "dieswell" and "delayed dieswell" using the UCM model are presented. The existing studies for these flows involve constitutive models that employs solvent viscosities such as Oldroyd-B, Phan-ThienTanner (PTT) and Finitely Extensibility Nonlinear Elastic (FENE-P) models.

Keywords: Viscoelastic flows, Free surface, UCM, Oldroyd-B, Finite differences. 



\section{LISTA DE ILUSTRAÇÕES}

Figura 1 - Diagrama apresentado por Delvaux e Crochet (1990) que identifica os valores do número de Reynolds $(R e)$ e $W i$ utilizados nos experimentos de Joseph, Matta e Chen (1987). . . . . . . . . . . . . . . . . . . . . . . . . . 34

Figura 2 - Representação dos tipos de fronteiras. . . . . . . . . . . . . . . 40

Figura 3 - (a) Malha deslocada; (b) Representação da superfície livre por spline linear; (c) Exemplo de classificação das células. . . . . . . . . . . . . . . .

Figura 4 - (a) Movimento da superfície livre (curva azul) perto de uma parede sólida (linha marron); velocidades mostradas na cor marron são calculadas pela condição de contorno de não-escorregamento enquanto que as velocidades na cor verde são calculadas pelas condições de contorno na superfície livre (ver Equação 2.15b) e a equação de conservação de massa. As velocidades marcadas pelos símbolos na cor preta são obtidas pela solução das equações de conservação de quantidade de movimento e conservação de massa. (b) Representação ilustrativa do cálculo das velocidades em células de superfície livre (as velocidades na cor verde) e aplicação das condições de superfície livre, Equação 2.15b. . . . . . . . . . . . . . . . . . . . . . . 46

Figura 5 - (a) Descrição do domínio do escoamento e (b) domínio computacional. . . . 48

Figura 6 - Comparação da componente $\tau^{z z}(r)$ com a solução analítica para o escoamento no tubo. Esses resultados foram obtidos $\operatorname{com} \beta=0.1,0.01,0.001$. . . . .

Figura 7 - Comparação de (a) $w(r)$ e (b) $\tau^{r z}(r)$ com a respectiva solução exata no tubo. Esses resultados foram obtidos com $\beta=0.001$ nas malhas $\mathrm{M}_{1}, \mathrm{M}_{2}$ e $\mathrm{M}_{3}$. . 50

Figura 8 - Erros referente ao escoamento no tubo. Resultados obtidos $\operatorname{com} \beta=0.001$ nas malhas $\mathrm{M}_{1}, \mathrm{M}_{2}$ e $\mathrm{M}_{3} \ldots \ldots \ldots \ldots \ldots$

Figura 9 - Simulação do impacto da gota. (a) Visualização 3D do estado incial; (b) domínio computacional; (c) células de referência. . . . . . . . . . . . . 52

Figura 10 - Simulação do impacto de uma gota em um disco. $R e=5, W i=1, \beta=0.1$.

(a) Refinamento de malha; (b) Comparação com resultados de outros autores.

Os resultados deste trabalho foram obtidos na malha M4 . . . . . . . . . . 53

Figura 11 - Simulação do impacto da gota em um disco $\operatorname{com} R e=5$ e variando $\beta$ : (a) $W i=1$, (b) $W i=20 \ldots \ldots \ldots \ldots \ldots$

Figura 12 - Simulação de uma gota espalhando sobre um disco - $R e=5, \beta=0.01 \mathrm{e}$ $W i=1$ e 20, nos tempos selecionados. Gráficos de contornos da velocidade $u$. Coluna à esquerda: $W i=1$, coluna à direita: $W i=20 . \ldots \ldots 6$ 
Figura 13 - Variação das velocidades $u(t)$ e $w(t)$ na célula $(1,10)$ identificada na Figura 9c. (a) $W i=1$; (b) $W i=20$. A descontinuidade nas velocidades se deve ao fato de que a célula $(1,10)$ torna-se vazia de fluido ao longo do intervalo de tempo $[2.78,4.2] \ldots \ldots \ldots \ldots \ldots \ldots$

Figura 14 - Visualização 3D em três tempos selecionados da simulação numérica do salto da gota para $W i=1, \beta=0.01$ e diferentes valores de $R e$. . . . . . . .

Figura 15 - Animações variando $R e$ - Clique PLAY para iniciar e PAUSE para interromper. Para executar o vídeo é necessário visualizar o arquivo PDF, disponiblizado no banco de teses da USP < https://www.teses.usp.br/>, com o programa ADOBE READER. . . . . . . . . . . . . . . . . . . . . .

Figura 16 - Campo de velocidade em três instantes distintos para o escoamento da gota com $W i=1, \beta=0.01$ e diferentes valores do número de Reynolds. . . . . .

Figura 17 - Primeira diferença de tensões normais $N_{1}=\tau^{z z}-\tau^{r r}$ para diferentes valores do número de Reynolds nos tempos $t=1.8,2.2,3.4$. Simulação do impacto da gota $\operatorname{com} \beta=0.01$ e $W i=1.0 \ldots \ldots \ldots$. . . . . . . .

Figura 18 - (a) Variação temporal de $N_{1}(t)$ na célula $(1,1)$ da Figura 9c para $W i=1$, $\beta=0.01$ e diferentes valores do número de Reynolds. (b) Ampliação dos resultados na região $[1,3] \times[-1.25,1] \ldots \ldots \ldots$

Figura 19 - Visualização 3D em três tempos específicos da simulação numérica do salto da gota para $W i=1, R e=0.25$ e diferentes valores de $\beta$. . . . . . .

Figura 20 - Animações variando $\beta$ - Clique PLAY para iniciar e PAUSE para interromper. Para executar o vídeo é necessário visualizar o arquivo PDF, disponiblizado no banco de teses da USP <https://www.teses.usp.br/>, com o programa ADOBE READER . . . . . . . . . . . . . . . . . . . . . .

Figura 21 - Alturas dos saltos da gota para $W i=1.0$ : (a) $\beta=0.01$ e variando $R e$; (b) $R e=0.25$ variando a razão de viscosidades $\beta \ldots$. . . . . . . . . . . 64

Figura 22 - Variação de $\mathbf{h}_{\max }$ como função do número de (a) Weissenberg e (b) Reynolds. 65

Figura 23 - Variação temporal de $d_{r}(t) / d_{z}(t)$. (a) $R e=0.25, \beta=0.01$ e diferentes valores de Weissenberg. (b) $W i=1.0, \beta=0.01$ e diferentes valores de Reynolds. .

Figura 24 - Variação das alturas máximas do salto $\mathbf{h}(\mathbf{t})$ da gota como função dos números de Reynolds e Weissenberg. (a) $W i=1.0$ fixo, variando $\beta$ e $R e$, (b) $R e=0.25$ fixo, variando $\beta$ e Wi. . . . . . . . . . . . . . . .

Figura 25 - Descrição do problema do inchamento retardado do extrudado. (a) Representação axissimétrica do problema. (b) Resultado experimental apresentado por Giesekus (1969).

Figura 26 - (a) Visualização tridimensional do inchamento do extrudado; (b) Representação do domínio computacional; (c) Descrição do domínio computacional utilizado nas simulações do inchamento do extrudado. . . . . . . . . . . . . 
Figura 27 - Simulação do inchamento do extrudado em diferentes malhas: (a) $w\left(0.5 \delta r, z_{j}\right)$ e (b) $N_{1}\left(0.5 \delta r, z_{j}\right)$. Resultados obtidos nas malhas M10, M15, M20, M25, e M30. . . . . . . . . . . . . . . . . . . . . .

Figura 28 - Superfícies livres obtidas em cada malha. Resultados mostrados para $z \in$

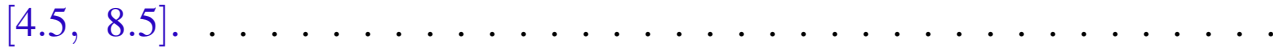

Figura 29 - Gráfico das superfícies livres das simulações do inchamento do extrudado para vários valores do recoverable shear na malha M25 com uma ampliação da região $[4.5,8.0] \times[0.6,1.8] \ldots \ldots \ldots 76$

Figura 30 - Comparação das taxas de inchamento $S_{r}=d_{e x} / d_{0}$ para $S_{\lambda} \in[0,4.0] \ldots$

Figura 31 - Comportamento da velocidade $w$ na direção próximo ao (a) eixo de simetria e (b) parede interna do tubo. . . . . . . . . . . . . . . . . . . . . 78

Figura 32 - Localização no domínio computacional das linhas de impressão da velocidade e tensões. (a) Próximo ao eixo de simetria. (b) Adjacente a parede interna do tubo.

Figura 33 - Descrição do domínio computacional para o problema do inchamento retardado do extrudado.

Figura 34 - Comparação da taxa de inchamento $d_{e x} / d_{0}$ calculada em diferentes malhas com resultados apresentados por Delvaux e Crochet (1990) obtidos utilizando a malha III.

Figura 35 - Comparação das distâncias de retardamento $l_{d} / d_{0}$ calculadas em diferentes malhas com resultados na malha MIII apresentados por Delvaux e Crochet

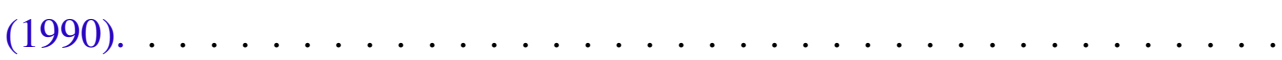

Figura 36 - Comparação entre escoamento newtoniano, viscoelástico com inércia e viscoelástico sem inércia obtidos por Delvaux e Crochet (1990). (a) Sobreposição das superfícies livres. Newtoniano: $W i=0$ e $R e=24.1$ (sem inchamento); viscoelástico com inércia: $W i=0.7$ e $R e=24.1$ (retardamento do inchamento); viscoelástico sem inércia: $W i=0.7$ e $R e=0$ (sem retardamento do inchamento). (b) Taxas de inchamento máximo do extrudado em função de Wi para escoamentos com e sem efeito de inércia. . . . . . . . . . .

Figura 37 - Comparação das superfícies livres dos escoamentos: newtoniano, com efeito de inércia e com Reynolds pequeno. . . . . . . . . . . . . . . . . .

Figura 38 - Comparação qualitativa entre as regiões subcríticas e supercríticas (região mostrada na cor escura) dos escoamentos do inchamento retardado do fluido Oldroyd-B ( $\beta=0.05$ ) para (a) $\mathrm{Ma}=2.3$ e (b) 5.9. Os resultados são comparados com os obtidos por Delvaux e Crochet (1990) (terceiro resultado da esquerda para direita) em (a) e (b) . . . . . . . . . . . . . . . 
Figura 39 - Regiões supercríticas e subcríticas do escoamento do inchamento retardado para diferentes valores de Ma e $E=0.03$. As regiões em cinza indicam escoamento supercrítico e as regiões em branco mostram as regiões de escoamento subcrítico. . . . . . . . . . . . . . . . . .

Figura 40 - Gráfico das superfícies livres do fluido Oldroyd-B $(\beta=5 \%)$ para diferentes valores de Ma e $\mathrm{E}=0.0375$. Uma ampliação da região $[2.75,6.0] \times[0.4,1.6]$ é apresentada abaixo. . . . . . . . . . . . . . .

Figura 41 - Resultados da taxa de inchamento e distância do retardamento do inchamento do fluido Oldroyd-B quando $\mathrm{E}=0.0375 \ldots$. . . . . . . . . . . .

Figura 42 - Linhas de corrente do campo de velocidade para diferentes valores do número Mach e número de elasticidade $\mathrm{E}=0.0375 \ldots$. . . . . . . . . . . . . .

Figura 43 - Taxas de inchamento $S_{r}$ obtidas variando $S_{\lambda}$. Comparação dos resultados nas malhas M10, M15 e M20 com a Lei de Tanner. . . . . . . . . . . . . . . . .

Figura 44 - Curvas da superfície livre do fluido UCM obtidas no problema do inchamento do extrudado para vários valores de $S_{\lambda}$ na malha M20. O segundo gráfico apresenta uma visualização dos resultados na região $[2.75,5.0] \times[0.4,1.6]$.

Figura 45 - Solução numérica da velocidade $w$ próximo ao eixo de simetria, para diferentes valores de $S_{\lambda}$ na malha M20. . . . . . . . . . . . . . . .

Figura 46 - Solução numérica (a) do tensor $\tau^{r z}$ e (b) da primeira diferença de tensão normal $N_{1}$ do fluido UCM próximo a parede do tubo, para diferentes valores de $S_{\lambda}$ na malha M20. . . . . . . . . . . . . . . . .

Figura 47 - Representação do domínio computacional utilizado para comparação com resultados tridimensionais do problema inchamento retardado do extrudado.

Figura 48 - Resultados do inchamento atrasado do extrudado de fluidos tipo UCM, para diferentes valores de Re e Wi. (a) Comparação com as taxas de inchamento obtidas por Merejolli (2017) com código 3D. (b) Distância de atraso do inchamento. A linha tracejada em vermelho é uma interpolação linear utilizando os pares de pontos $\left(W i, l_{d}\right)$ em que $W i=0.5$ e $1.0 \ldots \ldots$. . . . . . .

Figura 49 - Comparação qualitativa com os resultados obtidos por Merejolli (2017) (3D) para o problema do inchamento retardado do extrudado utilizando os seguintes valores de Reynolds: $R e=30.0,35.0$ e 40.0. Resultados com fluido na cor amarelo claro foram obtidos pelo código desse trabalho, as visualizações de fluidos na cor amarelo escuro foram obtidas por Merejolli (2017). . . . . 96

Figura 50 - Superfícies livres do fluido UCM para $E=0.0350$ e diferentes valores de Ma. 99

Figura 51 - Taxa de inchamento e distância de retardamento do inchamento do fluido para vários valores de Ma e E. Os resultados obtidos com o fluido Oldroyd-B $(\beta=5 \%)$ também são plotados para comparação. . . . . . . . . . . . . .

Figura 52 - Regiões supercríticas $(\operatorname{sgn}(\xi)=1)$ e variação dos autovalores $\xi_{1}, \xi_{2}$ e $\xi_{3}$ do tensor $\mathrm{T}^{*}$. (a) $\mathrm{Ma}=1.3 \mathrm{e}$ (b) $\mathrm{Ma}=2.6 \ldots \ldots 100$ 
Figura 53 - Regiões supercríticas $(\operatorname{sgn}(\xi)=1)$ e variação dos autovalores $\xi_{1}, \xi_{2}$ e $\xi_{3}$ do tensor $\mathrm{T}^{*}$. (a) $\mathrm{Ma}=4.0$ e (b) $\mathrm{Ma}=5.3 \ldots \ldots 101$

Figura 54 - Regiões supercríticas $(\operatorname{sgn}(\xi)=1)$ e variação dos autovalores $\xi_{1}, \xi_{2}$ e $\xi_{3}$ do tensor $\mathrm{T}^{*}$. (a) $\mathrm{Ma}=6.6 \mathrm{e}$ (b) $\mathrm{Ma}=8.0 \ldots \ldots$. . . . . . . . . . . 102

Figura 55 - Superfícies livres do fluido UCM para diferentes valores E e Ma=4.0. . . . 103

Figura 56 - Validação qualitativa entre resultados numéricos obtidos pelo código axissimétrico e resultados experimentais de Joseph, Matta e Chen (1987): Ma=4.0 e $\mathrm{E}=0.035 \ldots \ldots \ldots \ldots$. . . . . . . . . . . . . . . . . 104

Figura 57 - Validação qualitativa entre resultados numéricos obtidos pelo código axissimétrico e resultados experimentais de Joseph, Matta e Chen (1987): Ma=4.3

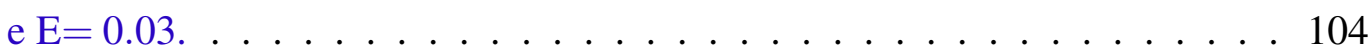

Figura 58 - Validação qualitativa entre resultados numéricos obtidos pelo código axissimétrico e resultados experimentais de Joseph, Matta e Chen (1987): Ma= 8.0 $\mathrm{e} \mathrm{E}=0.035 \ldots \ldots \ldots \ldots \ldots$. . . . . . . . . . . . . . . . . . . . . . . . .

Figura 59 - Validação qualitativa entre resultados numéricos obtidos pelo código axissimétrico e resultados experimentais de Joseph, Matta e Chen (1987): Ma=8.6

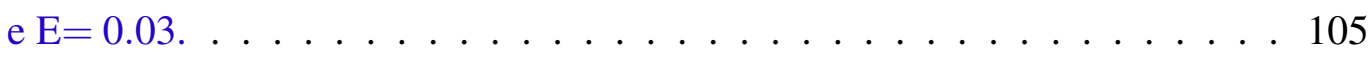

Figura 60 - Comparação de (a) $w(r)$; (b) $\tau^{z z}(r)$ e (c) $\tau^{r z}(r)$ obtidas nas malhas M10, M20, M30 e M40 com a respectiva solução exata obtida para o escoamento de Poisenille. . . . . . . . . . . . . . . . . . . . 128

Figura 61 - Decrescimento do erro como função do espaçamento da malha $\delta$ do escoamento de Poiseuille. . . . . . . . . . . . . . . . . . . . . . . . . . . . . 129 

Tabela 1 - Malhas utilizadas para simular o escoamento no tubo do fluido Oldroyd-B. . 48

Tabela 2 - Erros na norma $L_{2}$ entre as soluções exata e numéricas calculadas nas malhas $\mathrm{M}_{1}, \mathrm{M}_{2}$ e $\mathrm{M}_{3}$ variando $\beta \ldots \ldots \ldots \ldots$

Tabela 3 - Ordens de convergência obtidas com os erros determinados na norma $L_{2}$ para o escoamento no tubo com diferentes valores de $\beta$.

Tabela 4 - Dados de entrada (unidades SI) utilizadas na simulação do impacto da gota em uma placa rígida. . . . . . . . . . . . . . . . . 52

Tabela 5 - Malhas aplicadas na simulação do impacto da gota sobre uma superfície plana. 52

Tabela 6 - Valores de Re e $\beta$ utilizados nas simulações do fenômeno do salto da gota. . 58

Tabela 7 - Valores da altura máxima $\mathbf{h}(\mathbf{t})$ e o tempo associado $\mathbf{t}_{\max }$ dos saltos da gota. . 64

Tabela 8 - Números de Weissenberg e Reynolds utilizados nas simulações do salto da gota. . . . . . . . . . . . . . . . . . . 65

Tabela 9 - Dados utilizados nas simulações do salto da gota variando $\beta$, Re e Wi. . . . 67

Tabela 10 - Malhas utilizadas para simular o inchamento do extrudado. . . . . . . . . . 73

Tabela 11 - Valores do recoverable shear $S_{\lambda}$ e correspondente $W i=\lambda_{1}(L=U=1)$ calculados pela Equação 3.6 e aplicados nas simulações do inchamento do extrudado. . . . . . . . . . . . . . . . . 76

Tabela 12 - Valores de Ma utilizados para simular o inchamento retardado do extrudado e especificação das malhas empregadas. O valor do número de elasticidade $\mathrm{E}=0.03$ e $\beta=0.05$ foram mantidos fixos. Os valores de $\mathrm{Ma}, \mathrm{Re}$ e $W i$ mostrados abaixo são os mesmos utilizados por Delvaux e Crochet (1990). .

Tabela 13 - Valores de $\mathrm{Ma}=\sqrt{R e W i}$ utilizados para simular o inchamento retardado do extrudado com $\mathrm{E}=0.0375 \ldots \ldots \ldots$. . . . . . . . . . . 86

Tabela 14 - Valores de $S_{\lambda}$ e correspondente $W i=S_{\lambda} / 8$ e $\beta=0 \ldots \ldots$. . . . . . . 89

Tabela 15 - Valores de Re e Wi utilizados nas simulações do inchamento retardado do extrudado. . . . . . . . . . . . . . . . . . .

Tabela 16 - Valores dos números de Reynolds, Weissenberg, Mach e elasticidade utilizados para simular o inchamento retardado do extrudado de fluidos tipo UCM.

Tabela 17 - Resultados da distância de atraso $\left(l_{d}\right)$ e taxa de inchamento $\left(d_{e x}\right)$ para $\mathrm{Ma}=$ 4.0 fixo e números de elasticidade $\mathrm{E}=0.003,0.0350,0.0375$ e 0.04 . . . . . . 103

Tabela 18 - Malhas utilizadas para simular o escoamento de Poiseuille do fluido Oldroyd-B.128 
Tabela 19 - Erros adimensionais entre as soluções exata e numéricas calculadas nas malhas M10, M20, M30 e M40 do escoamento de Poiseuille. . . . . . . . . 129

Tabela 20 - Ordens de convergência obtidas no escoamento no tubo com $\beta=0.2$. . . 129 


\section{LISTA DE ABREVIATURAS E SIGLAS}

CUBISTA Bounded Interpolation Scheme for the Treatment of Advection

EVSS Elastic Viscous Stress Splitting

FENE-P Finitely Extensibility Nonlinear Elastic

HWNP The-high Weissenberg number problem

MAC Marker-and-Cell

Pom-Pom Extended Pom-Pom

PTT Phan-Thien-Tanner

R-K Runge-Kutta

SPH Smoothed Particle Hydrodynamics

UCM Upper Convected-Maxwell

VOF volume of fluid 

$\lambda$ — tempo de relaxação

$\mathbf{v}$ - vetor velocidade

g - campo gravitacional

$p$ - pressão

$\rho$ - densidade

$\tau-$ tensor tensão extra

D — tensor taxa de deformação

$\lambda_{1}$ - tempo de relaxação do fluido Oldroyd-B

$\lambda_{2}$ - tempo de retardamento do fluido Oldroyd-B

$\eta_{0}$ - viscosidade total do fluido

$\tau_{P}$ - tensor polimérico

$\eta_{S}$ - viscosidade do solvente

$\eta_{P}$ - viscosidade do polímero

$\beta$ - taxa de viscosidades do fluido Oldroyd-B

A - tensor conformação

I - tensor identidade

$\mathbf{S}$ - tensor não-newtoniano

$\boldsymbol{\sigma}$ - tensor tensão total

Re — número de Reynolds

$W i$ — número de Weissenberg

$\mathrm{Fr}$ — número de Froude

$L$ - escala de comprimento

$U$ — escala de velocidade: velocidade média ou velocidade inicial

$g$ - força da gravidade: $-9.81 \mathrm{~ms}^{-2}$

$R$ - raio do tubo 
$d_{0}$ — diâmetro inicial da gota

$N_{1}$ — primeira diferença de tensões normais

Ma - número de Mach viscoelástico

$c$ — velocidade da onda de cisalhamento

E - número de elasticidade

$\mathbf{T}^{*}$ — tensor que define as regiões subcríticas e supercríticas

$d_{e x}$ - diâmetro máximo do jato

$S_{r}$ - taxa de inchamento

$S_{\lambda}-$ recoverable shear

$l_{d}$ — distância do retardamento do extrudado 
INTRODUÇÃO . . . . . . . . . . . . . . . . . . . 29

$1.1 \quad 0$ fenômeno do salto de uma gota . . . . . . . . . . . . 31

$1.2 \quad 0$ fenômeno do inchamento retardado do extrudado . . . . . . . . 32

$1.3 \quad$ Objetivos e motivação . . . . . . . . . . . . . . . 35

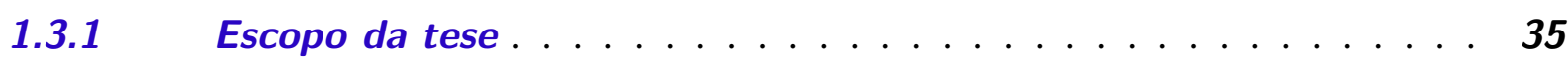

2 SOLUÇÃO DO MODELO OLDROYD-B PARA $0 \leq \beta \leq 1 \ldots$. . . . 37

2.1 Equações governantes . . . . . . . . . . . . . 37

$2.2 \quad$ Condições de contorno . . . . . . . . . . . . . . . 39

2.2.1 Condições de tensão na superfície livre . . . . . . . . . . . . . 40

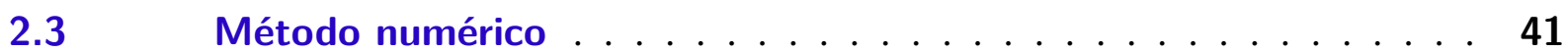

2.3.1 Algoritmo numérico . . . . . . . . . . . . . . . . 42

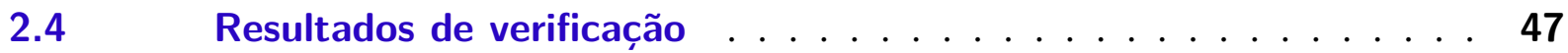

2.4.1 Escoamento laminar desenvolvido no tubo . . . . . . . . . . . 47

2.4.2 Simulação do impacto de uma gota viscoelástica sobre uma placa plana . . . . . . . . . . . . . . . . . . . 51

$2.5 \quad$ Impacto da gota sobre uma placa plana: novos resultados . . . . . 53

$2.6 \quad$ Estudo do salto da gota . . . . . . . . . . . . . . 57

2.6.1 Estudo do efeito dos números de Reynolds e Weissenberg no salto da gota . . . . . . . . . . . . . . . . . 64

3 SIMULAÇÃO DO INCHAMENTO RETARDADO DO EXTRUDADO 69

3.1 Simulação do inchamento do extrudado de fluidos Oldroyd-B . . . 71

3.1.1 Refinamento de malha . . . . . . . . . . . . . . . . . . 72

3.1.2 Comparação com resultados da literatura . . . . . . . . . . . . . . 75

3.2 O problema do inchamento retardado do extrudado: fluido Oldroyd-B 79

3.2.1 Comparação com resultados da literatura . . . . . . . . . . . . . 79

3.2.2 Inchamento retardado do extrudado para $E=0.0375 \ldots \ldots$. . . . 85

3.3 Inchamento retardado do extrudado para o fluido UCM . . . . . . 88

3.3.1 Inchamento do extrudado . . . . . . . . . . . . . . . . 89

3.3.2 Resultados de verificação . . . . . . . . . . . . . . . . 92

3.3.3 Efeito do número de Mach viscoelástico . . . . . . . . . . . . 97

3.3.4 Efeito do número de elasticidade $E \ldots \ldots$. . . . . . . . . . 103 
4 CONSIDERAÇÕES FINAIS . . . . . . . . . . . . . 107

$4.1 \quad$ Produção científica . . . . . . . . . . . . 109

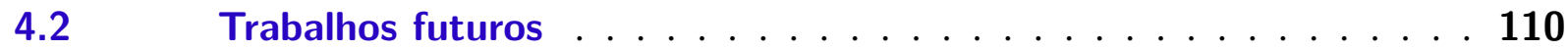

REFERÊNCIAS . . . . . . . . . . . . . . . . . . . 113

APÊNDICE A EQUAÇÕES ADIMENSIONAIS EM COORDENADAS CILÍNDRICAS . . . . . . . . . . . . . . . . 121

APÊNDICE B EQUAÇÕES DISCRETIZADAS . . . . . . . . 123

APÊNDICE C RESULTADOS COMPLEMENTARES: ESCOAMENTO NO TUBO . . . . . . . . . . . . . . . . . 127 


\section{1}

\section{INTRODUÇÃO}

O avanço tecnológico da computação científica e métodos computacionais para resolver equações diferenciais e integrais, tem motivado o estudo e desenvolvimento de métodos numéricos para simular fenômenos físicos existentes em processos industriais ou naturais. Muitos desses processos envolvem escoamentos complexos, como por exemplo, injeção em moldes, processos de extrusão, enchimento de containeres, entre muitos outros. Devido a essas aplicações, há grande interesse industrial e tecnológico no desenvolvimento de ferramentas computacionais para simular esses escoamentos, em particular aqueles que envolvem fluidos não-newtonianos. Fluidos com essa característica são complexos e não podem ser definidos por uma única equação constitutiva. Na literatura pode-se encontrar uma variedade de equações reológicas que foram desenvolvidas para descrever escoamentos de fluidos não-newtonianos.

Nas últimas décadas, vários modelos constitutivos diferenciais tem sido estudados, por exemplo, as equações constitutivas Upper Convected-Maxwell (UCM) (OWENS; PHILLIPS, 2002), Oldroyd-B (OLDROYD, 1950), Phan-Thien-Tanner (PTT) (TANNER, 1970), Giesekus (GIESEKUS, 1982), Extended Pom-Pom (Pom-Pom) (MCLEISH; LARSON, 1998; VERBEETEN; PETERS; BAAIJENS, 2001), entre outros. Em particular, os modelos UCM e Oldroyd-B tem sido extensivamente estudados por muitos autores empregando os métodos de elementos finitos, volumes finitos e diferenças finitas (veja por exemplo, Crochet e Keunings (1980), Crochet e Keunings (1982), Delvaux e Crochet (1990), Tomé et al. (2002), Bonito, Picasso e Laso (2006), Tomé et al. (2007), Tomé et al. (2008), Peng e Zhu (2011), Figueiredo et al. (2014), Xu et al. (2012), Jasak et al. (2007), Izbassarov e Muradoglu (2015), Izbassarov e Muradoglu (2016), Castillo, Baiges e Codina (2015), Xu e Deng (2016)). Esses modelos são capazes de descrever muitos fenômenos que ocorrem em escoamentos com superfícies livres. Além disso, do ponto de vista numérico, são os modelos mais difíceis de se resolver, especialmente se o escoamento contiver alta elasticidade.

A depender do escoamento, sua geometria e características, os métodos numéricos 
enfrentam dificuldades para obter soluções do sistema de equações que modelam o problema. Com relação a escoamentos viscoelásticos que envolvem superfícies livres, a dificuldade é consideravelmente maior, uma vez que o escoamento pode apresentar mudanças súbitas nas condições de contorno e consequentemente grandes variações no tensor tensão extra, o que pode resultar em instabilidades na superfície livre do fluido. O aumento da elasticidade do fluido, mais especificamente do número de Weissenberg - Wi definido por Fattal e Kupferman (2004) como a razão entre o tempo de relaxação $\lambda$ do fluido com a taxa de deformação local, provoca um aumento do divergente do tensor tensão extra, caracterizando um problema conhecido na literatura como o problema do alto número de Weissenberg (The-high Weissenberg number problem (HWNP)). Algumas técnicas numéricas foram desenvolvidas na tentativa de resolver esse problema e obter resultados para valores altos de Wi. Fattal e Kupferman (2004) e outros autores como Balci et al. (2011) e Afonso, Pinho e Alves (2012) se dedicaram a estudar a aplicação de transformações como a Logarítmica para resolver os modelos reológicos diferenciais (FATTAL; KUPFERMAN, 2005; CORONADO et al., 2007; AFONSO et al., 2009). Entretanto, esse ainda é um problema não resolvido totalmente, uma vez que essas técnicas conseguiram resolver bem problemas confinados até um determinado valor de $W i$, como por exemplo, o problema da tampa deslizante sobre uma cavidade (FATTAL; KUPFERMAN, 2005; HABLA et al., 2014; COMMINAL; SPANGENBERG; HATTEL, 2015; SOUSA et al., 2016), o escoamento do fluido passando ao redor de um cilíndro em um canal (HULSEN; FATTAL; KUPFERMAN, 2005; AFONSO et al., 2009; KANE; GUÉNETTE; FORTIN, 2009; DAMANIK et al., 2010; AFONSO; PINHO; ALVES, 2012; KNECHTGES; BEHR; ELGETI, 2014) e problemas em que o domínio é confinado e apresenta uma contração ou expansão (AFONSO et al., 2007; AFONSO et al., 2011; COMMINAL et al., 2016). No contexto de escoamentos com superfícies livres, as técnicas numéricas tem possibilitado considerar altos valores de $W i$ quando o escoamento não apresenta tensão de cisalhamento muito alta. Um dos problemas transientes com superfície livre que pode-se admitir valores razoavelmente altos para a constante de elasticidade é o escoamento do jato incidindo uma placa rígida (BONITO; PICASSO; LASO, 2006; PAULO; TOMÉ; MCKEE, 2007; TOMÉ et al., 2008; TOMÉ et al., 2010; FIGUEIREDO et al., 2013; CASTILLO; BAIGES; CODINA, 2015). No entanto, os fenômenos do inchamento do extrudado (dieswell) e inchamento retardado do extrudado (delayed dieswell) envolvem valores altos da tensão de cisalhamento e das diferenças de tensões normais próximo a parede do duto (tubo) dificultando a utilização de valores relativamente altos para a elasticidade $W i$. Nesse sentido, o modelo viscoelástico Oldroyd-B apresenta mais dificuldades numéricas para os escoamentos do inchamento do extrudado e do inchamento retardado do extrudado. Para se obter grandes taxas de inchamento, a constante da razão de viscosidades $\beta=\frac{\eta_{S}}{\eta_{P}+\eta_{S}}$, sendo $\eta_{S}$ e $\eta_{P}$ as viscosidades do polímero e do solvente, deve ser pequena o que resulta em um fluido com maior elasticidade efetiva, e portanto, instabilidades numéricas na superfície do fluido podem surgir independente da discretização utilizada (diferenças finitas, volumes finitos e elementos finitos) (OWENS; PHILLIPS, 2002). Quando a razão de viscosidades é nula $(\beta=0)$ o modelo Oldroyd-B reduz-se 
ao modelo UCM e verifica-se que poucos são os trabalhos numéricos que obtiveram algum sucesso na simulação desse tipo de fluido em escoamentos com superfícies livres onde ocorre alta variação do tensor tensão extra. Esse fato pode ser constatado no levantamento de trabalhos que utilizaram os modelos Oldroyd-B e UCM para resolver três tipos de fenômenos apresentados nas próximas seções: impacto da gota, inchamento do extrudado e inchamento retardado do extrudado.

\subsection{O fenômeno do salto de uma gota}

Pesquisadores que trabalham no desenvolvimento de métodos numéricos para resolver escoamentos que apresentam uma interface entre dois fluidos, por exemplo, água e ar ou água e óleo, consideram estudar e resolver problemas que envolvam o escoamento de gotas (GUNJAL; RANADE; CHAUDHARI, 2005; FANG et al., 2008; BERBEROVIC, 2010; SHIN; CHERGUI; JURIC, 2017).

Trabalhos envolvendo a dinâmica de uma gota newtoniana são mais recorrentes na literatura, principalmente quando considera-se a influência da tensão superficial (FRANCOIS; SHYY, 2003; GUNJAL; RANADE; CHAUDHARI, 2005; LUNKAD; BUWA; NIGAM, 2007; FANG et al., 2008; COYAJEE; BOERSMA, 2009; BERBEROVIC, 2010; SHIN; CHERGUI; JURIC, 2017; GRIEBEL; KLITZ, 2019). No âmbito de escoamentos viscoelásticos, alguns códigos numéricos que consideram resolver escoamentos transientes com superfícies livres, optam por simular numericamente o problema do impacto de uma gota sobre uma placa plana (drop impact) como teste inicial para verificar o desempenho do método numérico em aproximar e mover a superfície do fluido ao longo do tempo (TOMÉ et al., 2002; OISHI et al., 2011; XU et al., 2012; FIGUEIREDO et al., 2014; XU; DENG, 2016; XU; YU, 2018). Entretanto, resultados interessantes do problema do impacto da gota viscoelástica podem ser verificados. $\mathrm{Na}$ literatura encontram-se trabalhos com influência de tensão superficial e ângulo de contato para fluidos viscoelástico regidos apenas pelas equações constitutivas FENE-CR (IZBASSAROV; MURADOGLU, 2016) e Giesekus (WANG; DO-QUANG; AMBERG, 2017). Nesses trabalhos, os autores Izbassarov e Muradoglu (2016) e Wang, Do-Quang e Amberg (2017), dedicaram-se a estudar apenas os fenômenos de espalhamento e contração da gota. Entretanto, pode-se averiguar alguns estudos que não consideram ângulo de contato entre o fluido e a interface sólida, mas são relevantes uma vez que apresentam resultados relacionados a influência dos parâmetros reológicos dos modelos constitutivos no espalhamento e contração da gota. Nesse sentido, o fluido Oldroyd-B apresenta resultados interessantes uma vez que, quando a razão de viscosidades $\beta$ diminui a gota de fluido apresenta ambos os movimentos de expansão e contração em seu diâmetro logo após impactar a superfície rígida. Esses comportamentos foram constatados nos trabalhos de Tomé et al. (2002), Oishi et al. (2011), Figueiredo et al. (2014) e Junior et al. (2016) sem admitir a presença de tensão superficial e considerando valores de $\beta$ superiores a 0.1 . 
Os trabalhos encontrados na literatura que consideram uma gota viscoelástica de fluido UCM foram tratados apenas por Xu e colaboradores (XU et al., 2012; XU; DENG, 2016; XU; YU, 2018). Para fluidos UCM, o que chama a atenção é o surgimento de um outro fenômeno decorrente do impacto da gota sobre a superfície rígida: o fenômeno do salto da gota (bouncing drop). O código numérico utilizado por Xu nas simulações é um código Smoothed Particle Hydrodynamics (SPH) e em seus trabalhos não encontra-se um estudo sistemático desses resultados, os autores apenas identificam a ocorrência desse fenômeno mas não apresentam um estudo detalhado em relação as condições para que o salto da gota ocorra.

\subsection{O fenômeno do inchamento retardado do extrudado}

Segundo Joseph (2013) as primeiras fotografias experimentais que constataram o fenômeno do inchamento retardado do extrudado (delayed dieswell) foram registradas por pesquisadores da área de reologia entre os anos de 1943 e 1970. Essas fotografias podem ser observadas nos trabalhos de Merrington (1943), Metzner, White e Denn (1967), Middleman (1968), Giesekus (1969) e Brenschede e Klein (1970). Entre esses pesquisadores, apenas Giesekus (1969) e Brenschede e Klein (1970) notaram que esse é um fenômeno crítico, ou seja, observaram que a partir de certas condições ou valores críticos da velocidade no escoamento do inchamento do extrudado de fluidos poliméricos, esse fenômeno é detectado. Contudo, um estudo experimental sistemático sobre esse fenômeno só foi reportado mais tarde por Joseph, Matta e Chen (1987), onde os autores consideraram diferentes composições de fluido, velocidade e diâmetro da agulha. Com os resultados experimentais obtidos, Joseph, Matta e Chen (1987) classificaram o fenômeno do inchamento retardado do extrudado como uma consequência do inchamento do extrudado (dieswell) sob certas condições críticas, mais precisamente, quando o número de Mach viscoelástico é maior que 1.

O inchamento do extrudado, conhecido na literatura como extrudate swell ou dieswell é um fênomeno comum no processo de extrusão de fluidos viscoelásticos. A sua descrição é relatada na literatura como um jato de fluido que ao ser expelido de um duto ou orifício, deforma-se radialmente logo após seu contato com a atmosfera, adquirindo um novo diâmetro (no caso de tubos cilíndricos). Esse fenômeno é típico de fluidos não-newtonianos e tem sido extensivamente abordado por especialistas da área de dinâmica computacional por apresentar grandes dificuldades numéricas, em especial fluidos do tipo Oldroyd-B e UCM apresentam maior restrição numérica quando considera-se valores do número de Weissenberg altos. Seja através de uma abordagem bidimensional, axissimétrica ou tridimensional os códigos numéricos tem apresentado instabilidades na superfície livre acarretando na interrupção da simulação. Alguns trabalhos que trataram desse escoamento numericamente para fluidos Oldroyd-B e UCM, utilizando métodos de discretização diferentes são:

- Método de volumes finitos - Habla et al. (2011), Comminal et al. (2018); 
- Método de elementos finitos - Crochet e Keunings (1980), Crochet e Keunings (1982), Bush (1990), Brasseur et al. (1998), Russo e Phillips (2011);

- Método de diferenças finitas - Tomé et al. (2007), Tomé et al. (2008), Mompean et al. (2011), Tomé et al. (2012).

Além de diferentes técnicas de discretização das equações, observa-se também que muitos desses autores consideraram escoamentos estacionários (sem efeitos de inércia) e utilizaram diferentes métodos para determinar a superfície livre: front tracking (HARLOW; WELCH, 1965), level set (OSHER; SETHIAN, 1988) e volume of fluid (VOF) (HIRT; NICHOLS, 1981).

Recentemente, Comminal et al. (2018) apresentaram resultados para o problema do inchamento do extrudado planar aplicando o método VOF para mover a interface do fluido.

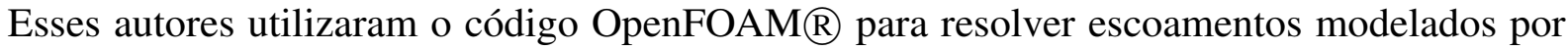
fluidos do tipo Giesekus e Oldroyd-B. As equações foram resolvidas utilizando uma formulação linha de correntes e vorticidade, e os tensores tensão extra, dos fluidos Oldroyd-B e Giesekus, foram calculados através da aplicação do método da matriz logarítmica do tensor conformação proposto por Fattal e Kupferman (2004). Diferentes solvers foram testados para verificar o máximo valor de $W i$ que o código consegue simular. Para o fluido Oldroyd-B foi considerada uma razão de viscosidade $\beta=1 / 9$ e o máximo valor de $W i$ que o código simulou foi $W i=2.5$ (os autores definem o número de Weissenberg como $W i=3 \lambda U / h$ onde $U$ é a velocidade média do escoamento no tubo e $h$ é metade da largura do canal). Para $W i=2.5$ os autores relatam instabilidades na superfície livre do fluido.

Adotando o método de discretização de diferenças finitas e uma adaptação do método front tracking para escoamentos tridimensionais, axissimétricos e planar, Tomé e co-autores apresentaram resultados do escoamento do inchamento do extrudado para fluidos Oldroyd-B apenas quando a razão de viscosidade $\beta$ é superior a 0.1 (ver por exemplo, Tomé et al. (2002) e Tomé et al. (2007)). Também encontra-se trabalhos de Tomé e co-autores para escoamentos tridimensionais do inchamento do extrudado do fluido UCM. Nesses trabalhos, o modelo UCM foi calculado pela matriz logarítmica do tensor conformação (TOMÉ et al., 2012) ou por meio de uma formulação algébrica (MOMPEAN et al., 2011). No trabalho Tomé et al. (2012) observa-se que embora tenha sido adotado valores para $W i=\lambda U / R$ da ordem de 2.5 as superfícies do fluido apresentaram oscilações. Já no trabalho algébrico (MOMPEAN et al., 2011), os autores apresentam resultados para valores de $W i=3$, porém, um parâmetro adimensional $\kappa$ presente no modelo algébrico é fixado igual a 0.05 , uma vez que quanto maior é seu valor mais o fluido incha, ou seja, maiores são as diferenças de tensões normais.

Pode-se verificar que os métodos numéricos tem avançado com o passar dos anos no sentido de conseguir simular o fenômeno do inchamento do extrudado em que as taxas de inchamento resultantes são altas, ou seja, as forças elásticas são predominantes. Entretanto, 
ainda há limitações numéricas a serem superadas e alguns matemáticos procuram estudar analiticamente esse problema.

O problema do inchamento retardado do extrudado pode ser considerado ainda mais complexo, principalmente do ponto de vista numérico. $\mathrm{O}$ único trabalho numérico publicado em periódicos que abordou esse fenômeno foi realizado por Delvaux e Crochet (1990). Nesse trabalho, Delvaux e Crochet (1990) consideram os modelos constitutivos Oldroyd-B e Giesekus. Como citado pelos autores, a grande dificuldade de simular esse fenômeno com os parâmetros adotados por Joseph, Matta e Chen (1987) (valores de Reynolds e Weissenberg) está associado ao fato de que é necessário considerar valores muito altos de $W i$ (ver o diagrama apresentado por Delvaux e Crochet (1990) na Figura 1). Esse fato, impossibilita a obtenção de resultados numéricos que reproduzam os experimentos de Joseph. Para contornar essa dificuldade, Delvaux e Crochet (1990) adotaram grandes valores do número de Reynolds $(R e)$ e para obter taxas de inchamento relativamente altas procuraram aumentar o fator de elasticidade $\mathrm{E}=W i / R e$. Entretanto, no caso de fluidos do tipo Oldroyd-B, Delvaux e Crochet (1990) consideraram uma pertubação no modelo UCM de modo que o fluido Oldroyd-B com $\beta=5 \%$ apresentou o fenômeno do inchamento retardado do extrudado para o número de elasticidade $\mathrm{E}=0.03 \mathrm{e}$ considerando valores do número de Mach viscoelástico entre 2.3 e 5.9. No caso do modelo Giesekus, Delvaux e Crochet também consideraram $\beta=5 \%$ e o parâmetro de mobilidade $\alpha=0$ ou 0.005 . Utilizando $\alpha=0.005$ os pesquisadores obtiveram altas taxas de inchamento quando aumentou-se o número de elasticidade E entre 0.03 e 0.05 .

Figura 1 - Diagrama apresentado por Delvaux e Crochet (1990) que identifica os valores do número de Reynolds $(R e)$ e $W i$ utilizados nos experimentos de Joseph, Matta e Chen (1987).

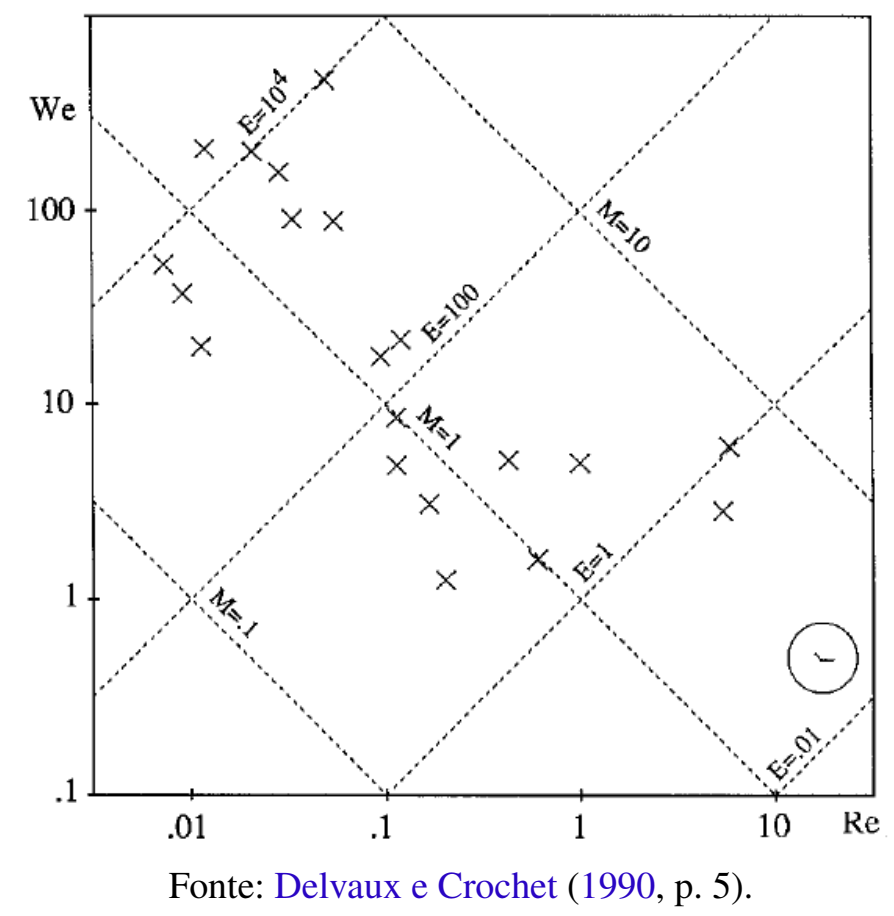


Recentemente, Merejolli (2017) em sua tese de doutorado, trabalhou com o modelo Giesekus e forneceu alguns resultados utilizando um código tridimensional para os escoamentos do inchamento do extrudado e inchamento retardado do extrudado. No caso do escoamento do inchamento retardado, Merejolli (2017) considerou o modelo Giesekus quando $\alpha=0$ e $\beta=0$, obtendo assim, um fluido UCM. Contudo, seus resultados foram comparados qualitativamente com os resultados experimentais de Joseph, Matta e Chen (1987) e não foi apresentado um estudo de refinamento de malha para verificar a convergência das soluções numéricas. Ainda observa-se instabilidades na superfície livre do fluido que podem ser devidas ao uso de uma malha não muito refinada para obtenção dos resultados.

\subsection{Objetivos e motivação}

Com o objetivo de resolver os fenômenos do salto de uma gota viscoelástica e o inchamento retardado do extrudado, neste trabalho estamos interessados em escoamentos viscoelásticos axissimétricos com superfície livre governados pelo modelo Oldroyd-B. A equação constitutiva desse modelo é resolvida utilizando uma técnica de diferenças finitas Euleriana. $\mathrm{O}$ tensor de tensão extra $\tau$ é calculado utilizando a transformação reológica: $\tau=\tau_{P}+2 \eta_{S} \mathbf{D}$ em que o tensor polimérico $\tau_{P}$ é obtido resolvendo um modelo UCM e $\mathbf{D}$ é o tensor deformação. A técnica de desacoplamento das tensões viscosas e elástica conhecida como Elastic Viscous Stress Splitting (EVSS) introduzida por Rajagopalan, Armstrong e Brown (1990) (ver também, Guénette e Fortin (1995), Matallah, Townsend e Webster (1998), Amoreira e Oliveira (2010)), tem provado ser eficiente na resolução de escoamentos confinados. O presente trabalho aplica esta técnica de decomposição de tensões para resolver as equações de conservação de quantidade de movimento, enquanto que a superfície livre do fluido é tratada pela técnica de rastreamento frontal (front tracking) desenvolvida por Tomé et al. (2007) e Tomé et al. (2000) para resolver escoamentos transientes com superfície livre.

Na abordagem proposta neste trabalho, o tensor tensão extra é algebricamente equacionado com o tensor conformação, o qual é então aproximado implicitamente por diferenças finitas de tal maneira que o sistema de equações resultante pode ser resolvido exatamente. A técnica EVSS introduz um segundo tensor não-newtoniano $(\mathbf{S})$ que é utilizado nas condições de contorno para a superfície livre, ao invés do tensor de tensão polimérica $\left(\boldsymbol{\tau}_{P}\right)$. Esta modificação minimiza instabilidades numéricas quando o escoamento for altamente elástico ou principalmente quando a taxa de viscosidade do solvente $(\beta)$ for muito pequena, isto é $\beta \approx 0$ (se $\beta=0$ existe uma singularidade).

\subsubsection{Escopo da tese}

A motivação inicial desse estudo deu-se há alguns anos quando o orientador desse trabalho fez algumas tentativas de resolver os seguintes escoamentos envolvendo fluidos viscoelásticos 
com superfícies livres utilizando o código Freeflow3D:

1. Simular o salto de uma gota viscoelástica;

2. Resolver o problema do inchamento retardado do extrudado.

Esses problemas podem ser descritos pela equação constitutiva do Oldroyd-B ou UpperConvected-Maxwell (UCM) que estão implementados no código Freeflow3D. Entretanto, no problema da gota o código falhou por não ser possível a utilização de malhas mais finas: o máximo conseguido foi uma malha com 10 pontos discretizados no raio da gota. No problema do inchamento retardado do extrudado o código Freeflow3D resolveu esse problema parcialmente. Embora resultados do inchamento retardado do extrudado foram obtidos, os mesmos não foram suficientemente precisos para fazer uma análise quantitativa dos resultados alcançados.

A solução para resolver esses problemas requeria o desenvolvimento de um código novo que pudesse ser robusto e que fornecesse resultados precisos na solução da equação constitutiva Oldroyd-B. Além disso, o código precisava ter a capacidade de resolver a equação constitutiva Oldroyd-B utilizando valores pequenos, tendendo para zero, da razão de viscosidade $\beta=\eta_{S} /\left(\eta_{P}+\eta_{S}\right)$.

Assim, esse trabalho tem desenvolvido um código axissimétrico que simula os problemas mencionados e os resultados obtidos estão reportados nessa tese nos seguintes capítulos:

Capítulo 1: Esse capítulo apresenta uma descrição dos problemas resolvidos nessa tese bem como uma pesquisa bibliográfica dos artigos recentes que tratam dos problemas citados.

Capítulo 2: Nesse capítulo é apresentado em detalhes um método numérico novo para resolver a equação constitutiva do modelo Oldroyd-B bem como a obtenção da solução de alguns escoamentos com geometria axissimétrica. Resultados de verificação e convergência são obtidos, e a seguir os problemas do impacto de uma gota contendo um fluido Oldroyd-B e UCM em uma superfície rígida e condições para a ocorrência do salto da gota são apresentados.

Capítulo 3: Nesse capítulo o código desenvolvido no capítulo 2 é utilizado para resolver o problema do inchamento retardado do extrudado. $\mathrm{O}$ inchamento do extrudado tem sido estudado intensivamente por muitos pesquisadores. No entanto, o problema do inchamento retardado do extrudado, devido as dificuldades do escoamento, tem sido considerado por muito poucos pesquisadores. Com o objetivo de obter novos resultados relacionados a esse fenômeno, o código desse trabalho foi aplicado para resolver esse problema. Resultados de verificação para esse escoamento entre geometrias axissimétrica e tridimensional são apresentados. Resultados adicionais desse problema foram obtidos utilizando ambos os modelos Oldroyd-B e UCM.

Capítulo 4: Os resultados da tese são discutidos e propõe-se estudos futuros. 


\section{SOLUÇÃO DO MODELO OLDROYD-B PARA}

$$
0 \leq \beta \leq 1
$$

Nesse capítulo são descritas as principais ideias da metodogia numérica empregada para resolver escoamentos incompressíveis e isotérmicos de fluidos viscoelásticos, modelados pela equação reológica Oldroyd-B. Inicialmente apresenta-se as equações diferenciais que compõem o conjunto de equações que foram discretizadas no método numérico. Uma formulação baseada na obtenção do tensor conformação é considerada, de modo que o tensor tensão extra é determinado através de uma equação algébrica. Em seguida, as condições de contorno também são apresentadas, com maior evidência as condições na superfície livre. Na sequência o método numérico é explicado e a técnica implícita para obtenção do tensor conformação apresentada. $\mathrm{O}$ tratamento numérico das condições de contorno na superfície livre também é detalhado.

Uma primeira verificação da metodologia proposta é apresentada para o escoamento confinado e totalmente desenvolvido no tubo. Um estudo de convergência entre as soluções numéricas e analíticas é demonstrado. Para escoamentos transientes, considerou-se o problema do impacto de uma gota sobre uma superfície rígida plana (drop impact problem) e resultados obtidos para a variação temporal do diâmetro da gota foram comparados com soluções encontradas na literatura. Na sequência, apresenta-se um estudo do fenômeno de salto da gota, cuja a ocorrência é factível apenas em casos em que o fluido considerado seja caracterizado por uma pequena razão de viscosidades $(\beta \approx 0)$. Um estudo da influência de parâmetros como número de Reynolds, Weissenberg e $\beta$ para o fenômeno do salto da gota finaliza esse capítulo.

\subsection{Equações governantes}

As equações de conservação de massa e de quantidade de movimento são as equações básicas para escoamentos incompressíveis e podem ser escritas como,

$$
\nabla \cdot \mathbf{v}=0
$$




$$
\rho\left[\frac{\partial \mathbf{v}}{\partial t}+\nabla \cdot(\mathbf{v v})\right]=-\nabla p+\nabla \cdot \boldsymbol{\tau}+\rho \mathbf{g}
$$

onde $\mathbf{v}$ é o vetor velocidade, $\mathbf{g}$ o campo gravitacional, $p$ a pressão, $\rho$ a densidade do fluido e $\tau$ é o tensor tensão extra.

Esse trabalho, trata de escoamentos governados pela equação constitutiva Oldroyd-B que é definida pela seguinte equação

$$
\boldsymbol{\tau}+\lambda_{1} \stackrel{\nabla}{\boldsymbol{\tau}}=2 \eta_{0}\left[\mathbf{D}+\lambda_{2} \stackrel{\nabla}{\mathbf{D}}\right]
$$

em que D é o tensor taxa de deformação definido por

$$
\mathbf{D}=\frac{1}{2}\left[(\nabla \mathbf{v})+(\nabla \mathbf{v})^{\top}\right],\left(\text { o símbolo }(\bullet)^{\top} \text { denota transposição }\right)
$$

As constantes $\lambda_{1}$ e $\lambda_{2}$ são respectivamente o tempo de relaxação e tempo de retardamento do fluido Oldroyd-B. A constante $\eta_{0}$ é a viscosidade total do fluido. A derivada convectada superior (upper-convected derivative) do tensor tensão extra, denotada pelo símbolo $\underset{\tau}{\tau}$, é calculada pela expressão

$$
\stackrel{\nabla}{\boldsymbol{\tau}}=\frac{\partial \boldsymbol{\tau}}{\partial t}+\nabla \cdot(\mathbf{v} \boldsymbol{\tau})-\boldsymbol{\tau}(\nabla \mathbf{v})-(\nabla \mathbf{v})^{\top} \boldsymbol{\tau}
$$

A equação constitutiva 2.3 é usualmente resolvida utilizando a decomposição reológica

$$
\boldsymbol{\tau}=\boldsymbol{\tau}_{P}+2 \beta \eta_{0} \mathbf{D}
$$

em que $\tau_{P}$ é calculado pela equação do modelo UCM

$$
\boldsymbol{\tau}_{P}+\lambda_{1} \stackrel{\nabla}{\boldsymbol{\tau}_{P}}=2(1-\beta) \eta_{0} \mathbf{D}
$$

e $\eta_{0}=\eta_{P}+\eta_{S}$ é a soma das viscosidades do solvente $\left(\eta_{S}\right)$ e polimérica $\left(\eta_{P}\right)$. O coeficiente $\beta=\frac{\eta_{S}}{\eta_{0}}$ é a razão entre a viscosidade do solvente e a viscosidade total do fluido. Quando $\beta=0$, a Equação 2.3 reduz ao modelo Upper Convected-Maxwell (UCM) $\left(\eta_{0}=\eta_{P}\right)$ e se $\beta=1$ temos um escoamento newtoniano desde que o tempo de relaxação também é zero (de acordo com a teoria cinética das soluções de polímeros quando $\eta_{P} \rightarrow 0, \lambda_{1} \rightarrow 0$, conferir em Bird, Armstrong e Hassager (1987)).

Pode-se mostrar que o tensor tensão extra $\tau$ pode ser calculado em função do tensor conformação $\mathbf{A}$ (desde que $\tau_{P}=\frac{\eta_{0}}{\lambda_{1}}(1-\beta)[\mathbf{A}-\mathbf{I}]$ ) pela equação

$$
\boldsymbol{\tau}=\frac{\eta_{0}}{\lambda_{1}}(1-\beta)[\mathbf{A}-\mathbf{I}]+2 \beta \eta_{0} \mathbf{D}
$$

resultando na seguinte equação de evolução para o cálculo do tensor conformação

$$
\mathbf{A}+\lambda_{1} \stackrel{\nabla}{\mathbf{A}}=\mathbf{I}
$$


Esta equivalência é facilmente verificada substituindo-se a Equação 2.8 na Equação 2.3 e utilizando a relação entre os tempos de relaxamento e retardamento: $\lambda_{2}=\beta \lambda_{1}$.

Para resolver a equação de conservação de quantidade de movimento, Equação 2.2, aplicamos a seguinte transformação, conhecida como Elastic Viscous Stress Splitting (EVSS) (RAJAGOPALAN; ARMSTRONG; BROWN, 1990) (ver também (GUÉNETTE; FORTIN, 1995; MATALLAH; TOWNSEND; WEBSTER, 1998; AMOREIRA; OLIVEIRA, 2010))

$$
\boldsymbol{\tau}=\mathbf{S}+2 \eta_{0} \mathbf{D}
$$

onde $\mathbf{S}$ é um tensor não-newtoniano. Após introduzir essa transformação na Equação 2.2 obtemos

$$
\rho\left[\frac{\partial \mathbf{v}}{\partial t}+\nabla \cdot(\mathbf{v v})\right]=-\nabla p+\eta_{0} \nabla^{2} \mathbf{v}+\nabla \cdot \mathbf{S}+\rho \mathbf{g} .
$$

As soluções $(\mathbf{v}, p, \tau)$ podem, portanto, serem obtidas resolvendo a equação de conservação de massa, Equação 2.1, juntamente com a equação de conservação da quantidade de movimento (Equação 2.11) utilizando o método da projeção, enquanto que o tensor conformação A pode ser calculado resolvendo a Equação 2.9. O tensor tensão extra $\tau$ e o tensor não-newtoniano $\mathbf{S}$ são então obtidos pelas Equações algébricas 2.8 e 2.10, respectivamente.

Entretanto, na literatura, muitos trabalhos (por exemplo, Crochet e Keunings (1982), Tomé et al. (2007), Comminal et al. (2018)) resolvem o modelo Oldroyd-B fazendo uso da decomposição reológica, Equação 2.6, que após ser inserida na equação de conservação de quantidade de movimento, Equação 2.2, fornece a seguinte equação

$$
\rho\left[\frac{\partial \mathbf{v}}{\partial t}+\nabla \cdot(\mathbf{v v})\right]=-\nabla p+\beta \eta_{0} \nabla^{2} \mathbf{v}+\nabla \cdot \boldsymbol{\tau}_{P}+\rho \mathbf{g}
$$

Note que esta equação introduz o termo $\beta \eta_{0} \nabla^{2} \mathbf{v}$ na equação de conservação de quantidade de movimento.

\subsection{Condições de contorno}

Nos problemas abordados neste trabalho as condições de contorno são ilustradas na Figura 2 e descritas como:

- contornos rígidos: nesses contornos a condição de não-escorregamento (no-slip) é imposta;

- contornos de entrada de fluido: um perfil de velocidade é prescrito enquanto que o tensor tensão extra obedece uma solução para escoamentos desenvolvidos (detalhes são dados na Subseção 2.4.1);

- contornos de saída de fluido: condições homogêneas de Neumann são assumidas. 
As condições de contorno na superfície livre são discutidas na Subseção 2.2.1 a seguir.

Figura 2 - Representação dos tipos de fronteiras.

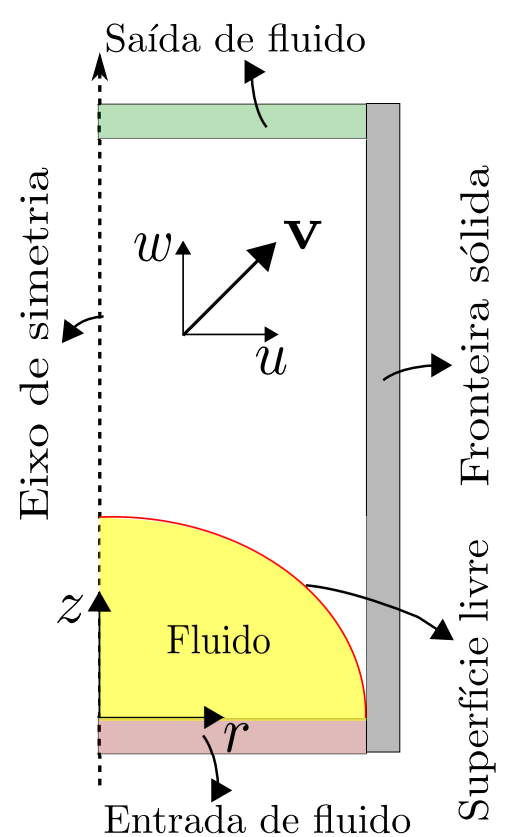

Fonte: Elaborada pelo autor.

\subsubsection{Condições de tensão na superfície livre}

Considera-se escoamentos transientes com superfície livre de fluidos muito viscosos e altamente elásticos em uma atmosfera não resistente e assume-se que as forças de tensão superficial são desprezíveis. Sob essas hipóteses, as condições de contorno apropriadas para as tensões normais e tangenciais podem ser especificadas como (ver Batchelor (2000, p. 167))

$$
\begin{aligned}
& \mathbf{n}^{\top} \cdot(\boldsymbol{\sigma} \cdot \mathbf{n})=0, \\
& \mathbf{m}^{\top} \cdot(\boldsymbol{\sigma} \cdot \mathbf{n})=0,
\end{aligned}
$$

em que $\boldsymbol{\sigma}=-p \mathbf{I}+\boldsymbol{\tau}$ é o tensor tensão total, $\mathbf{n}=\left[n_{r}, n_{z}\right]^{\top}$ e $\mathbf{m}=\left[n_{z},-n_{r}\right]^{\top}$ são vetores unitários, respectivamente, normal e tangencial à superfície livre.

Assumindo escoamentos axissimétricos e utilizando coordenadas cilíndricas, ao inserir a decomposição definida pela Equação 2.6 nas condições de tensão superficial 2.13 (para mais detalhes ver Crochet e Keunings (1982), Tomé et al. (2007), Comminal et al. (2018)) obtemos as seguintes equações adimensionais (ver constantes adimensionais definidas na Subseção 2.3.1)

$$
\begin{aligned}
& p=\frac{2 \beta}{R e}\left[\frac{\partial u}{\partial r} n_{r}^{2}+\left(\frac{\partial u}{\partial z}+\frac{\partial w}{\partial r}\right) n_{r} n_{z}+\frac{\partial w}{\partial z} n_{z}^{2}\right]+\tau_{P}^{r r} n_{r}^{2}+2 \tau_{P}^{z r} n_{r} n_{z}+\tau_{P}^{z z} n_{z}^{2} \\
& 2\left(\frac{\partial w}{\partial z}-\frac{\partial u}{\partial r}\right) n_{r} n_{z}+\left(\frac{\partial u}{\partial z}+\frac{\partial w}{\partial r}\right)\left(n_{r}^{2}-n_{z}^{2}\right)=\frac{R e}{\beta}\left[\left(\tau_{P}^{r r}-\tau_{P}^{z z}\right) n_{r} n_{z}+\tau_{P}^{r z}\left(n_{z}^{2}-n_{r}^{2}\right)\right]
\end{aligned}
$$


A Equação 2.14a é comumente utilizada para calcular a pressão na superfície livre e não apresenta problema para qualquer valor de $\beta$, enquanto que, a Equação $2.14 \mathrm{~b}$ torna-se singular quando $\beta$ se aproxima de zero (modelo UCM). Contudo, se $\beta$ é pequeno, instabilidades numéricas podem aparecer, especialmente se o escoamento é altamente elástico ou apresenta elevados gradientes da tensão. Possivelmente por este motivo, quando utiliza-se a decomposição reológica 2.6, muitos pesquisadores (por exemplo, Crochet e Keunings (1982), Tomé et al. (2007), Comminal et al. (2018)) resolveram escoamentos com superficie livre de fluidos Oldroyd-B adotando $\beta \geq 0.1$. Uma solução para este problema é desenvolvida a seguir.

Considera-se a transformação EVSS, Equação 2.10, nas condições de tensão, Equação 2.13, estas podem ser escritas como

$$
\begin{aligned}
& p=\frac{2}{\operatorname{Re}}\left[\frac{\partial u}{\partial r} n_{r}^{2}+\left(\frac{\partial u}{\partial z}+\frac{\partial w}{\partial r}\right) n_{r} n_{z}+\frac{\partial w}{\partial z} n_{z}^{2}\right]+S^{r r} n_{r}^{2}+2 S^{z r} n_{r} n_{z}+S^{z z} n_{z}^{2} \\
& 2\left(\frac{\partial w}{\partial z}-\frac{\partial u}{\partial r}\right) n_{r} n_{z}+\left(\frac{\partial u}{\partial z}+\frac{\partial w}{\partial r}\right)\left(n_{r}^{2}-n_{z}^{2}\right)=\operatorname{Re}\left[\left(S^{r r}-S^{z z}\right) n_{r} n_{z}+S^{r z}\left(n_{z}^{2}-n_{r}^{2}\right)\right] .
\end{aligned}
$$

Portanto, ao utilizar a transformação EVSS o multiplicador $1 / \beta$ no lado direito da Equação $2.14 \mathrm{~b}$ é evitado e consequentemente as instabilidades numéricas associadas quando $\beta$ é pequeno. Consequentemente, neste trabalho optou-se por utilizar as Equações 2.15a e 2.15b ao invés das Equações 2.14a e 2.14b.

\subsection{Método numérico}

As equações apresentadas na Seção 2.1 são resolvidas utilizando o método de diferenças finitas em uma malha deslocada (a Figura 3a apresenta a localização das váriáveis em uma célula). O fluido é modelado por uma versão aprimorada do método Marker-and-Cell (MAC) (AMSDEN; HARLOW, 1970) desenvolvida por Tomé et al. (2000), onde a superfície do fluido é descrita por uma curva spline linear fechada que é definida por marcadores (ver Figura 3b). Para implementar esta técnica, as células dentro da malha são classificadas da seguinte maneira (ver Figura 3c):

- Fronteira rígida (B): células que definem a localização dos contornos rígidos;

- Fronteira de entrada de fluido (I): células que modelam a entrada de fluido (inflows);

- Fronteira de saída de fluido (O): células que definem a saída do fluido (outflows);

- Células vazias (E): células que não contém fluido;

- Células de fluido $(\mathbf{F})$ : células que contém fluido e não tem faces em contato com células $\mathbf{E}$;

- Células de superfície (S): células que contém fluido e tem ao menos uma das faces em contanto com uma célula $\mathbf{E}$. 
Figura 3 - (a) Malha deslocada; (b) Representação da superfície livre por spline linear; (c) Exemplo de classificação das células.

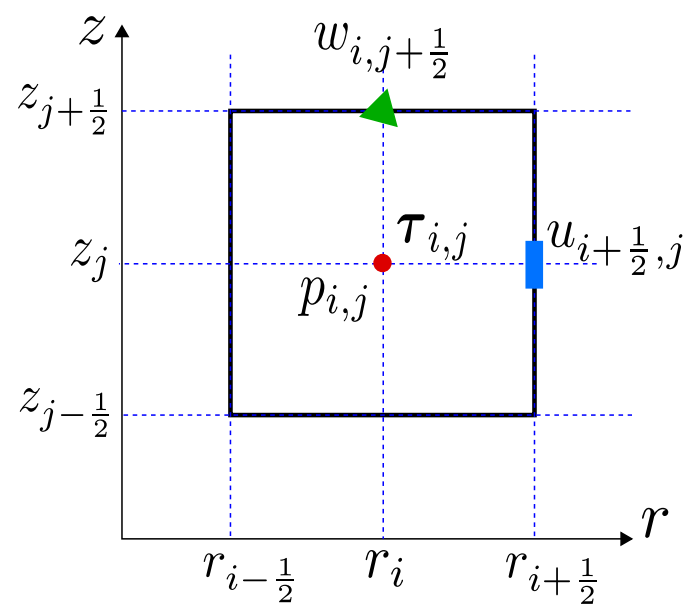

(a)

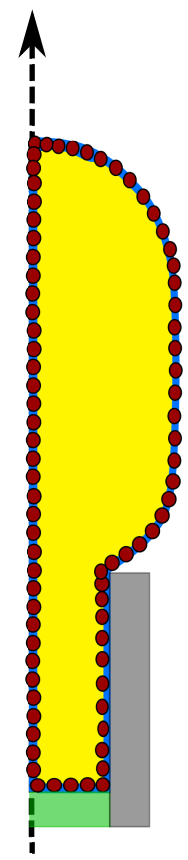

(b)

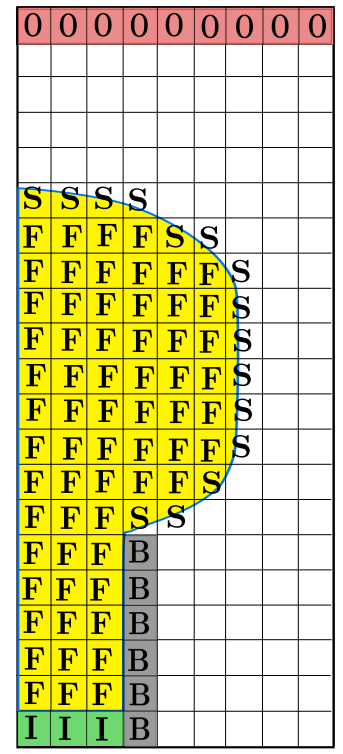

(c)

Fonte: Elaborada pelo autor.

\subsubsection{Algoritmo numérico}

As Equações 2.1 e 2.8 à 2.11, escritas em coordenadas cilíndricas, são resolvidas para determinar as soluções das seguintes variáveis: $\mathbf{v}(r, z, t)=(u(r, z, t), w(r, z, t))^{\top}, p(r, z, t), \boldsymbol{\tau}(r, z, t)$, $\mathbf{A}(r, z, t)$ e $\mathbf{S}(r, z, t)$. Essas equações são resolvidas na forma adimensional que contém os seguintes números adimensionais:

As constantes de adimensionalização $L, U, \rho$ e

os Número de Reynolds: $R e=\frac{\rho U L}{\eta_{0}}$;

$g$ são parâmetros típicos de escala para compri-

\& Número de $W$ eissenberg: $W i=\lambda_{1} \frac{U}{L}$;

mento, velocidade, densidade e gravidade, res-

s.s Número de Froude: $F r=\frac{U}{\sqrt{L g}}$. pectivamente. $\mathrm{O}$ processo de adimensionalização tem como referência o trabalho de Tomé et al. (2007) que apresenta detalhes da obtenção dessas equações na forma adimensional que são utilizadas nas seções seguintes.

No Apêndice A encontra-se detalhes das equações em coordenadas cilíndricas e adimensionalizadas que foram utilizadas na implementação numérica.

O ciclo computacional é realizado em três passos, que são descritos a seguir.

PASSO 1: Cálculo da velocidade $\mathbf{v}^{n+1}=\mathbf{v}\left(r, z, t_{n+1}\right)$ e pressão $p^{n+1}=p\left(r, z, t_{n+1}\right)$

$\mathrm{O}$ algoritmo para calcular a velocidade $\mathbf{v}^{n+1}=\mathbf{v}\left(r, z, t_{n+1}\right)$ e pressão $p^{n+1}=p\left(r, z, t_{n+1}\right)$ 
incorpora algumas ideias da técnica apresentada por Tomé et al. (2007) e Oishi et al. (2011). O campo de pressão é desacoplado das equações de conservação de massa (Equação 2.1) e conservação de quantidade de movimento (Equação 2.11) aplicando o método da projeção de Chorin (1968).

Seja $\delta t$ o passo de tempo utilizado, $t_{n+1}=t_{n}+\delta t$, e considere $\mathbf{v}^{n}=\mathbf{v}\left(r, z, t_{n}\right), \tau^{n}=$ $\boldsymbol{\tau}\left(r, z, t_{n}\right), \mathbf{D}^{n}, \mathbf{A}^{n}$ e $\mathbf{S}^{n}$ conhecidos no tempo $t_{n}$. Um campo de velocidade tentativo $\widetilde{\mathbf{v}}^{n+1}$ é calculado pelo método de Euler implícito aplicado a equação de conservação de quantidade de movimento resolvendo a equação

$$
\widetilde{\mathbf{v}}^{n+1}-\frac{\delta t}{R e}\left(\nabla^{2} \widetilde{\mathbf{v}}\right)^{n+1}=\widetilde{\mathbf{v}}^{n}+\delta t\left[-\nabla p-\nabla \cdot(\mathbf{v v})+\nabla \cdot \mathbf{S}+\frac{1}{F r^{2}} \mathbf{g}\right]^{n} .
$$

A discretização da Equação 2.16 aplicada nas células $\mathbf{F}$ e $\mathbf{S}$, produz um sistema linear esparso que é eficientemente resolvido pelo método dos gradientes conjugados (ver as equações na forma discreta no Apêndice B). Pode-se mostrar que este campo de velocidade contém a vorticidade correta no tempo $t$ mas em geral, não conserva massa. Assim, uma função potencial $\psi\left(r, z, t_{n+1}\right)$ é determinada pela equação de Poisson

$$
\nabla^{2} \psi^{n+1}=\nabla \cdot \widetilde{\mathbf{v}}^{n+1}
$$

enquanto que o campo de velocidade, $\mathbf{v}^{n+1}$, é obtido da equação

$$
\mathbf{v}^{n+1}=\widetilde{\mathbf{v}}^{n+1}-\nabla \psi^{n+1} .
$$

Dessa maneira, a velocidade $\mathbf{v}^{n+1}$ garante que a massa é conservada e a vorticidade gerada por $\widetilde{\mathbf{v}}^{n+1}$ permanece inalterada.

Neste trabalho, como mencionado no início dessa seção, nós incorporamos as ideias da técnica implícita de Oishi et al. (2011) que acopla a condição de contorno para a pressão na superfície livre, fornecida pela Equação 2.15a, e a conservação de massa, Equação 2.1. Essa técnica consiste em aplicar a equação de conservação de massa juntamente com a condição de contorno para a pressão na superfície livre e a equação para a velocidade $\mathbf{v}^{n+1}$, Equação 2.18, nas células de superfície $\mathbf{S}$. Ao realizar este processo, novas equações para a função potencial $\psi^{n+1}$ são obtidas e adicionadas ao conjunto de equações originadas da aplicação da versão discreta da Equação de Poisson 2.17 em células F. O agrupamento destas equações resulta em um sistema linear assimétrico que é resolvido pelo método dos gradientes bi-conjugados (QUARTERONI; SACCO; SALERI, 2000) (ver Apêndice B). Após a obtenção de $\psi^{n+1}$, a pressão é calculada pela equação

$$
p^{n+1}=p^{n}+\frac{\psi^{n+1}}{\delta t}-\frac{1}{\operatorname{Re}} \nabla^{2} \psi^{n+1} .
$$

\section{PASSO 2: Cálculo do tensor extra tensão $\tau^{n+1}$}

Nesta etapa primeiro calcula-se o tensor conformação $\mathbf{A}^{n+1}=\mathbf{A}\left(r, z, t_{n+1}\right)$ resolvendo a Equação 2.9 discretizada por diferenças finitas da seguinte maneira. 
Em cada células $\mathbf{S}_{i, j}$ e $\mathbf{F}_{i, j}$, a Equação 2.9 é aproximada implicitamente pela equação

$$
\begin{aligned}
\mathbf{A}^{n+1}+\delta t & \left\{\frac{1}{W i} \mathbf{A}^{n+1}-\left(\nabla \mathbf{v}^{n+1}\right)^{\top} \mathbf{A}^{n+1}-\mathbf{A}^{n+1}\left(\nabla \mathbf{v}^{n+1}\right)\right\}= \\
\mathbf{A}^{n}+\delta t & \left\{\frac{1}{W i} \mathbf{I}-\nabla \cdot\left(\mathbf{v}^{n+1} \mathbf{A}^{n}\right)\right\},
\end{aligned}
$$

resultando no seguinte sistema linear $(4 \times 4)$ para as componentes do tensor $\mathbf{A}^{n+1}$ :

$$
\begin{gathered}
\text { I. }\left[A^{r r}\right]_{i, j}^{n+1}+\delta t *\left\{\frac{1}{W i}\left[A^{r r}\right]_{i, j}^{n+1}-2\left(\frac{\partial u}{\partial r}\left[A^{r r}\right]+\frac{\partial u}{\partial z}\left[A^{r z}\right]\right)_{i, j}^{n+1}\right\}= \\
{\left[A^{r r}\right]_{i, j}^{n}+\delta t *\left\{\frac{1}{W i}-\left.\frac{1}{r_{i}} \frac{\partial\left(r u^{n+1}\left[A^{r r}\right]^{n}\right)}{\partial r}\right|_{i, j}-\left.\frac{\partial\left(w^{n+1}\left[A^{r r}\right]^{n}\right)}{\partial z}\right|_{i, j}\right\} ;} \\
\text { II. } \quad\left[A^{\theta \theta}\right]_{i, j}^{n+1}+\delta t *\left\{\frac{1}{W i}\left[A^{\theta \theta}\right]_{i, j}^{n+1}-2 \frac{u_{i, j}^{n+1}}{r_{i}}\left[A^{\theta \theta}\right]_{i, j}^{n+1}\right\}= \\
{\left[A^{\theta \theta}\right]_{i, j}^{n}+\delta t *\left\{\frac{1}{W i}-\left.\frac{1}{r_{i}} \frac{\partial\left(r u^{n+1}\left[A^{\theta \theta}\right]^{n}\right)}{\partial r}\right|_{i, j}-\left.\frac{\partial\left(w^{n+1}\left[A^{\theta \theta}\right]^{n}\right)}{\partial z}\right|_{i, j}\right\} ;} \\
\text { III. }\left[A^{z z}\right]_{i, j}^{n+1}+\delta t *\left\{\frac{1}{W i}\left[A^{z z}\right]_{i, j}^{n+1}-2\left(\frac{\partial w}{\partial r}\left[A^{r z}\right]+\frac{\partial w}{\partial z}\left[A^{z z}\right]\right)_{i, j}^{n+1}\right\}= \\
{\left[A^{z z}\right]_{i, j}^{n}+\delta t *\left\{\frac{1}{W i}-\left.\frac{1}{r_{i}} \frac{\partial\left(r u^{n+1}\left[A^{z z}\right]^{n}\right)}{\partial r}\right|_{i, j}-\left.\frac{\partial\left(w^{n+1}\left[A^{z z}\right]^{n}\right)}{\partial z}\right|_{i, j}\right\} ;} \\
\text { IV. }\left[A^{r z}\right]_{i, j}^{n+1}+\delta t *\left\{\frac{1}{W i}\left[A^{r z}\right]_{i, j}^{n+1}-\left(\frac{\partial w}{\partial r}\left[A^{r r}\right]-\frac{u}{r}\left[A^{r z}\right]+\frac{\partial u}{\partial z}\left[A^{z z}\right]\right)_{i, j}^{n+1}\right\}= \\
{\left[A^{r z}\right]_{i, j}^{n}+\delta t *\left\{\frac{0}{W i}-\left.\frac{1}{r_{i}} \frac{\partial\left(r u^{n+1}\left[A^{r z}\right]^{n}\right)}{\partial r}\right|_{i, j}-\left.\frac{\partial\left(w^{n+1}\left[A^{r z}\right]^{n}\right)}{\partial z}\right|_{i, j}\right\} .}
\end{gathered}
$$

na forma matricial este sistema linear produz

$$
\left[\begin{array}{cccc}
a_{11} & 0 & 0 & a_{14} \\
0 & a_{22} & 0 & 0 \\
0 & 0 & a_{33} & a_{34} \\
a_{41} & 0 & a_{43} & a_{44}
\end{array}\right]_{i, j}\left[\begin{array}{c}
A^{r r} \\
A^{\theta \theta} \\
A^{z z} \\
A^{r z}
\end{array}\right]_{i, j}^{n+1}=\left[\begin{array}{c}
F_{1} \\
F_{2} \\
F_{3} \\
F_{4}
\end{array}\right]_{i, j}
$$

onde os coeficientes da matriz são dados por,

$$
\left\{\begin{array}{l}
a_{11}=1.0+\delta t\left(\frac{1}{W i}-2 \frac{\partial u^{n+1}}{\partial r}\right), \quad a_{22}=1.0+\delta t\left(\frac{1}{W i}-2 \frac{u^{n+1}}{r}\right), \quad a_{14}=-2 \delta t \frac{\partial u^{n+1}}{\partial z} \\
a_{33}=1.0+\delta t\left(\frac{1}{W i}-2 \frac{\partial w^{n+1}}{\partial z}\right), \quad a_{34}=-2 \delta t \frac{\partial w^{n+1}}{\partial r}, \quad a_{41}=-\delta t \frac{\partial w^{n+1}}{\partial r} \\
a_{44}=1.0+\delta t\left(\frac{1}{W i}+\frac{u^{n+1}}{r}\right), \quad a_{43}=-\delta t \frac{\partial u^{n+1}}{\partial z},
\end{array}\right.
$$


e as componentes do vetor indepente pelas expressões,

$$
\left\{\begin{array}{l}
F_{1}=\left[A^{r r}\right]^{n}+\delta t\left[\frac{1}{W i}-\frac{1}{r} \frac{\partial\left(r u^{n+1}\left[A^{r r}\right]^{n}\right)}{\partial r}-\frac{\partial\left(w^{n+1}\left[A^{r r}\right]^{n}\right)}{\partial z}\right] \\
F_{2}=\left[A^{\theta \theta}\right]^{n}+\delta t\left[\frac{1}{W i}-\frac{1}{r} \frac{\partial\left(r u^{n+1}\left[A^{\theta \theta}\right]^{n}\right)}{\partial r}-\frac{\partial\left(w^{n+1}\left[A^{\theta \theta}\right]^{n}\right)}{\partial z}\right] \\
F_{3}=\left[A^{z z}\right]^{n}+\delta t\left[\frac{1}{W i}-\frac{1}{r} \frac{\partial\left(r u^{n+1}\left[A^{z z}\right]^{n}\right)}{\partial r}-\frac{\partial\left(w^{n+1}\left[A^{z z}\right]^{n}\right)}{\partial z}\right] \\
F_{4}=\left[A^{r z}\right]^{n}+\delta t\left[\frac{0}{W i}-\frac{1}{r} \frac{\partial\left(r u^{n+1}\left[A^{r z}\right]^{n}\right)}{\partial r}-\frac{\partial\left(w^{n+1}\left[A^{r z}\right]^{n}\right)}{\partial z}\right]
\end{array}\right.
$$

As derivadas na Equação 2.23 são aproximadas por diferenças finitas de segunda ordem, enquanto que os termos convectivos na Equação 2.24 são calculados pelo método upwind de alta ordem Bounded Interpolation Scheme for the Treatment of Advection (CUBISTA) (ALVES; OLIVEIRA; PINHO, 2003). A solução do sistema linear 2.22 é obtida exatamente e é determinada pelas expressões

$$
\left\{\begin{array}{l}
{\left[A^{\theta \theta}\right]^{n+1}=\frac{F_{2}}{a_{22}}, \quad\left[A^{r z}\right]^{n+1}=\frac{F_{4}-\frac{a_{41}}{a_{11}} F_{1}-\frac{a_{43}}{a_{33}} F_{3}}{a_{44}-\frac{a_{41}}{a_{11}} a_{14}-\frac{a_{43}}{a_{33}} a_{34}}} \\
{\left[A^{r r}\right]^{n+1}=\frac{1}{a_{11}}\left[F_{1}-a_{14}\left[A^{r z}\right]^{n+1}\right], \quad\left[A^{z z}\right]^{n+1}=\frac{1}{a_{33}}\left[F_{3}-a_{34}\left[A^{r z}\right]^{n+1}\right] .}
\end{array}\right.
$$

Logo, o tensor $\tau^{n+1}$ pode ser agora determinado diretamente pela equação

$$
\tau^{n+1}=\frac{1}{\operatorname{Re} W i}(1-\beta)\left(\mathbf{A}^{n+1}-\mathbf{I}\right)+\frac{2}{R e} \beta \mathbf{D}^{n+1},
$$

e o tensor não-newtoniano $\mathbf{S}^{n+1}$ é obtido por (após introduzir $\boldsymbol{\tau}^{n+1}$ na Equação 2.10)

$$
\mathbf{S}^{n+1}=\frac{1}{R e W i}(1-\beta)\left(\mathbf{A}^{n+1}-\mathbf{I}\right)+\frac{2}{R e}(\beta-1) \mathbf{D}^{n+1} .
$$

\section{PASSO 3: Movimentação da superfície livre}

Emprega-se um método de rastreamento frontal, no qual, a superfície livre do fluido é composta por um conjunto de marcadores $\left\{\mathbf{x}_{k}\right\}=\left\{\left(r_{k}, z_{k}\right)\right\}$ que definem uma curva linear por partes, onde aqui, o índice $k$ denota um marcador específico. Uma vez atualizada a velocidade $\mathbf{v}^{n+1}$, a posição dos marcadores é atualizada utilizando as velocidades locais $\mathbf{v}_{k}^{n+1}=\left(u_{k}, w_{k}\right)^{n+1}$ que são calculadas ao fazer uma interpolação bilinear envolvendo as quatro velocidades mais próximas do marcador $\mathbf{x}_{k}$. Por exemplo, com relação a Figura $4 \mathrm{a}$, a velocidade $u_{k}$ do marcador $\mathbf{x}_{k}$ é calculada utilizando as velocidades alocadas nos três quadrados pretos ( $\left.\mathbf{\square}\right)$ e um quadrado verde ( $\square$ ) enquanto que a velocidade $w_{k}$ é obtida utilizando uma velocidade posicionada no 
círculo preto $(\bullet)$, uma velocidade posicionada no circulo verde $(\bullet)$ e dois círculos marrons $(\bullet)$ próximos ao marcador $\mathbf{x}_{k}$. A nova posição do marcador $\left\{\mathbf{x}_{k}\right\}$ é então calculada resolvendo

$$
\frac{d \mathbf{x}_{k}}{d t}=\mathbf{v}_{k}^{n+1}
$$

aplicando um método Runge-Kutta (R-K) de segunda ordem.

No método de rastreamento frontal, não é premitido que as partículas marcadoras colidam com paredes sólidas onde ambas as velocidades no marcador $\left(r_{k}, z_{k}\right)$ se anulam. Não obstante, elas podem estar tão próximas da parede quanto $(1 / N) \delta$ onde $N$ é um número inteiro e $\delta$ é o espaçamento da malha. Dessa maneira, supõe-se que a superfície livre está em contato com uma parede sólida quando um marcador estiver a uma distância inferior a $(1 / N) \delta$ da mesma. Isto faz com que a velocidade normal do marcador fique pequena $\left(u_{n} \approx 0\right)$ enquanto que sua velocidade tangencial pode ser grande. Nos resultados apresentados neste trabalho utilizou-se $N=8$.

Figura 4 - (a) Movimento da superfície livre (curva azul) perto de uma parede sólida (linha marron); velocidades mostradas na cor marron são calculadas pela condição de contorno de nãoescorregamento enquanto que as velocidades na cor verde são calculadas pelas condições de contorno na superfície livre (ver Equação 2.15b) e a equação de conservação de massa. As velocidades marcadas pelos símbolos na cor preta são obtidas pela solução das equações de conservação de quantidade de movimento e conservação de massa. (b) Representação ilustrativa do cálculo das velocidades em células de superfície livre (as velocidades na cor verde) e aplicação das condições de superfície livre, Equação $2.15 b$.

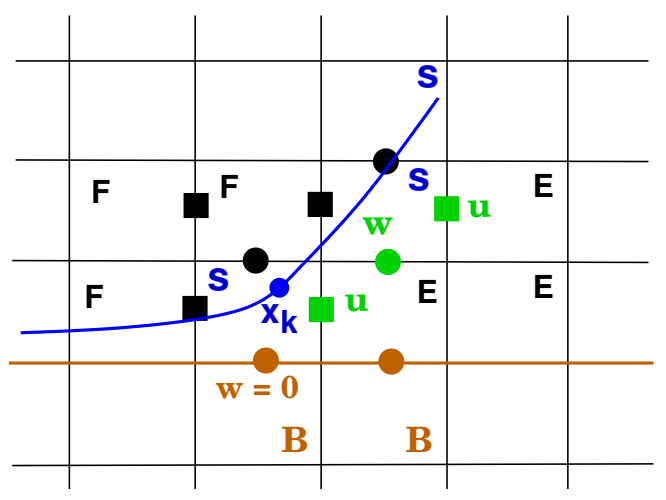

(a)

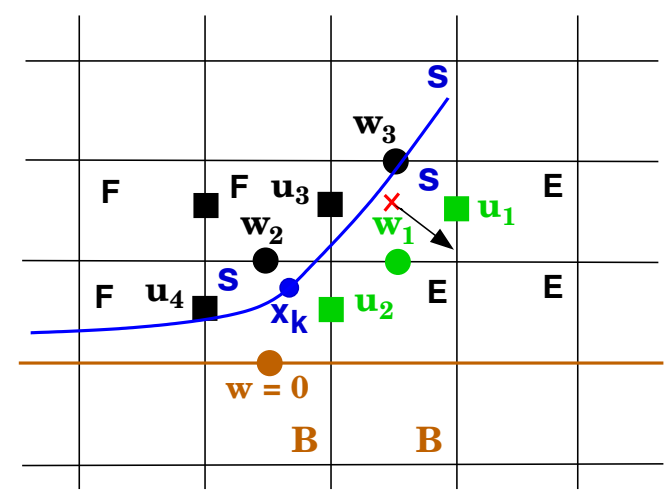

(b)

Fonte: Elaborada pelo autor.

Para ilustrar como as condição de contorno para a superfície livre, Equação 2.15b é aplicada, considera-se as velocidades na cor verde mostradas na Figura 4b. A velocidade $\mathbf{u}_{2}$ é calculada diretamente pela equação de conservação de massa discretizada no centro $(i, j)$ da célula $\mathbf{S}$ que contém o marcador $\left(r_{k}, z_{k}\right)$, fornecendo

$$
\frac{1}{r_{i}}\left[\frac{r_{i+1 / 2} \mathbf{u}_{2}-r_{i-1 / 2} \mathbf{u}_{\mathbf{4}}}{\delta r}\right]+\frac{\mathbf{w}_{\mathbf{2}}-\mathbf{0}}{\delta z}=0, \text { que implica, } \mathbf{u}_{2}=\left\{\frac{r_{i-1 / 2}}{r_{i+1 / 2}}\right\} \mathbf{u}_{\mathbf{4}}-\left\{\frac{r_{i}}{r_{i+1 / 2}}\right\}\left(\frac{\delta r}{\delta z}\right) \mathbf{w}_{\mathbf{2}} \text {. }
$$


Para calcular as velocidades $\mathbf{u}_{1}$ e $\mathbf{w}_{1}$, as equações de conservação de massa e a condição de contorno na superfície livre, Equação 2.15b, são aplicadas no centro $(i, j)$ da célula de superfície que tem $\mathbf{u}_{1}$ e $\mathbf{w}_{1}$ alocadas em suas faces (ver Figura $4 b$ ). Se considerada a configuração da superfície livre exposta na Figura $4 \mathrm{~b}$, admite-se que o vetor normal local faz um ângulo de $-45^{0}$ entre os eixos das coordenadas (ver o vetor na Figura $4 b$ ), logo, $\mathbf{n}=\left(\frac{\sqrt{2}}{2},-\frac{\sqrt{2}}{2}\right)$. Inserindo o vetor normal na Equação 2.15b e considerando a equação de conservação de massa obtém-se

$$
\begin{aligned}
& \frac{\partial u}{\partial r}-\frac{\partial w}{\partial z}=\frac{R e}{2}\left(S^{z z}-S^{r r}\right) \\
& \frac{1}{r} \frac{\partial(r u)}{\partial r}+\frac{\partial w}{\partial z}=0 .
\end{aligned}
$$

Discretizando essas equações no centro $(i, j)$ da célula $\mathbf{S}$ tem-se,

$$
\begin{aligned}
& \frac{\mathbf{u}_{1}-\mathbf{u}_{\mathbf{3}}}{\delta r}-\frac{\mathbf{w}_{\mathbf{3}}-\mathbf{w}_{\mathbf{1}}}{\delta z}=\frac{\operatorname{Re}}{2}\left(S_{i, j}^{z z}-S_{i, j}^{r r}\right) \\
& \frac{1}{r_{i}}\left[\frac{r_{i+1 / 2} \mathbf{u}_{1}-r_{i-1 / 2} \mathbf{u}_{\mathbf{3}}}{\delta r}\right]+\frac{\mathbf{w}_{\mathbf{3}}-\mathbf{w}_{\mathbf{1}}}{\delta z}=0 .
\end{aligned}
$$

A Equação 2.32 e Equação 2.33 formam um sistema linear $(2 \times 2)$ para as velocidades $\mathbf{u}_{1}$ e $\mathbf{w}_{1}$ que tem a seguinte solução

$$
\begin{aligned}
& \mathbf{u}_{1}=\left[\frac{r_{i}+r_{i-1 / 2}}{r_{i}+r_{i+1 / 2}}\right] \mathbf{u}_{3}+0.5 \delta r R e\left[\frac{r_{i}}{r_{i}+r_{i+1 / 2}}\right]\left(S_{i, j}^{z z}-S_{i, j}^{r r}\right), \\
& \mathbf{w}_{1}=\mathbf{w}_{\mathbf{3}}+\frac{\delta z}{\delta r} \frac{1}{r_{i}}\left[r_{i+1 / 2} \mathbf{u}_{1}-r_{i-1 / 2} \mathbf{u}_{3}\right] .
\end{aligned}
$$

O cálculo das velocidades em outras configurações das células de superfície livre são similares ao caso tratado acima. O trabalho de Tomé et al. (2008) apresenta detalhes de como são definidos os vetores normais para configurações mais gerais da superfície livre.

Este tratamento possibilitou simular escoamentos com superfície livre em movimento interagindo com paredes sólidas (ver por exemplo, Tomé et al. (2000)) sem a necessidade de definir um ângulo de contato.

\subsection{Resultados de verificação}

Para verificar o método numérico descrito na Seção 2.3 foi simulado o escoamento totalmente desenvolvido no tubo e os resultados são apresentados na Subseção 2.4.1. Uma segunda verificação é apresentada na Subseção 2.4.2 onde os resultados das simulações do escoamento transiente causado pelo impacto de uma gota incidindo sobre uma placa sólida são comparados com outros resultados numéricos da literatura.

\subsubsection{Escoamento laminar desenvolvido no tubo}

O domínio computacional consiste de um tubo de raio $R=1.0 \mathrm{~m}$ e comprimento $H=$ $10 R$ m como ilustrado na Figura 5. Inicialmente o tubo encontra-se vazio e o fluido é injetado 
na entrada do tubo (INFLOW) impondo o seguinte perfil de escoamento desenvolvido:

$$
\begin{gathered}
w(r)=\left(1-r^{2}\right), \quad u(r)=0, \quad \dot{\gamma}=\frac{d w}{d r}=-2 r, \\
\tau^{z z}(r)=\frac{2}{R e} W i(1-\beta) \dot{\gamma}^{2}, \quad \tau^{r z}(r)=\frac{1}{R e} \dot{\gamma}, \quad \tau^{r r}(r)=\tau^{\theta \theta}(r)=0 .
\end{gathered}
$$

Figura 5 - (a) Descrição do domínio do escoamento e (b) domínio computacional.

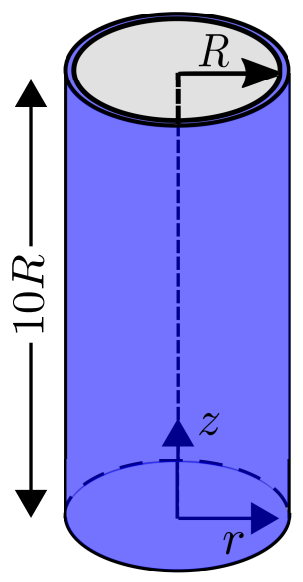

(a)

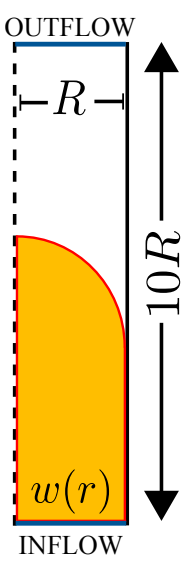

(b)

Fonte: Elaborada pelo autor.

Os dados que caracterizam o escoamento são: $L=R=1 \mathrm{~m}, U=1 \mathrm{~m} \mathrm{~s}^{-1}, \rho=1000 \mathrm{~kg} \mathrm{~m}^{-3}$, $\eta_{0}=1000$ Pa.s, $\lambda_{1}=1.0 \mathrm{~s}, \lambda_{2}=\beta \lambda_{1}$ s. Os valores de $\beta$ utilizados são: 0.1, 0.01, 0.001. Portanto, $R e=\frac{\rho U L}{\eta_{0}}=1.0$ e $W i=\lambda_{1} \frac{U}{L}=1.0$. As malhas computacionais utilizadas são definidas na Tabela 1. Esse problema foi simulado até o tempo $t(U / L)=100.0$ e assume-se que após esse tempo o escoamento já atingiu o regime permanente.

Tabela 1 - Malhas utilizadas para simular o escoamento no tubo do fluido Oldroyd-B.

\begin{tabular}{l||c|c|c}
\hline Malha $\mathrm{M}_{K}$ & $\mathrm{M}_{1}$ & $\mathrm{M}_{2}$ & $\mathrm{M}_{3}$ \\
\hline \hline$\delta_{K}=\delta r=\delta z$ & 0.1000 & 0.0500 & 0.0250 \\
No. de células na malha & $(10 \times 100)$ & $(20 \times 200)$ & $(40 \times 400)$ \\
\hline
\end{tabular}

Fonte: Dados da pesquisa.

A Figura 6 apresenta as soluções obtidas para $\tau^{z z}\left(r, z_{m}\right)$ utilizando os valores de $\beta=$ $0.1,0.01,0.001$ e a Figura 7 mostra as soluções numéricas e analícas para $w\left(r, z_{m}\right)$ e $\tau^{r z}\left(r, z_{m}\right)$ obtidas $\operatorname{com} \beta=0.001$. Essas soluções são plotadas no meio do tubo em $z_{m}=5 R$. Pode-se ver que as soluções numéricas nas diferentes malhas concordam bem com a solução analítica. A Tabela 2 mostra que os erros, calculados com a norma $L_{2}$ definida na Equação 2.37, decaem quando a malha é refinada (por exemplo, a Figura 8 mostra os erros obtidos com $\beta=0.001$ ) e a Tabela 3 mostra que a ordem de convergência determinada pela Equação 2.38 é $p \approx 2$. Esses 
resultados indicam que a ordem de convergência da solução numérica está de acordo com as aproximações de diferenças finitas de segunda ordem aplicadas para resolver as equações.

$$
\begin{gathered}
E(\cdot)_{K}=\sqrt{\delta_{K} \sum\left[(\cdot)_{\text {exata }}-(\cdot)_{\text {num }}\right]^{2}}, \quad\left(\delta_{K} \quad \text { é o espaçamento da malha } \mathrm{M}_{K}\right) \\
O\left(\mathrm{M}_{K}, \mathrm{M}_{K+1}\right)=\log \left[\frac{E\left(\mathrm{M}_{K}\right) / E\left(\mathrm{M}_{K+1}\right)}{\delta_{K} / \delta_{K+1}}\right] .
\end{gathered}
$$

Tabela 2 - Erros na norma $L_{2}$ entre as soluções exata e numéricas calculadas nas malhas $\mathbf{M}_{1}, \mathbf{M}_{2}$ e $\mathbf{M}_{3}$ variando $\beta$.

\begin{tabular}{c||c|c|c}
\multicolumn{5}{c}{$\beta=0.1$} \\
\hline Malha & $E(w)$ & $E\left(\tau^{r z}\right)$ & $E\left(\tau^{z z}\right)$ \\
\hline \hline $\mathrm{M}_{1}$ & $1.683826 \mathrm{e}-03$ & $5.701254 \mathrm{e}-03$ & $3.161501 \mathrm{e}-02$ \\
$\mathrm{M}_{2}$ & $4.260340 \mathrm{e}-04$ & $1.437037 \mathrm{e}-03$ & $8.004787 \mathrm{e}-03$ \\
$\mathrm{M}_{3}$ & $1.065525 \mathrm{e}-04$ & $3.600521 \mathrm{e}-04$ & $2.007141 \mathrm{e}-03$ \\
\hline \multicolumn{4}{|c}{$\beta=0.01$} \\
\hline Malha & $E(w)$ & $E\left(\tau^{r z}\right)$ & $E\left(\tau^{z z}\right)$ \\
\hline \hline $\mathrm{M}_{1}$ & $1.683826 \mathrm{e}-03$ & $5.700822 \mathrm{e}-03$ & $3.478049 \mathrm{e}-02$ \\
$\mathrm{M}_{2}$ & $4.260340 \mathrm{e}-04$ & $1.436409 \mathrm{e}-03$ & $8.804556 \mathrm{e}-03$ \\
$\mathrm{M}_{3}$ & $1.065525 \mathrm{e}-04$ & $3.600521 \mathrm{e}-04$ & $2.208561 \mathrm{e}-03$ \\
\hline \multicolumn{4}{|c}{$\beta=0.001$} \\
\hline $\mathrm{Malha}$ & $E(w)$ & $E\left(\tau^{r z}\right)$ & $E\left(\tau^{z z}\right)$ \\
\hline \hline $\mathrm{M}_{1}$ & $1.683826 \mathrm{e}-03$ & $5.700822 \mathrm{e}-03$ & $3.509690 \mathrm{e}-02$ \\
$\mathrm{M}_{2}$ & $4.260340 \mathrm{e}-04$ & $1.436409 \mathrm{e}-03$ & $8.884225 \mathrm{e}-03$ \\
$\mathrm{M}_{3}$ & $1.065525 \mathrm{e}-04$ & $3.600521 \mathrm{e}-04$ & $2.227821 \mathrm{e}-03$ \\
\hline \multicolumn{4}{c}{}
\end{tabular}

Fonte: Dados da pesquisa.

Tabela 3 - Ordens de convergência obtidas com os erros determinados na norma $L_{2}$ para o escoamento no tubo com diferentes valores de $\beta$.

\begin{tabular}{c|c|c|c}
\multicolumn{5}{c}{$\beta=0.1$} \\
\hline Malha & $E(w)$ & $E\left(\tau^{r z}\right)$ & $E\left(\tau^{z z}\right)$ \\
\hline \hline$O\left(\mathrm{M}_{1}, \mathrm{M}_{2}\right)$ & $1.982702 \mathrm{e}+00$ & $1.988182 \mathrm{e}+00$ & $1.981675 \mathrm{e}+00$ \\
$O\left(\mathrm{M}_{2}, \mathrm{M}_{3}\right)$ & $1.999404 \mathrm{e}+00$ & $1.996820 \mathrm{e}+00$ & $1.995721 \mathrm{e}+00$ \\
\hline \multicolumn{4}{c}{$\beta=0.01$} \\
\hline Malha & $E(w)$ & $E\left(\tau^{r z}\right)$ & $E\left(\tau^{z z}\right)$ \\
\hline \hline$O\left(\mathrm{M}_{1}, \mathrm{M}_{2}\right)$ & $1.982702 \mathrm{e}+00$ & $1.988704 \mathrm{e}+00$ & $1.981956 \mathrm{e}+00$ \\
$O\left(\mathrm{M}_{2}, \mathrm{M}_{3}\right)$ & $1.999404 \mathrm{e}+00$ & $1.996189 \mathrm{e}+00$ & $1.995143 \mathrm{e}+00$ \\
\hline \multicolumn{4}{c}{$\beta=0.001$} \\
\hline $\mathrm{Malha}^{\prime}$ & $E(w)$ & $E\left(\tau^{r z}\right)$ & $E\left(\tau^{z z}\right)$ \\
\hline \hline$O\left(\mathrm{M}_{1}, \mathrm{M}_{2}\right)$ & $1.979781 \mathrm{e}+00$ & $1.988903 \mathrm{e}+00$ & $1.982123 \mathrm{e}+00$ \\
$O\left(\mathrm{M}_{2}, \mathrm{M}_{3}\right)$ & $1.997175 \mathrm{e}+00$ & $1.995657 \mathrm{e}+00$ & $1.995681 \mathrm{e}+00$ \\
\hline
\end{tabular}

Fonte: Dados da pesquisa. 
Figura 6 - Comparação da componente $\tau^{z z}(r)$ com a solução analítica para o escoamento no tubo. Esses resultados foram obtidos $\operatorname{com} \beta=0.1,0.01,0.001$.

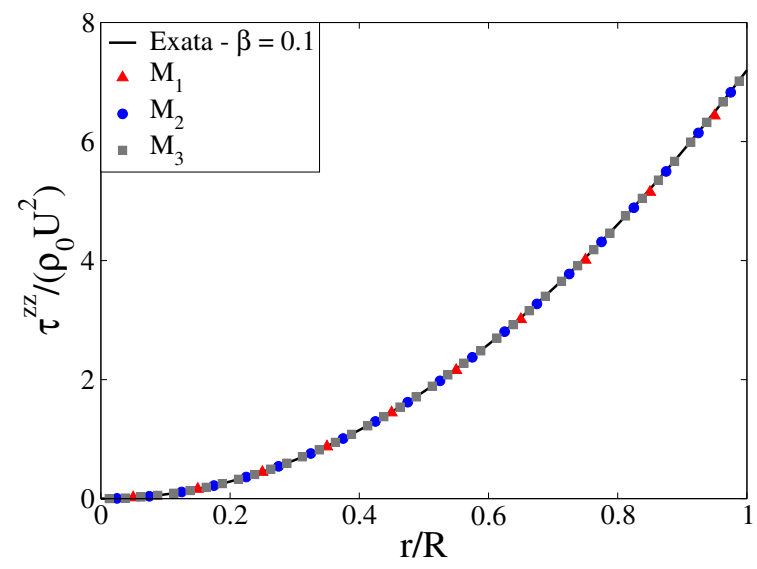

(a)

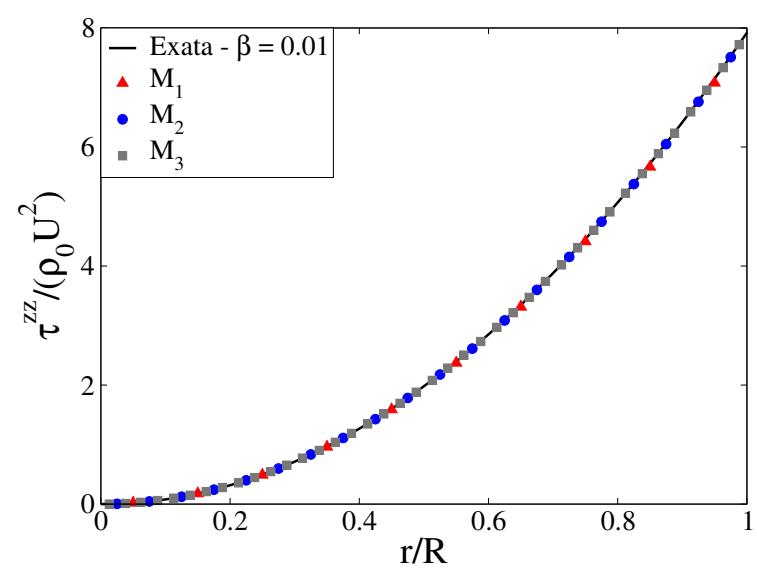

(b)

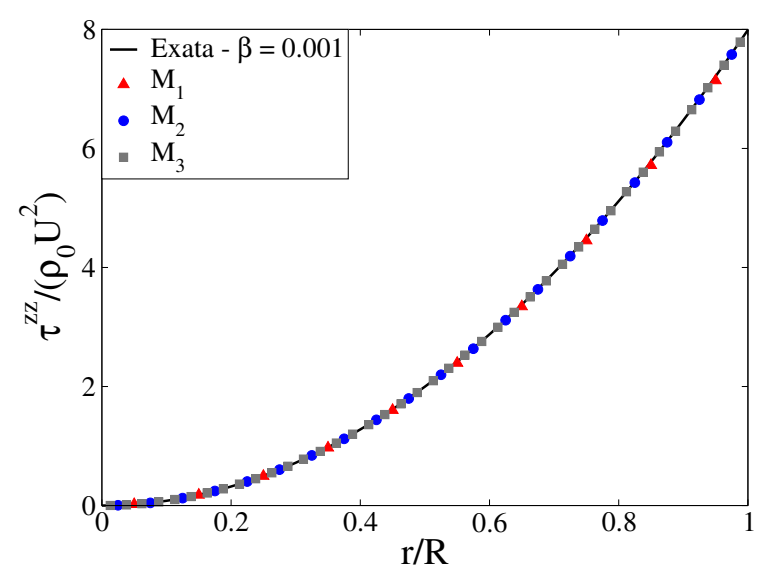

(c)
Figura 7 - Comparação de (a) $w(r)$ e (b) $\tau^{r z}(r)$ com a respectiva solução exata no tubo. Esses resultados foram obtidos com $\beta=0.001$ nas malhas $\mathrm{M}_{1}, \mathrm{M}_{2}$ e $\mathrm{M}_{3}$.

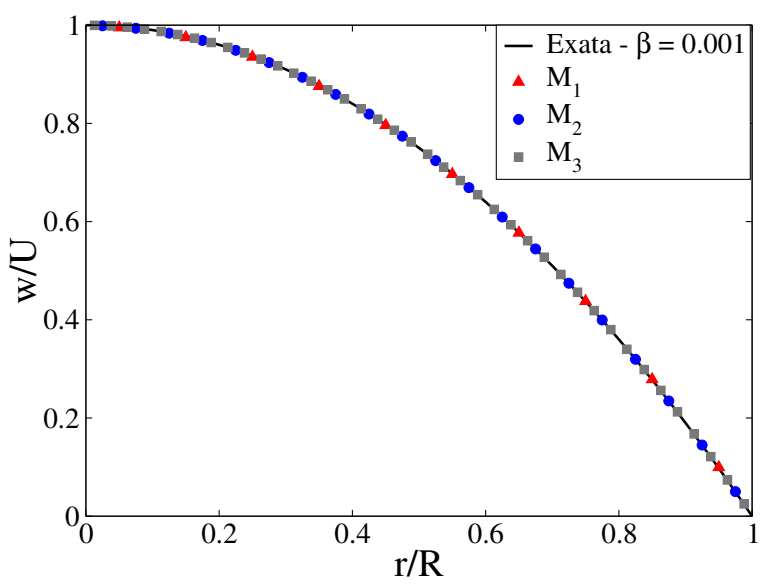

(a)

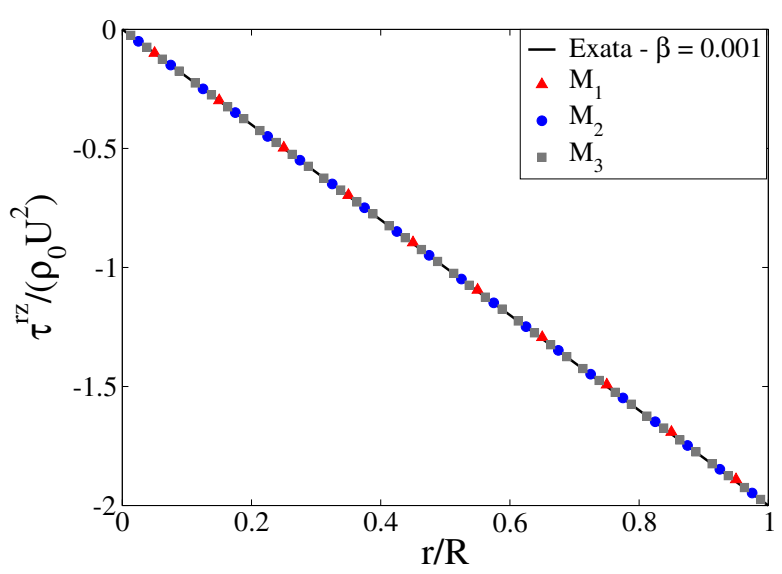

(b)

Fonte: Elaborada pelo autor. 
Figura 8 - Erros referente ao escoamento no tubo. Resultados obtidos $\operatorname{com} \beta=0.001$ nas malhas $\mathrm{M}_{1}, \mathrm{M}_{2}$ $\mathrm{e}_{3}$.

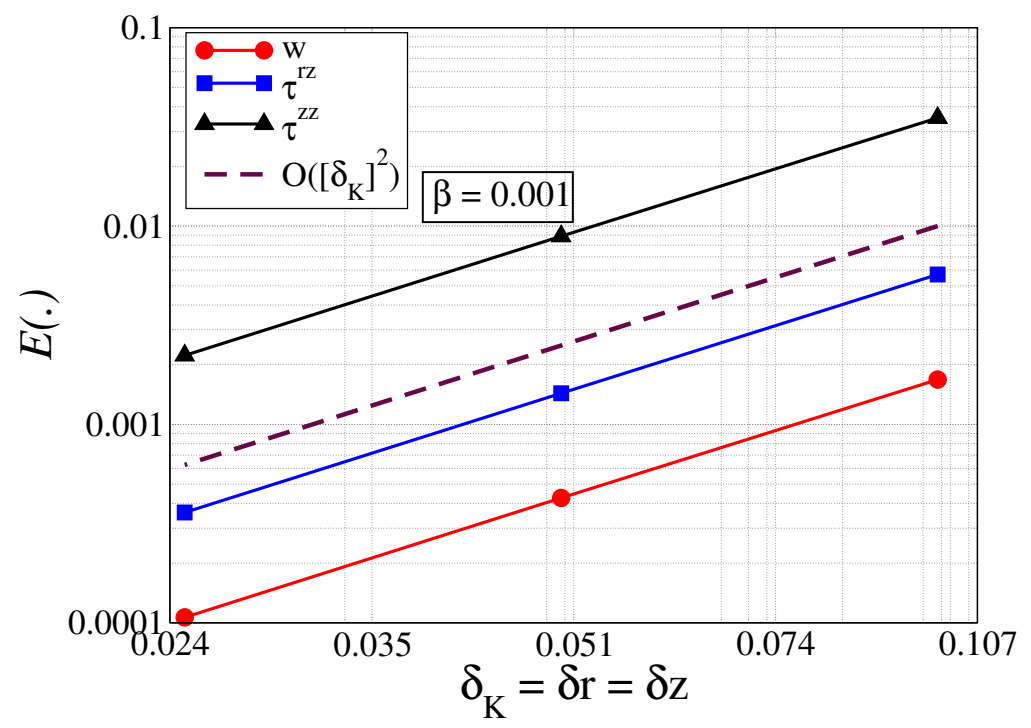

Fonte: Elaborada pelo autor.

Os resultados obtidos nesta seção mostram que para escoamentos confinados o método numérico desenvolvido nesse trabalo obteve resultados quantitativamente corretos. Resultados adicionais desse escoamento estão disponíveis no Apêndice $\mathrm{C}$.

\subsubsection{Simulação do impacto de uma gota viscoelástica sobre uma placa plana}

Para testar o código em escoamentos com superfícies livres em movimento, simulou-se o escoamento de uma gota axissimétrica (ver Figura 9a), modelada pelo fluido Oldroyd-B, incidindo sobre uma superfície rígida plana. Esse é um bom problema para aferir o algoritmo numérico em escoamentos em que a superfície livre sofre grandes deformações. Além disso, pode-se fazer comparações com soluções obtidas por outras técnicas numéricas.

Considerou-se uma gota esférica de diâmetro inicial $d_{0}=2 R$ posicionada à uma altura $H$ acima de um disco circular (ver Figura $9 \mathrm{~b}$ ). Em $t=0$, a gota começa a escoar para baixo devido ao efeito da gravidade com uma velocidade inicial $w(r, z, 0)=-U$ e assume-se que inicialmente, o tensor extra tensão $\tau$ é nulo. Após a gota colidir com o disco, a mesma escoa radialmente aumentando seu diâmetro $d(t)$, e após um curto período de tempo as forças elásticas começam a se desenvolver e espera-se que as velocidades dentro da gota mudem de sinal, fazendo com que a gota comece a se contrair e consequentemente diminua seu diâmetro $d(t)$. O interesse nesse problema é estudar os efeitos dos parâmetros $W i$ e $\beta$ na variação temporal do diâmetro $d(t)$ da gota.

Como uma verificação do código, um refinamento de malha seguido de comparações com resultados numéricos de outros pesquisadores foram realizados. Os dados utilizados nes- 
sas simulações estão listados na Tabela 4. Com esses dados, obtém-se os seguintes números adimensionais: $\operatorname{Re}=5, W i=1, \beta=0.1$ e $F r=2.2576$. As simulações foram realizadas até $t *\left(U / d_{0}\right)=10.0$ empregando as malhas definidas na Tabela 5. Os resultados obtidos são mostrados na Figura 10a onde pode-se observar que as soluções apresentam uma boa convergência para os resultados da malha M5. Além disso, a Figura 10b compara o diâmetro $d(t)$ com os resultados publicados por Figueiredo et al. (2014) e Xu et al. (2012) e com os resultados obtidos

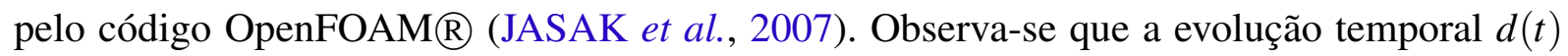
calculada pelo método numérico descrito na Seção 2.3 concorda bem com esses resultados.

Tabela 4 - Dados de entrada (unidades SI) utilizadas na simulação do impacto da gota em uma placa rígida.

\begin{tabular}{c|c|c|c|c|c|c|c}
\hline $\begin{array}{c}d_{0}=2 R \\
{[\mathrm{~m}]}\end{array}$ & $\begin{array}{c}H \\
{[\mathrm{~m}]}\end{array}$ & $\begin{array}{c}U \\
{\left[\mathrm{~ms}^{-1}\right]}\end{array}$ & $\begin{array}{c}\lambda_{1} \\
{[\mathrm{~s}]}\end{array}$ & $\begin{array}{c}\eta_{0} \\
{[\mathrm{~Pa} . \mathrm{s}]}\end{array}$ & $\begin{array}{c}\rho \\
{\left[\mathrm{kgm}^{-3}\right]}\end{array}$ & $\begin{array}{c}g \\
{\left[\mathrm{~ms}^{-2}\right]}\end{array}$ & $F r$ \\
\hline \hline 0.02 & 0.04 & 1.0 & 0.02 & 4.0 & 1000.0 & -9.81 & 2.2576 \\
\hline
\end{tabular}

Tabela 5 - Malhas aplicadas na simulação do impacto da gota sobre uma superfície plana.

\begin{tabular}{l||c|c|c|c|c}
\hline Malha & M1 & M2 & M3 & M4 & M5 \\
\hline \hline espaçamento $\left(\delta / d_{0}\right)$ & 0.050000 & 0.025000 & 0.016666 & 0.012500 & 0.006250 \\
\hline
\end{tabular}

Figura 9 - Simulação do impacto da gota. (a) Visualização 3D do estado incial; (b) domínio computacional; (c) células de referência.

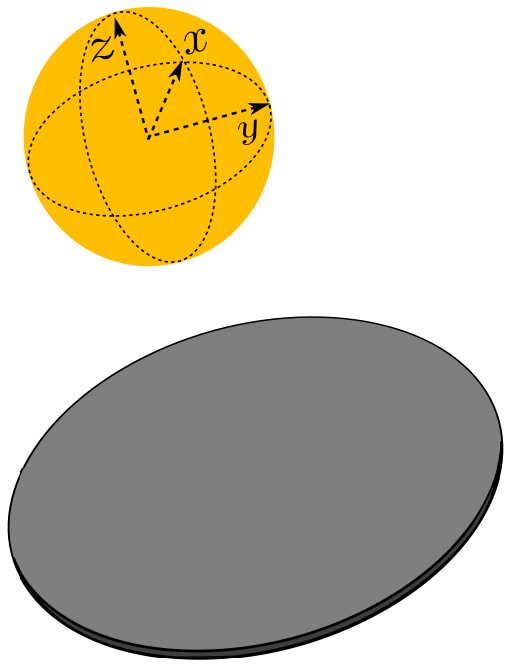

(a)

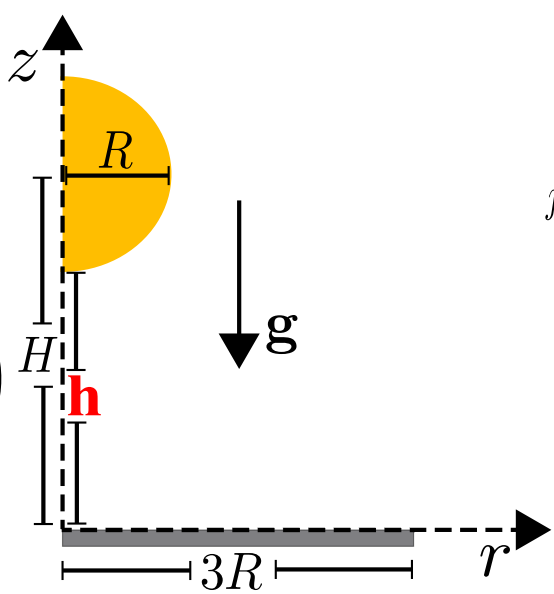

(b)

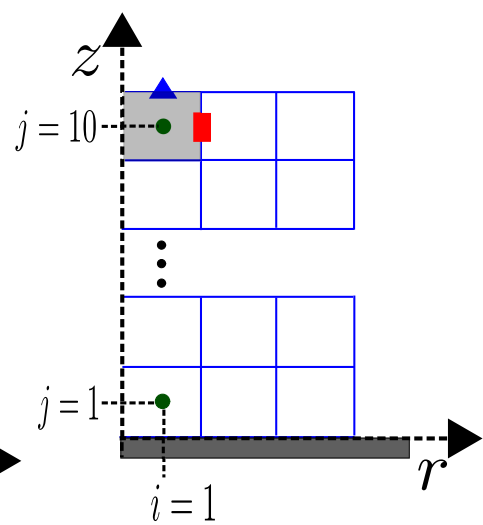

(c)

Fonte: Elaborada pelo autor. 
Figura 10 - Simulação do impacto de uma gota em um disco. $R e=5, W i=1, \beta=0.1$. (a) Refinamento de malha; (b) Comparação com resultados de outros autores. Os resultados deste trabalho foram obtidos na malha M4.

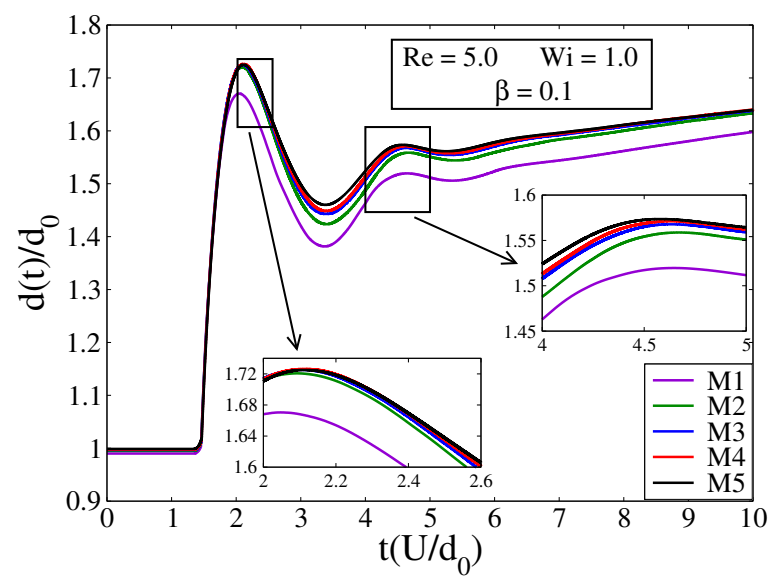

(a)

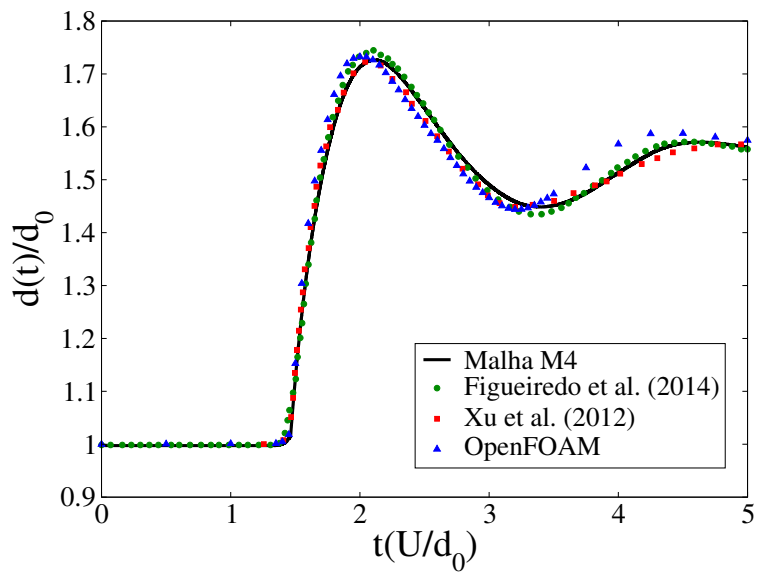

(b)

Fonte: Elaborada pelo autor.

\subsection{Impacto da gota sobre uma placa plana: novos resul- tados}

Para demonstrar a capacidade da técnica numérica implementada, para resolver escoamentos viscoelásticos transientes com superfície livre, os dados da Tabela 4 e a malha M4 foram utilizados para simular o problema do impacto da gota para valores de $\beta$ entre $[0,1]$. Para demonstrar que essa técnica numérica é capaz de resolver o modelo Oldroyd-B para qualquer valor de $\beta$ no intervalo $[0,1]$, realizou-se várias simulações do problema da gota utilizando $W i=1,20$ e $R e=5$. Nessas simulações, utilizou-se os seguintes valores da razão de viscosidades $\beta=0,0.001,0.01,0.02,0.1,0.3,0.5,0.7,0.9,0.95,0.99$. O escoamento newtoniano, corresponde ao valor $\beta=1$ também foi simulado. Essas simulações foram executadas até o tempo adimensional $t *\left(U / d_{0}\right)=20$.

A Figura 11a mostra a variação temporal do diâmetro $d(t)$ para cada valor de $\beta$ e $W i=1.0$. Observa-se que os resultados $\operatorname{com} \beta=0.9,0.95$ e 0.99 são semelhantes e estão próximos do resultado da gota newtoniana $(\beta=1)$ que após impactar o disco, no tempo $t \approx 1.4$, escoa radialmente de modo que $d(t)$ cresce monotonicamente. Os resultados $\operatorname{com} \beta=0.3,0.5$ e 0.7 mostram uma pequena expansão e uma pequena contração da gota nos tempos $t \approx 2.1 \mathrm{e}$ $t \approx 3.7$, respectivamente. Após a contração, a gota escoa radialmente e monotonicamente.

Para $\beta=0.001,0.01,0.02$ e 0.1 o comportamento de $d(t)$ é mais distinto. O aumento de polímero dentro da gota, proporcional a $1-\beta$, propiciou uma maior elasticidade ao fluido, de modo que o fluido teve uma maior tensão polimérica. Isso permitiu que o diâmetro da gota tenha expandido e contraido várias vezes. A magnitude dessas oscilações tornou-se mais pronunciada 
à medida que o valor de $\beta$ diminuiu e para $\beta=0.001$ o diâmetro $d(t)$ é aproximadamente o mesmo obtido com o modelo UCM ( $\beta=0$, ver a curva pontilhada preta na Figura 11a).

Para observar os efeitos do alto número de Weissenberg na ampliação do raio da gota, simulações com $R e=5, W i=20$ e $\beta=0.01,0.1,0.3,0.5,0.7,0.9,0.95,0.99$ foram realizadas. A evolução do diâmetro $d(t)$ obtido nestas simulações são plotadas na Figura 11b para cada valor de $\beta$. Observa-se que após o impacto da gota no disco, os valores de $d(t)$ correspondentes a $\beta=0.3,0.5,0.7$ e 0.9 aumentam sem a ocorrência de contrações, enquanto que os resultados correspondentes a $\beta=0.95$ e 0.99 aproximam-se do escoamento newtoniano, como esperado. Entretanto, para $\beta=0.01$ e 0.1 os diâmetros $d(t)$ tiveram uma maior expansão, mais precisamente, $d(t)>2.5 * d_{0}$ para $\beta=0.01$ e $d(t)>2 d_{0}$ quando $\beta=0.1$. Para esses valores de $\beta$ a expansão da gota é seguida por uma contração. As oscilações não são presentes nas simulações dos escoamentos com $W i=20$ devido ao crescimento das tensões normais responsáveis pela inversão do escoamento, que subsequentemente são dissipadas. Estas tensões normais também levam mais tempo para se acumular e não crescem muito devido aos baixos gradientes de velocidade que aparecem após o impacto.

Para melhor visualizar a deformação na superfície da gota quando $R e=5, \beta=0.01$, $W i=1$ e $W i=20$, a Figura 12 apresenta visualizações tridimensionais do escoamento transiente em tempos selecionados. Para $W i=1$ (ver a coluna à esquerda), a gota expande inicialmente até $t=2.1$ e então começa a contrair até $t=3.1$ quando uma elevação no centro da gota pode ser obervada (ver o quadro 3D correspondente). Subsequentemente, a gota inicia novamente uma expansão, e observa-se uma depressão em seu centro em $t \approx 3.8$. Após esse tempo as velocidades na gota são pequenas e a sua superfície não apresenta grandes deformações. Devido a ação da gravidade a gota escoa monotonicamente. Acredita-se que estes efeitos são devido as forças elásticas do modelo Oldroyd-B. Estas observações estão de acordo com o traço temporal da componente de velocidade $w(r, z)$ mostrado na Figura 13a que plota as velocidades na célula $(1,10)$ ilustrada na Figura 9c. Em particular, observa-se que a velocidade $w$ muda seu sinal várias vezes, sinalizando a ocrência das fases de expansão e contração.

Os resultados com $W i=20$ são interessantes. O alto número de Weissenberg significa que demora mais tempo para que as tensões de cisalhamento do polímero cresçam após o impacto e desacelere o fluido radialmente. Assim, a gota espalhou mais que a gota com $W i=1$; semelhantemente, a fase de retração demorou mais para se desenvolver devido as tensões normais levarem mais tempo para atingir valores mais baixos porque essas tensões dependem diretamente dos gradientes de velocidade. O espalhamento máximo ocorreu em $t=3.1$ (ver Figura 12) onde pode-se constatar ondulações na superfície livre. A fina camada de fluido no perímetro do disco aparenta ser afetada pelas forças elásticas causando no fluido uma retração e avançando em direção ao centro. Note que a Figura 13 b mostra que ambas as velocidades são nulas no intervalo $[2.78,4.2]$; isso significa que a célula $(1,10)$ (identificada na Figura 9c) não conteve fluido nesse intervalo de tempo. No tempo $t=5.7$, um pequeno jato emerge no centro da gota e um 
ciclo de expansão e contração é observado, e ao longo do tempo, devido as forças viscosas e de gravidade (ver quadros $t=6.1,7.6,10.0$ ) essas fases são atenuadas deixando de ocorrer. Subsequentemente, nota-se pequenas modificações no formato da gota uma vez que o fluido encontra-se quase inativo (não observado nas figuras). Estas observações são confirmadas na Figura 13 b onde a variação das velocidades na célula $(1,10)$ (identificada na Figura 9c) são plotadas. Observa-se também que após $t=8$, as velocidades são muito pequenas resultando em pequenas mudanças no formato da superfície da gota.

Figura 11 - Simulação do impacto da gota em um disco com $R e=5$ e variando $\beta$ : (a) $W i=1$, (b) $W i=20$.

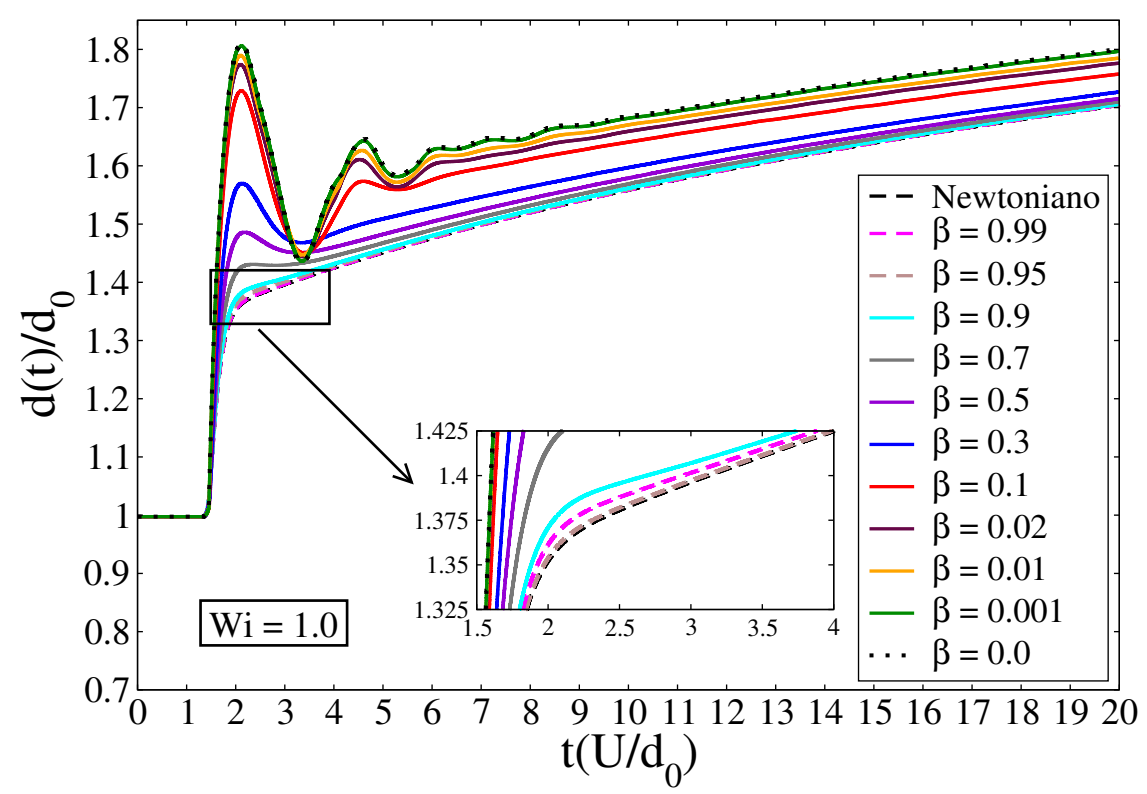

(a)

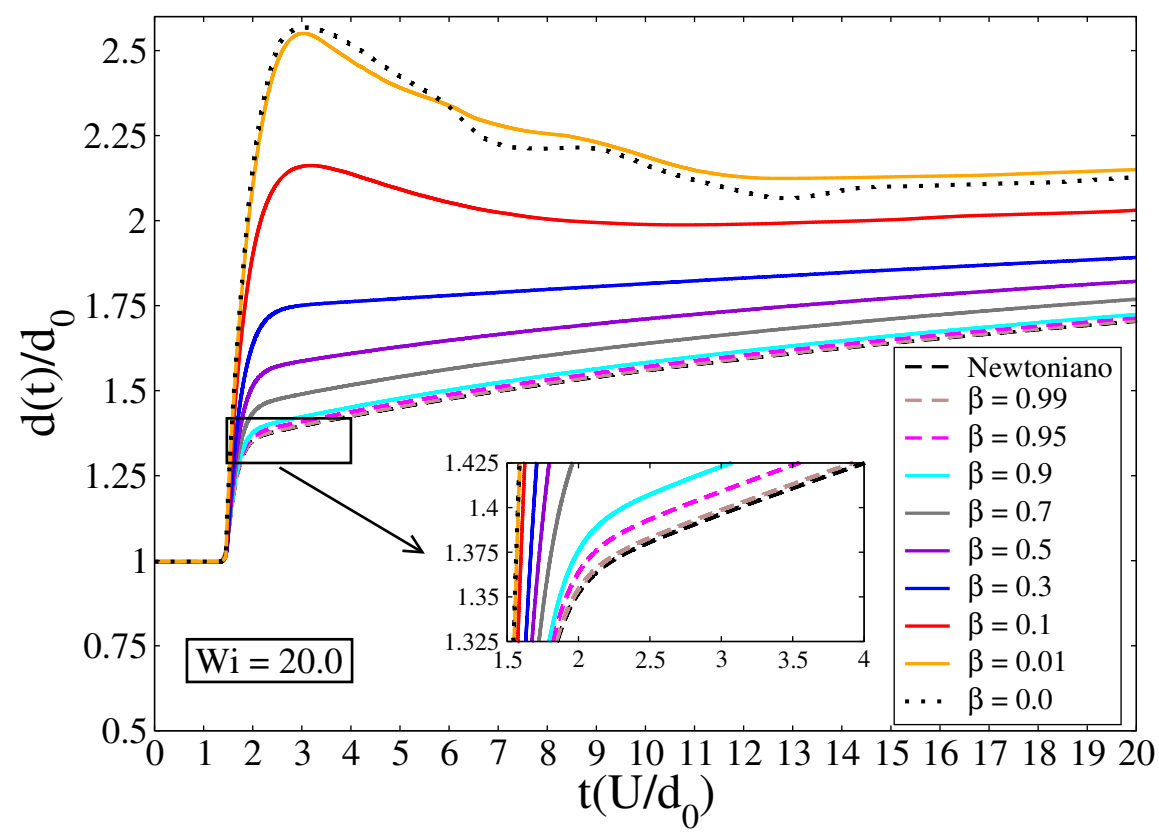

(b)

Fonte: Elaborada pelo autor. 
Figura 12 - Simulação de uma gota espalhando sobre um disco - $R e=5, \beta=0.01$ e $W i=1$ e 20, nos tempos selecionados. Gráficos de contornos da velocidade $u$. Coluna à esquerda: $W i=1$, coluna à direita: $W i=20$.
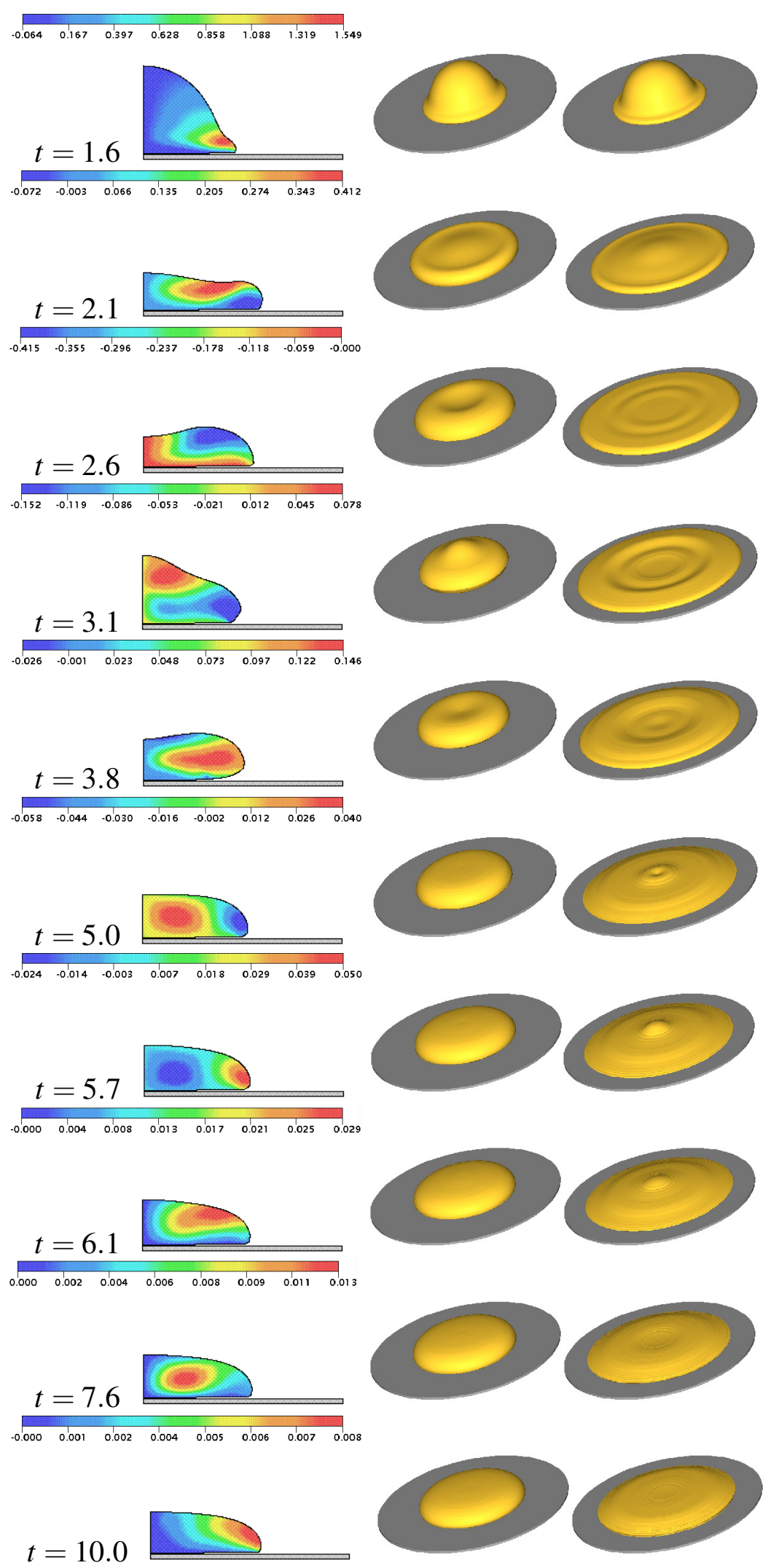

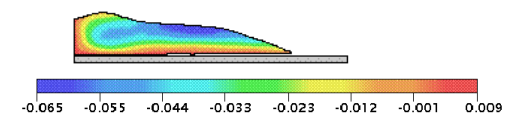

Fonte: Elaborada pelo autor.
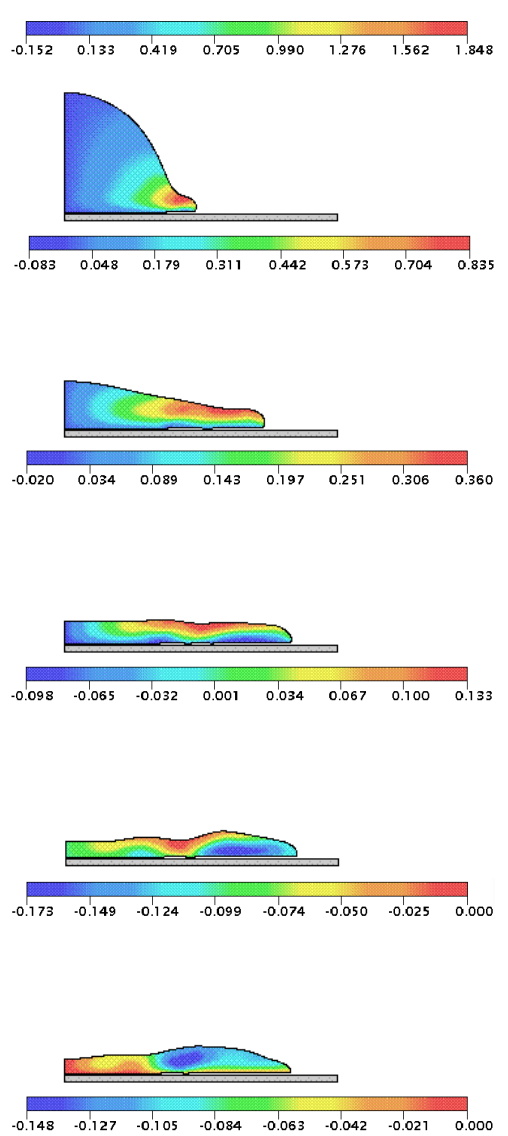
$\begin{array}{llllllll}0.065 & -0.055 & -0.044 & -0.033 & -0.023 & -0.012 & -0.001 & 0.009\end{array}$
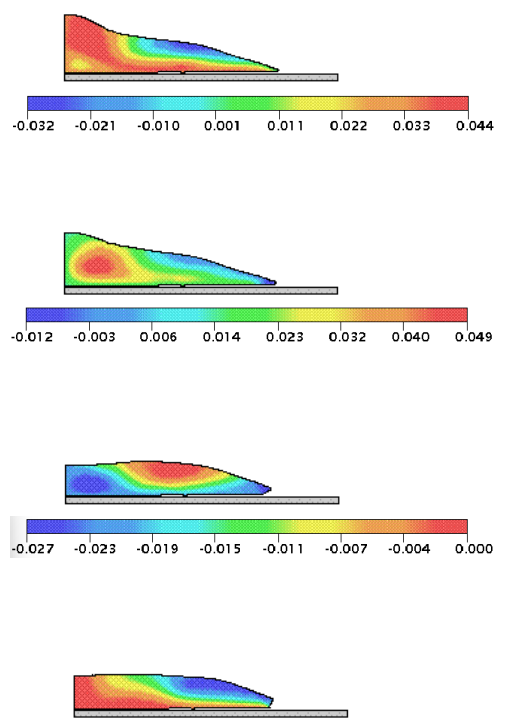
Figura 13 - Variação das velocidades $u(t)$ e $w(t)$ na célula $(1,10)$ identificada na Figura 9c. (a) $W i=1$; (b) $W i=20$. A descontinuidade nas velocidades se deve ao fato de que a célula $(1,10)$ torna-se vazia de fluido ao longo do intervalo de tempo $[2.78,4.2]$.

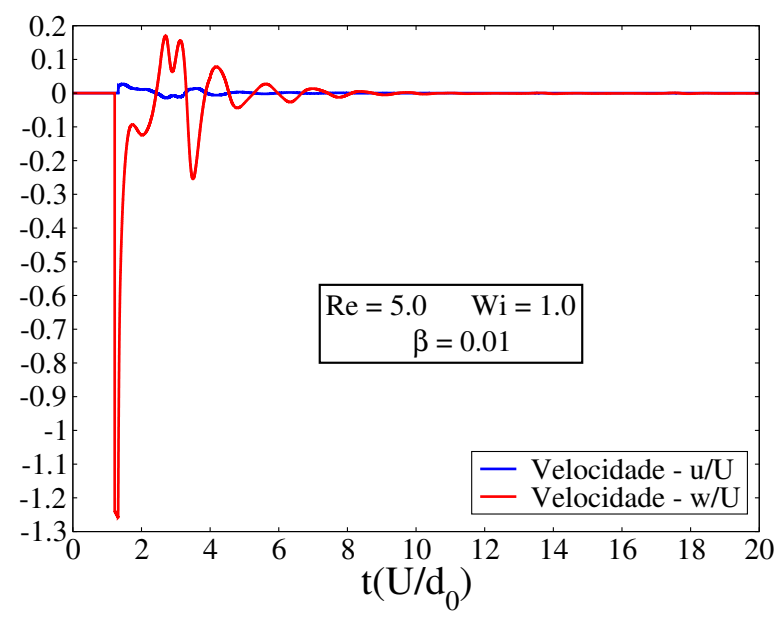

(a)

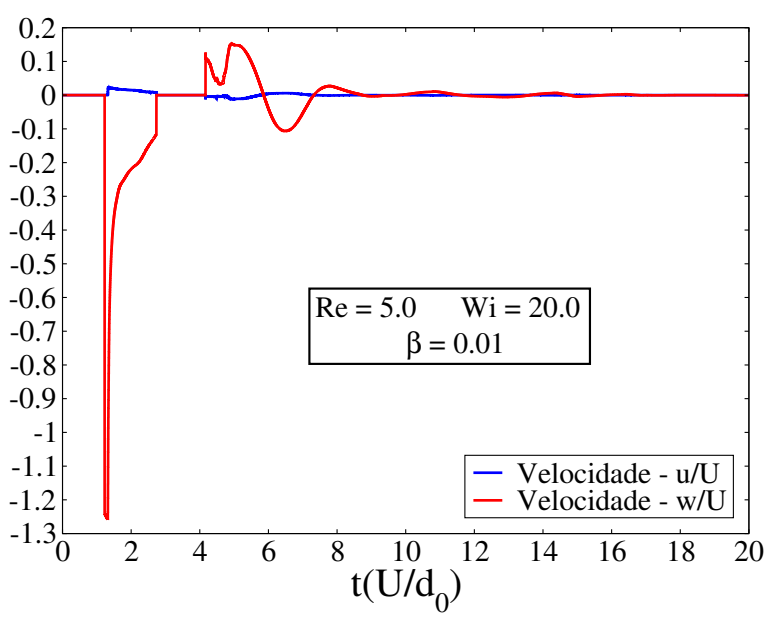

(b)

Fonte: Elaborada pelo autor.

\subsection{Estudo do salto da gota}

Quando a quantidade de solvente é pequena ou o fluxo é muito elástico, uma gota viscoelástica pode apresentar o fenômeno de saltar ('rebound'). Esse tipo de problema é bastante complexo e somente poucos pesquisadores da área reologia computacional tem pesquisado esse fenômeno. Por exemplo, Xu e colaboradores (XU et al., 2012; XU; DENG, 2016; XU; YU, 2018) simularam esse problema utilizando um código Smoothed Particle Hydrodynamics (SPH) e o modelo UCM, e conseguiram capturar o efeito do salto da gota após a mesma atingir uma superfície rígida plana.

Para demonstrar que o método numérico desenvolvido nesse trabalho é capaz de simular o fenômeno do salto da gota (bouncing drop) com o modelo Oldroyd-B, foram realizadas várias simulações para pequenos valores do parâmetro $\beta$ e as condições que conduzem a esse evento no espaço de fase $\beta-R e-W i$ foram estudadas.

O domínio computacional é descrito na Figura 9b. Para verificar se a gota salta após o impacto, a distância $\mathbf{h}(\mathbf{t})$ entre a gota e o disco, ver Figura $9 \mathrm{~b}$, é calculada ao longo do tempo. Assim, quando a gota está em contato com o disco tem-se $\mathbf{h}(\mathbf{t})=0$ e se a gota saltar, desconectando-se do disco, então $\mathbf{h}(\mathbf{t})>0$. Se ocorrer o salto, devido à força da gravidade a gota iniciará um processo de descida atingindo o disco novamente e então $\mathbf{h}(\mathbf{t})=0$. Antecipa-se que, a depender dos valores de $\beta, \operatorname{Re}$ e $W i$, a gota pode saltar várias vezes ou até mesmo não saltar.

Para observar esse fenômeno, inicialmente foram executadas simulações com diferentes valores do número de Reynolds e da razão de viscosidades fornecidos na Tabela 6 e adotou-se 
$W i=1.0$, fixo. A malha M4 definida na Tabela $5(\delta r=\delta z=0.0125)$ e o domínio computacional ilustrado na Figura 9 foram considerados. Os demais dados necessários nas simulações são fornecidos na Tabela 4 , com excessão de $\eta_{0}$ e $\lambda_{2}$ que foram ajustados para obter os números de Reynolds e os valores de $\beta$ da Tabela 6.

Tabela 6 - Valores de $\operatorname{Re}$ e $\beta$ utilizados nas simulações do fenômeno do salto da gota.

\begin{tabular}{|c||c|c|c|c|}
\hline \multicolumn{5}{|c|}{$W i=1$} \\
\hline$\beta$ fixo & \multicolumn{4}{|c|}{ Varia: $\operatorname{Re}$} \\
\hline$\beta=0.01$ & 0.25 & 0.5 & 1.0 & 2.0 \\
\hline \multicolumn{5}{|c|}{ Varia: $\beta$} \\
\hline $\operatorname{Re}$ fixo & \multicolumn{5}{|c|}{} \\
\hline $\operatorname{Re}=0.25$ & 0.0 & 0.01 & 0.05 & 0.1 \\
\hline
\end{tabular}

A Figura 14 apresenta a visualização tridimensional da gota nos tempos $t=1.8,2.2 \mathrm{e}$ 3.4 referente a $W i=1, \beta=0.01$ e $R e=0.25,0.5$ e 2.0, enquanto a Figura 16 mostra o vetor velocidade nesses tempos. Para visualizar os escoamentos transientes correspondentes a essas simulações, a Figura $15^{1}$ fornece um vídeo com os resultados dessas simulações.

Observa-se que no tempo $t=1.8$, as três gotas atingem o disco e verifica-se que o número de Reynolds tem uma grande influência na velocidade e formato da gota. De fato, nesse tempo as gotas com $R e=0.25$ e 0.5 estão contraindo (conforme é mostrado na Figura 16) equanto que a gota com $R e=2.0$ está expandindo (ver Figura 16). As diferenças são mais evidentes em $t=2.2$ quando observa-se que a gota com $R e=0.25$ saltou e se move para cima enquanto que as duas outras gotas estão contraindo. No tempo $t=3.4$, as gotas com $R e=0.25$ e 0.5 estão escoando na atmosfera (ver o campo de velocidade na Figura 16) enquanto que a gota com $R e=2.0$ contraiu e inicia um processo de expansão (ver o vetor velocidade na Figura 16). O fato da gota com $R e=2.0$ não descolar do disco é devido, provavelmente, a uma maior força inercial em relação a força devida aos efeitos de elasticidade no escoamento.

1 Para executar o vídeo é necessário visualizar o arquivo PDF, disponiblizado no banco de teses da USP $<$ https://www.teses.usp.br/>, com o programa ADOBE READER. 
Figura 14 - Visualização 3D em três tempos selecionados da simulação numérica do salto da gota para $W i=1, \beta=0.01$ e diferentes valores de $R e$.

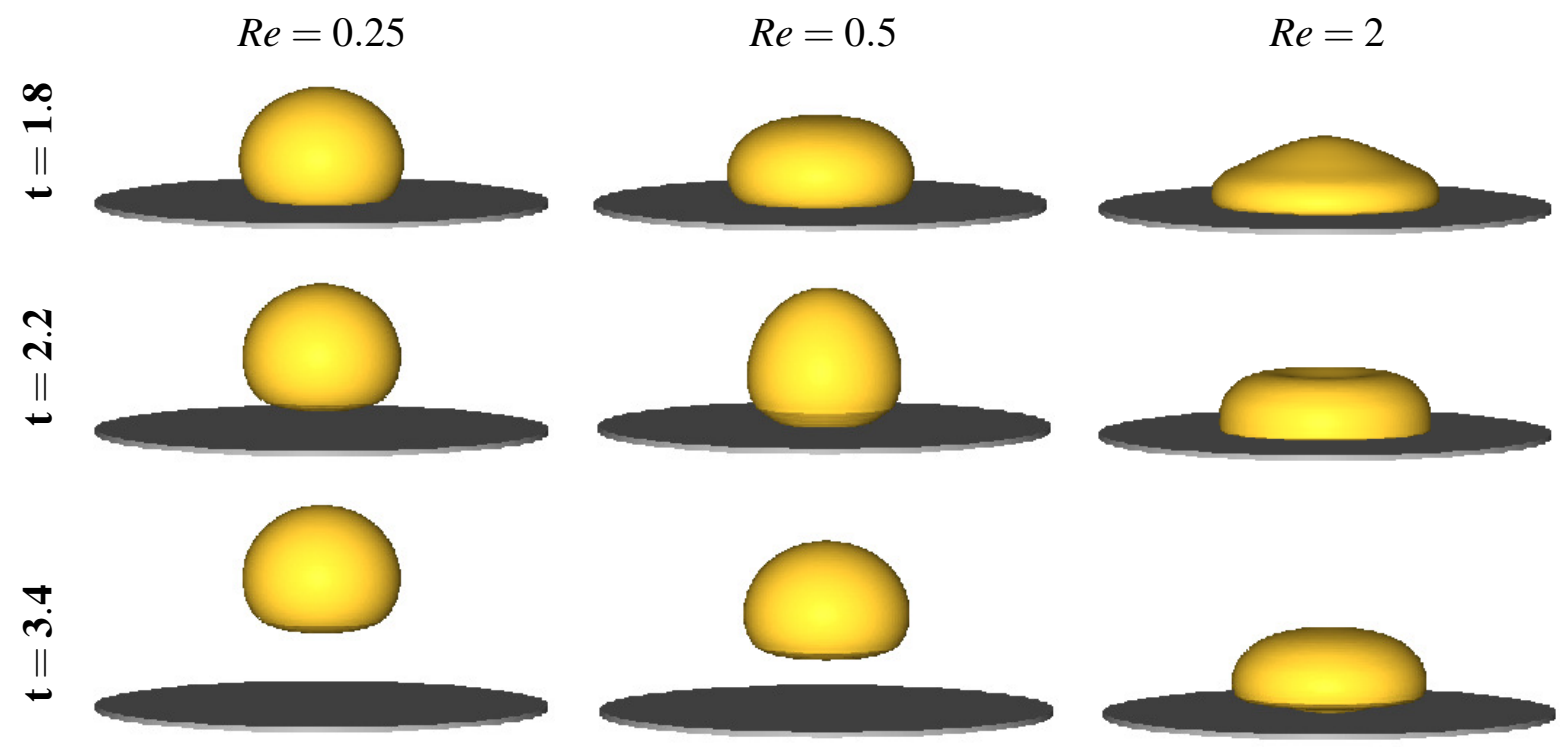

Fonte: Elaborada pelo autor.

Figura 15 - Animações variando Re - Clique PLAY para iniciar e PAUSE para interromper. Para executar o vídeo é necessário visualizar o arquivo PDF, disponiblizado no banco de teses da USP $<$ https://www.teses.usp.br/>, com o programa ADOBE READER.
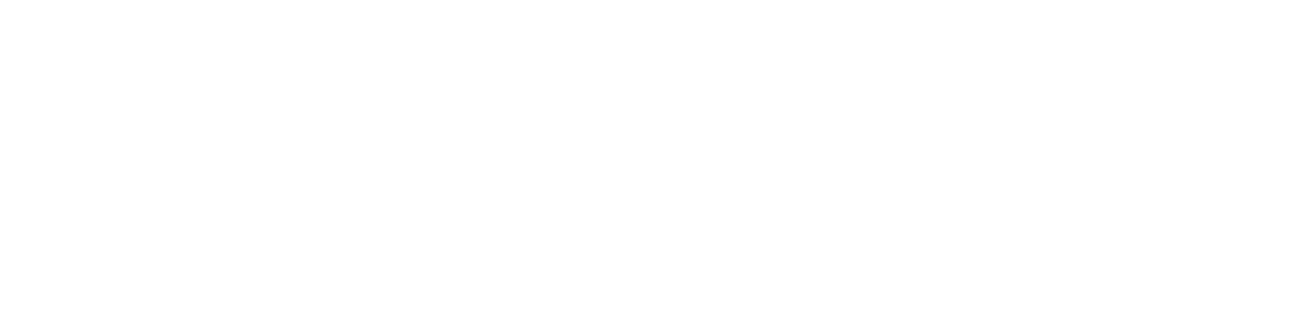

$$
R e=0.25
$$

\section{PLAY PAUSE}

$$
R e=0.5
$$
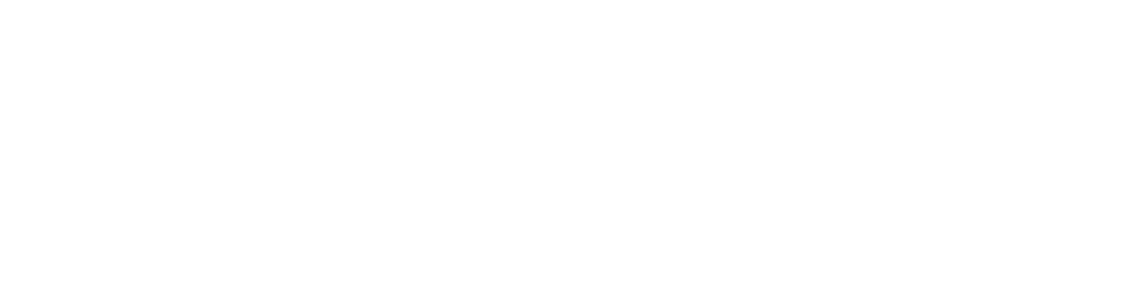

$R e=1.0$

\begin{tabular}{|l|l|}
\hline PLAY & PAUSE \\
\hline
\end{tabular}

$$
\operatorname{Re}=2.0
$$

Fonte: Elaborada pelo autor. 
Figura 16 - Campo de velocidade em três instantes distintos para o escoamento da gota com $W i=1$, $\beta=0.01$ e diferentes valores do número de Reynolds.
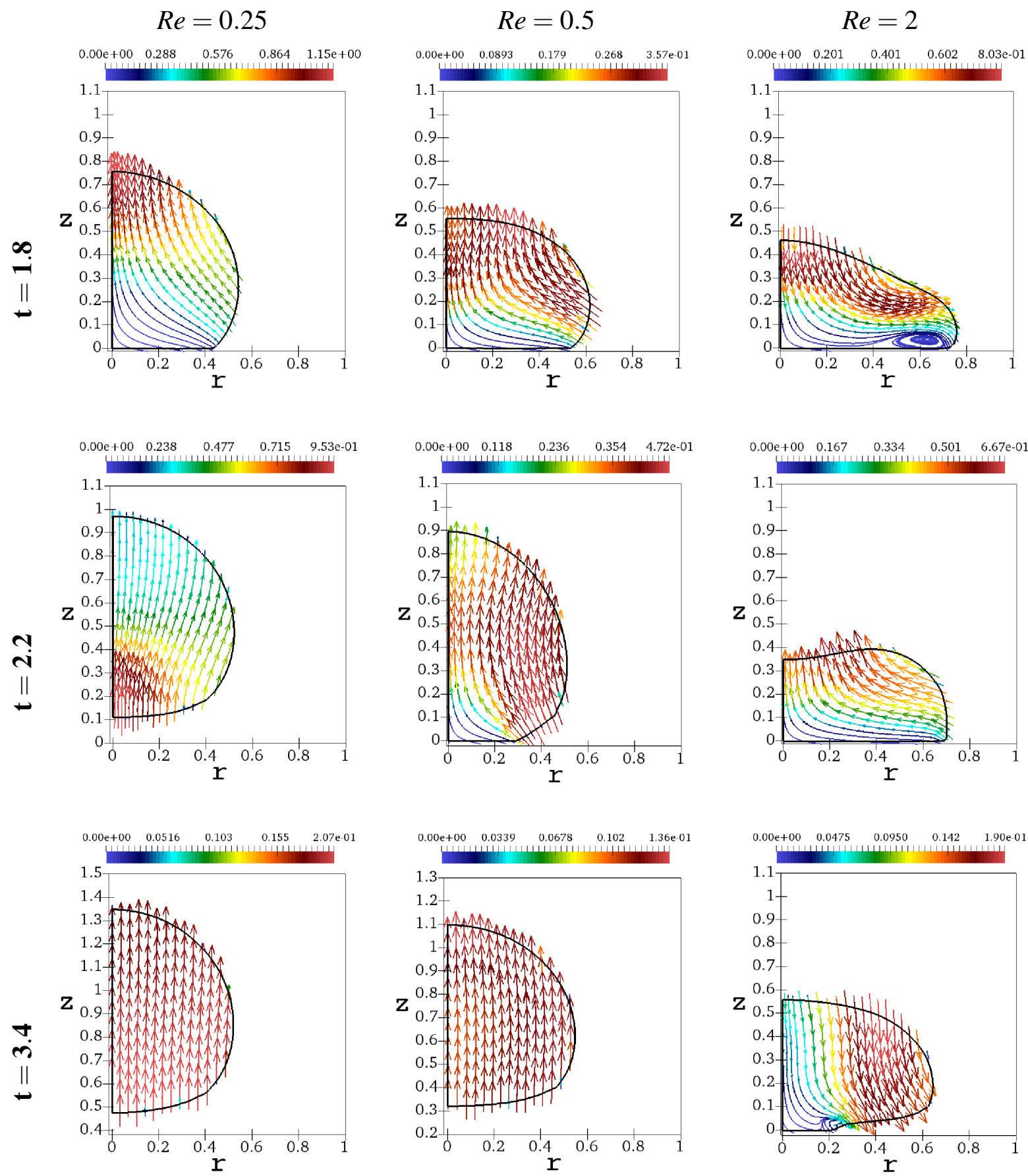

Fonte: Elaborada pelo autor.

Para fornecer informações adicionais sobre o fenômeno do salto da gota, a Figura 17 apresenta as curvas de nível da primeira diferença de tensões normais $N_{1}(t)=\tau^{z z}(t)-\tau^{r r}(t)$ na gota para $R e=0.25,0.5$ e 2.0 nos três tempos selecionados. Observa-se que no tempo $t=1.8$ as três gotas impactam o disco e tem altos valores de $N_{1}(t)$ e no tempo $t=2.2$ a gota com $R e=0.25$ já saltou e apresenta valores de $N_{1}(t)$ menores que no tempo $t=1.8$. As gotas com $R e=0.5$ e 2 
estão contraindo, em contato com a placa, e apresentam valores de $N_{1}(t)$ razoavelmente altos. No tempo $t=3.4$ as gotas com $R e=0.25$ e 0.5 estão escoando verticalmente (devido ao salto das mesmas) e apresentam valores de $N_{1}(t)$ baixos enquanto a gota que não salta $(R e=2.0)$ apresenta valores de $N_{1}(t)$ razoavelmente altos. Constata-se que quando a primeira diferença de tensões normais muda de sinal de negativo para positivo ocorre o salto da gota. Esse fato pode ser verificado na Figura 18a (uma ampliação no intervalo de tempo que a gota desprende da placa por completo é destacado na Figura 18b) e as regiões com valores positivos de $N_{1}(t)$ acumulam-se em torno do ponto de separação. Observa-se que essa região move para o centro da gota e muda seu sinal (como pode ser observado na Figura 17).

Figura 17 - Primeira diferença de tensões normais $N_{1}=\tau^{z z}-\tau^{r r}$ para diferentes valores do número de Reynolds nos tempos $t=1.8,2.2,3.4$. Simulação do impacto da gota $\operatorname{com} \beta=0.01 \mathrm{e}$ $W i=1.0$.
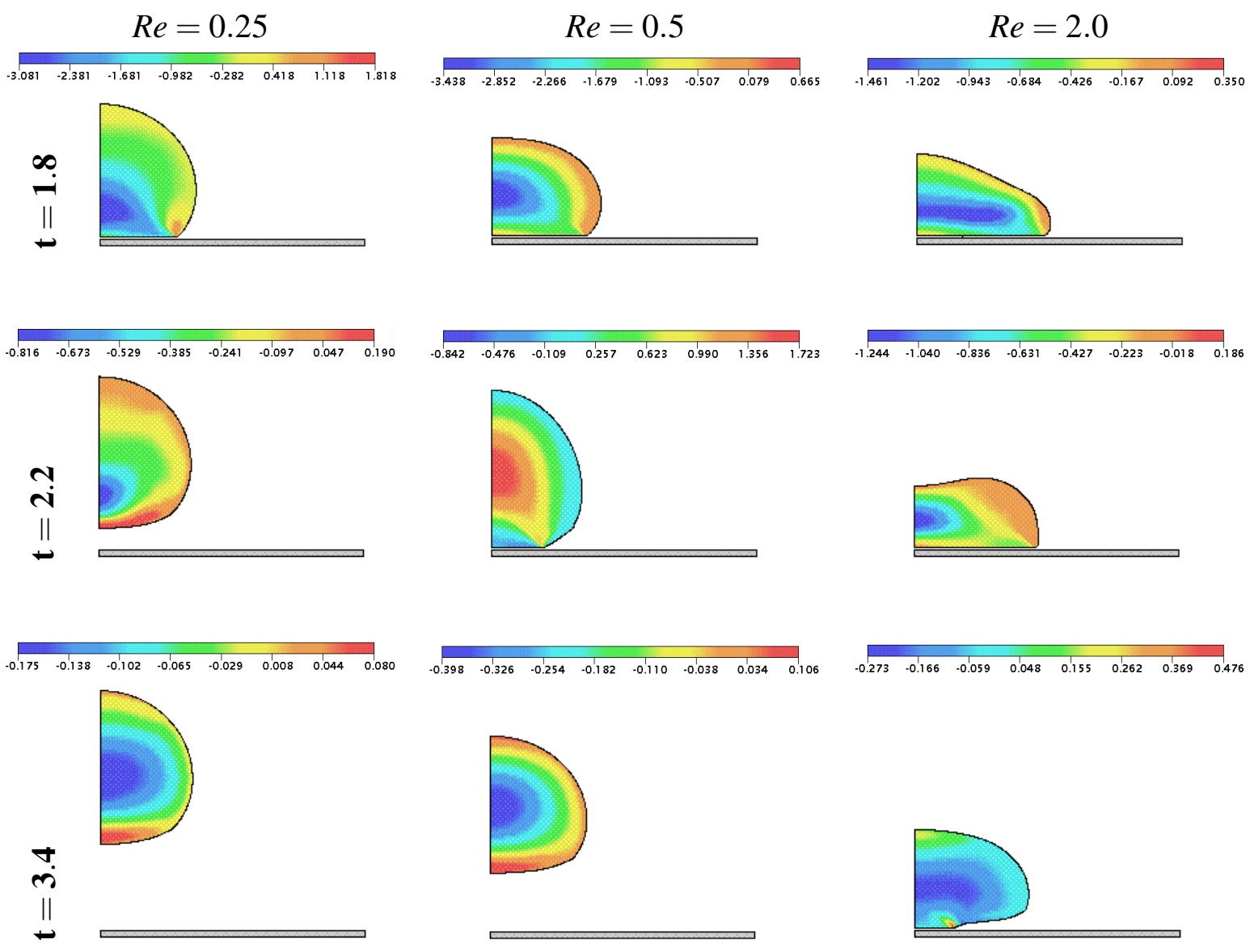

Fonte: Elaborada pelo autor.

Além disso, observa-se que no tempo que a gota impacta o disco em aproximadamente $t=1.3$ (ver Figura 18), os valores de $N_{1}(t)$ decrescem rapidamente atingindo altos valores negativos (por exemplo $N_{1}(t) \approx-11.8$ para $R e=0.25, N_{1}(t) \approx-5.5$ para $R e=0.5, N_{1}(t) \approx$ -2.5 para $R e=1.0$ e $N_{1}(t) \approx-1.5$ para $R e=2.0$ ). 
Por exemplo, para $R e=0.25$, pode-se ver na Figura 18a que, antes da gota saltar, $N_{1}(t)$ muda de sinal em $t=2.1$, tornando-se positivo e depois atingindo um valor de pico de $N_{1}(t) \approx 2.0$. O instante em que ocorre o valor de pico é o mesmo que a gota salta e começa a manter um fluxo ascendente. Observe que a célula $(1,1)$ deixa de conter fluido no intervalo de tempo $\approx[2.1,6.5]$. Durante esse intervalo de tempo, as velocidade e o tensor extra tensão tornam-se nulos justificando a descontinuidade de $N_{1}(t)$ mostrada na Figura 18b. Os valores de $N_{1}(t)$ plotados no centro da célula $(1,1)$ permanecem nulos até que a gota impacta o disco novamente e $N_{1}(t)$ atinge outro pico de valor negativo, $N_{1}(t) \approx-4.5$. Durante o intervalo de tempo [2.1,6.5], $\mathbf{h}(\mathbf{t})$ é positivo e a gota está acima do disco (ver Figura 21a). Após a gota atingir o disco novamente em $t \approx 6.5$ o processo se repete até a gota não ter mais energia para saltar. Esse processo se repete três vezes para $R e=0.25$, duas vezes para $R e=0.5$ e apenas uma vez para $R e=1.0$. Para $R e=2.0$ a gota não salta, uma vez que $\mathbf{h}(\mathbf{t})$ permanece zero após a gota finalizar o processo de queda e impactar a placa inicialmente (ver Figura 21a).

Figura 18 - (a) Variação temporal de $N_{1}(t)$ na célula $(1,1)$ da Figura 9 c para $W i=1, \beta=0.01$ e diferentes valores do número de Reynolds. (b) Ampliação dos resultados na região $[1,3] \times[-1.25,1]$.

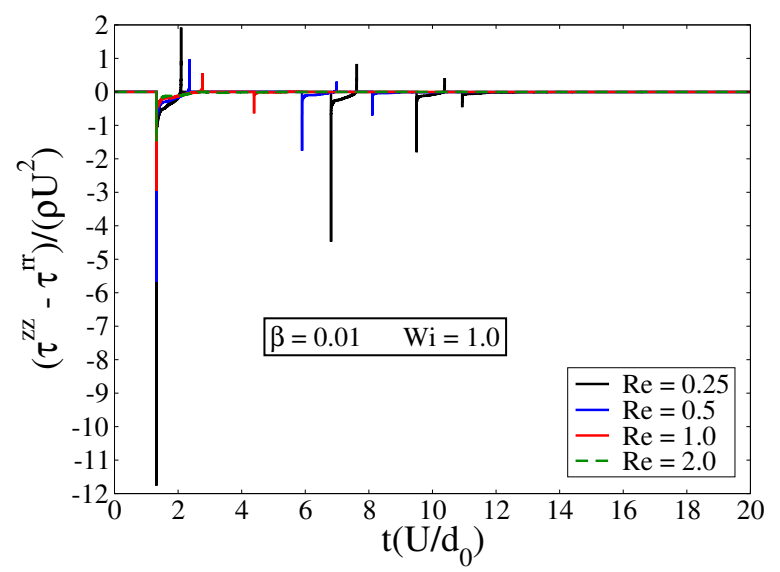

(a)

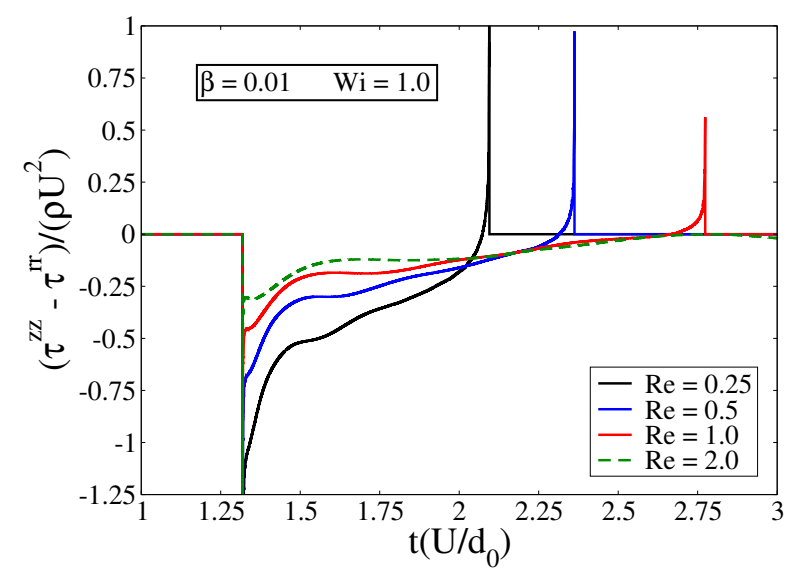

(b)

Fonte: Elaborada pelo autor.

A Figura 19 apresenta o estágio de deformação da gota para as simulações com $R e=0.25$ fixo e $\beta=0.0,0.01,0.1$ em três instantes de tempo selecionados. As animações 3D desses escoamentos podem ser visualizadas na Figura $20^{2}$. Essas simulações mostram claramente que o fenômeno do salto da gota é fortemente influênciado pela quantidade de solvente no fluido e mostra que quanto menos solvente na solução, maior é o efeito do salto da gota (veja os resultados $\operatorname{com} \beta=0$ ). Aumentando o valor de $\beta$, mesmo para valores pequenos como 0.01 , é notado um efeito de redução na altura do salto da gota comparado com o modelo UCM. Quando a viscosidade do solvente atinge $10 \%(\beta=0.1)$ da viscosidade total do fluido, a gota experimenta um pequeno salto, o que fica evidente ao analisar o gráfico da Figura $21 \mathrm{~b}$.

2 Para executar o vídeo é necessário visualizar o arquivo PDF, disponiblizado no banco de teses da USP $<$ https://www.teses.usp.br/>, com o programa ADOBE READER. 
Figura 19 - Visualização 3D em três tempos específicos da simulação numérica do salto da gota para $W i=1, R e=0.25$ e diferentes valores de $\beta$.
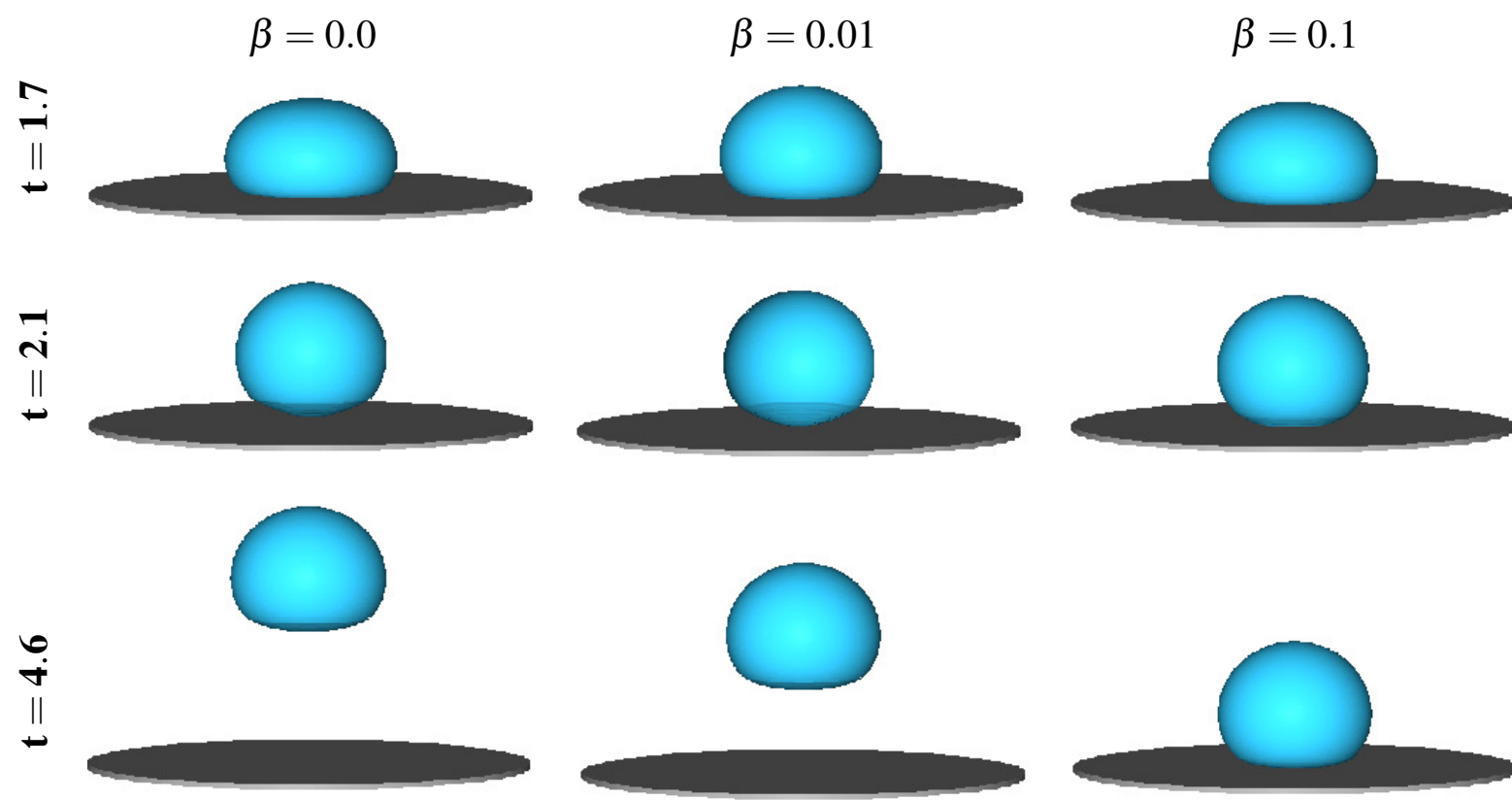

Fonte: Elaborada pelo autor.

Figura 20 - Animações variando $\beta$ - Clique PLAY para iniciar e PAUSE para interromper. Para executar o vídeo é necessário visualizar o arquivo PDF, disponiblizado no banco de teses da USP $<$ https://www.teses.usp.br/>, com o programa ADOBE READER.
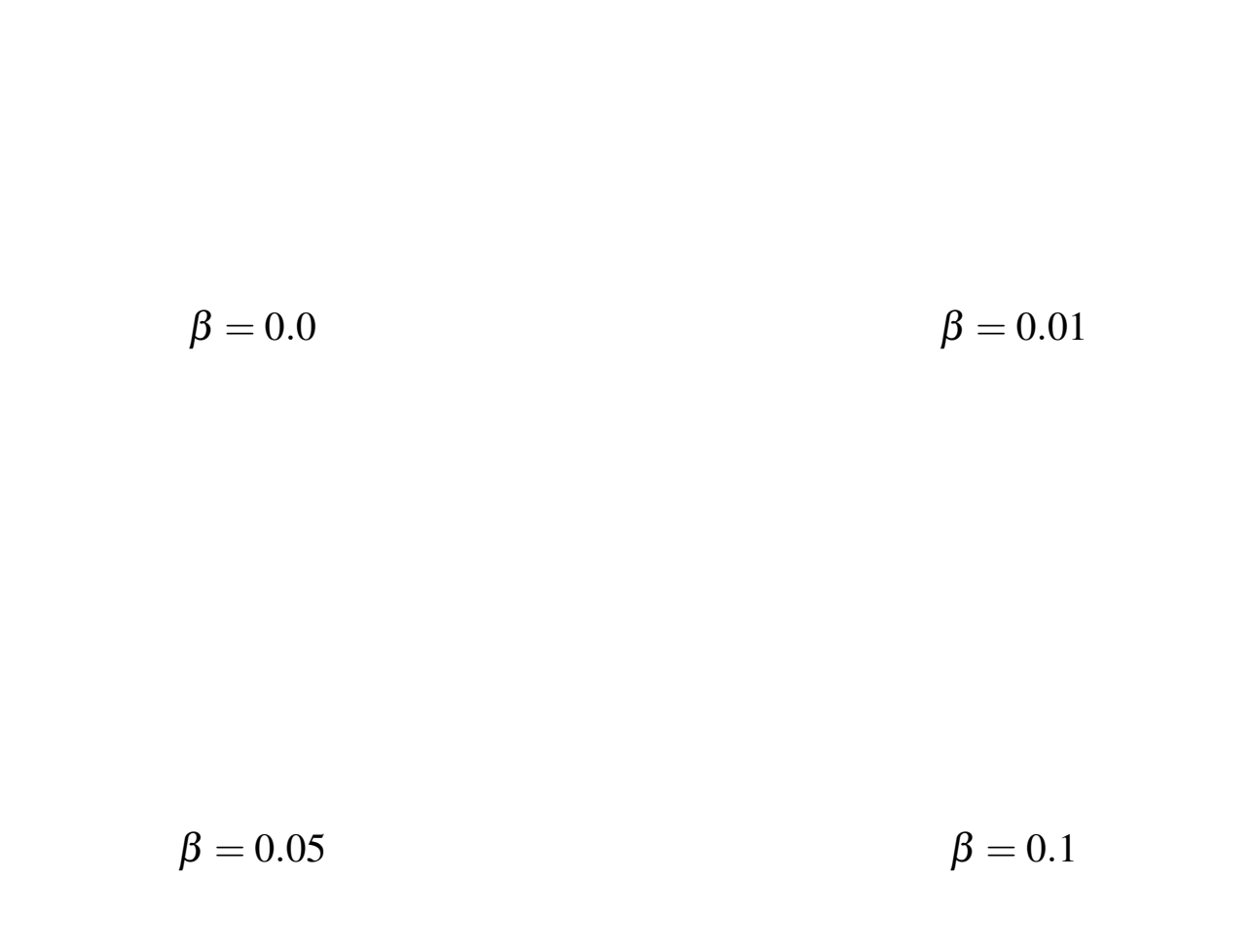

$$
\beta=0.1
$$

Fonte: Elaborada pelo autor. 
A Figura 21 apresenta a variação temporal de $\mathbf{h}(\mathbf{t})$ obtida nas simulações variando $R e$ e $\beta$. Essa figura mostra que a gota $\operatorname{com} \beta=0.0$ (modelo $\mathrm{UCM}$ ) e $\beta=0.01$ apresentam saltos acentuados e múltiplos, enquanto que as gotas $\operatorname{com} \beta=0.05$ e 0.1 , apresentam pequenos saltos com valores de $\mathbf{h}(\mathbf{t})$ abaixo de 0.085 (veja Tabela 7 ).

Tabela 7 - Valores da altura máxima $\mathbf{h}(\mathbf{t})$ e o tempo associado $\mathbf{t}_{\max }$ dos saltos da gota.

\begin{tabular}{|c||c|c|c|c|}
\hline \multicolumn{5}{|c|}{$W i=1$ e $\beta=0.01$} \\
\hline$R e$ & 0.25 & 0.50 & 1.0 & 2.0 \\
\hline $\mathbf{h}(\mathbf{t})$ & 0.582 & 0.361 & 0.161 & 0.0 \\
\hline $\mathbf{t}_{\max }$ & 4.450 & 4.121 & 3.116 & - \\
\hline \multicolumn{5}{|c|}{$W i=1$ e $\operatorname{Re}=0.25$} \\
\hline$\beta$ & 0.0 & 0.01 & 0.05 & 0.1 \\
\hline $\mathbf{h}(\mathbf{t})$ & 0.934 & 0.582 & 0.083 & 0.036 \\
\hline $\mathbf{t}_{\max }$ & 5.058 & 4.450 & 2.966 & 2.737 \\
\hline
\end{tabular}

Figura 21 - Alturas dos saltos da gota para $W i=1.0$ : (a) $\beta=0.01$ e variando $R e$; (b) $R e=0.25$ variando a razão de viscosidades $\beta$.

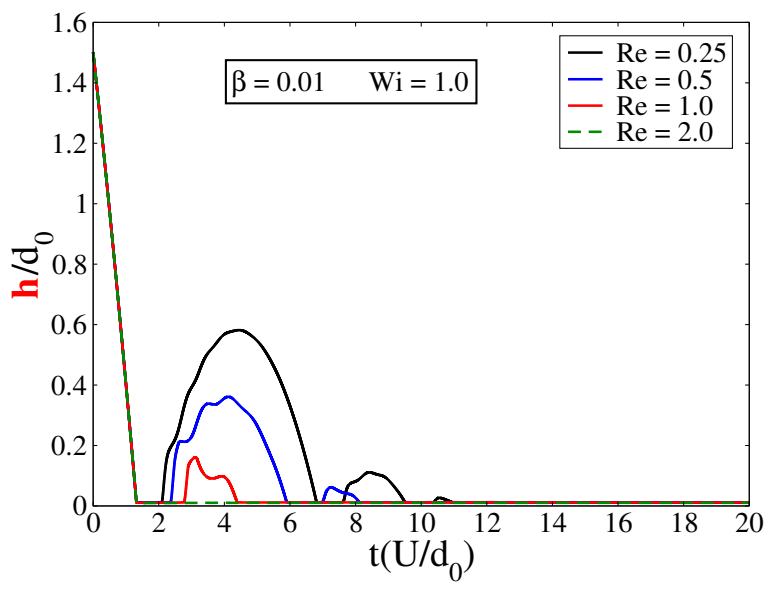

(a)

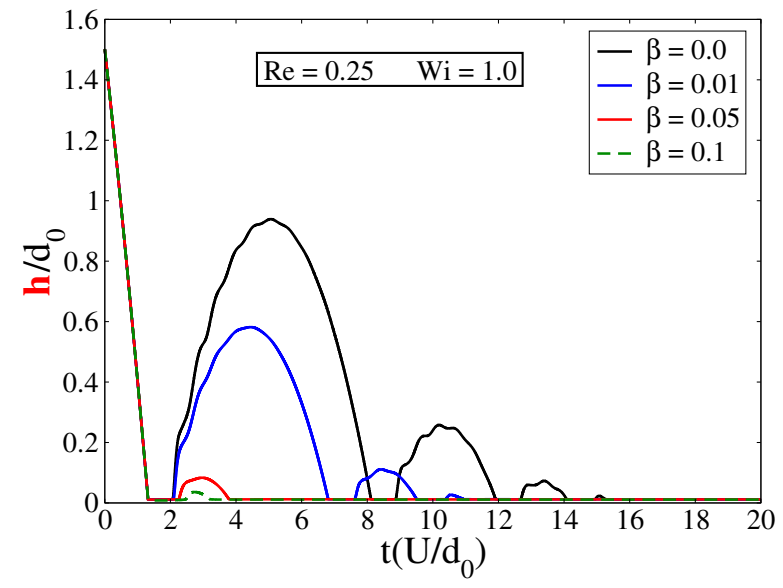

(b)

Fonte: Elaborada pelo autor.

\subsubsection{Estudo do efeito dos números de Reynolds e Weissenberg no salto da gota}

Para examinar os efeitos dos números de Reynolds e de Weissenberg no fenômeno do salto da gota, várias simulações foram executadas utilizando os valores de $W i$ e $R e$ mostrados na Tabela 8 (os valores de $\eta_{0}$ e $\lambda_{1}$ foram ajustados para obter os valores de $R e$ e $W i$ apresentados nessa tabela). Os dados considerados nessas simulações são os mesmo fornecidos na Tabela $4 \mathrm{e}$ a malha adotada foi a malha M4 definida na Tabela 5. O interesse é investigar os efeitos de $W i$ e $R e$ na altura máxima do primeiro salto da gota $\left(\mathbf{h}_{\mathbf{m a x}}\right)$. (Note que a gota pode saltar várias vezes, 
como pode ser observado nas Figura 15 e Figura 20). Também é de interesse determinar um intervalo dos valores do número de Reynolds e Weissenberg para os quais esse fenômeno ocorre.

Os valores da altura máxima $\left(\mathbf{h}_{\max }\right)$ obtidos nessas simulações são plotados na Figura 22. Pode-se ver que o número de Weissenberg tem uma influência significativa no problema do salto da gota. Para valores de $R e$ e $\beta$ empregados nessas simulações, as gotas saltam se o número de Weissenberg estiver no intervalo $[0.02,8.0]$; a maior altura obtida deu-se para $W i=0.5$. A razão pela qual a gota não salta para pequenos valores de $W i$ é que esses escoamentos se aproximam do escoamento newtoniano e os efeitos de elasticidade são pequenos enquanto que se $W i$ é suficientemente grande $(W i=8.0)$, então a gota é muito elástica, após impactar a superfície sólida o aumento da tensão elástica é mais vagoroso e as fases de espalhamento e contração dissipam muita energia, consequentemente, a gota não salta. Na Figura 23a pode-se observar que com o aumento de $W i$ as deformções no formato da gota são mais demoradas, ou seja, a frequência das oscilações da razão entre o diâmetro radial máximo $d_{r}(t)=d(t)$ e a altura máxima da gota $d_{z}(t)$ são menores e a magnitude das deformações radiais maiores.

Tabela 8 - Números de Weissenberg e Reynolds utilizados nas simulações do salto da gota.

\begin{tabular}{|c|c|}
\hline \multicolumn{2}{|c|}{ Variação de $W i: R e=0.25$ e $\beta=0.01$} \\
\hline \multirow{2}{*}{$W i$} & $0.001,0.01,0.02,0.1,0.3,0.5$ \\
& $0.7,1.0,2.0,3.0,4.0,6.0,8.0$ \\
\hline
\end{tabular}

\begin{tabular}{|c|c|}
\hline \multicolumn{2}{|c|}{ Variação de $R e: W i=1$ e $\beta=0.01$} \\
\hline \multirow{2}{*}{$\operatorname{Re}$} & $0.001,0.01,0.05,0.1,0.25$, \\
& $0.5,1.0,2.0,3.0$ \\
\hline
\end{tabular}

Figura 22 - Variação de $\mathbf{h}_{\max }$ como função do número de (a) Weissenberg e (b) Reynolds.

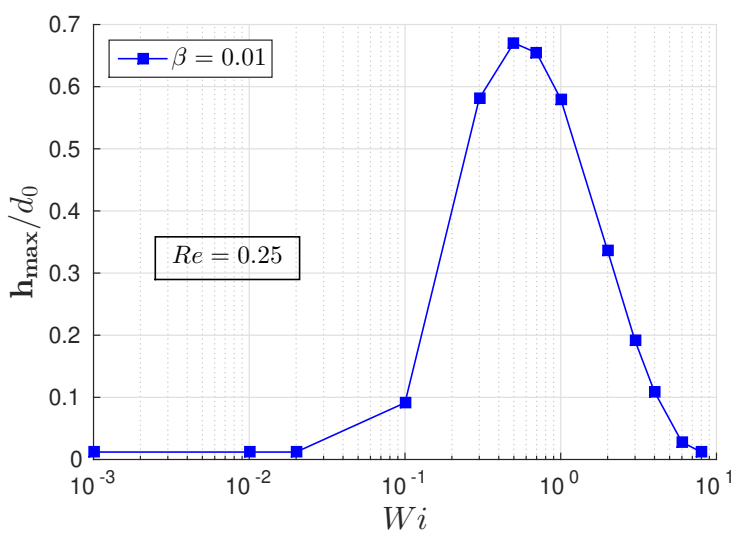

(a)

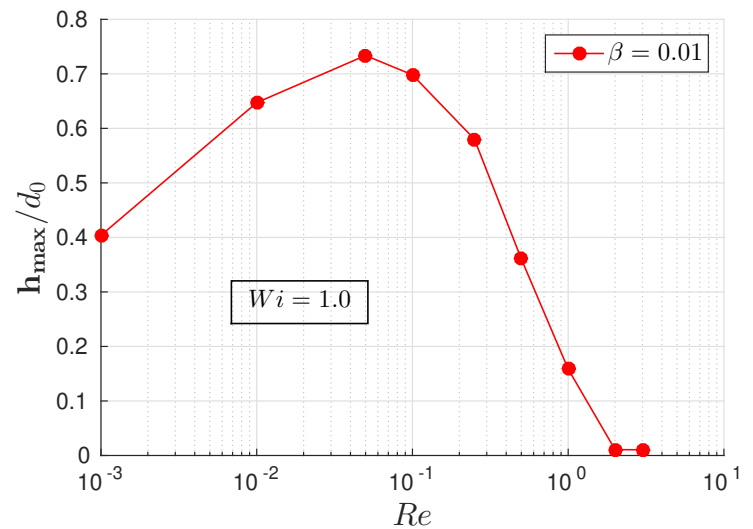

(b)

Fonte: Elaborada pelo autor.

Os resultados obtidos variando o número de Reynolds são apresentados na Figura $22 \mathrm{~b}$ onde é possível observar que o número de Reynolds também tem um grande efeito sobre o fenômeno do salto da gota. Se $R e$ aumenta então a altura máxima do salto da gota diminui e quando $R e$ é suficientemente grande $(R e=2.0)$ o salto não ocorre: acredita-se que esse efeito é decorrente das deformações que o fluido sofre ao impactar a placa. Ao observar a razão 
$d_{r}(t) / d_{z}(t)$ ao longo do tempo para diferentes valores de $\operatorname{Re}$ quando $\beta=0.01$ e $W i=1.0$ na Figura 23b, nota-se que a magnitude das oscilações são maiores quando $R e$ aumenta, porém, a frequência de tais oscilações são menores, ou seja, a razão $d_{r}(t) / d_{z}(t)$ oscila em intervalos de tempo maiores. Entretanto, note que quando $R e$ tende a zero a magnitude das oscilações tornam-se pequenas, praticamente zero quando $R e=0.01$ e 0.001 . Inversamente, se $R e$ diminui então a altura do salto da gota decresce (pelo menos para os números de Reynolds simulados).

Figura 23 - Variação temporal de $d_{r}(t) / d_{z}(t)$. (a) $R e=0.25, \beta=0.01$ e diferentes valores de Weissenberg. (b) $W i=1.0, \beta=0.01$ e diferentes valores de Reynolds.
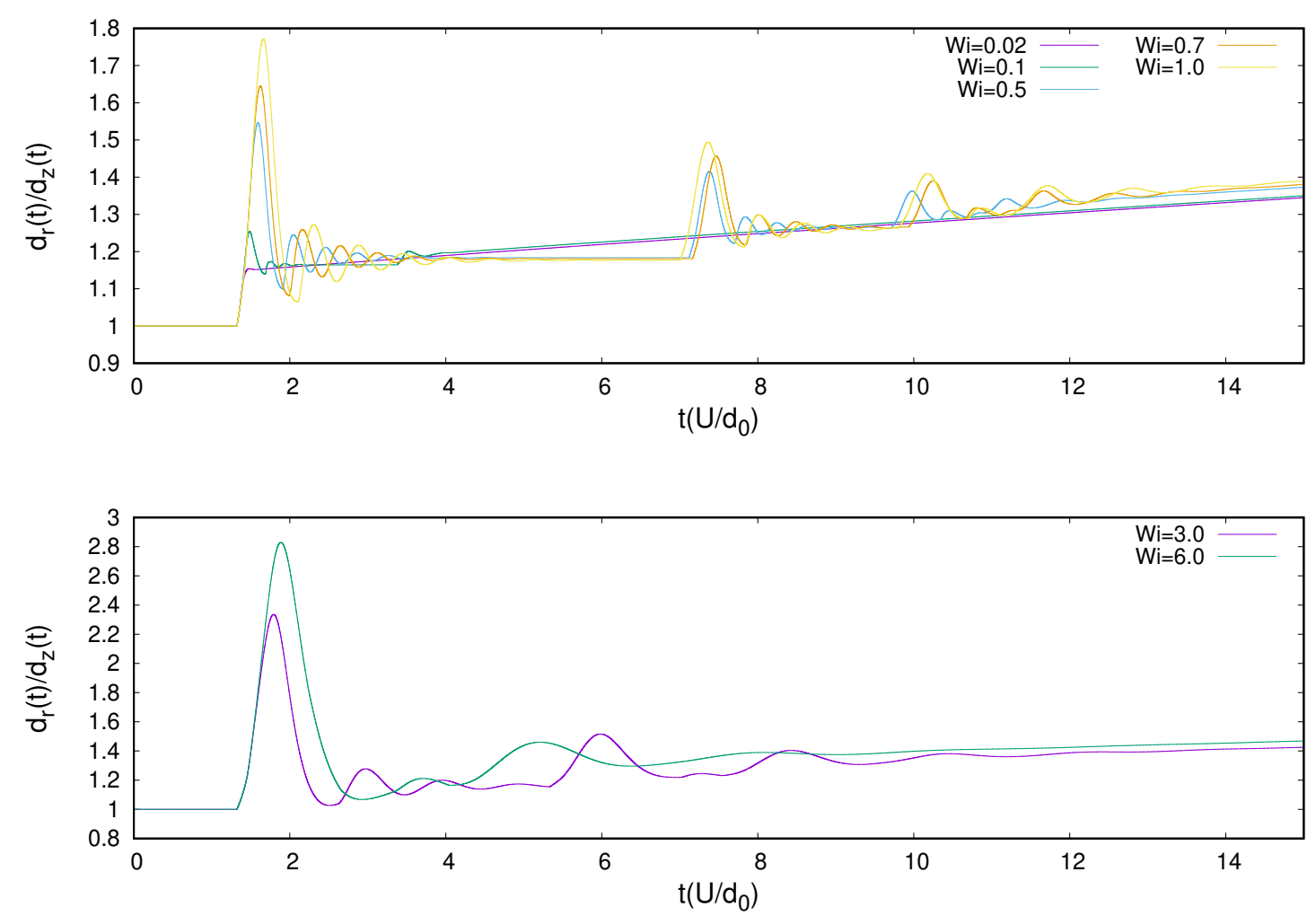

(a)

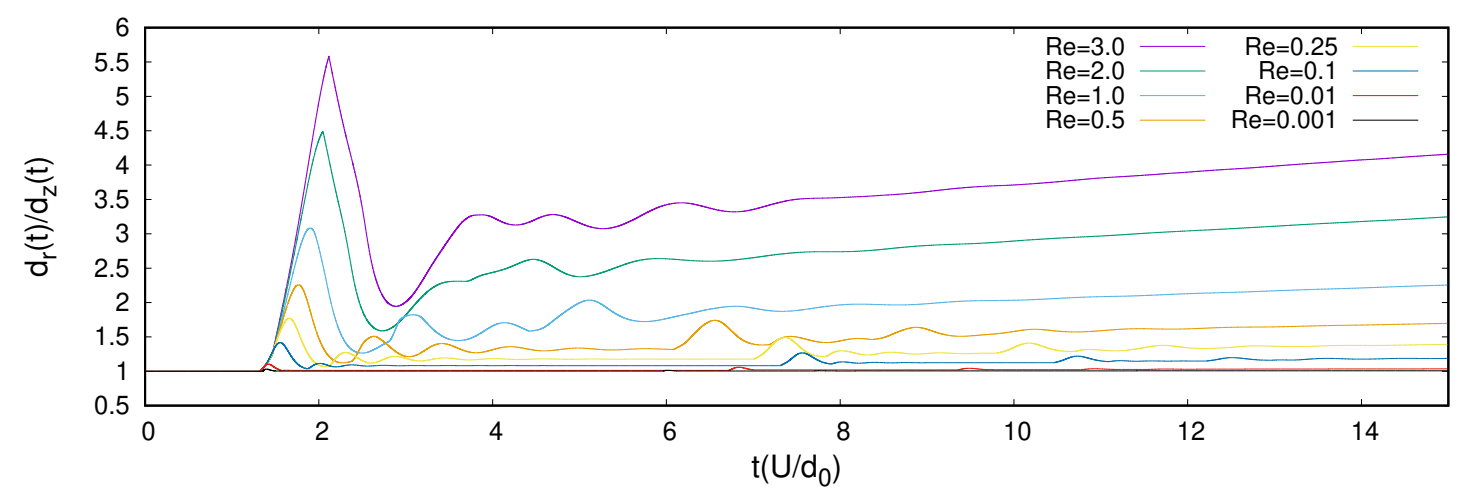

(b)

Fonte: Elaborada pelo autor. 
Para investigar o efeito da razão de viscosidades $\beta$ na altura máxima do salto da gota quando $R e$ e $W i$ são variados, foram realizadas simulações adicionais usando os valores de $\beta, R e$ e $W i$ apresentados na Tabela 9. A Figura 24a mostra as alturas máximas obtidas para os valores de $\beta$ e $R e$ simulados. Vê-se que quando o número de Reynolds aumenta, a altura máxima decresce para zero mostrando que a gota deixa de saltar se o número de Reynolds é suficientemente grande. Os resultados obtidos com a variação do número de Weissenberg são exibidos na Figura 24b. Pode-se ver que para pequenos valores de $W i$ a altura máxima do maior salto da gota decresce para zero devido ao fato do fluido aproximar-se de um fluido newtoniano, enquanto que para valores de $W i>1$ a altura máxima decresce devido a razão entre o tempo característico do fluido e o tempo característico do fluxo aumentar, de modo que, as tensões elásticas demoram muito tempo para crescer. A diminuição da constante $\beta$ implica numa gota mais elástica uma vez que o fluido se aproxima do fluido UCM.

Tabela 9 - Dados utilizados nas simulações do salto da gota variando $\beta, R e$ e $W i$.

\begin{tabular}{|c|c|}
\hline \multicolumn{3}{|c|}{ Fixo: $W i=1.0$} \\
\hline$\beta$ & $0.0,0.001,0.05,0.01$ \\
\hline \multirow{2}{*}{$R e$} & $0.01,0.05,0.1,0.25$ \\
& $0.5,1.0,2.0,3.0$ \\
\hline
\end{tabular}

\begin{tabular}{|c|c|}
\hline & Fix \\
\hline$\beta$ & $\begin{array}{llll}0.0, & 0.001, & 0.05, & 0.01\end{array}$ \\
\hline$W i$ & $\begin{array}{c}0.01,0.02,0.1,0.3,0.5 \\
0.7,1.0,2.0,3.0,4.0\end{array}$ \\
\hline
\end{tabular}

Figura 24 - Variação das alturas máximas do salto $\mathbf{h}(\mathbf{t})$ da gota como função dos números de Reynolds e Weissenberg. (a) $W i=1.0$ fixo, variando $\beta$ e $R e$, (b) $R e=0.25$ fixo, variando $\beta$ e $W i$.

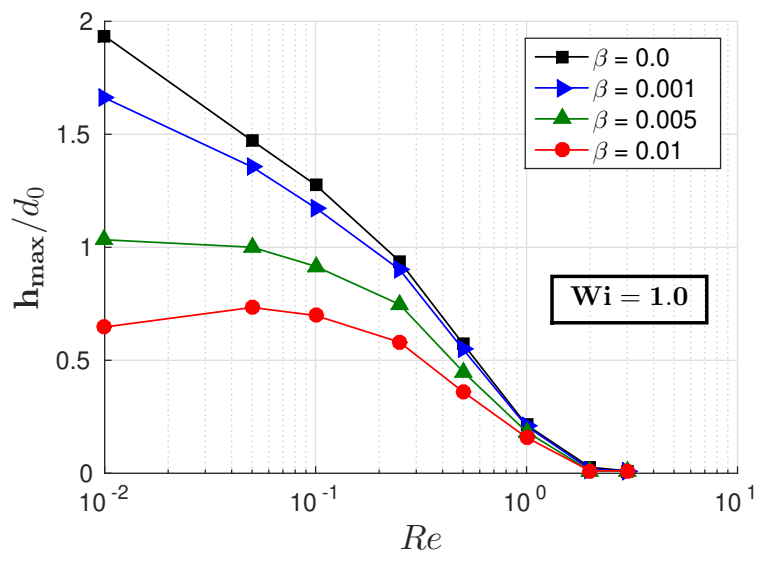

(a)

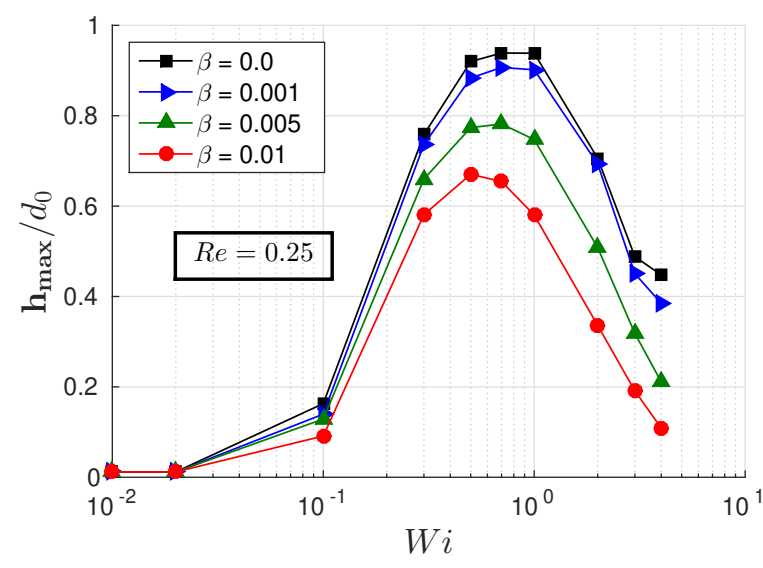

(b)

Fonte: Elaborada pelo autor. 



\section{3}

\section{SIMULAÇÃO DO INCHAMENTO RETARDADO DO EXTRUDADO}

Um fenômeno decorrente do processo de extrusão de fluidos viscoelásticos é conhecido como inchamento retardado do extrudado (Delayed dieswell). Como o nome sugere, esse problema é caracterizado por um atraso no inchamento de um jato de fluído viscoelástico que é expelido de um tubo para o ar atmosférico. Experimentos realizador por Merrington (1943), Metzner, White e Denn (1967), Giesekus (1969), Middleman (1968), Brenschede e Klein (1970) mostraram que sobre certas condições, alguns fluidos incham radialmente após uma certa distância $l_{d}$ da saída do tubo, ocorrendo um "atraso" no surgimento do inchamento, como pode ser esquematizado na Figura 25a e experimentalmente na Figura 25b. Esse fenômeno foi constatado por Giesekus (1969) e Brenschede e Klein (1970), que o classificaram como não-linear e instável após o jato sair do tubo. Mais tarde, Joseph, Matta e Chen (1987) estudaram esse problema sistematicamente por meio de analises experimentais e verificaram a ocorrência desse fenômeno para números de Mach viscoelásticos (Ma) maiores que 1. Com o objetivo de verificar os resultados obtidos por Joseph, Matta e Chen (1987), Delvaux e Crochet (1990) utilizaram um método de elementos finitos e fizeram um estudo numérico desse fenômeno, os pesquisadores simularam o inchamento retardado do extrudado utilizando fluidos descritos pelas equações constitutivas Oldroyd-B e Giesekus. Entretanto, devido a limitações computacionais, os resultados apresentados por Delvaux e Crochet (1990) foram obtidos em malhas relativamente grossas.

Após os trabalhos de Joseph e Delvaux não encontramos na literatura outros artigos que estudaram este problema, o que nos motivou a aplicar as ferramentas desenvolvidas no Capítulo 2 para simular o fenômeno do inchamento retardado do extrudado. 
Figura 25 - Descrição do problema do inchamento retardado do extrudado. (a) Representação axissimétrica do problema. (b) Resultado experimental apresentado por Giesekus (1969).

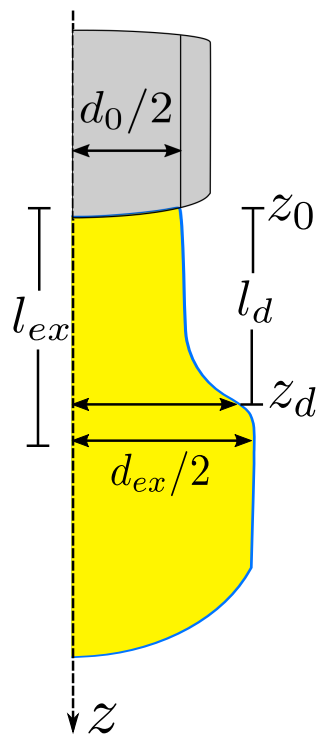

(a)

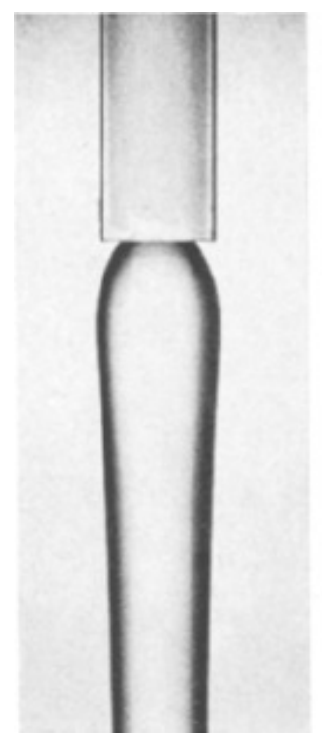

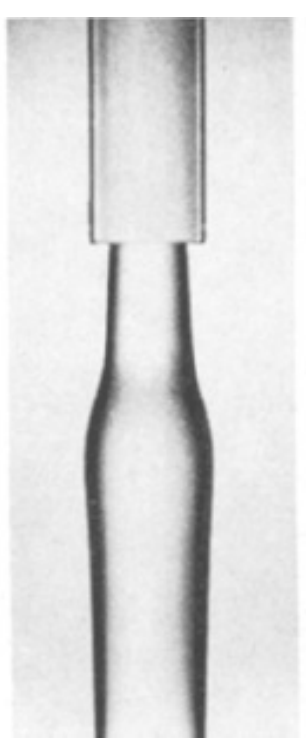

(b)

Fonte: Elaborada pelo autor.

Fonte: Giesekus (1969).

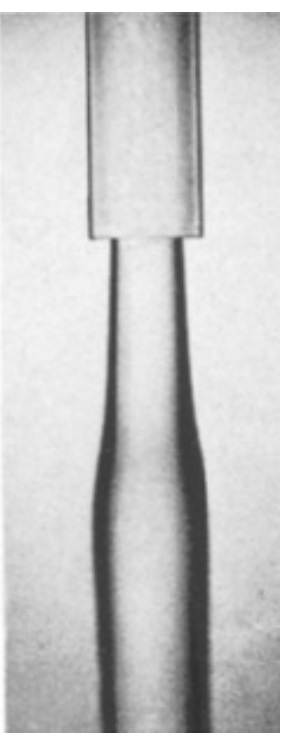

$$
\text { (1) }
$$


Adicionalmente, esses autores indicaram que esse fenômeno está relacionado com a mudança de regime da equação de vorticidade. Quando Ma é maior que 1, a equação de vorticidade pode mudar de um regime elíptico para um regime hiperbólico, que corresponde a perda da positividade do tensor

$$
\mathbf{T}^{*}=\tau_{P}+\frac{1}{R e W i} \mathbf{I}-\mathbf{v} \mathbf{v}
$$

As regiões onde $\mathbf{T}^{*}$ não é definido positivo $\left(\operatorname{Det}\left(\mathbf{T}^{*}\right)<0\right)$ são denominadas regiões supercríticas do escoamento. Ao contrário, as regiões onde $\mathbf{T}^{*}$ é definido positivo $\left(\operatorname{Det}\left(\mathbf{T}^{*}\right)>0\right)$ indicam que a região do escoamento é subcrítica. Esse fato demonstra a complexidade desse problema e requer que um método numérico seja robusto para resolvê-lo. Talvez essa seja uma das razões pela qual não se encontram muitos trabalhos que tenham estudado esse fenômeno. Desse modo, o código computacional desenvolvido nesse trabalho pode ser aplicado para realizar um estudo numérico desse problema, de modo que se possa verificar sua robustez.

Antes do estudar o escoamento do inchamento retardado do extrudado, primeiro foi verificado o desempenho do código na resolução do escoamento do inchamento do extrudado que é considerado um problema de menor complexidade.

\subsection{Simulação do inchamento do extrudado de fluidos Oldroyd-B}

O fenômeno do inchamento do extrudado, conhecido como Dieswell, extrudate swell ou efeito de Barus (ver Figura 26a) ocorre quando um jato escoando dentro de um tubo com diâmetro $d_{0}$ é expelido na atmosfera, onde sob certas condições, o mesmo se expande radialmente adquirindo um diâmentro $d_{e x}$ imediatamente após a saída do tubo, como exemplificado na Figura 26b. Esse fenômeno é característico de fluidos viscoelásticos e acontece frequentemente no processo de extrusão de polímeros. Além disso, esse fenômeno está associado à entropia e ao relaxamento das moléculas de polímero na corrente de fluxo (BIRD; ARMSTRONG; HASSAGER, 1987).

Esse problema tem sido estudado por muitos investigadores (ver por exemplo, (CROCHET; KEUNINGS, 1980; CROCHET; KEUNINGS, 1982; GOUBLOMME; DRAILY; CROCHET, 1992; TOMÉ et al., 2007; OISHI et al., 2008; MITSOULIS, 2010; OISHI et al., 2011; KONAGANTI et al., 2016; COMMINAL et al., 2018)) que desenvolveram ferramentas computacionais com o objetivo de calcular a taxa de inchamento definida pela razão dos diâmetros $d_{0} \mathrm{e}$ $d_{e x}$, ou seja, $S_{r}=\frac{d_{e x}}{d_{0}}$. 
Figura 26 - (a) Visualização tridimensional do inchamento do extrudado; (b) Representação do domínio computacional; (c) Descrição do domínio computacional utilizado nas simulações do inchamento do extrudado.

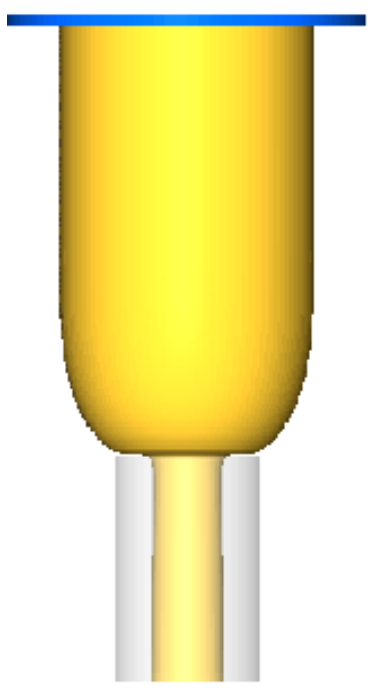

(a)

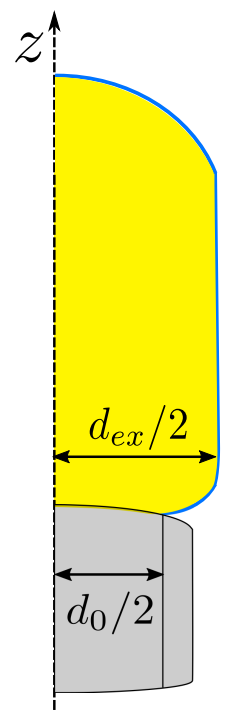

(b)

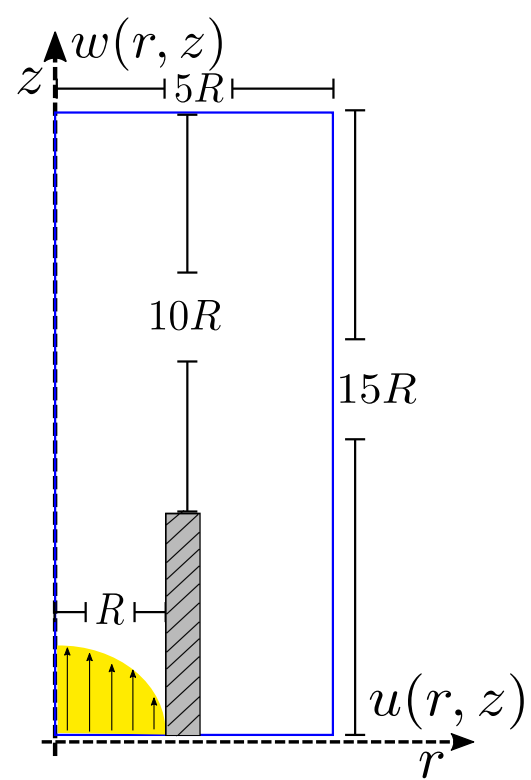

(c)

Fonte: Elaborada pelo autor.

Uma expressão analítica para a solução das equações diferenciais que modelam esse problema ainda não é conhecida. Nas seções seguintes, vamos fazer um estudo de convergência do método numérico utilizando refinamento de malha e também comparações com resultados encontrados na literatura.

\subsubsection{Refinamento de malha}

No estudo de refinamento de malha do problema do inchamento do extrudado foi considerado o domínio computacional conforme mostrado na Figura 26c e os seguintes dados foram utilizados:

A Tubo com raio $R=1.0 \mathrm{~m}$ e comprimento $L_{1}=5 R \mathrm{~m}$;

\$ Distância entre a saída do tubo e a região de saída do fluido (outflow): $L_{2}=10 R \mathrm{~m}$;

ค. $\rho=1000 \mathrm{~kg} \mathrm{~m}^{-3}, \eta_{0}=4000$ Pa.s, $\lambda_{1}=0.9844 \mathrm{~s} \mathrm{e} U=1.0 \mathrm{~ms}^{-1}$;

A $R e=\frac{\rho U R}{\eta_{0}}=0.25, W i=\lambda_{1} \frac{U}{R}=0.9844$ e $\beta=1 / 9$. Efeitos de gravidade foram desconsiderados. 
Na entrada do tubo, foram impostos os seguinte perfis de velocidade e do tensor tensão extra em escoamento totalmente desenvolvido:

$$
\begin{aligned}
& w(r)=2\left[1-r^{2}\right], \quad u(r)=0, \quad \dot{\gamma}=\frac{d w}{d r}=-4 r, \\
& \tau^{z z}(r)=\frac{2}{\operatorname{Re}} W i(1-\beta) \dot{\gamma}^{2}, \quad \tau^{r z}(r)=\frac{1}{\operatorname{Re}} \dot{\gamma}, \quad \tau^{r r}(r)=\tau^{\theta \theta}(r)=0,
\end{aligned}
$$

As malhas utilizadas nessas simulações são definidas na Tabela 10.

Tabela 10 - Malhas utilizadas para simular o inchamento do extrudado.

\begin{tabular}{l||c|c|c|c|c}
\hline Malha & M10 & M15 & M20 & M25 & M30 \\
\hline$\delta r=\delta z$ & 0.10000 & 0.06666 & 0.05000 & 0.0 .0400 & 0.03333 \\
Células da malha & $(50 \times 150)$ & $(75 \times 225)$ & $(100 \times 300)$ & $(125 \times 375)$ & $(150 \times 450)$ \\
\hline
\end{tabular}

Fonte: Dados da pesquisa.

As simulações iniciaram em $t=0$ e foram executadas até $t=200 \mathrm{~s}$; após esse tempo assumiu-se que o estado estacionário foi atingido. Na Figura 27, estão plotadas a velocidade $w$ e a diferença de tensões normais $N_{1}=\left(\tau^{z z}-\tau^{r r}\right)(z)$ no centro das células adjacentes ao eixo de simetria, $\left(0.5 \delta r, z_{j}\right)$, nas malhas utilizadas. Dentro do tubo, observa-se que as soluções numéricas para a velocidade $w\left(0.5 \delta r, z_{j}\right)$ concordam com a solução analítica imposta na entrada do tubo (veja uma ampliação desses valores que são mostrados na Figura 27b). Devido a singularidade nas condições de contorno, observa-se também um salto nos valores de $w\left(0.5 \delta r, z_{j}\right)$ na vizinhança da saída do tubo, e longe da saída do tubo os valores de $w\left(0.5 \delta r, z_{j}\right)$ convergem para valores constantes. Conforme a malha é refinada, vê-se que os valores na malhas mais grossas (M10, M15, M20 e M25) se aproximam do valor obtido na malha M30. A Figura 27c, mostra que as diferenças de tensões normais, numa vizinhança próxima a saída do tubo, também apresentam um salto nos valores mostrados. Observa-se que dentro do tubo, as soluções numéricas convergem para a solução analítica (que é nula) e durante a transição que ocorre antes da saída e após a saída do tubo (veja a Figura 27d), os valores nas malhas consideradas convergem para os valores obtidos na malha mais fina (M30). A Figura 28 mostra que as superfícies do jato nas malhas mais grossas convergem para a curva do jato obtida na malha mais fina (M30). Em resumo, esses resultados demonstram a convergência do código utilizado para resolver esse problema. 
Figura 27 - Simulação do inchamento do extrudado em diferentes malhas: (a) $w\left(0.5 \delta r, z_{j}\right)$ e (b) $N_{1}\left(0.5 \delta r, z_{j}\right)$. Resultados obtidos nas malhas M10, M15, M20, M25, e M30.

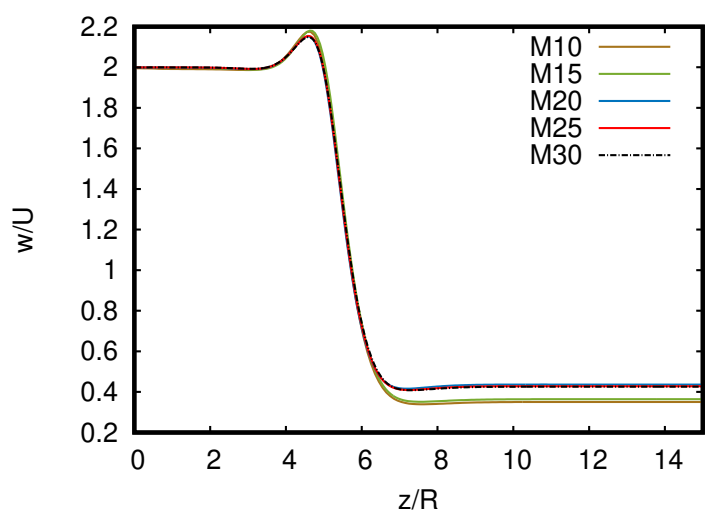

(a)

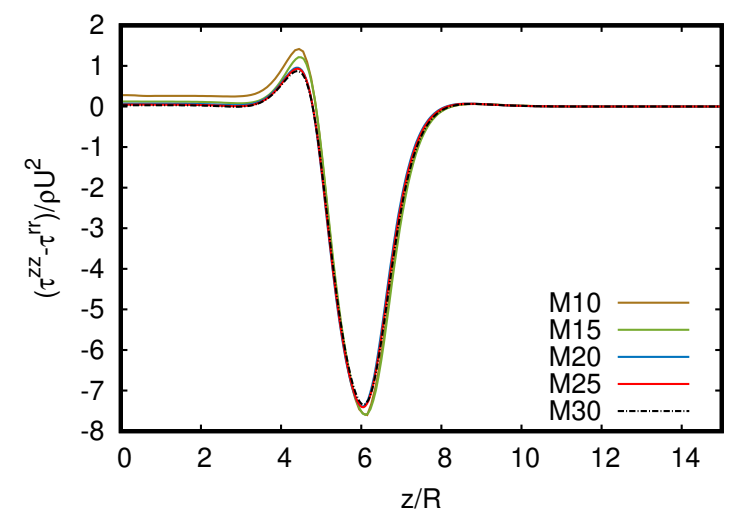

(c)

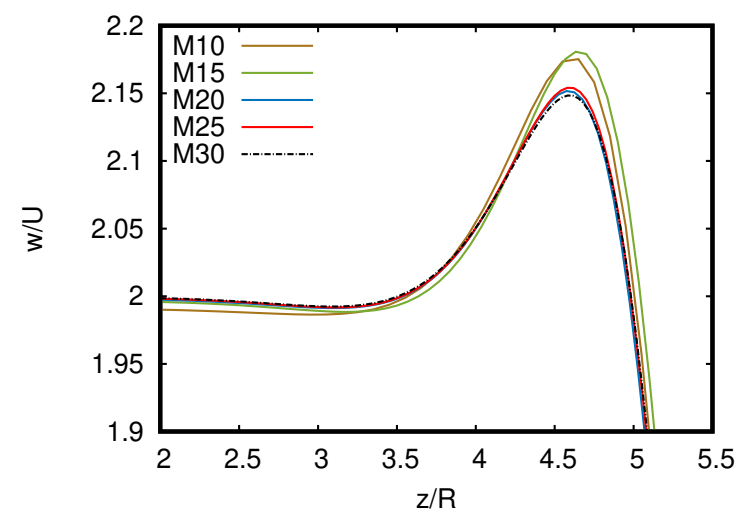

(b)

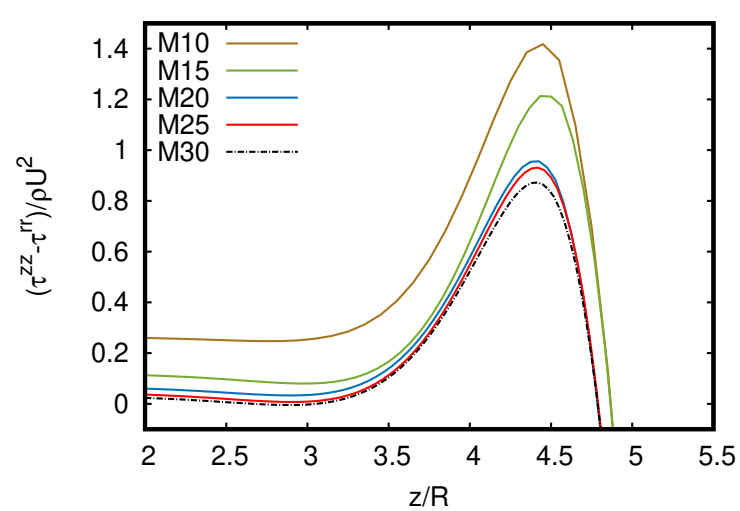

(d)

Fonte: Elaborada pelo autor.

Figura 28 - Superfícies livres obtidas em cada malha. Resultados mostrados para $z \in[4.5,8.5]$.

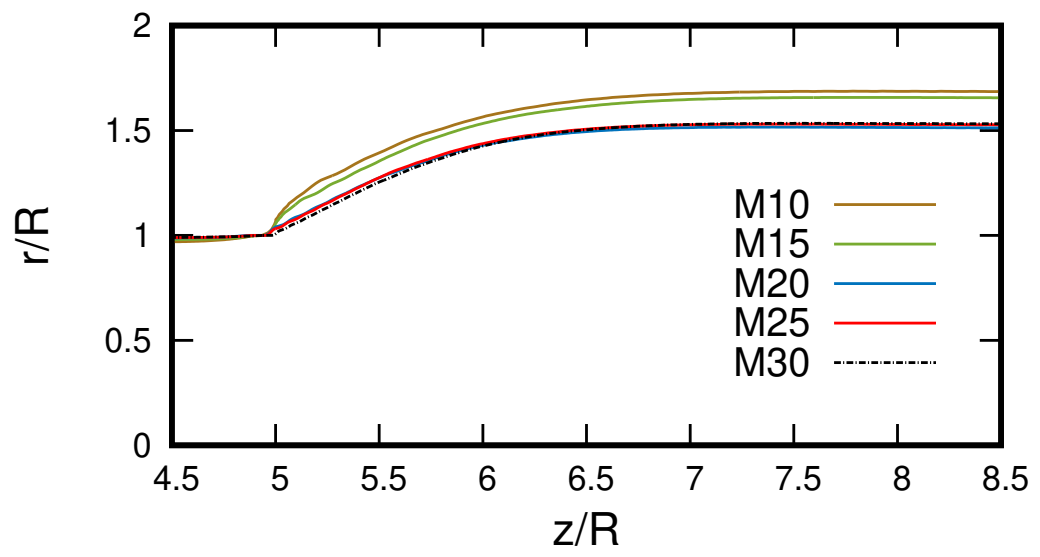

Fonte: Elaborada pelo autor. 


\subsubsection{Comparação com resultados da literatura}

Para demonstrar a aplicabilidade do código numérico no problema do inchamento do extrudado, uma série de simulações variando o número de Weissenberg $(W i)$ foram executadas para um número de Reynolds ( $R e$ ) fixo. O domínio do escoamento e dados utilizados são os mesmos do refinamento de malha (veja Subseção 3.1.1, Figura 26) juntamente com as malhas da Tabela 10.

Objetivando fazer uma verificaçao com resultados de outros autores, nas simulações foram utilizados $R e=0.25, \beta=1 / 9$ e na entrada do tubo, os perfis de velocidade e tensão dados na Equação 3.5, foram impostos respectivamente. Com a finalidade de realizar uma comparação com resultados da literatura, as simulações foram executadas variando o recoverable shear $\left(S_{\lambda}\right)$ utilizado nos trabalhos de Crochet e Keunings (1982) e Tanner (1970) e definido pela expressão:

$$
S_{\lambda}=\frac{N_{1 w}}{2\left|\tau_{w}^{r z}\right|}=W i(1-\beta)|\dot{\gamma}|_{w}=4(1-\beta) W i
$$

em que, $N_{1 w}$ e $\left|\tau_{w}^{r z}\right|$ são os valores dados pela solução analítica na parede do tubo, e portanto, avaliados em $r=1$. Os valores de $S_{\lambda}$ e de $W i$ quando $\beta=1 / 9$ utilizados nas simulações são apresentados na Tabela 11. As simulações iniciaram em $t=0$ e foram executadas até $t *(U / L)=200$. Em $t=0$ o tubo está vazio e foi continuamente preenchido até $t=5$ quando o jato está saindo do tubo e sendo extrudado no ar. Depois deste tempo, o fluido inicia o processo de inchamento que muda de acordo com o valor de $S_{\lambda}$. Pressupõe-se que valores altos de $S_{\lambda}$ resulte em taxas de inchamento $S_{r}$ maiores. As curvas das superfícies livres obtidas na malha M25 são mostradas na Figura 29 onde observa-se que o inchamento aumenta com o aumento de $S_{\lambda}$ conforme foi pressuposto.

Uma comparação entre os resultados obtidos por este trabalho e os apresentados por Crochet e Keunings (1982) e previstos pela Lei de Tanner (ver Equação 3.7, (TANNER, 1970)) são plotados na Figura 30. Observa-se que os resultados obtidos pelo código axissimétrico concordam bem com a predição da Lei de Tanner, principalmente nas malhas mais finas. Além disso, verifica-se que em malhas mais grossas os resultados não são tão próximos dos descritos pela Lei de Tanner. Nota-se ainda que conforme $S_{\lambda}$ cresce $\left(S_{\lambda}=4.0\right)$ o resultado apresentado pelo código axissimétrico converge para uma valor acima do obtido por Tanner. Contudo, cabe evidenciar que a Lei de Tanner, Equação 3.7, foi obtida realizando simplificações nas equações governantes e os resultados previstos por essa lei podem não ser precisos para altos valores de $S_{\lambda}$. Vale mencionar que esses são os primeiros resultados que verificam a Lei de Tanner. Os resultados encontrados na literatura concordam com Tanner apenas para valores bem pequenos de $S_{\lambda}$ (quando $S_{\lambda}$ tende a 0 aproximando-se de um fluido newtoniano).

Os resultados apresentados por Crochet e Keunings (1982) foram obtidos via um método de elementos finitos e utilizando malhas muito grossas com 3 pontos no raio do tubo (ver (CROCHET; KEUNINGS, 1982)). Talvez, esse seja o motivo pelo qual os resultados apresentados por 
Crochet não concordam com a Lei de Tanner nem com os resultados obtidos nesse trabalho.

$$
S_{r}=0.14+\left[1.0+\frac{S_{\lambda}^{2}}{2}\right]^{\frac{1}{6}} .
$$

Tabela 11 - Valores do recoverable shear $S_{\lambda}$ e correspondente $W i=\lambda_{1}(L=U=1)$ calculados pela Equação 3.6 e aplicados nas simulações do inchamento do extrudado.

\begin{tabular}{l||c|c|c|c|c|c|c|c}
\hline$S_{\lambda}$ & 0.5 & 1.0 & 1.5 & 2.0 & 2.5 & 3.0 & 3.5 & 4.0 \\
\hline$W i=\lambda_{1}$ & 0.1406 & 0.2812 & 0.4219 & 0.5625 & 0.7031 & 0.8437 & 0.9844 & 1.1250 \\
\hline \multicolumn{8}{c}{ Fonte: Dados da pesquisa. }
\end{tabular}

Figura 29 - Gráfico das superfícies livres das simulações do inchamento do extrudado para vários valores do recoverable shear na malha M25 com uma ampliação da região $[4.5,8.0] \times[0.6,1.8]$.
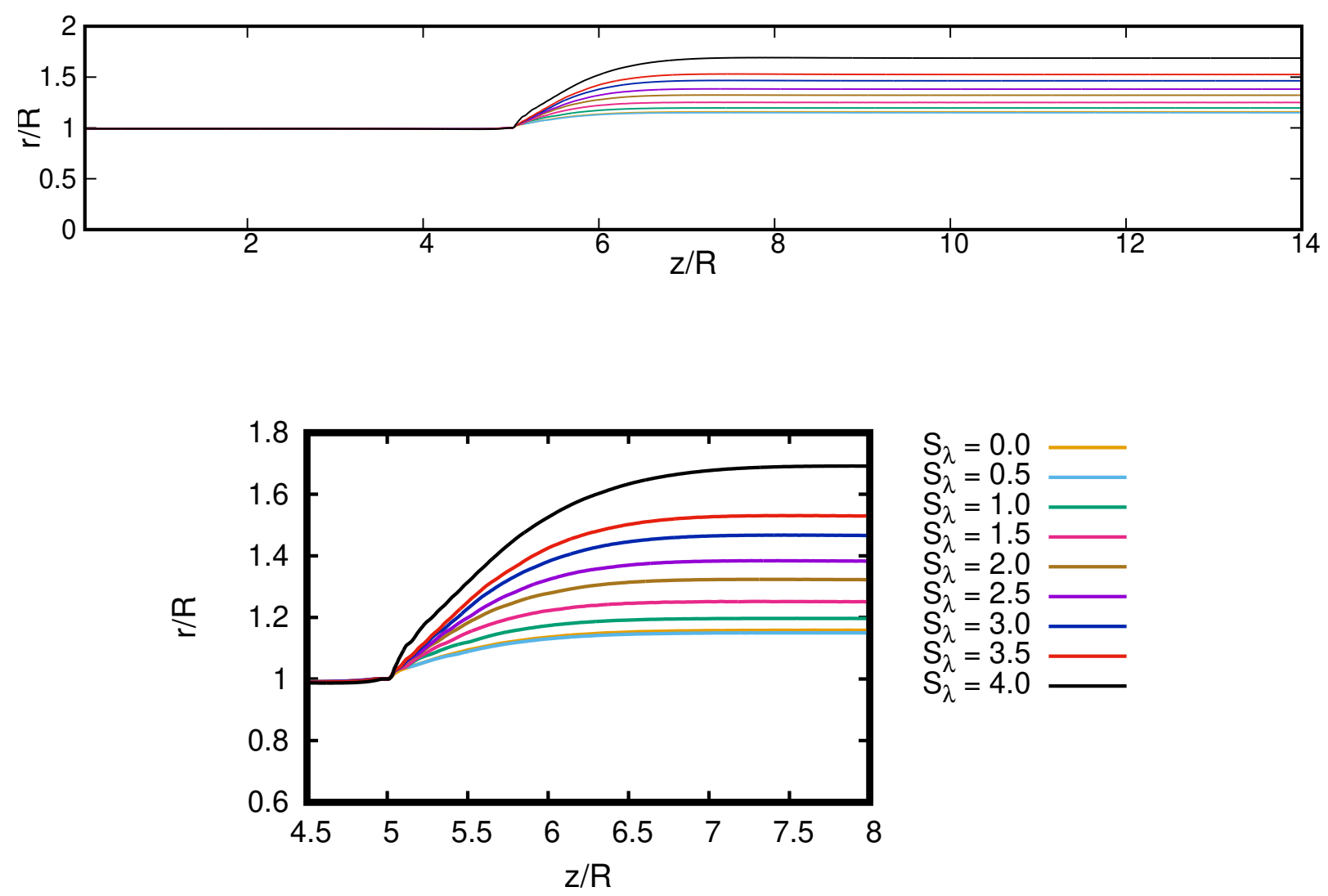

Fonte: Elaborada pelo autor. 
Figura 30 - Comparação das taxas de inchamento $S_{r}=d_{e x} / d_{0}$ para $S_{\lambda} \in[0,4.0]$.

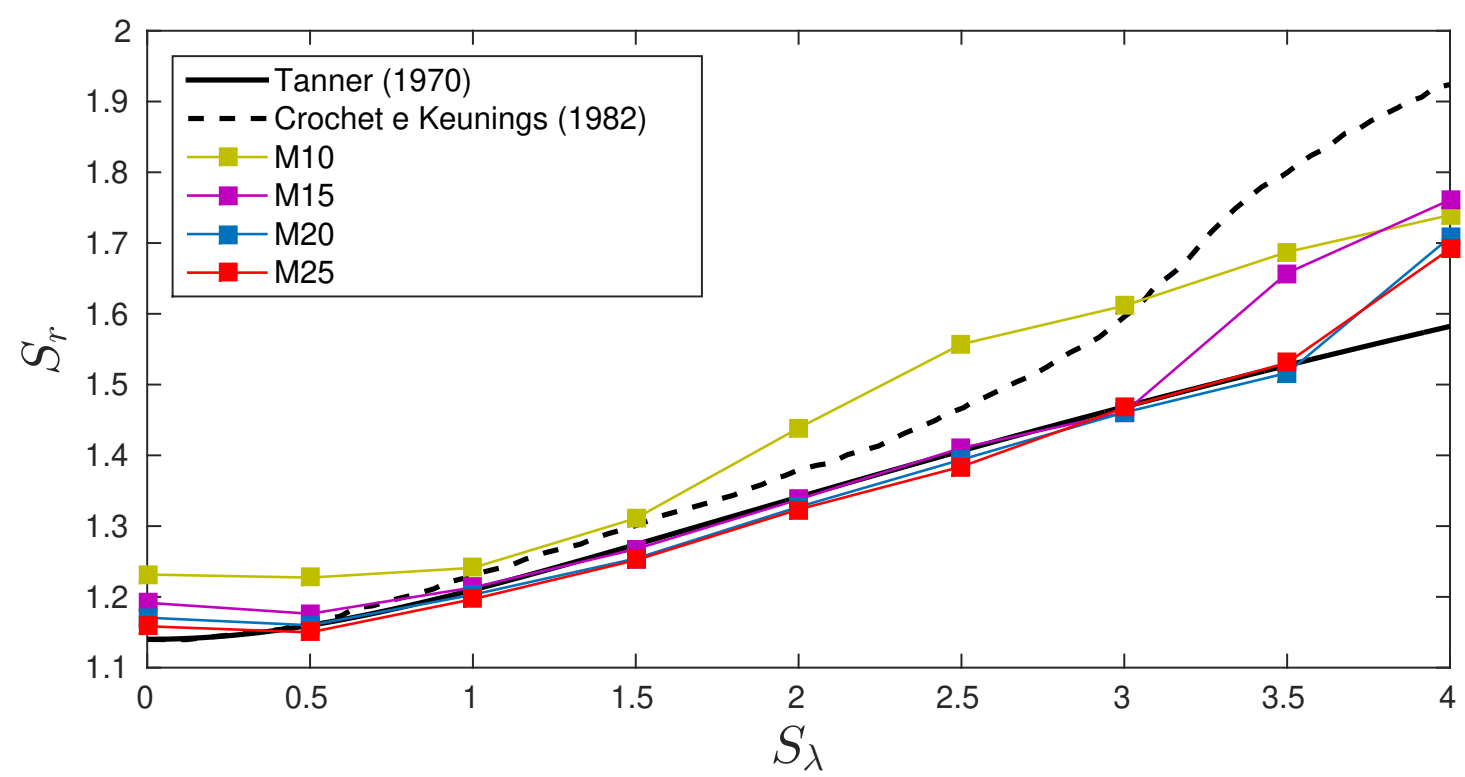

Fonte: Elaborada pelo autor.

Para observar os efeitos do parâmetro $S_{\lambda}$ no escoamento, os valores da velocidade $w\left(r_{w}, z_{j}\right)$ e das diferenças de tensões normais $N_{1}\left(r_{w}, z_{j}\right)$ nos pontos da malha M20 adjacentes a parede interna do tubo (veja a linha pontilhada na Figura 32b), $r_{w}=0.975$ (desde que $\delta r=0.05$ ) e $j=1, \cdots, 300$, são mostrados na Figura 31

A velocidade $w$, mostrada na Figura 31a, dentro do tubo admite um valor estacionário e fora do tubo atinge outro valor estacionário cujo valor varia com $S_{\lambda}$. Nota-se que quanto maior é o valor de $S_{\lambda}$ menor é o valor da velocidade fora do tubo. Esses resultados estão de acordo com os apresentados na Figura 29, que mostra o aumento do inchamento com o aumento do valor de $S_{\lambda}$, e além disso, devido a equação de conservação de massa, o valor da velocidade deve diminuir para que o volume de fluido seja conservado. Dentro do tubo e próximo a parede (ver Figura 31b), vê-se que a primeira diferença de tensões normais $N_{1}$ apresenta uma grande variação: começa com zero para $S_{\lambda}=0$ e atinge o valor máximo de 120 para $S_{\lambda}=4.0$. Na saída do tubo, há uma variação brusca devido a singularidade nas condições de contorno. Essa variação fica mais pronunciada com o aumento de $S_{\lambda}$. Fora do tubo, as tensões tendem para zero uma vez que não há cisalhamento nessa região do escoamento. 
Figura 31 - Comportamento da velocidade $w$ na direção próximo ao (a) eixo de simetria e (b) parede interna do tubo.

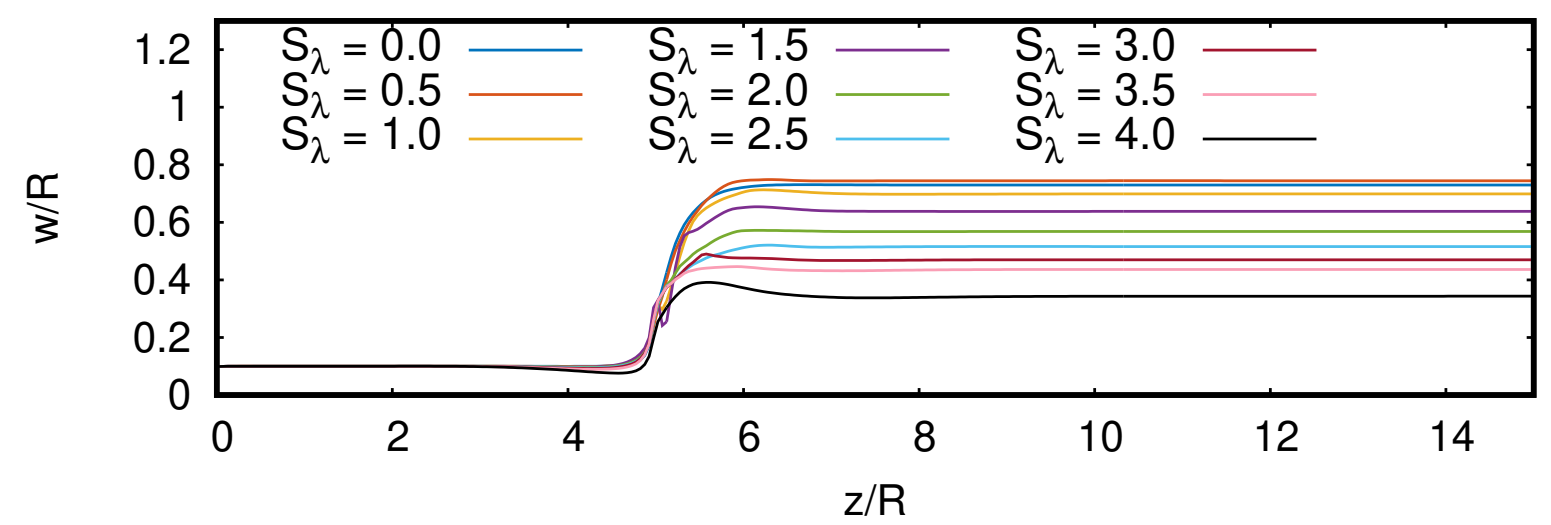

(a) Valor da velocidade $w$ nos pontos $\left(0.975, z_{j}\right)$.

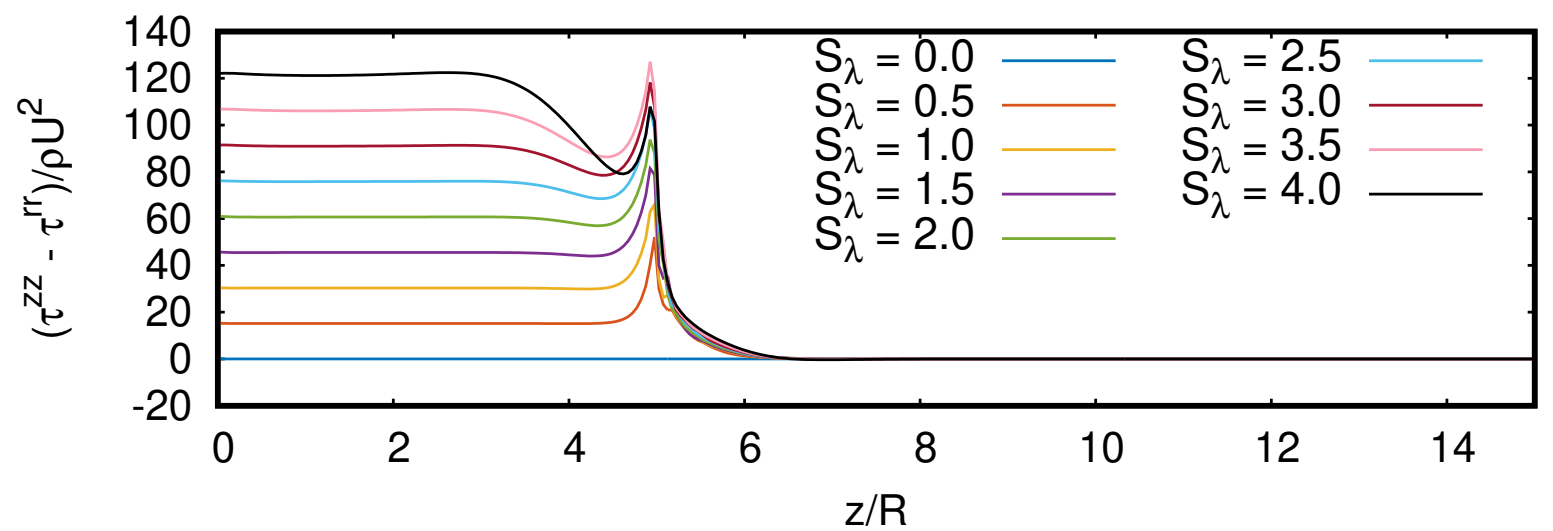

(b) Valor de $N_{1}$ nos pontos $\left(0.975, z_{j}\right)$.

Fonte: Elaborada pelo autor.

Figura 32 - Localização no domínio computacional das linhas de impressão da velocidade e tensões. (a) Próximo ao eixo de simetria. (b) Adjacente a parede interna do tubo.

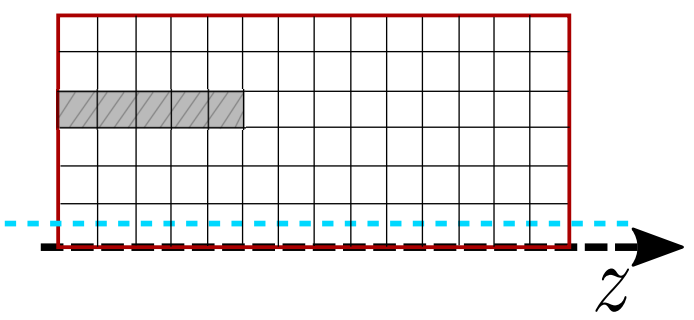

(a)

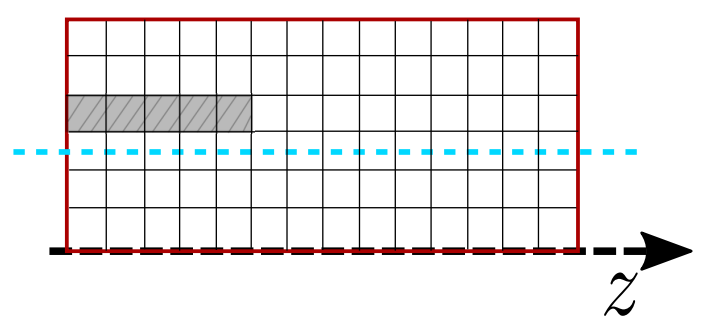

(b)

Fonte: Elaborada pelo autor. 


\subsection{O problema do inchamento retardado do extrudado: fluido Oldroyd-B}

Para demonstrar que o código axissimétrico é capaz de simular o fenômeno do inchamento retardado de fluidos Oldroyd-B, nessa seção são apresentados resultados de verificação utilizando o número de elasticidade $\mathrm{E}=0.03$. A seguir, resultados novos com $\mathrm{E}=0.0375$ são apresentados.

\subsubsection{Comparação com resultados da literatura}

Nessa seção, são apresentados resultados de verificação da eficiência do código axissimétrico na simulação do fenômeno do inchamento retardado do extrudado. A verificação é realizada utilizando o estudo publicado por Delvaux e Crochet (1990) que considerou um código de elementos finitos em suas simulações.

Nas simulações, os números de Reynolds e de Weissenberg foram definidos por:

$$
R e=\frac{\rho_{0} U d_{0}}{\eta_{0}}, \quad W i=\lambda_{1} \frac{U}{d_{0}} .
$$

O domínio computacional empregado é mostrado na Figura 33 e os dados da Tabela 12 foram utilizados. Com o objetivo de verificar a convergência do código axissimétrico nesse problema, foram utilizadas várias malhas também apresentadas na Tabela 12.

Tabela 12 - Valores de Ma utilizados para simular o inchamento retardado do extrudado e especificação das malhas empregadas. $\mathrm{O}$ valor do número de elasticidade $\mathrm{E}=0.03$ e $\beta=0.05$ foram mantidos fixos. Os valores de Ma, Re e Wi mostrados abaixo são os mesmos utilizados por Delvaux e Crochet (1990).

\begin{tabular}{|c||ccccccc|}
\hline $\mathrm{Ma}$ & 2.3 & 2.58 & 2.9 & 3.52 & 4.1 & 5.1 & 5.9 \\
\hline$R e$ & 13.5 & 15.2 & 17.0 & 20.7 & 24.1 & 29.9 & 34.6 \\
\hline$W i$ & 0.39 & 0.44 & 0.49 & 0.60 & 0.70 & 0.87 & 1.0 \\
\hline
\end{tabular}

\begin{tabular}{|c||cccc|}
\hline Malhas & M10 & M15 & M20 & M25 \\
\hline$\delta r=\delta z$ & 0.1000 & 0.0666 & 0.0500 & 0.0400 \\
\hline células & $(70 \times 180)$ & $(105 \times 270)$ & $(140 \times 360)$ & $(175 \times 450)$ \\
\hline
\end{tabular}

Fonte: Dados da pesquisa.

O código axissimétrico simulou esse escoamento para cada valor de Ma da Tabela 12 iniciando em $t=0$, com o tubo vazio, até $t=200$ s onde após esse tempo assumiu-se que o estado estacionário foi atingido.

A Figura 34, mostra a taxa de inchamento obtida para cada valor de Ma nas quatro malhas utilizadas. Para efeito de comparação, os resultados de Delvaux e Crochet (1990) também são mostrados. Observa-se uma discrepância entre os resultados de Delvaux e Crochet (1990) e 
os calculados pelo código axissimétrico. As diferenças entre os resultados talvez sejam devidas ao fato que a malha irregular MIII, a malha mais fina apresentada por Delvaux e Crochet, seja razoavelmente grosseira com seis células na direção radial enquanto que os resultados do código axissimétrico empregou as malhas uniformes M10, M15, M20 e M25 contendo 10, 15, 20 e 25 pontos distribuidos no raio, respectivamente. Vê-se que os resultados nas quatro malhas concordam bem com os da malha M25. Por esta razão, acredita-se que os resultados obtidos são consistentes e considerados mais precisos do que aqueles apresentados por Delvaux e Crochet (1990).

Figura 33 - Descrição do domínio computacional para o problema do inchamento retardado do extrudado.

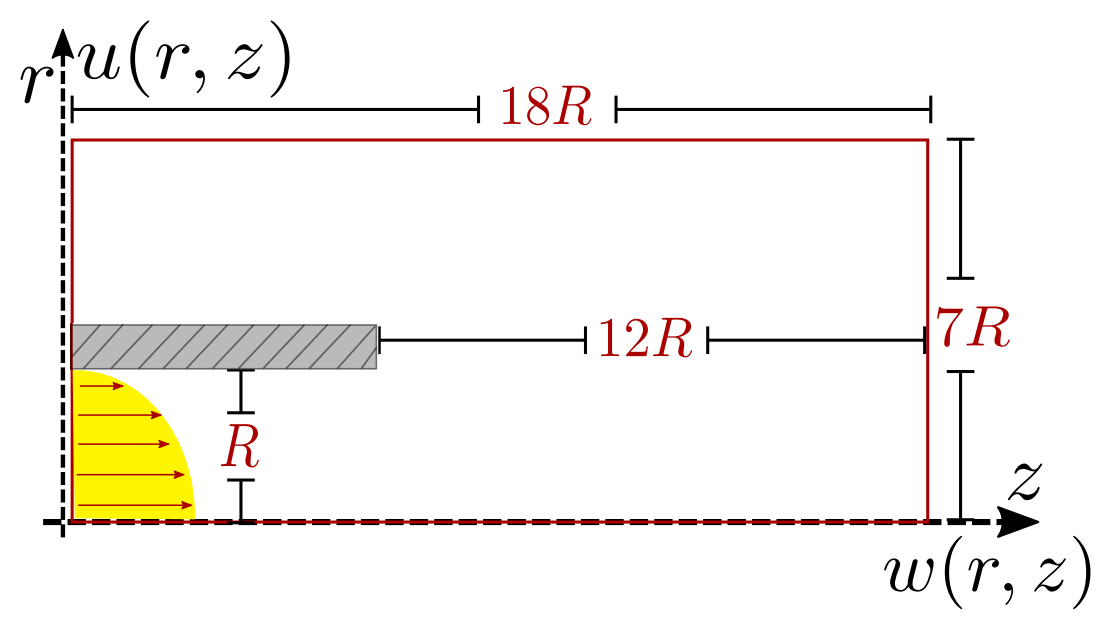

Fonte: Elaborada pelo autor.

Figura 34 - Comparação da taxa de inchamento $d_{e x} / d_{0}$ calculada em diferentes malhas com resultados apresentados por Delvaux e Crochet (1990) obtidos utilizando a malha III.

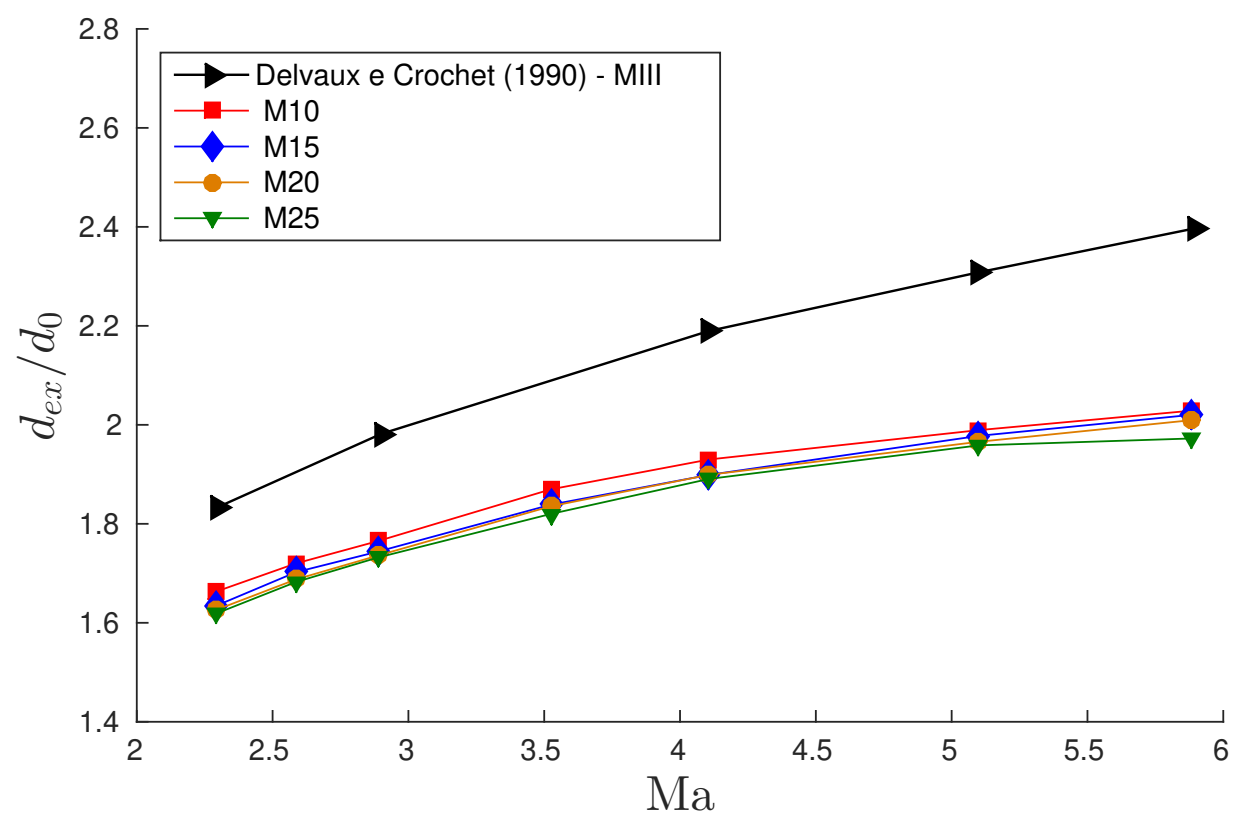

Fonte: Elaborada pelo autor. 
Outro resultado importante que pode ser verificado é a distância do retardamento (delayed distance) $l_{d} / d_{0}$ (ver Figura 25a) que foi publicada por Delvaux e Crochet (1990).

Para essa finalidade, Delvaux e Crochet (1990) sugerem o seguinte procedimento para calcular a distância de retardo do jato.

- seleciona-se uma linha de corrente específica onde $\dot{\gamma}\left(r^{*}\right)=\left.11 \% \dot{\gamma}\right|_{w}$ e calcula-se o ponto $z_{d}$ onde essa linha de corrente muda o sinal da sua curvatura.

- O ponto $z_{d}$ é calculado como sendo o ponto onde a curvatura da linha de corrente $\Psi\left(r^{*}, z\right)$, dada pelas equações,

$$
u=-\frac{1}{r} \frac{\partial \Psi}{\partial z} \quad \text { e } \quad w=\frac{1}{r} \frac{\partial \Psi}{\partial r}
$$

muda de sinal.

Para isso, basta calcular a coordenada $z_{d}$ em que

$$
\frac{\partial^{2} \Psi\left(r^{*}, z_{d}\right)}{\partial z^{2}}=-r^{*} \frac{\partial u\left(r^{*}, z_{d}\right)}{\partial z}=0
$$

Percorre-se as coordenadas $z_{j}$ e verifica-se quando $\frac{\partial u\left(r^{*}, z_{j}\right)}{\partial z}$ muda de sinal, logo, aplica-se uma interpolação linear para calcular o ponto de inflexão onde $\frac{\partial u}{\partial z}=0$ obtendo o ponto $z_{d}$. A distância do retardamento é então calculada como $l_{d}=z_{d}-z_{0}$ em que $z_{0}$ determina o valor da coordenada $z$ na saída do tubo, como representado na Figura 25a. Note que o escoamento dentro do tubo é caracterizado pelo perfil de velocidade fornecido pela Equação 3.9, onde $\left.\dot{\gamma}\right|_{w}=-8$.

$$
w(r)=2\left[1-4\left(r / d_{0}\right)^{2}\right], \quad \dot{\gamma}(r)=-16\left(r / d_{0}\right),\left.\quad \dot{\gamma}\right|_{w}=-8 \quad r \in[0,1] .
$$

Os resultados obtidos no cálculo da distância de retardamento são apresentados na Figura 35, onde também é realizada uma comparação com os resultados obtidos por Delvaux e Crochet (1990). Observa-se que os resultados obtidos nas malhas M10, M15 e M20 aproximam-se daqueles obtidos na malha M25 e que os resultados do código axissimétrico concordam bem com os obtidos por Delvaux e Crochet (embora uma pequena discrepância com os resultados de Delvaux e Crochet (1990) pode ser constatada). Por se tratarem de metodologias distintas, podemos afirmar que o código axissimétrico apresentou uma boa performance na resolução do problema do inchamento retardado do extrudado indicando que podemos utiliza-lo para obter resultados com valores de Ma e E superiores aos apresentados em Delvaux e Crochet (1990). 
Figura 35 - Comparação das distâncias de retardamento $l_{d} / d_{0}$ calculadas em diferentes malhas com resultados na malha MIII apresentados por Delvaux e Crochet (1990).

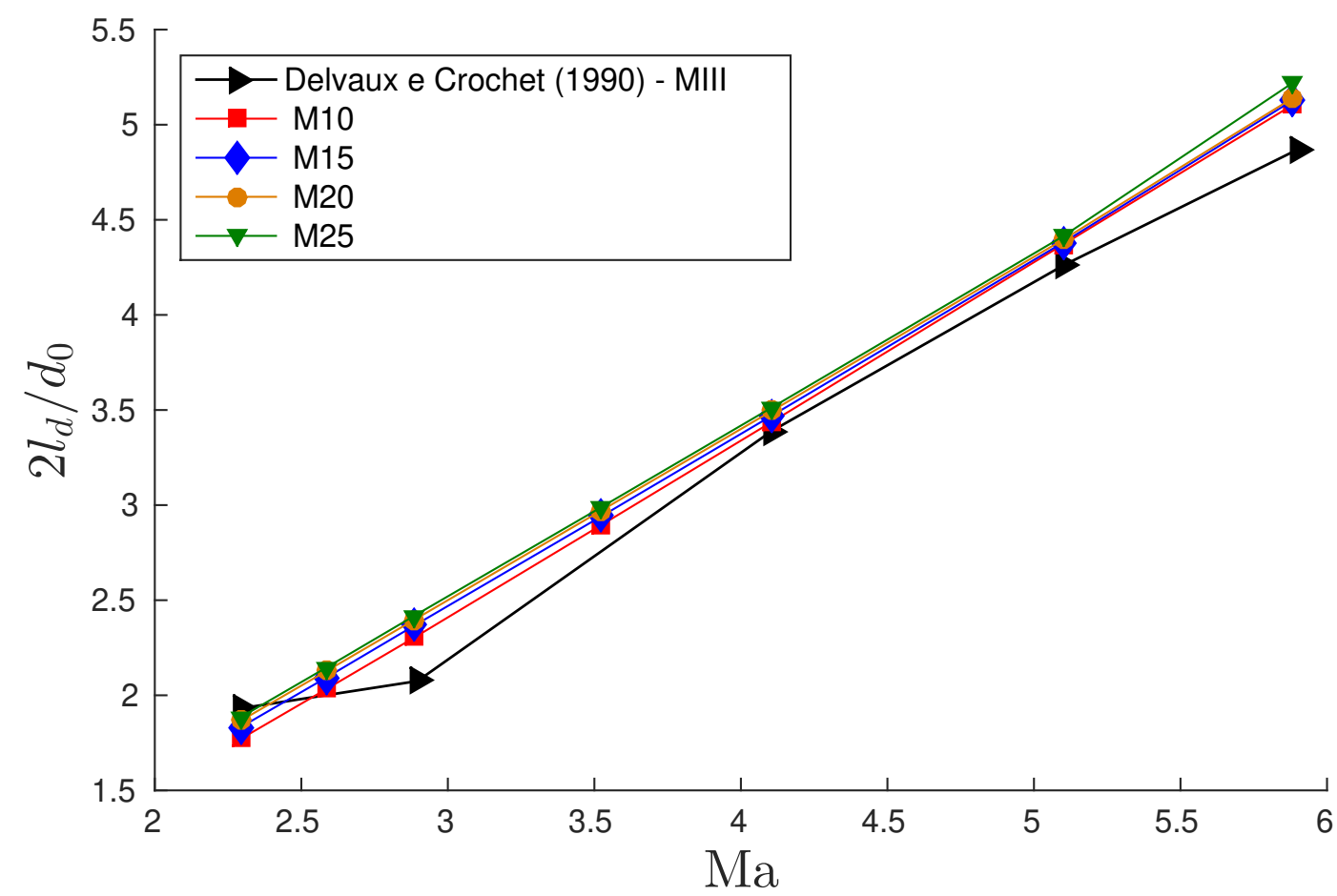

Fonte: Elaborada pelo autor.

Um outro resultado publicado por Delvaux e Crochet (1990), mostra que para valores de Wi pequenos e mantendo fixo o número de elasticidade $\mathrm{E}$, a taxa de inchamento $\left(d_{e x} / d_{0}\right)$ obtida em um escoamento com efeitos de inércia $(R e>1)$ é semelhante aquela obtida em um escoamento sem efeitos de inércia $(\operatorname{Re} \ll 1)$ (ver Figura 36).

Para comprovar essa condição, foram realizadas 3 simulações e comparadas as curvas finais (no estado estacionário) da superfície livre nesses três escoamentos. Os escoamentos foram simulados com os seguintes dados:

1. Número de $R e$ pequeno: $R e=0.2, W i=0.4$ que fornece $\mathrm{E}=4.0, \mathrm{Ma}=0.28$.

2. Efeito de inércia: $R e=13.6, W i=0.4$ que resulta em $\mathrm{E}=0.03, \mathrm{Ma}=2.33$.

3. Escoamento newtoniano: $R e=13.6, W i=0$. 
Figura 36 - Comparação entre escoamento newtoniano, viscoelástico com inércia e viscoelástico sem inércia obtidos por Delvaux e Crochet (1990). (a) Sobreposição das superfícies livres. Newtoniano: $W i=0$ e $R e=24.1$ (sem inchamento); viscoelástico com inércia: $W i=0.7$ e $R e=24.1$ (retardamento do inchamento); viscoelástico sem inércia: $W i=0.7$ e $R e=0$ (sem retardamento do inchamento). (b) Taxas de inchamento máximo do extrudado em função de Wi para escoamentos com e sem efeito de inércia.

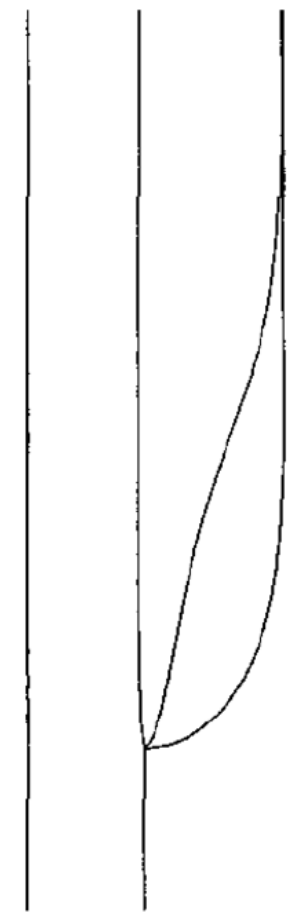

(a)

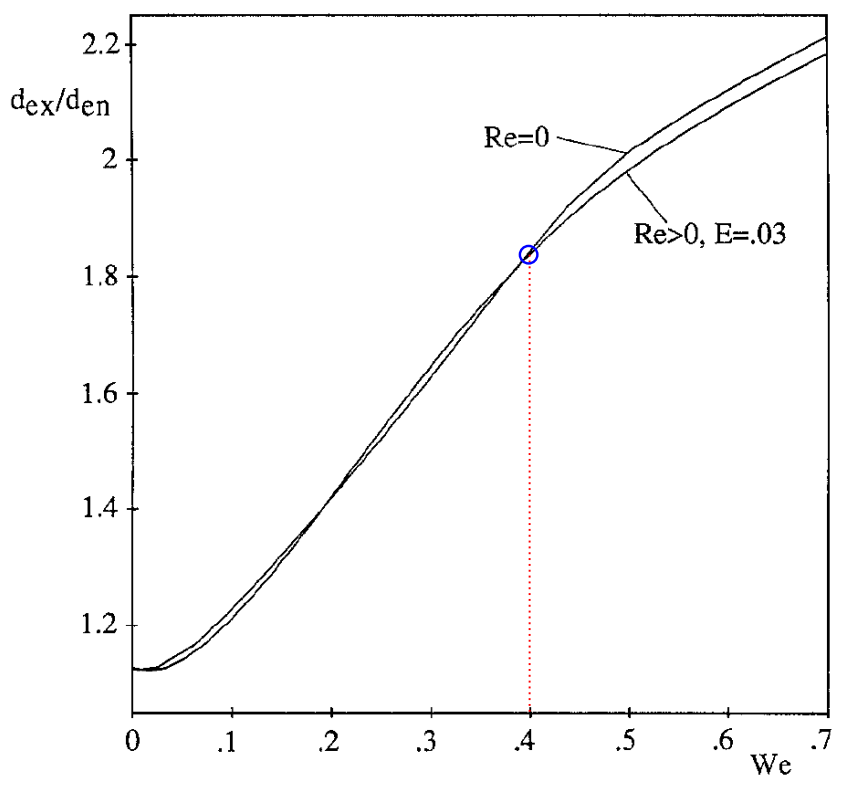

(b)

Fonte: Adaptada de Delvaux e Crochet (1990, p. 6 e 7).

Os três escoamentos foram simulados e os resultados são mostrados na Figura 37 onde pode-se ver que os resultados obtidos com o código axissimétrico apresentam a mesma taxa de inchamento para os escoamentos com $R e=13.6$ e $R e=0.2$. Esse fato confirma a análise de Delvaux e Crochet (1990) e verifca que o código axissimétrico fornece resultados coerentes com resultados da literatura para escoamentos do inchamento do extrudado.
Figura 37 - Comparação das superfícies livres dos escoamentos: newtoniano, com efeito de inércia e com Reynolds pequeno.

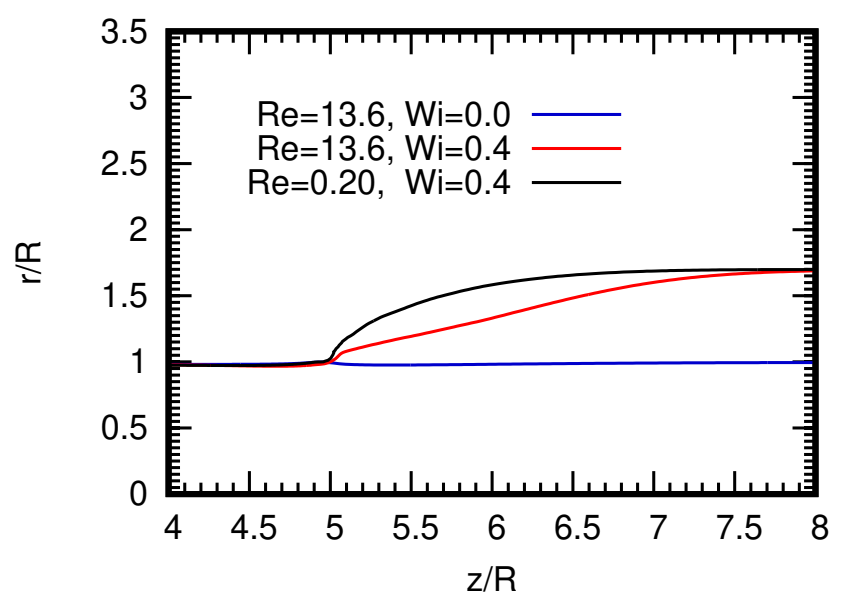

Fonte: Elaborada pelo autor. 
Delvaux e Crochet (1990) mapearam as regiões supercríticas e subcríticas do escoamento para os valores de Ma considerados na Tabela 12. Na Figura 38 realiza-se uma comparação qualitativa das regiões supercríticas e subcríticas para dois valores de $\mathrm{Ma}: \mathrm{Ma}=2.3$ e $\mathrm{Ma}=5.9$. Com base na definição dessas regiões, também é apresentada a variação do determinante do tensor $\mathrm{T}^{*}$ em que a sua positividade determina a região subcrítica do escoamento, caso contrário, se $\operatorname{Det}\left(\mathbf{T}^{*}\right)$ é negativo então a região é supercrítica, ou seja, a equação de vorticidade nesta região é caracterizada por um regime hiperbólico. Para realizar esta comparação, utilizou-se os resultados obtidos pelo código axissimétrico na malha M20. A Figura 38 mostra que para $\mathrm{Ma}=2.3$ os resultados são bem semelhantes. Entretanto, para $\mathrm{Ma}=5.9$ há uma diferença no tamanho da região subcrítica próximo ao eixo de simetria e próximo do ponto onde o jato atinge o inchamento máximo. Essa diferença pode ser devida a diferentes malhas adotadas, e também, ao critério de definição da região supercrítica. Nesse trabalho considerou-se $\operatorname{Det}\left(\mathbf{T}^{*}\right) \leq 10^{-12}$ enquanto que no trabalho de Delvaux e Crochet (1990) não foi mencionado o valor utilizado. Na Figura 39 são mostradas as regiões supercríticas para cada valor de Ma simulado. Observa-se que o aumento do número de Mach viscoelástico resulta em regiões supercríticas maiores no escoamento, como conjecturado por Joseph, Matta e Chen (1987).

Figura 38 - Comparação qualitativa entre as regiões subcríticas e supercríticas (região mostrada na cor escura) dos escoamentos do inchamento retardado do fluido Oldroyd-B ( $\beta=0.05$ ) para (a) $\mathrm{Ma}=2.3$ e (b) 5.9. Os resultados são comparados com os obtidos por Delvaux e Crochet (1990) (terceiro resultado da esquerda para direita) em (a) e (b) .

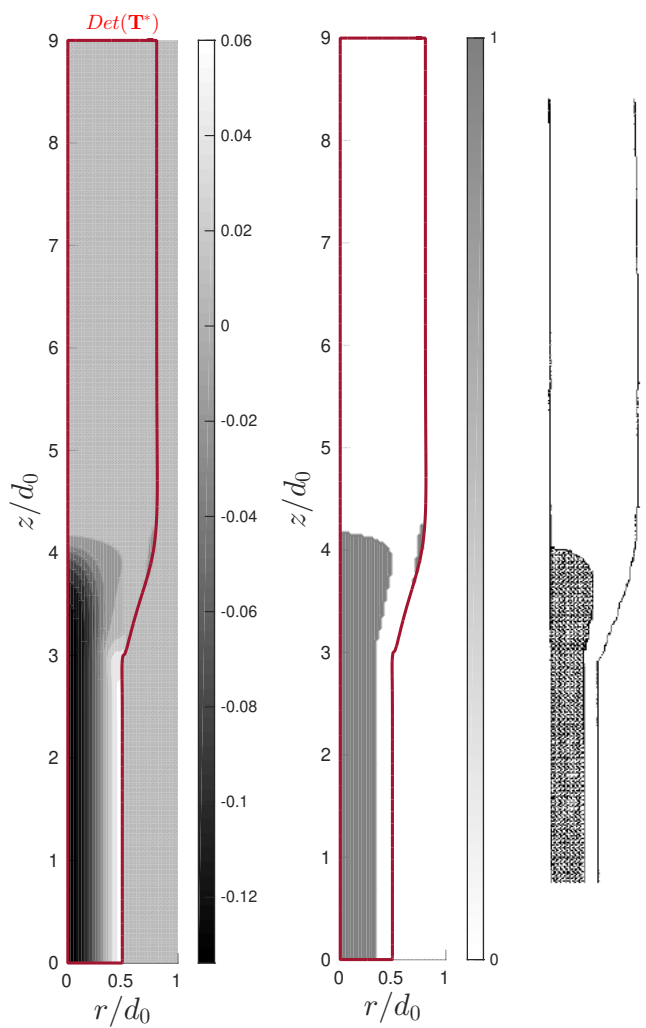

(a) $\mathrm{Ma}=2.3$
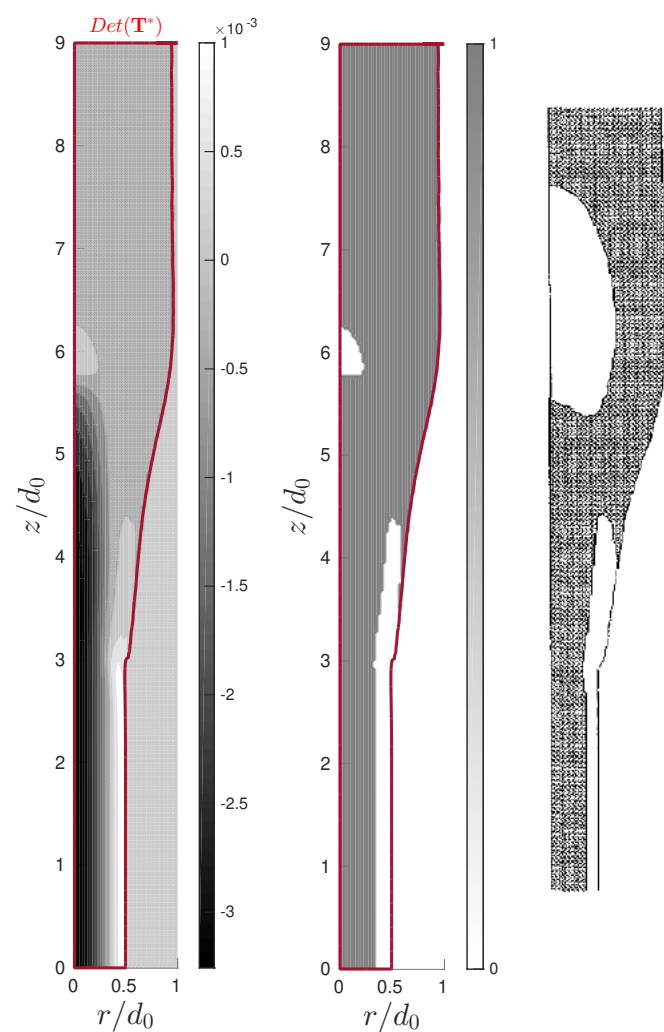

(b) $\mathrm{Ma}=5.9$

Fonte: Elaborada pelo autor. 
Figura 39 - Regiões supercríticas e subcríticas do escoamento do inchamento retardado para diferentes valores de Ma e $E=0.03$. As regiões em cinza indicam escoamento supercrítico e as regiões em branco mostram as regiões de escoamento subcrítico.

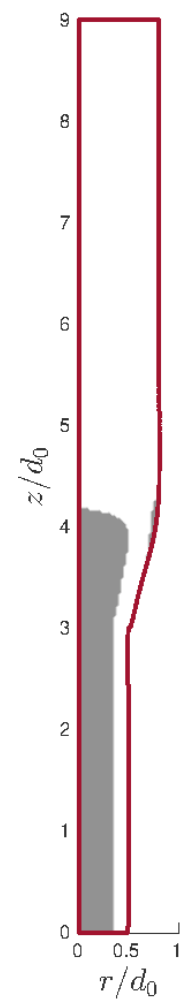

(a) $\mathrm{Ma}=2.3$

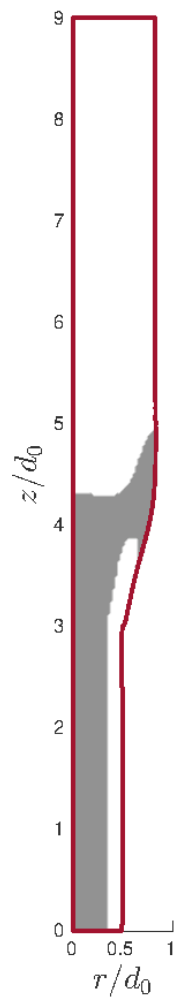

(b) $\mathrm{Ma}=2.5$

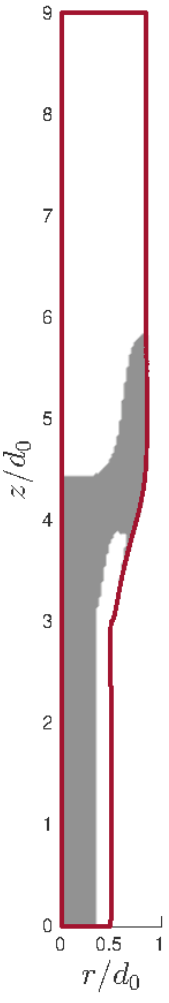

(c) $\mathrm{Ma}=2.9$

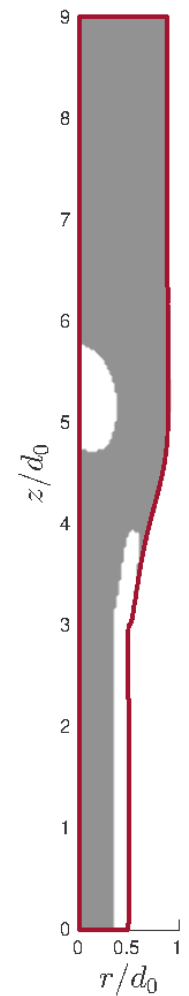

(d) $\mathrm{Ma}=3.5$

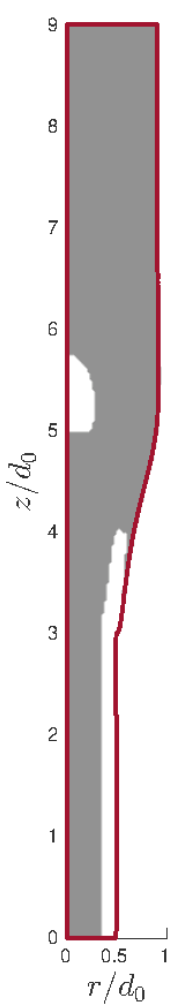

(e) $\mathrm{Ma}=4.1$

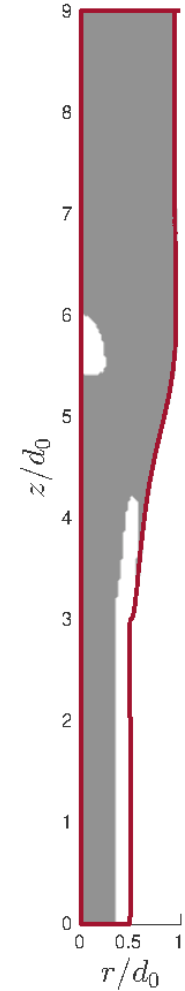

(f) $\mathrm{Ma}=5.1$

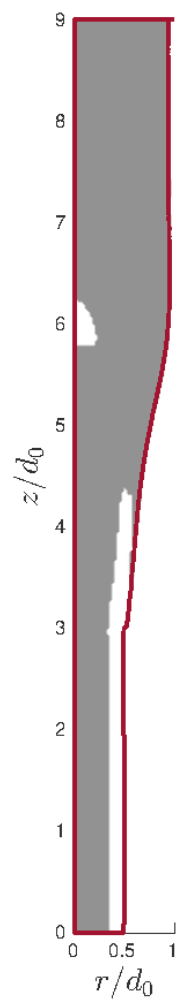

(g) $\mathrm{Ma}=5.9$

Fonte: Elaborada pelo autor.

Pode-se concluir que os resulados obtidos nessa seção são verificados com os apresentados por Delvaux e Crochet (1990). Além disso, acredita-se que os resultados do código axissimétricos são mais precisos que os publicados por Delvaux e Crochet (1990).

\subsubsection{Inchamento retardado do extrudado para $E=0.0375$}

Uma das dificuldades numéricas na simulação do inchamento retardado do extrudado é o aumento nos números de Mach viscoelástico e da elasticidade. Valores altos de Ma e E implicam em valores maiores de $W i$. O único trabalho que estudou esse problema foi o apresentado por Delvaux e Crochet (1990) que utilizaram um fluido Oldroyd-B com 5\% de solvente. Nesta Subseção apresenta-se resultados novos para este problema considerando um valor do número de elasticidade $\mathrm{E}$ maior, ou seja, $\mathrm{E}=0.0375$ (o que indica taxas de inchamento maiores). Além disso, é de interesse verificar se o código axissimétrico consegue obter resultados para números de Mach viscoelástico superiores aos já estudados.

Os resultados mostrados a seguir, foram obtidos nas malhas M10, M15 e M20 da Tabela 12 e o domínio computacional descrito na Figura 33. A Tabela 13 apresenta os valores de 
Ma, Re e $W i$ considerados nessas simulações. O perfil de velocidade imposto na entrada do tubo é especificado na Equação 3.9.

Tabela 13 - Valores de $\mathrm{Ma}=\sqrt{\operatorname{ReWi}}$ utilizados para simular o inchamento retardado do extrudado com $\mathrm{E}=0.0375$.

\begin{tabular}{|c||ccccccccc|}
\hline$R e$ & 6.666 & 10.00 & 13.33 & 16.66 & 20.00 & 23.33 & 26.66 & 30.00 & 33.33 \\
\hline$W i$ & 0.250 & 0.375 & 0.500 & 0.625 & 0.750 & 0.875 & 1.000 & 1.125 & 1.250 \\
\hline $\mathrm{Ma}$ & 1.291 & 1.936 & 2.582 & 3.227 & 3.873 & 4.518 & 5.164 & 5.810 & 6.455 \\
\hline
\end{tabular}

Fonte: Dados da pesquisa.

Na Figura 40 estão plotadas as superfícies livres variando o número Mach viscoelástico obtidos na malha M20. Note que a taxa de inchamento e a distância do retardamento do inchamento $\left(d_{l} / d_{0}\right)$ crescem quando Ma é aumentado. A Figura 41a mostra as taxas de inchamento obtidas, $d_{e x} / d_{0}$, nas três malhas consideradas e pode-se observar que quando a malha é refinada as taxas de inchamento ficam mais próximas. Além disso, os resultados na malha M20 com $\mathrm{E}=0.03$, obtidos na Subseção 3.2.1, são plotados para efeito de comparação com os obtidos com $\mathrm{E}=0.0375$. Observe que um pequeno aumento no valor de $\mathrm{E}$, ocasionou taxas de inchamento superiores em relação as obtidas com $\mathrm{E}=0.03$. No entanto, as distâncias de atraso do inchamento $d_{l} / d_{0}$, mostradas na Figura $41 \mathrm{~b}$, indicam uma pequena variação com o refinamento de malha.

Note que, para os dois valores do número de elasticidade, o aumento do número de Mach viscoelástico estabelece um aumento linear na distância de atraso do inchamento.

A Figura 42 apresenta as linhas de correntes para alguns valores de Ma da Tabela 13. Note que para $\mathrm{Ma}=1.2$ praticamente não há atraso no inchamento, uma vez que as linhas de corrente próximas ao eixo de simetria não mudam o sinal da curvatura. Com o aumento do número de Mach, observa-se que as linhas de correntes próximas ao eixo de simetria mostram uma mudança de sinal na curvatura após sairem do tubo indicando que houve um atraso no inchamento do extrudado. Esse fato fica mais evidente para números de Mach viscoelásticos maiores. 
Figura 40 - Gráfico das superfícies livres do fluido Oldroyd$\mathrm{B}(\beta=5 \%)$ para diferentes valores de $\mathrm{Ma}$ e $\mathrm{E}=$ 0.0375. Uma ampliação da região $[2.75,6.0] \times$ $[0.4,1.6]$ é apresentada abaixo.
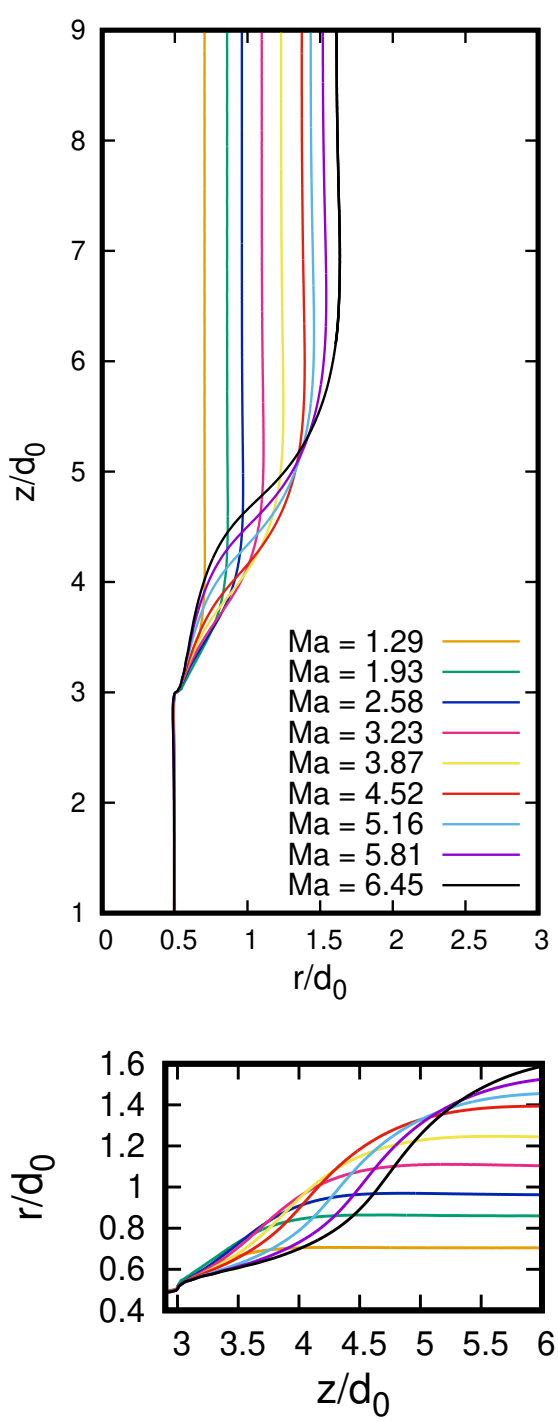

Fonte: Elaborada pelo autor.
Figura 41 - Resultados da taxa de inchamento e distância do retardamento do inchamento do fluido Oldroyd-B quando $\mathrm{E}=0.0375$.

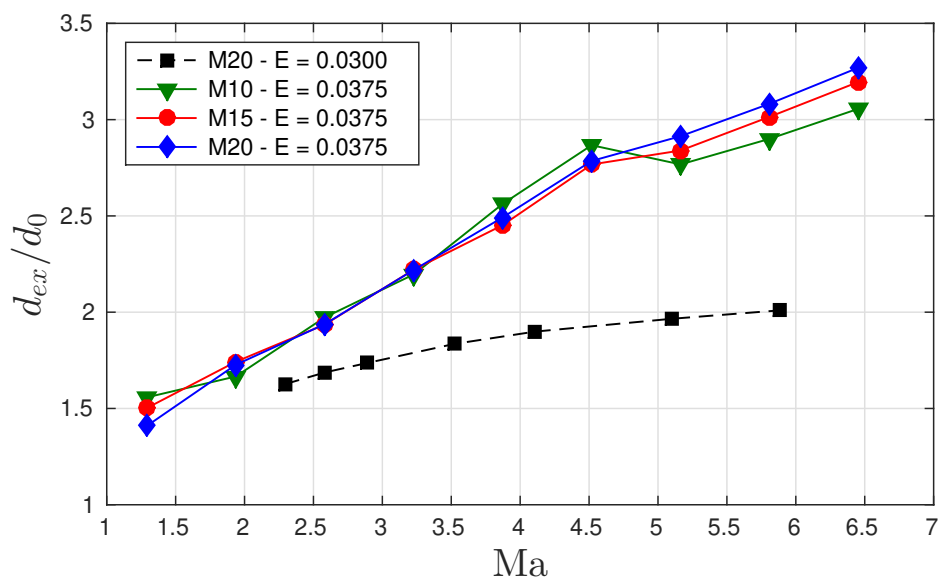

(a) Taxa de inchamento

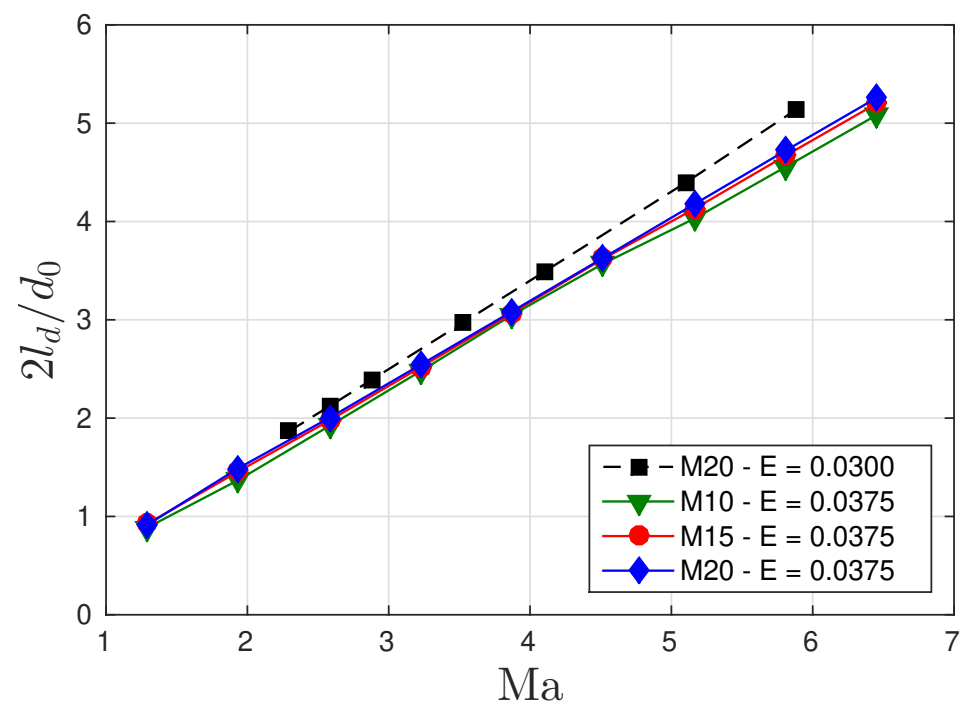

(b) Distância de retardamento

Fonte: Elaborada pelo autor. 
Figura 42 - Linhas de corrente do campo de velocidade para diferentes valores do número Mach e número de elasticidade $\mathrm{E}=0.0375$.

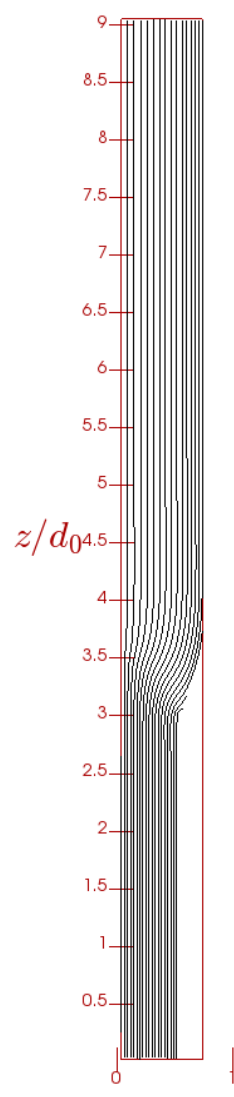

$r / d_{0}$

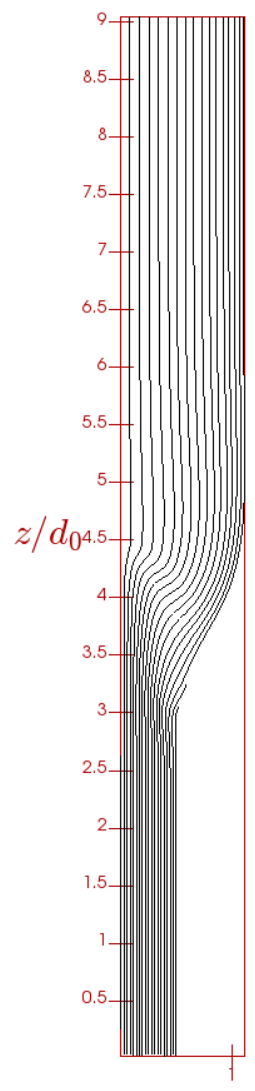

$r / d_{0}$

(a) $\mathrm{Ma}=1.2$

(b) $\mathrm{Ma}=3.2$

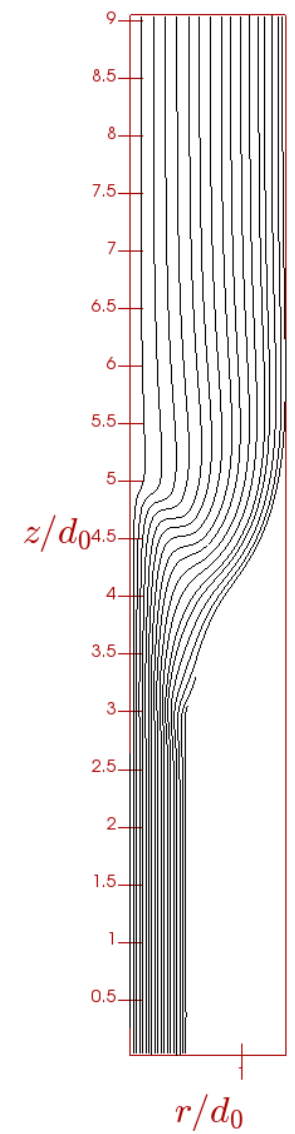

(c) $\mathrm{Ma}=4.5$

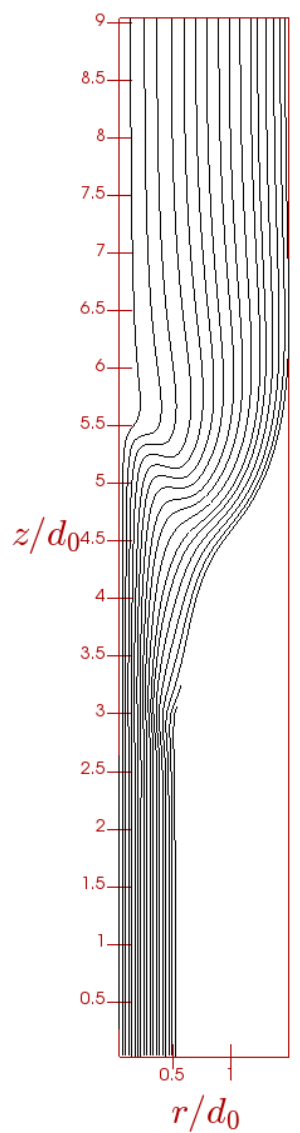

(d) $\mathrm{Ma}=5.8$

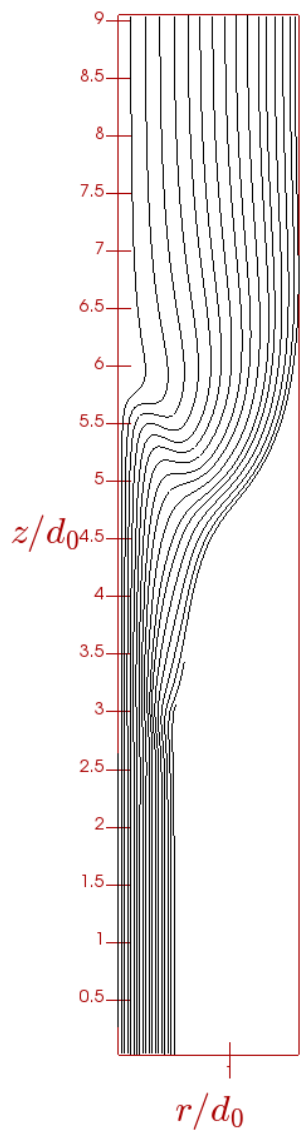

(e) $\mathrm{Ma}=6.4$

Fonte: Elaborada pelo autor.

\subsection{Inchamento retardado do extrudado para o fluido UCM}

Fluidos do tipo UCM $(\beta=0)$ podem apresentar taxas de inchamento muito altas e são mais complexos do ponto de vista computacional. Talvez por essa razão, muito poucos trabalhos que tratam do inchamento do extrudado utilizando fluidos UCM podem ser encontrados na literatura (ver por exemplo, Crochet e Keunings (1982) e Tomé et al. (2012)). O trabalho mais recente que trata do inchamento retardado do extrudado pode ser encontrado na tese de Merejolli (2017) onde o autor utilizou o modelo constitutivo Giesekus com $\alpha=0$ e $\beta=0$ para modelar um fluido UCM utilizando uma formulação para escoamentos tridimensionais. Entretanto, esse trabalho se restringiu a variação dos números adimensionais $R e$ e $W i$, em uma malha razoavelmente grossa, e foram apresentadas comparações qualitativas com os resultados experimentais de Joseph, Matta e Chen (1987).

Nessa seção, ambos os problemas, inchamento do extrudado e inchamento retardado 
do extrudado de fluidos UCM, são analisados utilizando o código axissimétrico desse trabalho. Inicialmente, são apresentados resultados para o inchamento do extrudado em que as taxas de inchamento são obtidas pela variação do recoverable shear, $S_{\lambda}$. Em seguida, uma comparação com os resultados obtidos por Merejolli (2017) para o problema do inchamento retardado do extrudado do fluido UCM é realizada. Esse capítulo é finalizado com resultados obtidos por um estudo do inchameto retardado do extrudado fazendo uma variação dos números de Mach viscoelástico e elasticidade.

\subsubsection{Inchamento do extrudado}

Com o objetivo de demonstrar a capacidade do código axissimétrico em resolver o problema do inchamento do extrudado para escoamentos com altas taxas de deformação, foi considerado $\beta=0$ na equação constitutiva do modelo Oldroyd-B.

Considera-se também o domínio apresentado na Figura 33 e as malhas M10, M15 e M20 definidas na Tabela 12. O interesse é verificar a eficácia do código em resolver problemas com valores de $S_{\lambda}$ alto. Espera-se que as taxas de inchamento para fluidos UCM sejam superiores as obtidas pelo modelo Oldroyd-B e reportadas na Subseção 3.1.2. Os dados utilizados para essas simulações são:

\$. Raio do tubo $R=1.0 \mathrm{~m}$, comprimento de escala: $L=d_{0}=2.0 \mathrm{~m} ; \rho=1000 \mathrm{~kg} \mathrm{~m}^{-3}, \eta_{0}=$ 8000 Pa.s, $U=1.0 \mathrm{~m}$. Portanto, $R e=0.25$ e os efeitos da gravidade foram desconsiderados. Os valores de $W i$ são determinados conforme a escolha dos $S_{\lambda}$ descritos na Tabela 14.

Tabela 14 - Valores de $S_{\lambda}$ e correspondente $W i=S_{\lambda} / 8$ e $\beta=0$.

\begin{tabular}{l||c|c|c|c|c|c|c|c}
\hline$S_{\lambda}$ & 0.0 & 1.0 & 2.0 & 3.0 & 4.0 & 6.0 & 8.0 & 10.0 \\
\hline$W i$ & 0.0 & 0.125 & 0.25 & 0.375 & 0.5 & 0.75 & 1.0 & 1.25 \\
\hline \multicolumn{8}{c}{ Fonte: Dados da pesquisa. }
\end{tabular}

O perfil de velocidade especificado na entrada do tubo, utilizando a constante de escala $L=d_{0}$, é fornecido pela Equação 3.9.

Os resultados obtidos e comparados com a Lei de Tanner (TANNER, 1970) são mostrados na Figura 43. Nota-se que as taxas de inchamento obtidas pelo código axissimétrico nas três malhas concordam com a Lei de Tanner para valores de $S_{\lambda} \leq 3$. Porém, para valores de $S_{\lambda}$ superiores, as taxas de inchamento do modelo UCM tornam-se superiores aos da Lei de Tanner e as diferenças aumentam com o valor de $S_{\lambda}$. Acredita-se que essas diferenças são devidas ao fato que a Lei de Tanner foi desenvolvida por meio de simplificações das equações governantes e portanto, espera-se que essa Lei seja precisa quando o valor de $S_{\lambda}$ é pequeno. Os resultados do código axissimétrico apresentou resultados convergentes nas três malhas e concordou com a Lei 
de Tanner para valores de $S_{\lambda}$ pequenos; esses resultados verificam que o código axissimétrico tem um bom desempenho na resolução das equações do modelo UCM para escoamentos do inchamento do extrudado.

A Figura 44 mostra as superfícies livres obtidas nas simulações. Observa-se que o inchamento cresce monotonicamente em função do parâmetro $S_{\lambda}$. Para $S_{\lambda}=10$, o fluido UCM apresenta um taxa de inchamento $>200 \%$. Fluidos do tipo UCM são puramente poliméricos e apresentam primeira diferença de tensões normais superiores as apresentadas por fluidos Oldoyd-B.

Figura 43 - Taxas de inchamento $S_{r}$ obtidas variando $S_{\lambda}$. Comparação dos resultados nas malhas M10, M15 e M20 com a Lei de Tanner.

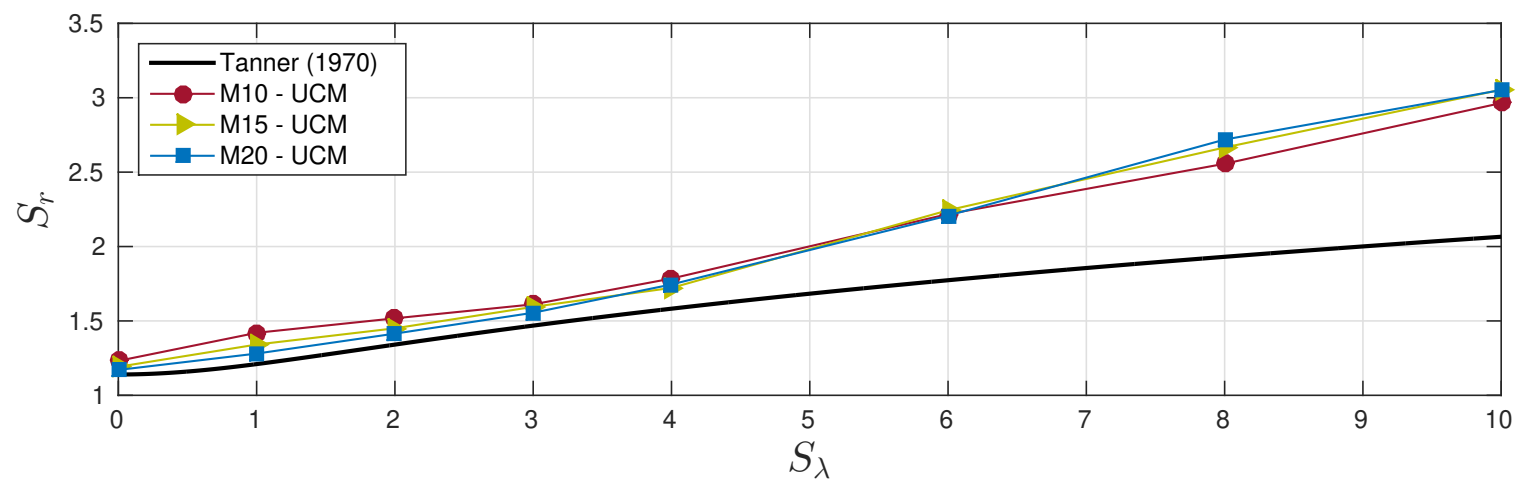

Fonte: Elaborada pelo autor.

Figura 44 - Curvas da superfície livre do fluido UCM obtidas no problema do inchamento do extrudado para vários valores de $S_{\lambda}$ na malha M20. O segundo gráfico apresenta uma visualização dos resultados na região $[2.75,5.0] \times[0.4,1.6]$.
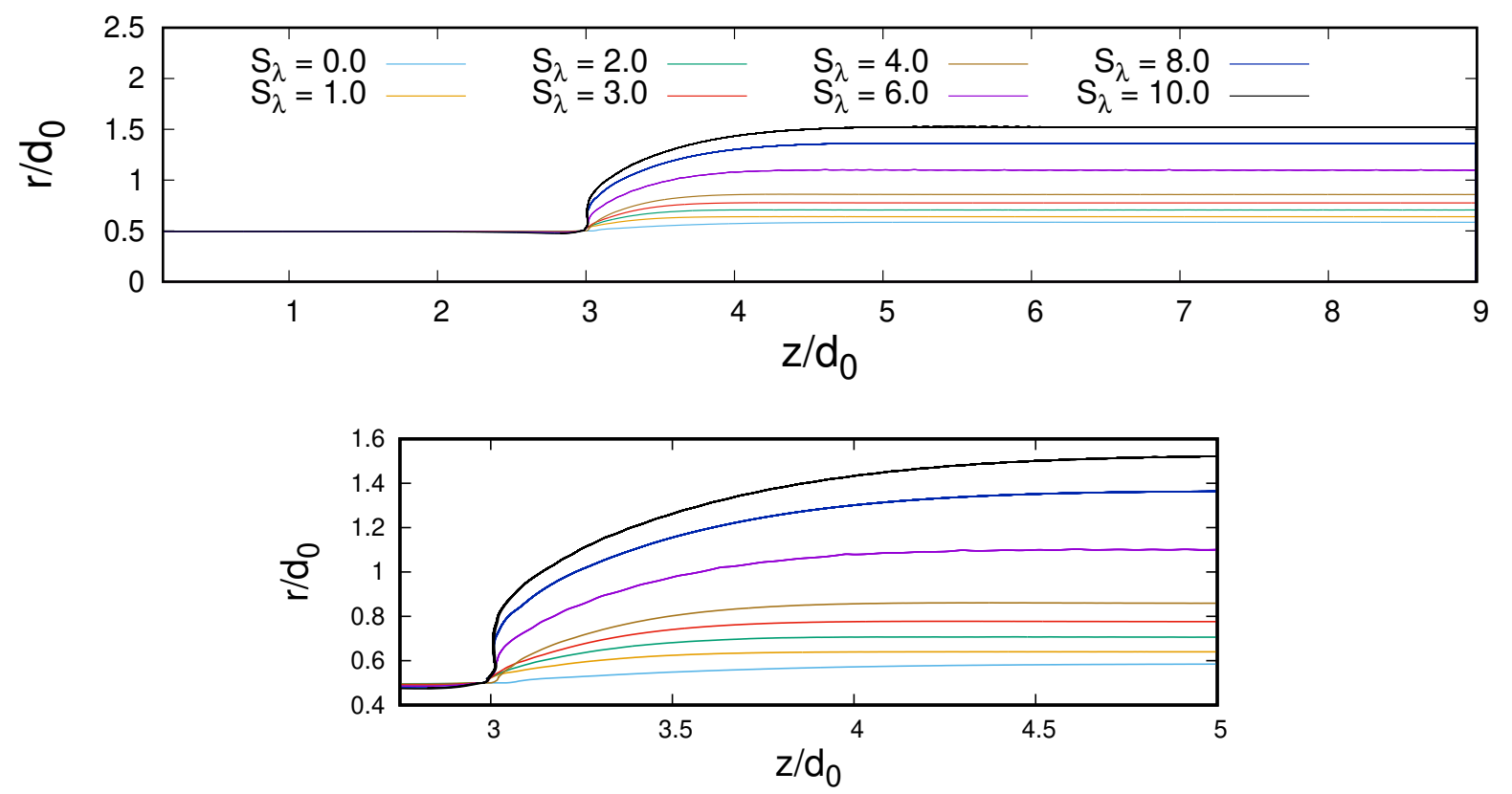

Fonte: Elaborada pelo autor. 
Outro fator que pode ser analisado são os valores da velocidade e tensão próximos a região de saída do tubo, onde encontra-se uma singularidade devido a mudança nas condições de contorno. Para isso, foram plotados os resultados próximos ao eixo de simetria na direção do escoamento. Considerou-se a variação da velocidade $w$ sobre a linha pontilhada representada na Figura 32a enquanto que as tensões foram analisadas na linha pontilhada da Figura 32b próxima a parede interna do tubo onde ocorre grandes variações do tensor $\tau$ numa vizinhança da saída do tubo. Como observa-se na Figura 45, o aumento de $S_{\lambda}$ acarretou grandes saltos no valor da velocidade. Observa-se que fora do tubo, quanto maior é o valor de $S_{\lambda}$, maior é o inchamento, e portanto, menor é a velocidade do jato. Esse fato é devido a conservação de massa, ou seja, a vazão dentro do tubo $Q_{0}$ deve ser igual a vazão do jato fora do tubo $\left(Q_{e x}\right)$. Logo, $U d_{0}^{2}=U_{e x} d_{e x}^{2}$, onde $U$ é a velocidade média dentro do tubo e $U_{e x}$ é a velocidade uniforme do jato fora do tubo. Quando $d_{e x}$ cresce implica diretamente que a velocidade uniforme do jato $U_{e x}$ diminui para que a conservação de massa seja satisfeita. A região mais afetada pela singularidade é a região próxima a parede na saída do tubo. Na Figura 46a, podemos ver que o aumento de $S_{\lambda}$ causa uma grande variação no tensor cisalhante $\tau^{r z}$. Observa-se que quanto maior $S_{\lambda}$ maior é o salto no valor de $\tau^{r z}$. Além disso, na Figura $46 \mathrm{~b}$ verifica-se que próximo a parede interna do tubo a primeira diferença de tensões normais cresce muito com o aumento de $S_{\lambda}$. Verifica-se também, que a região de influência da singularidade na solução próximo a saída do tubo é muito maior se comparada com as regiões de resultados $\operatorname{com} S_{\lambda}$ relativamente pequenos. Portanto, ao aumentar o valor de $S_{\lambda}$ as tensões normais crescem dentro do tubo e a singularidade na saída do tubo ocasiona o surgimento de altos valores do gradiente de tensão que podem acarretar instabilidades numéricas; esse fato não ocorreu com o código axissimétrico.

Figura 45 - Solução numérica da velocidade $w$ próximo ao eixo de simetria, para diferentes valores de $S_{\lambda}$ na malha M20.

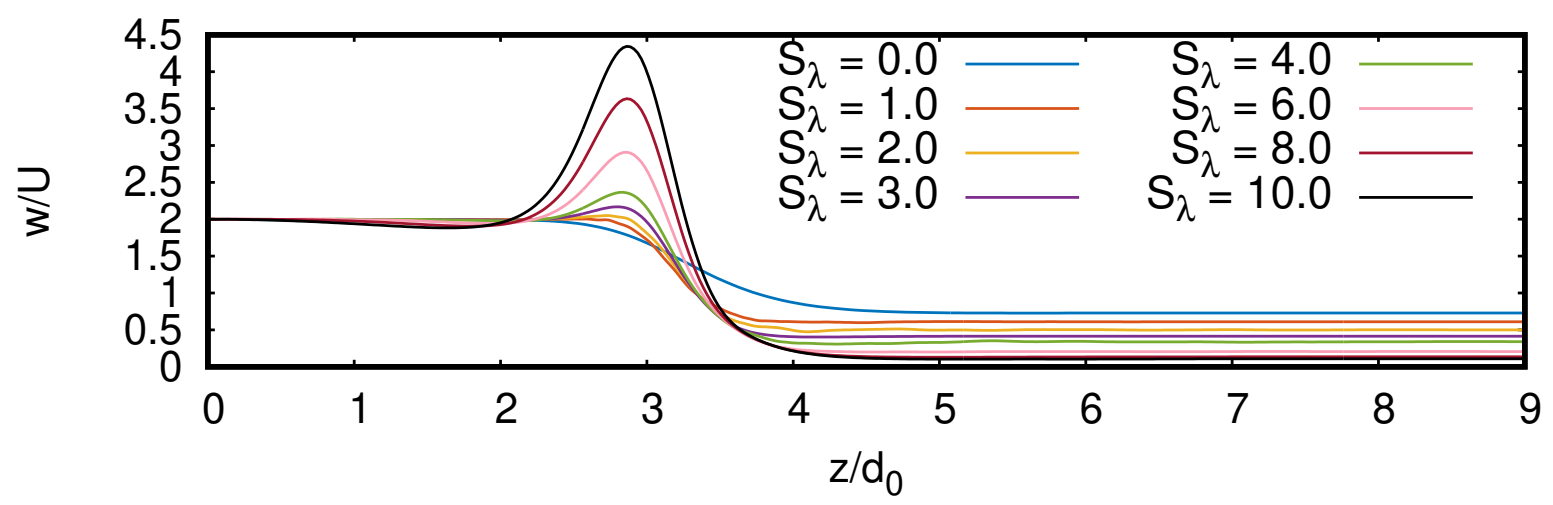

Fonte: Elaborada pelo autor. 
Figura 46 - Solução numérica (a) do tensor $\tau^{r z}$ e (b) da primeira diferença de tensão normal $N_{1}$ do fluido UCM próximo a parede do tubo, para diferentes valores de $S_{\lambda}$ na malha M20.

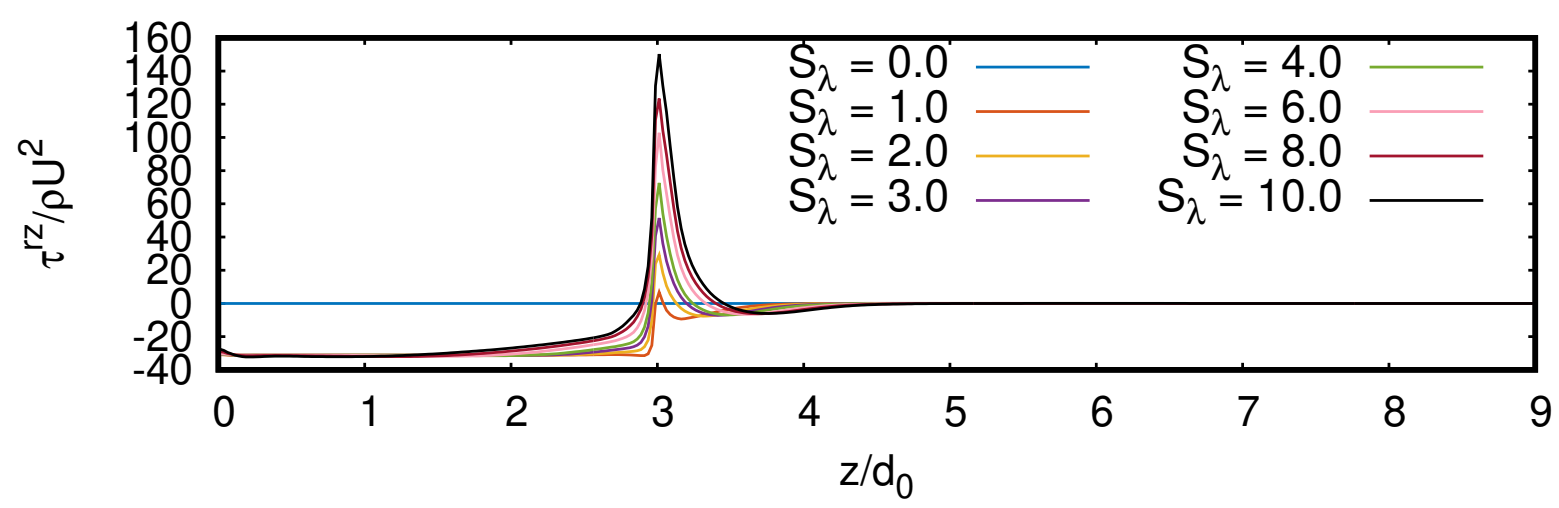

(a)

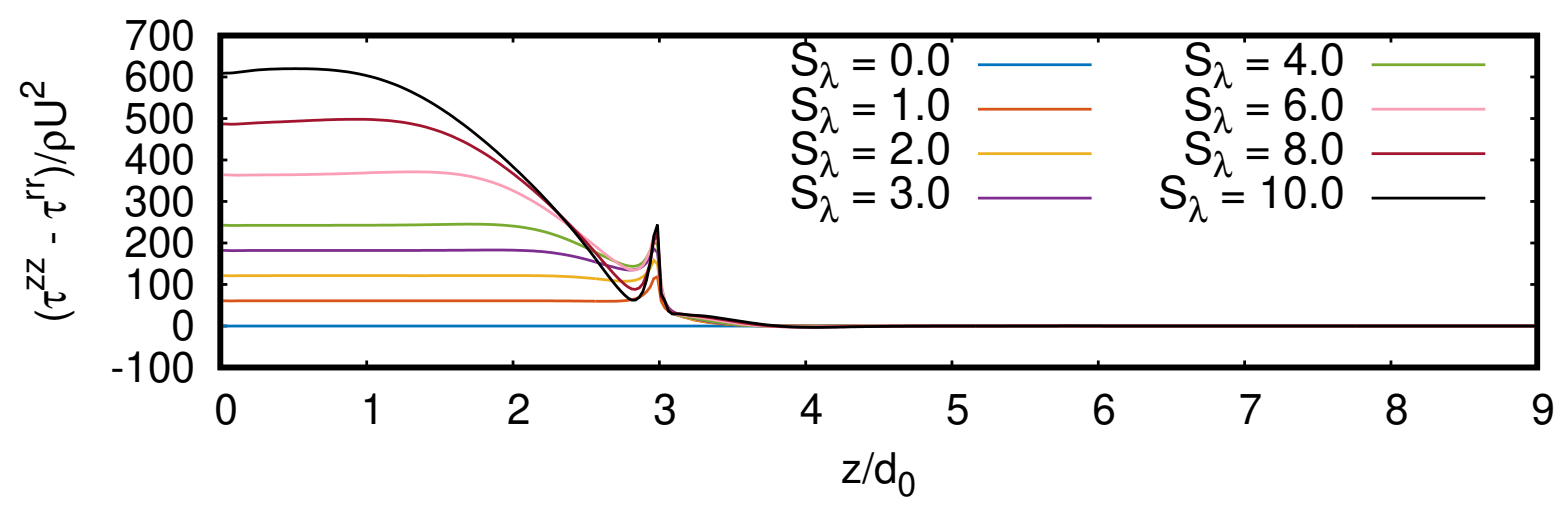

(b)

Fonte: Elaborada pelo autor.

\subsubsection{Resultados de verificação}

Nessa seção vamos empregar o código axissimétrico para simular o fenômeno do inchamento retardado do extrudado de fluidos UCM. Esse é um problema difícil de resolver computacionalmente porque o tensor tensão extra pode assumir valores muito altos perto da parede do tubo conforme mostrado na Figura 46. Na literatura, o único trabalho que trata desse problema foi apresentado por Merejolli (2017).

Merejolli utilizou uma implementação do modelo Giesekus para escoamentos tridimensionais e realizou simulações com o objetivo de capturar esse fenômeno. A equação constitutiva UCM foi obtida fazendo $\alpha=0$ e $\beta=0$ na equação constitutiva de Giesekus. Os resultados apresentados por Merejolli (2017) foram então considerados para realizar uma comparação com os resultados obtidos pelo código axissimétrico desse trabalho. Uma comparação quantitativa considerando a taxa de inchamento $d_{e x} / d_{0}$ e uma comparação qualitativa entre as visualizações tridimensionais dos escoamentos obtidos por ambos os códigos são realizadas. 
Figura 47 - Representação do domínio computacional utilizado para comparação com resultados tridimensionais do problema inchamento retardado do extrudado.

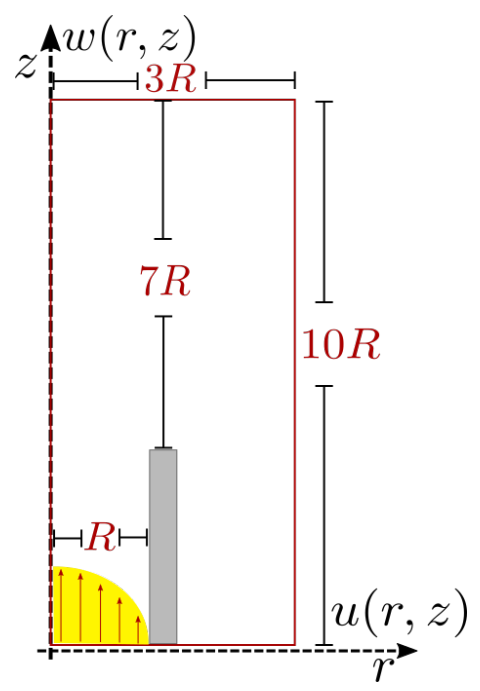

Fonte: Elaborada pelo autor.

Para efetuar uma comparação com as soluções apresentadas por Merejolli (2017), o código axissimétrico simulou o fenômeno do inchamento retardado do extrudado utilizando os seguintes dados:

口 Domínio computacional: $\Omega=[0,3 R] \times[0,10 R]$, como mostrado na Figura 47;

- Raio do tubo $R=1.0 \mathrm{~m}$, comprimento do tubo $L_{1}=3 R \mathrm{~m}$ e comprimento de escala: $L=d_{0}=2.0 \mathrm{~m}$;

— Distância entre a saída do tubo e a região de saída do fluido (outflow): $L_{2}=7 R \mathrm{~m}$;

口 $\rho=1000 \mathrm{~kg} \mathrm{~m}^{-3}$ e $U=1.0 \mathrm{~m}$;

- Razão de viscosidade: $\beta=0$. Efeitos de gravidade foram desconsiderados. Os valores de $W i$ e $R e$ estão disponíveis na Tabela 15.

Espaçamento da malha: $\delta_{r}=\delta_{z}=1 / 9$.

Tabela 15 - Valores de Re e Wi utilizados nas simulações do inchamento retardado do extrudado.

\begin{tabular}{|c|c|c|c|c|c|c|}
\hline & \multicolumn{5}{|c|}{$R e$} & \\
\hline & 20.0 & 25.0 & 30.0 & 35.0 & 40.0 & \\
\hline \multicolumn{7}{|c|}{$W i$} \\
\hline 0.5 & 0.625 & 0.75 & 0.875 & 1.0 & 1.125 & 1.25 \\
\hline
\end{tabular}

Fonte: Dados da pesquisa. 
Figura 48 - Resultados do inchamento atrasado do extrudado de fluidos tipo UCM, para diferentes valores de $R e$ e Wi. (a) Comparação com as taxas de inchamento obtidas por Merejolli (2017) com código 3D. (b) Distância de atraso do inchamento. A linha tracejada em vermelho é uma interpolação linear utilizando os pares de pontos $\left(W i, l_{d}\right)$ em que $W i=0.5$ e 1.0 .

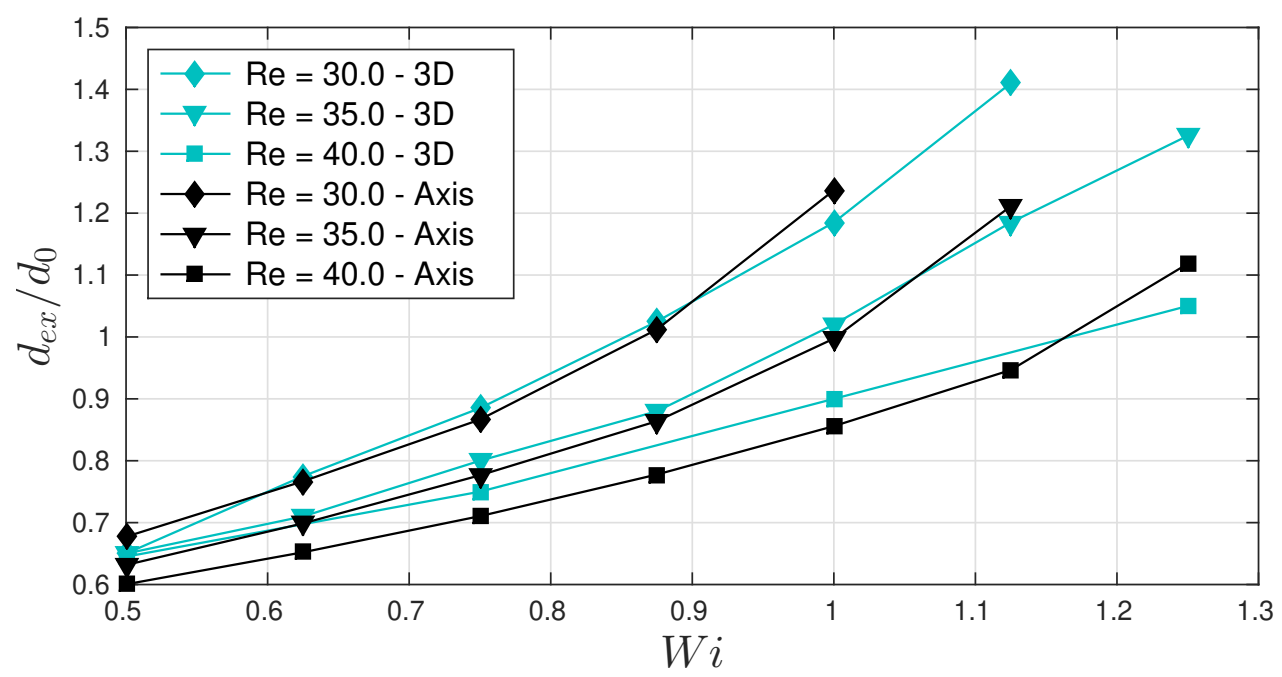

(a)

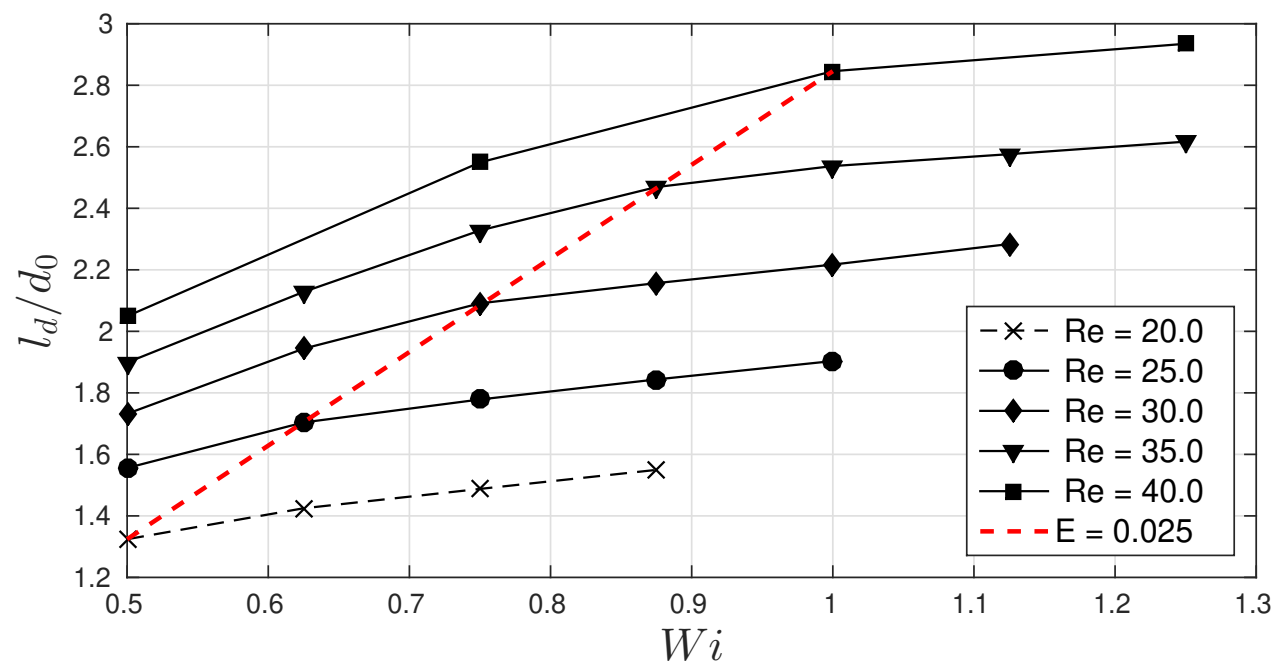

(b)

Fonte: Elaborada pelo autor.

Os resultados apresentados na Figura 48a mostram que os resultados obtidos pelo código axissimétrico, apresentam uma boa concordância com as predições de Merejolli (2017). Observe que os resultados com $R e=30.0$ e 35.0 apresentam taxas de inchamento muito próximas. No entanto, para $R e=40.0$ constata-se uma pequena discrepância entre as taxas de inchamento obtidas pelos dois códigos. Entretanto, para $W i=0.5$, quando aumenta-se o valor de $R e$ a taxa de inchamento $d_{e x}$ diminui nos resultados obtidos pelo código axissimétrico o que não ocorre nos resultados 3D. Esse fato pode ser explicado pelo número de elasticidade E: para $R e=30.0$ e $W i=0.5$ obtém-se $\mathrm{E} \approx 0.01667$ enquanto que para $R e=40.0$ e $W i=0.5$ resulta-se 
em $\mathrm{E}=0.0125$, indicando que a influência das forças de elasticidade são menores para $R e=40.0$ e portanto, espera-se que a taxa de inchamento também seja menor. A diminuição do inchamento em função do número de elasticidade foi analisado no trabalho de Delvaux e Crochet (1990), onde mostrou-se que a taxa do inchamento retardado diminui quando o número E decresce conforme foi obtido pelo código axissimétrico. A Figura 48b mostra os resultados das distâncias de retardo obtidas nas simulações. Observa-se que as distâncias $l_{d}$ crescem e convergem assintóticamente para um valor limite para cada valor do número de Reynolds. Nota-se ainda que os pontos do gráfico que interceptam a reta tracejada em vermelho compartilham do mesmo valor do número de elasticidade, $\mathrm{E}=0.025$. Essa reta foi calculada utilizando dois pontos $\left(W i, l_{d}\right)$ do gráfico em que $W i=0.5$ e 1.0. Verifica-se que a reta tracejada em vermelho interpola três pontos, indicando que para E fixo há uma relação linear entre o aumento do número de Mach viscoelástico (Ma) e a distância $l_{d}$, conforme foi obtido utilizando o fluido Oldroyd-B (ver Figura 41b).

Adicionalmente, uma comparação qualitativa com as soluções obtidas por Merejolli (2017) podem ser visualizadas na Figura 49. Considerando que os resultados foram calculados utilizando uma geometria e malha semelhantes, cujo comprimento do tubo e a distância da saída do tubo ao outflow são as mesmas, nota-se que o inchamento máximo do fluido obtido nesse trabalho apresenta uma distância $l_{d}$ maior que a distância obtida pelo código tridimensional de Merejolli. Também, nota-se que os resultados do código axissimétrico não apresentou as imperfeições na superfície livre que são visualizadas nos resultados do código tridimensional. 
Figura 49 - Comparação qualitativa com os resultados obtidos por Merejolli (2017) (3D) para o problema do inchamento retardado do extrudado utilizando os seguintes valores de Reynolds: $R e=$ 30.0,35.0 e 40.0. Resultados com fluido na cor amarelo claro foram obtidos pelo código desse trabalho, as visualizações de fluidos na cor amarelo escuro foram obtidas por Merejolli (2017).

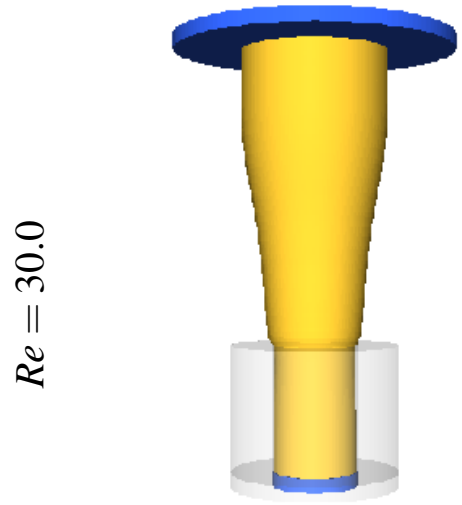

Axis

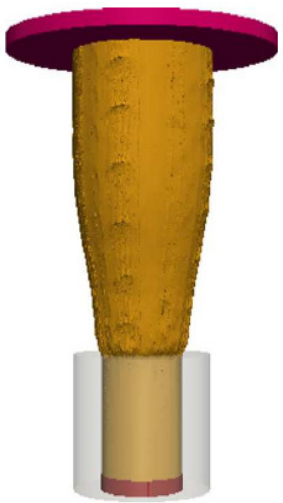

$3 \mathrm{D}$

(a) $W i=0.75$

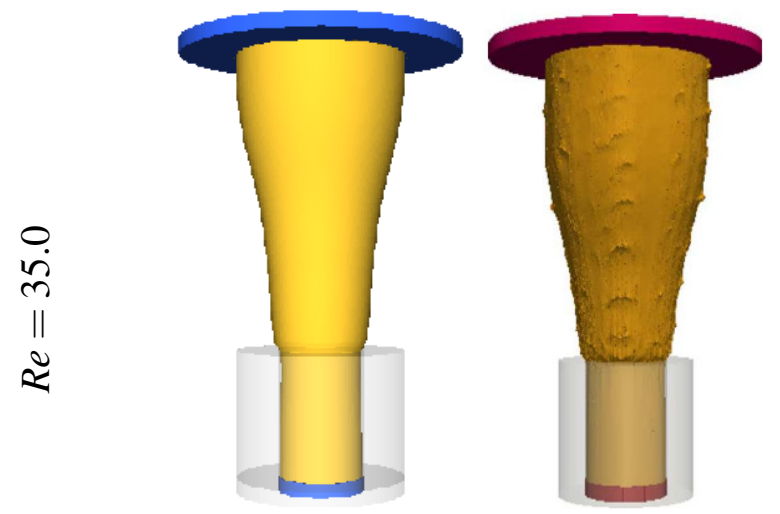

Axis

$3 \mathrm{D}$

(c) $W i=1.0$

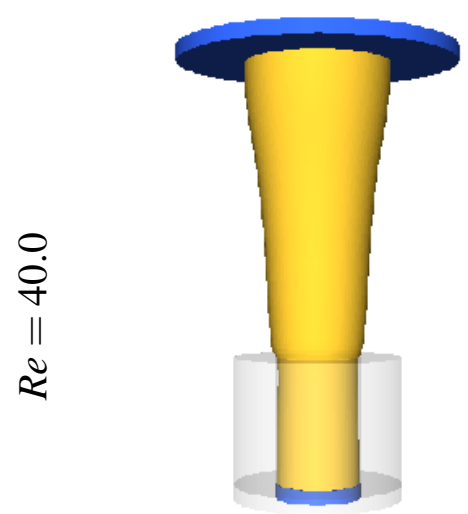

Axis

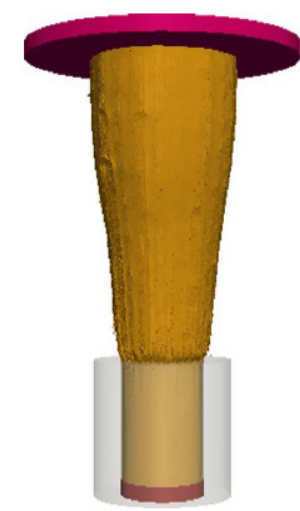

3D

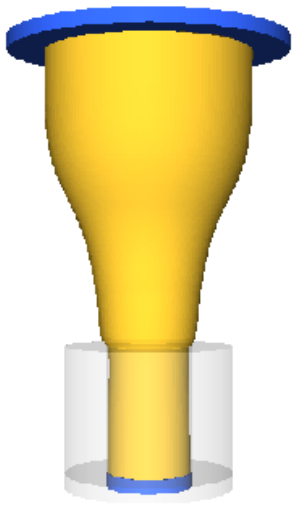

Axis

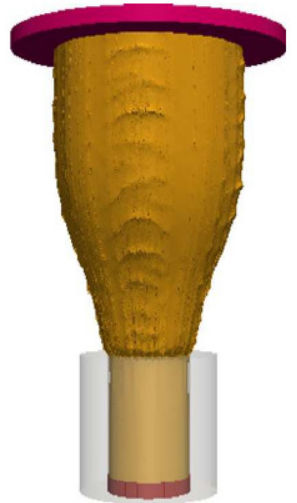

$3 \mathrm{D}$

(b) $W i=1.0$

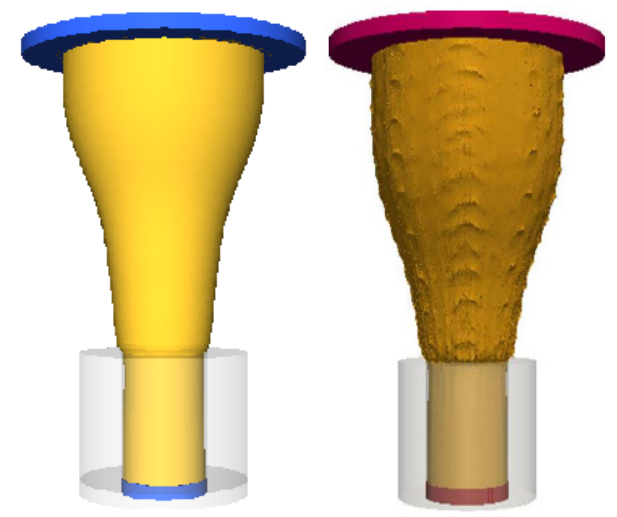

Axis

$3 \mathrm{D}$ (d) $W i=1.125$
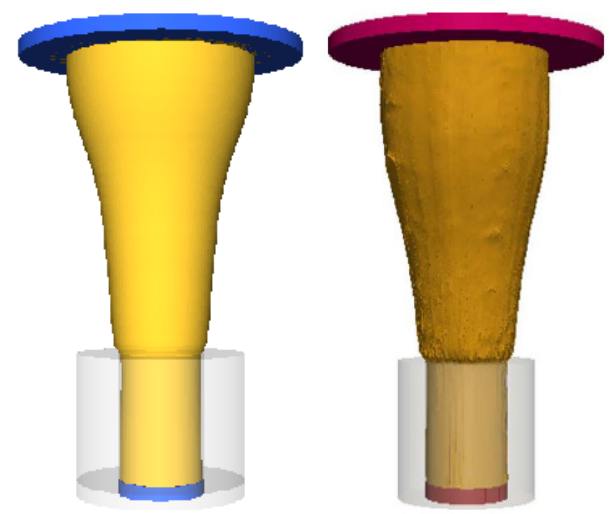

Axis

(e) $W i=1.0$

(f) $W i=1.25$

Fonte: Elaborada pelo autor. 


\subsubsection{Efeito do número de Mach viscoelástico}

Na Subseção 3.2.2 foi mostrado que para um fluido Oldroyd-B, as distâncias de retardo do inchamento variam linearmente com o número de Mach (ver Figura 41b).

Para verificar se essa relação ocorre para fluidos totalmente poliméricos, o código axissimétrico simulou o inchamento retardado de um fluido UCM para 3 valores de E e vários valores de Ma que são mostrados na Tabela 16, a malha M20 e o domínio computacional como representado na Figura 33 foram considerados. O perfil de velocidade na entrada do tubo é fornecido pela Equação 3.9. As simulações iniciaram em $t=0$ e foram executadas até que o regime estacionário foi alcançado.

A Figura 50 apresenta as superfícies do fluido para $\mathrm{E}=0.035$ para cada valor de $\mathrm{Ma}$ simulado. Observa-se que as distâncias de retardo aumentam com o número de Mach e que para $\mathrm{Ma}=8.0$ obteve-se a maior distância de retardo. Esses resultados estão de acordo com aqueles obtidos utilizando o fluido Oldroyd-B apresentados na Subseção 3.2.2. Como constatado nas simulações desse capítulo, a taxa de inchamento aumenta consideravelmente quando aumentase a constante de elasticidade E, o que pode ser verificado na Figura 51a. Além disso, se compararmos os resultados com $\beta=5 \%$ verifica-se que um pequeno aumento do número de elasticidade para fluidos UCM, resulta em uma taxa de inchamento bem superior quando comparada ao inchamento obtido pelo modelo Oldroyd-B. As distâncias de retardamento estão plotadas na Figura 51b para os três valores de E considerados juntamente com os resultados que foram obtidos para o fluido Oldroyd-B ( $5 \%$ de solvente). Observa-se novamente, um crescimento linear da distância de atraso do inchamento $l_{d}$. Ao comparar com os resultados para $\beta=5 \%$ percebe-se que as distâncias $l_{d}$ do fluido Oldroyd-B são semelhantes as distâncias do fluido UCM. Note que para os três valores de E considerados nas simulações do fluido UCM a inclinação das retas também são semelhantes.

Tabela 16 - Valores dos números de Reynolds, Weissenberg, Mach e elasticidade utilizados para simular o inchamento retardado do extrudado de fluidos tipo UCM.

\begin{tabular}{|c|cccccc|}
\hline \multicolumn{7}{|c|}{$\mathrm{E}=0.03$} \\
\hline$W i$ & 0.2500 & 0.5000 & 0.7500 & 1.0000 & 1.2500 & 1.5000 \\
\hline$R e$ & 8.3333 & 16.6667 & 25.0000 & 33.3333 & 41.6667 & 50.0000 \\
\hline $\mathrm{Ma}$ & 1.4434 & 2.8868 & 4.3301 & 5.7735 & 7.2169 & 8.6603 \\
\hline \hline \multicolumn{7}{|c|}{$\mathrm{E}=0.035$} \\
\hline$W i$ & 0.2500 & 0.5000 & 0.7500 & 1.0000 & 1.2500 & 1.5000 \\
\hline$R e$ & 7.1429 & 14.2857 & 21.4286 & 28.5714 & 35.7143 & 42.8571 \\
\hline $\mathrm{Ma}$ & 1.3363 & 2.6726 & 4.0089 & 5.3452 & 6.6815 & 8.0178 \\
\hline \hline \multicolumn{7}{|c|}{$\mathrm{E}=0.0375$} \\
\hline$W i$ & 0.2500 & 0.5000 & 0.7500 & 1.0000 & 1.2500 & 1.5000 \\
\hline$R e$ & 6.6667 & 13.3333 & 20.0000 & 26.6667 & 33.3333 & 40.0000 \\
\hline $\mathrm{Ma}$ & 1.2910 & 2.5820 & 3.8730 & 5.1640 & 6.4550 & 7.7460 \\
\hline
\end{tabular}

Fonte: Dados da pesquisa. 
As regiões subcríticas e supercríticas foram classificadas pesquisando o sinal do determinante do tensor $\mathbf{T}^{*}$ que é denotado por $\xi(r, z)=\operatorname{Det}\left(\mathbf{T}^{*}\right)$, conforme a Equação 3.10 em que $\xi_{1}, \xi_{2}$ e $\xi_{3}$ são os autovalores de $\mathrm{T}^{*}$, que foram calculados em toda a região de fluido.

Logo, se $\xi(r, z) \leq 0$ então o ponto $(r, z)$ é considerado supercrítico caso contrário é definido como subcrítico. No entanto, essas regiões podem também ser identificadas examinando os sinais dos autovalores $\xi_{1}, \xi_{2}$ e $\xi_{3}$.

$$
\xi(r, z)=\operatorname{Det}\left(\mathbf{T}^{*}\right)=\xi_{1}(r, z) * \xi_{2}(r, z) * \xi_{3}(r, z),
$$

A função sinal, Equação 3.11, foi aplicada para mapear as regiões supercríticas e subcríticas.

$$
\operatorname{sgn}(\xi(r, z))=\left\{\begin{array}{l}
1, \text { se } \xi(r, z) \leq 0 \rightarrow \text { supercrítica }, \\
0, \text { se } \xi(r, z)>0 \rightarrow \text { subcrítica. }
\end{array}\right.
$$

As Figuras 52-54, mostram as regiões supercríticas e subcríticas dos escoamentos do inchamento retardado do extrudado para diferentes valores de Ma e mantendo o valor $\mathrm{E}=0.035$, fixo. Nota-se que as regiões supercríticas ampliam com o aumento do número Mach. Esse mesmo efeito foi observado nas simulações do fluido Oldroyd-B com $E=0.03$ (ver Figura 39).

Um resultado interessante é que esses resultados mostram que a região supercrítica pode ser determinada pelo sinal do autovalor $\xi_{1}(r, z)$ que é sempre negativo na região supercrítica conforme mostrado nas Figuras 52-54, Compare as regiões correspondentes nas figuras que $\operatorname{mostram} \operatorname{sgn}(\xi(r, z))$ e $\xi_{1}(r, z)$. 
Figura 50 - Superfícies livres do fluido UCM para $\mathrm{E}=0.0350$ e diferentes valores de Ma.

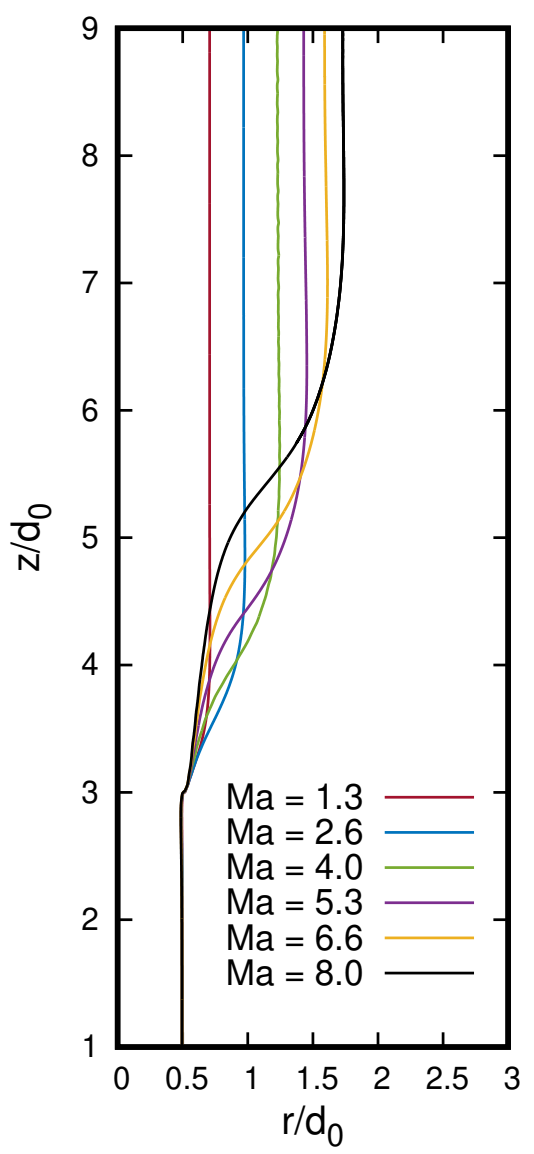

Fonte: Elaborada pelo autor.
Figura 51 - Taxa de inchamento e distância de retardamento do inchamento do fluido para vários valores de $\mathrm{Ma} \mathrm{e}$ E. Os resultados obtidos com o fluido Oldroyd-B $(\beta=5 \%)$ também são plotados para comparação.

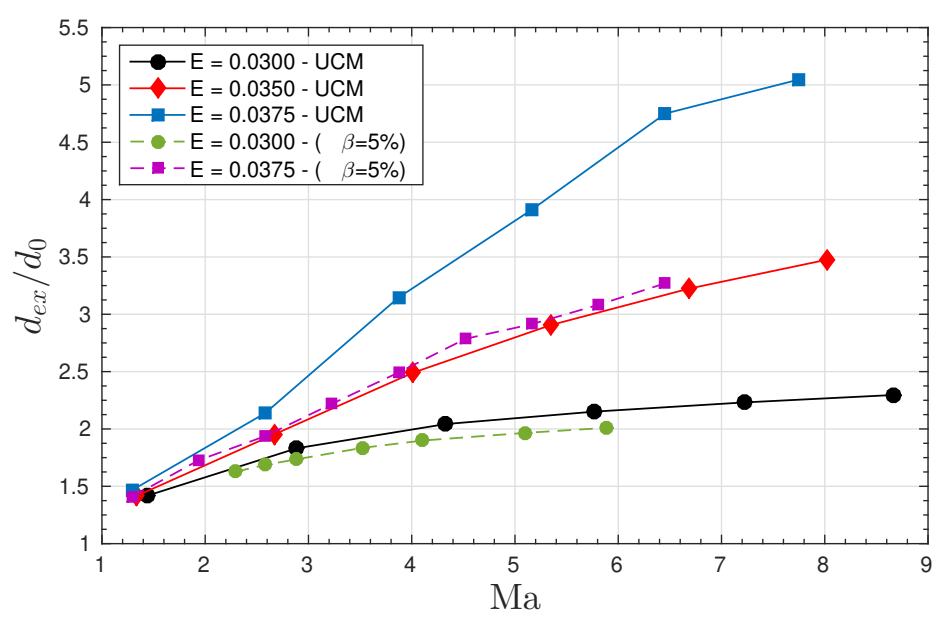

(a) Taxa de inchamento

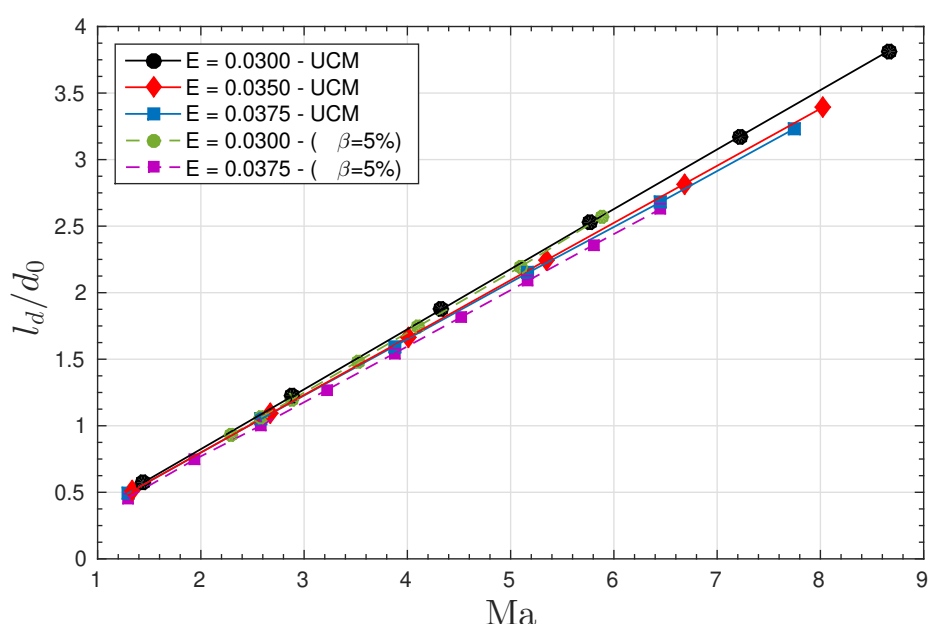

(b) Distância de retardamento

Fonte: Elaborada pelo autor. 
Figura 52 - Regiões supercríticas $(\operatorname{sgn}(\xi)=1)$ e variação dos autovalores $\xi_{1}, \xi_{2}$ e $\xi_{3}$ do tensor $\mathbf{T}^{*}$. (a) $\mathrm{Ma}=1.3$ e (b) $\mathrm{Ma}=2.6$.
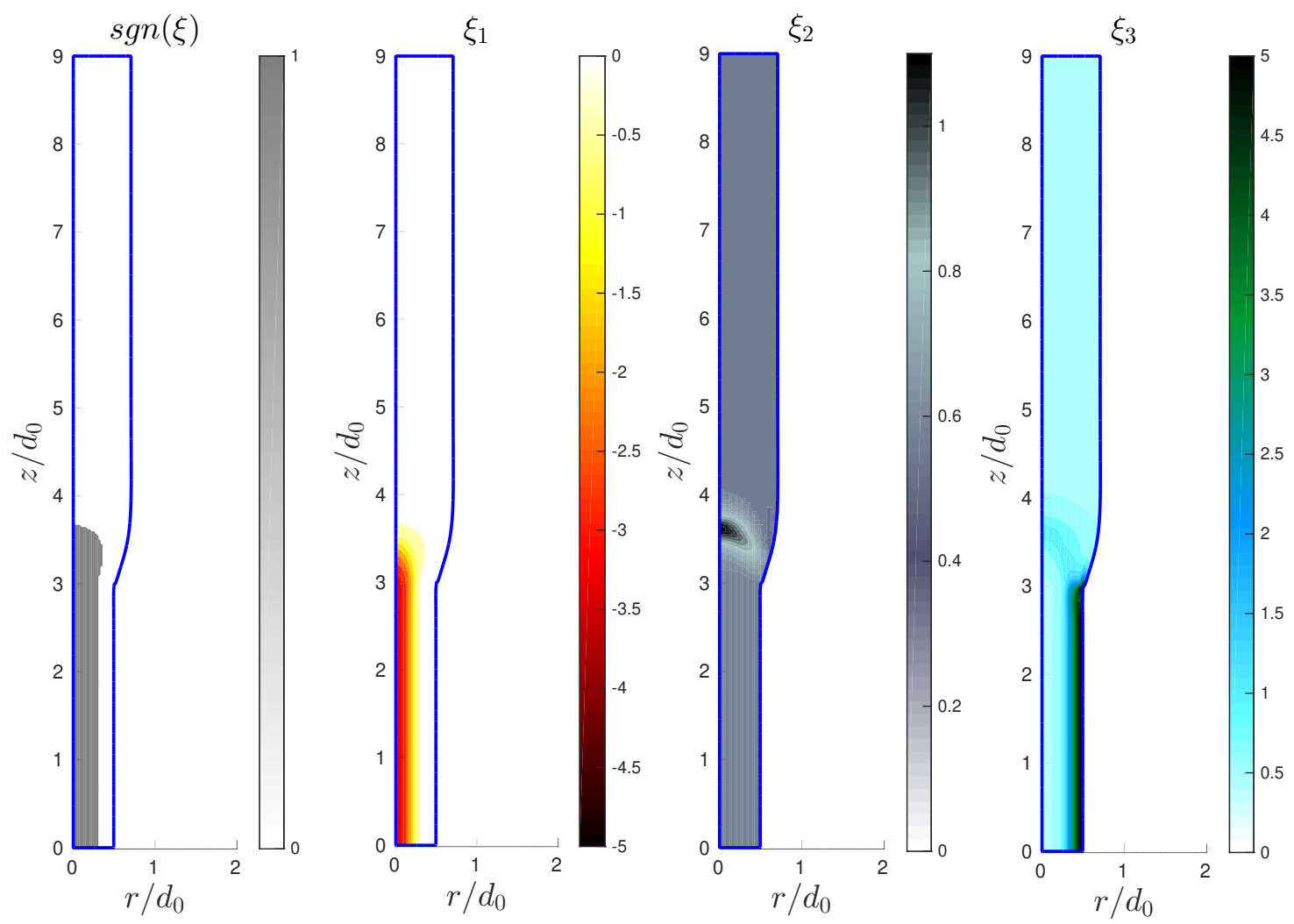

(a) $\mathrm{Ma}=1.3$
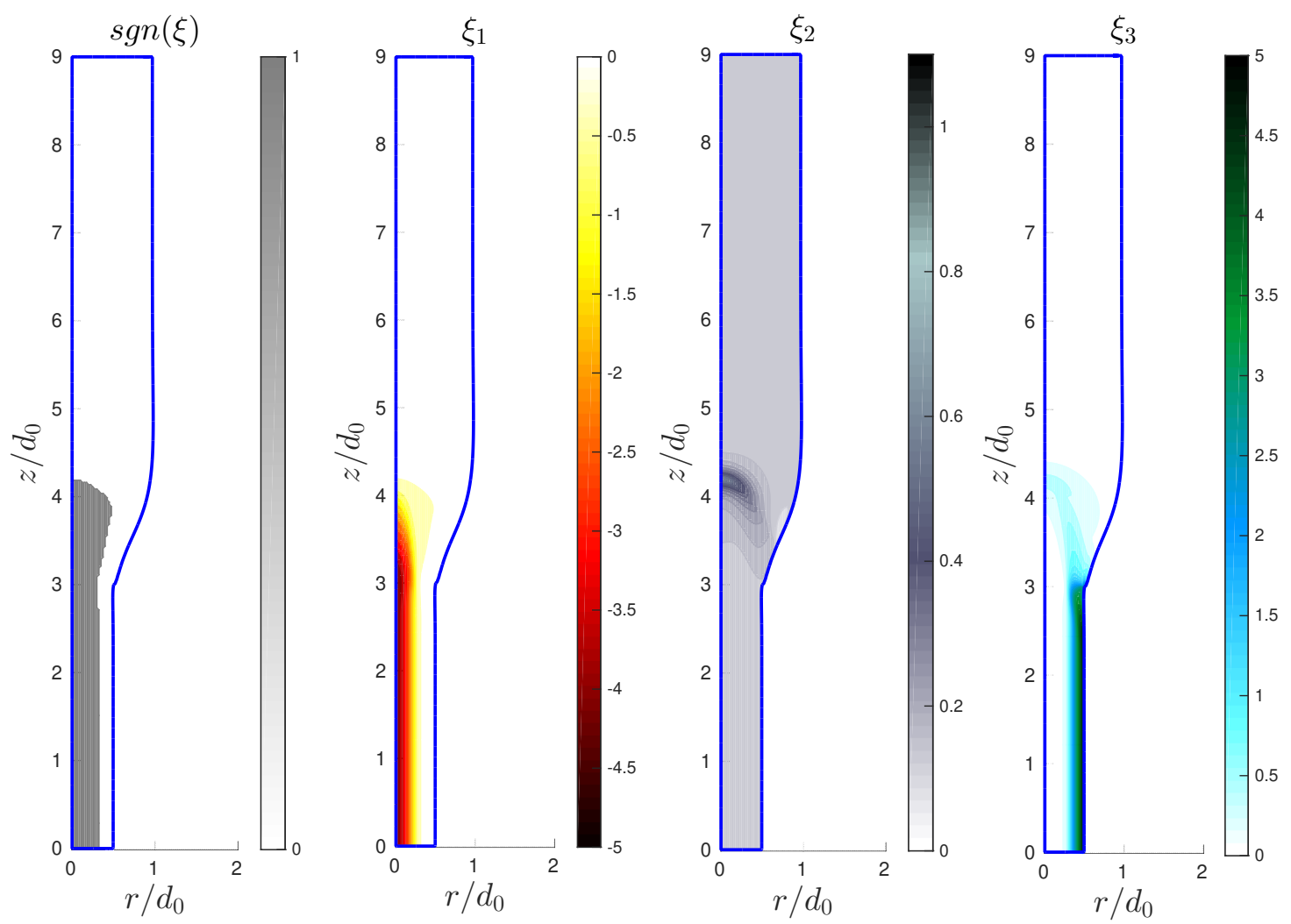

(b) $\mathrm{Ma}=2.6$

Fonte: Elaborada pelo autor. 
Figura 53 - Regiões supercríticas $(\operatorname{sgn}(\xi)=1)$ e variação dos autovalores $\xi_{1}, \xi_{2}$ e $\xi_{3}$ do tensor $\mathbf{T}^{*}$. (a) $\mathrm{Ma}=4.0$ e (b) $\mathrm{Ma}=5.3$.
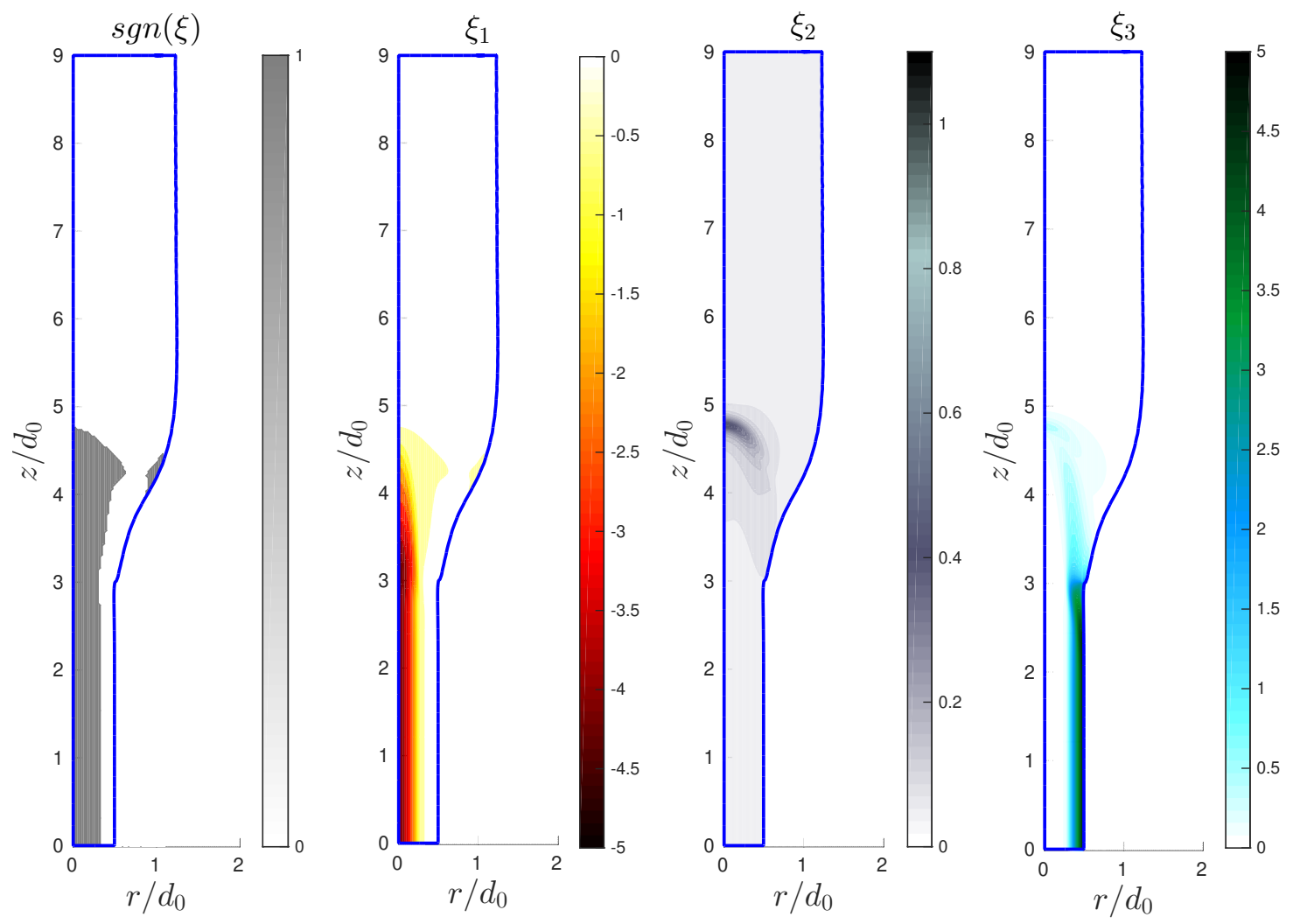

(a) $\mathrm{Ma}=4.0$
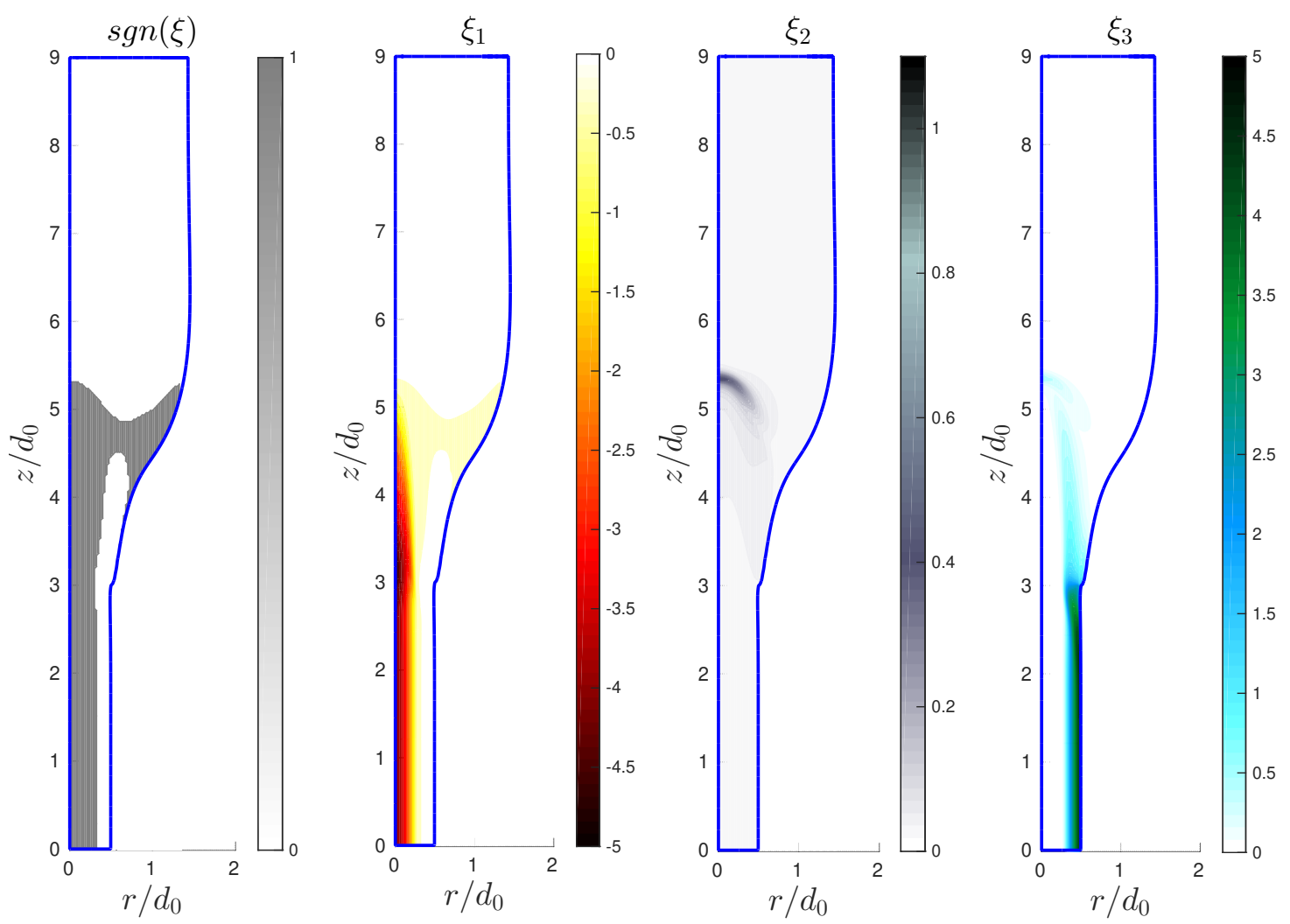

(b) $\mathrm{Ma}=5.3$

Fonte: Elaborada pelo autor. 
Figura 54 - Regiões supercríticas $(\operatorname{sgn}(\xi)=1)$ e variação dos autovalores $\xi_{1}, \xi_{2}$ e $\xi_{3}$ do tensor $\mathbf{T}^{*}$. (a) $\mathrm{Ma}=6.6$ e (b) $\mathrm{Ma}=8.0$.
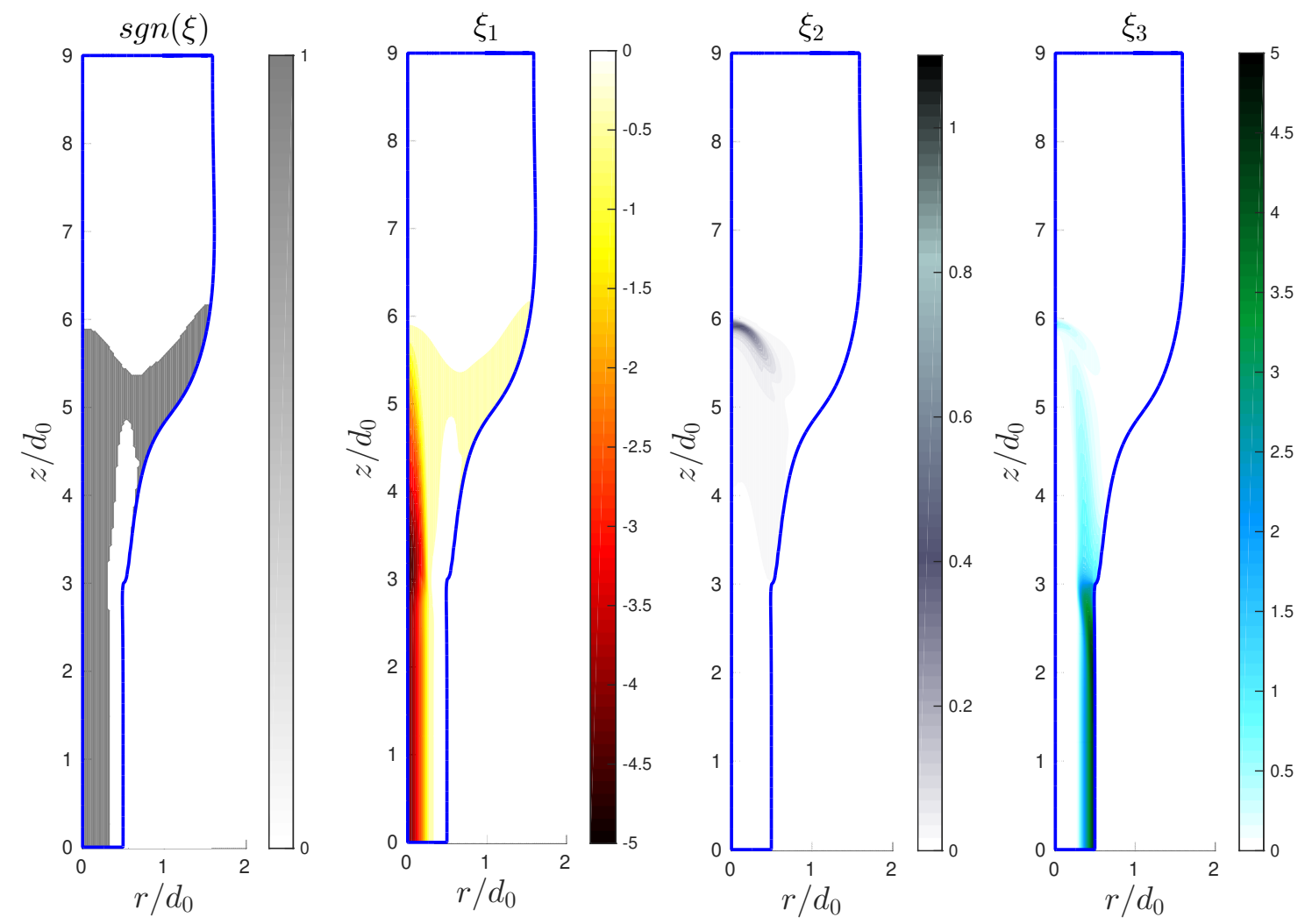

(a) $\mathrm{Ma}=6.6$
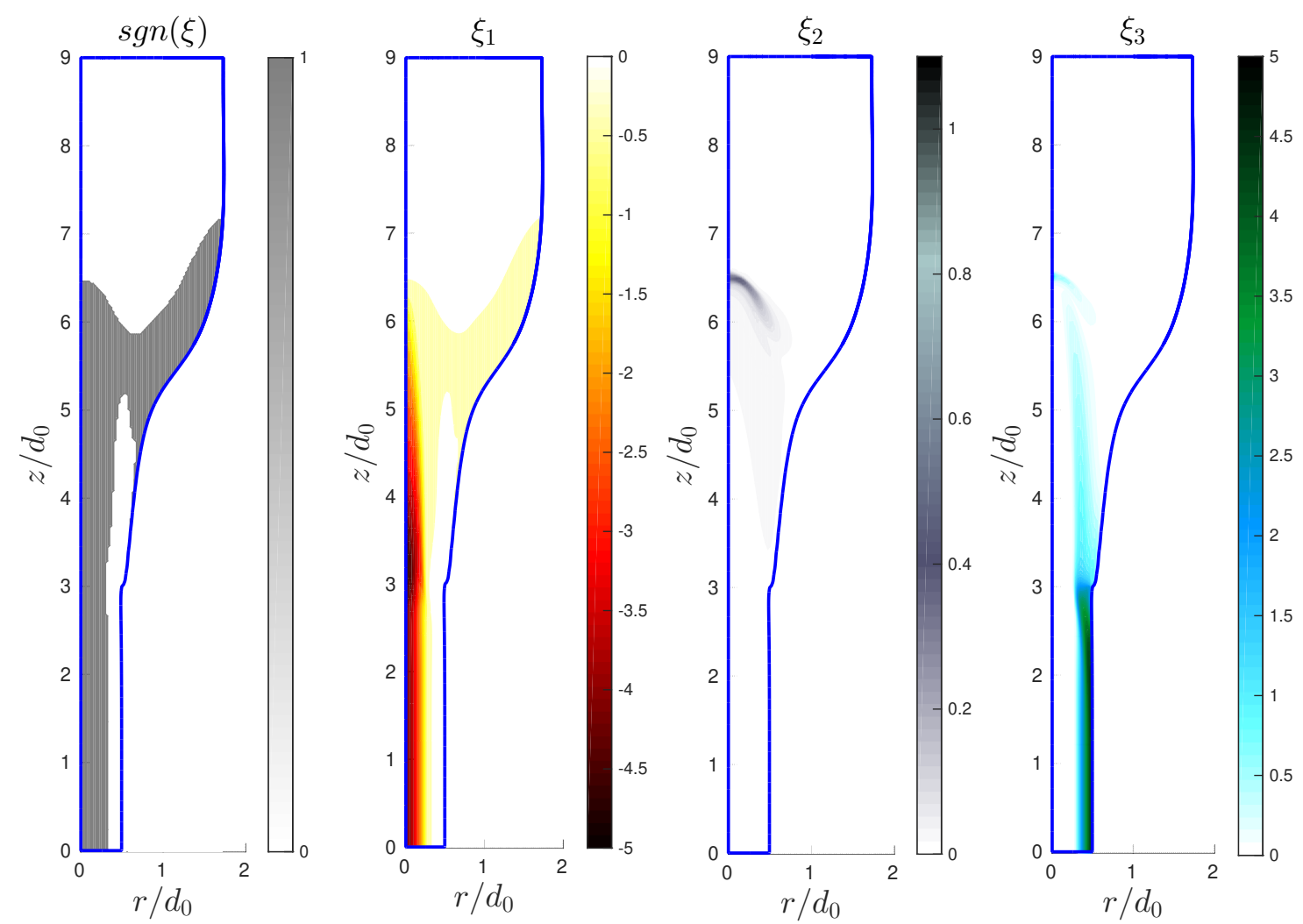

(b) $\mathrm{Ma}=8.0$

Fonte: Elaborada pelo autor. 


\subsubsection{Efeito do número de elasticidade $E$}

Com o objetivo de verificar o efeito do número de elasticidade no inchamento do extrudado e também na distância do retardo do inchamento, foram realizadas quatro simulações mantendo o número de Mach fixo, Ma=4.0, e E=0.03, 0.035, 0.0375 e 0.04. Os respectivos números de Reynolds e Weissenberg são apresentados na Tabela 17. As superfícies livres do jato podem ser visualizadas na Figura 55 e a Tabela 17 contém os valores de $l_{d} / d_{0}$ e $d_{e x} / d_{0}$ obtidos. Pode-se verificar na Figura 55 que o número E tem uma grande influência em ambas medidas, na taxa de inchamento e também na distância do retardo do jato como pode ser constatado na Tabela 17. De fato, a taxa de inchamento varia de 2.0224 até 3.9112 mostrando uma variação entre $100 \%$ e $300 \%$ enquanto que a distância diminui de 1.7243 até 1.6394 .

Figura 55 - Superfícies livres do fluido UCM para diferentes valores $\mathrm{E} \mathrm{e}$ $\mathrm{Ma}=4.0$.

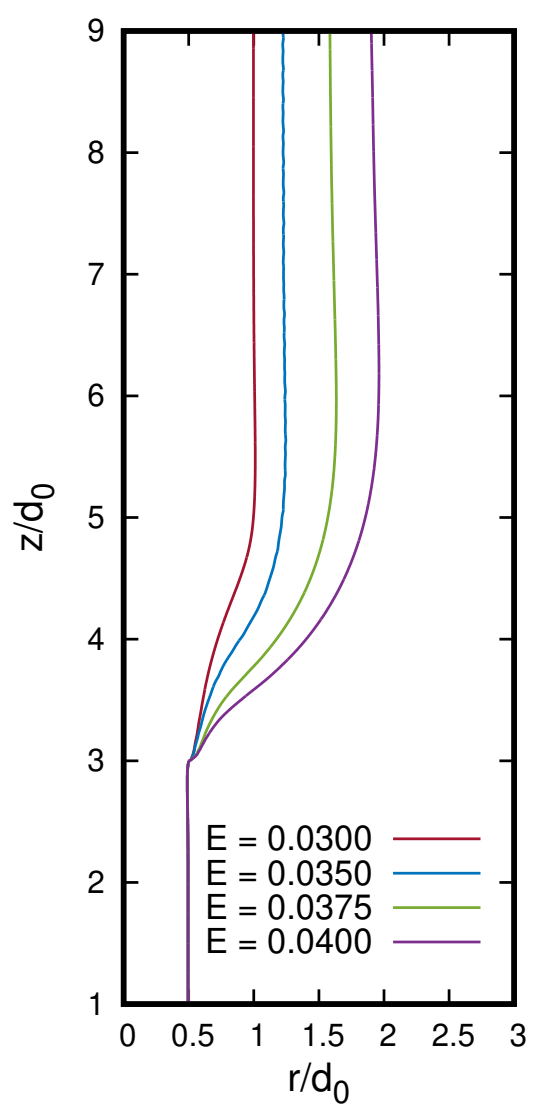

Tabela 17 - Resultados da distância de atraso $\left(l_{d}\right)$ e taxa de inchamento $\left(d_{e x}\right)$ para $\mathrm{Ma}=4.0$ fixo e números de elasticidade $\mathrm{E}=0.003,0.0350,0.0375$ e 0.04 .

\begin{tabular}{|c||cccc|}
\hline \multicolumn{5}{|c|}{$\mathrm{Ma}=4.0$} \\
\hline $\mathrm{E}$ & 0.0300 & 0.0350 & 0.0375 & 0.0400 \\
\hline$W i$ & 0.6928 & 0.7483 & 0.7746 & 0.8000 \\
\hline$R e$ & 23.0940 & 21.3809 & 20.6560 & 20.0000 \\
\hline$l_{d} / d_{0}$ & 1.7243 & 1.6610 & 1.6515 & 1.6394 \\
\hline$d_{e x} / d_{0}$ & 2.0224 & 2.4922 & 3.2677 & 3.9112 \\
\hline
\end{tabular}

Fonte: Dados da pesquisa.

Fonte: Elaborada pelo autor. 


\subsubsection{Comparação com resultados experimentais}

Nessa seção apresentamos uma validação qualitativa entre uma seleção dos resultados obtidos pelo código axissimétrico e os resultados experimentais de Joseph, Matta e Chen (1987). As Figuras 56 - 59 mostram as comparações dos resultados obtidos com números de Mach, Ma = 4.0, 4.3, 8.0 e 8.6, respectivamente. Pode-se observar uma boa concordância entre os resultados.

Figura 56 - Validação qualitativa entre resultados numéricos obtidos pelo código axissimétrico e resultados experimentais de Joseph, Matta e Chen (1987): $\mathrm{Ma}=4.0$ e $\mathrm{E}=0.035$.

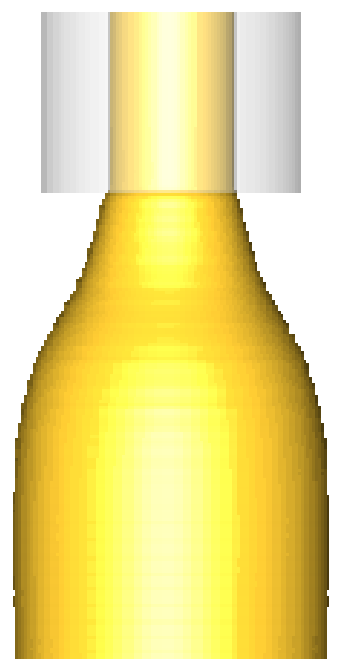

(a) Código axissimétrico - $\mathrm{E}=0.035$ e $\mathrm{Ma}=4.0$.

Fonte: Elaborada pelo autor.

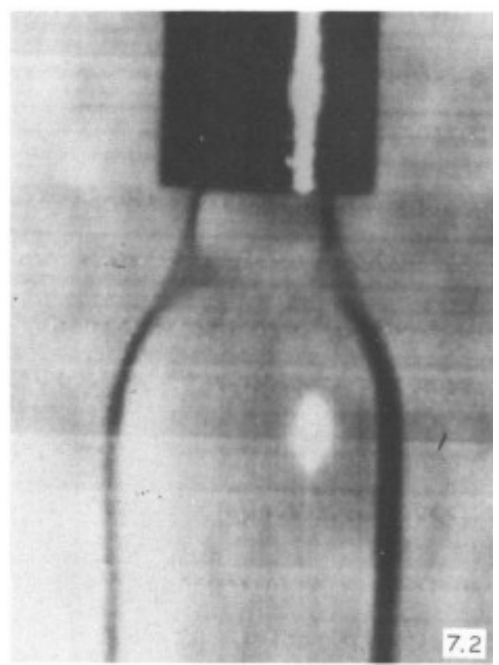

(b) Experimental - Fig 7.2

Fonte: Joseph, Matta e Chen (1987, p. 53).

Figura 57 - Validação qualitativa entre resultados numéricos obtidos pelo código axissimétrico e resultados experimentais de Joseph, Matta e Chen (1987): $\mathrm{Ma}=4.3$ e $\mathrm{E}=0.03$.

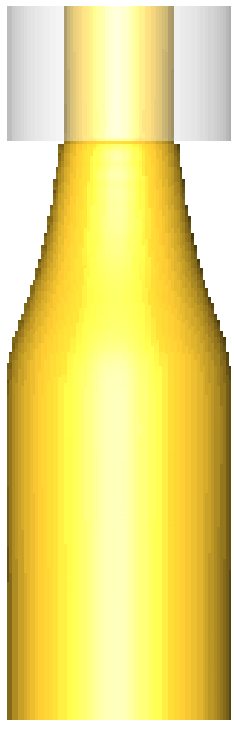

(a) Código axissimétrico $-\mathrm{E}=0.03$ e $\mathrm{Ma}=4.3$.

Fonte: Elaborada pelo autor.

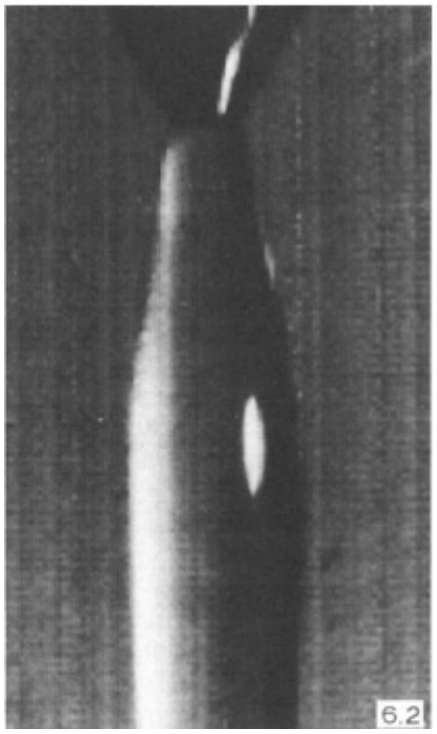

(b) Experimental - Fig 6.2.

Fonte: Joseph, Matta e Chen (1987, p. 44). 
Figura 58 - Validação qualitativa entre resultados numéricos obtidos pelo código axissimétrico e resultados experimentais de Joseph, Matta e Chen (1987): $\mathrm{Ma}=8.0$ e $\mathrm{E}=0.035$.

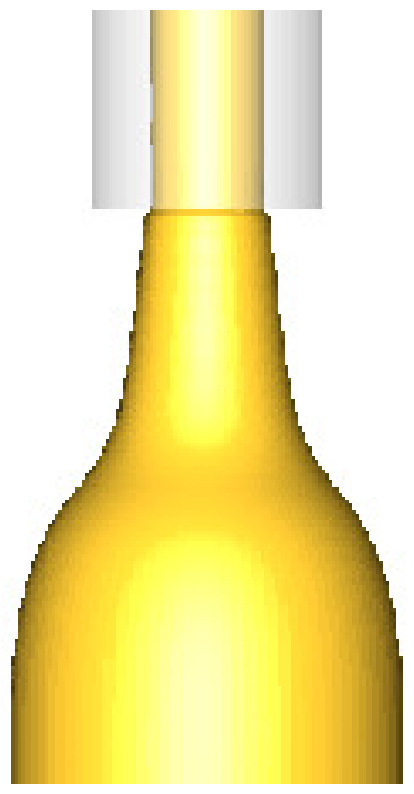

(a) Código axissimétrico $-\mathrm{E}=0.035$ e $\mathrm{Ma}=8.0$.

Fonte: Elaborada pelo autor.

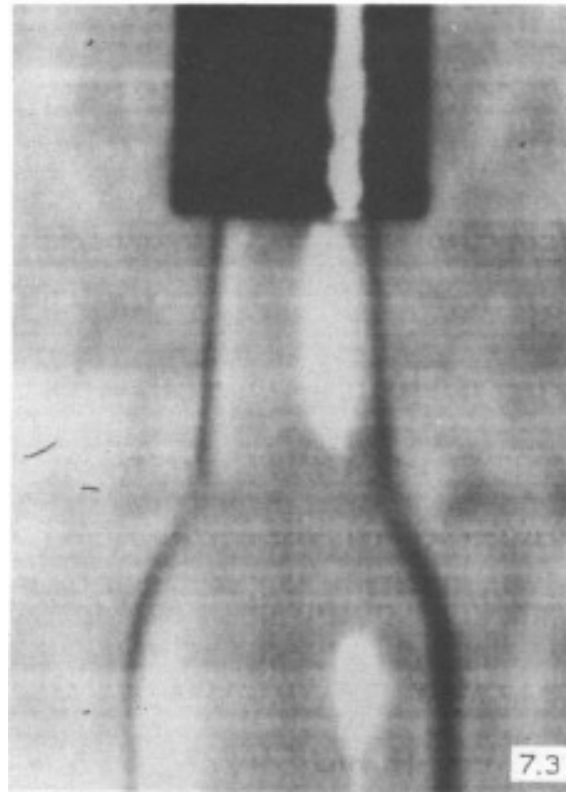

(b) Experimental - Fig 7.3

Fonte: Joseph, Matta e Chen (1987, p. 53).

Figura 59 - Validação qualitativa entre resultados numéricos obtidos pelo código axissimétrico e resultados experimentais de Joseph, Matta e Chen (1987): $\mathrm{Ma}=8.6$ e $\mathrm{E}=0.03$.

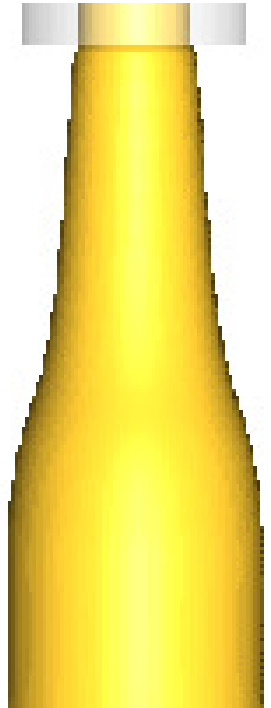

(a) Código axissimétrico - $\mathrm{E}=0.03$ e $\mathrm{Ma}=8.6$.

Fonte: Elaborada pelo autor.

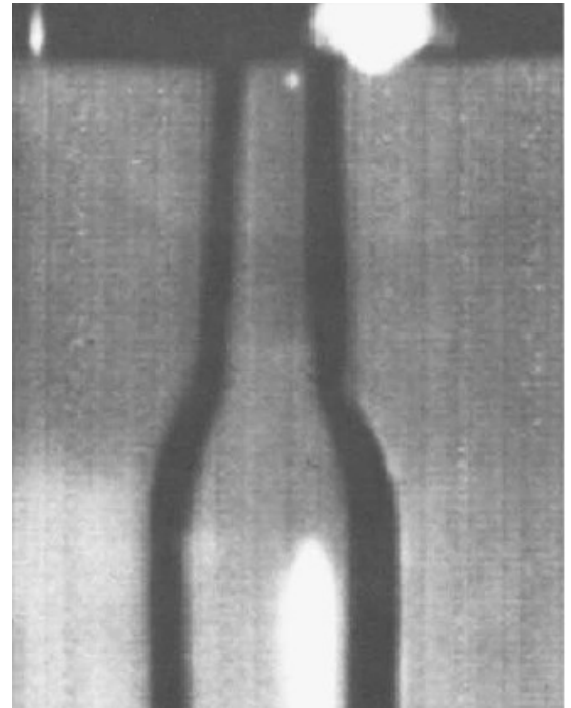

(b) Experimental - Fig 7.16.

Fonte: Joseph, Matta e Chen (1987, p. 57). 

CAPÍTULO

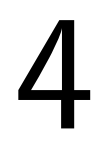

\section{CONSIDERAÇÕES FINAIS}

Esse trabalho abordou o tema simulação numérica de escoamentos viscoelásticos axissimétricos com superfícies livres governados pelo modelo constitutivo Oldroyd-B e teve como objetivo simular o salto de uma gota viscoelástica e a predição numérica do fenômeno conhecido como inchamento retardado do extrudado.

Inicialmente, realizou-se uma revisão bibliográfica sobre esses problemas e verificou-se que poucos trabalhos numéricos foram encontrados na literatura (ver por exemplo Seção 1.1 e Seção 1.2). Esses escoamentos são complexos e envolvem a solução do modelo Oldroyd-B para valores muito pequenos da razão de viscosidades $\beta=\eta_{S} / \eta_{0}$, em que $\eta_{S}$ denota a viscosidade do solvente e $\eta_{0}$ representa a viscosidade total do fluido. Os códigos existentes resolvem o modelo Oldroyd-B somente para valores de $\beta>0.1$ e assim, um método numérico capaz de resolver o modelo Oldroyd-B para escoamentos axissimétricos com superfícies livres para qualquer valor de $\beta$ no intervalo $[0,1]$ foi desenvolvido. Uma importante característica do código construido é que fazendo $\beta=0$ obtém-se o modelo UCM, e portanto, o código tem a capacidade de prever escoamentos axissimétricos para ambos os fluidos: Oldroyd-B e UCM. Com relação ao modelo UCM, poucos códigos são capazes de resolver numericamente esse modelo, especialmente se o número de Weissenberg for alto.

Detalhes do método numérico e da metodologia empregada para resolver as equações governantes foram apresentados no Capítulo 2. Nesse capítulo foi desenvolvido um método numérico para resolver escoamentos transientes com superfícies livres para um fluido OldroydB, que provou-se ser estável para todos valores da razão entre a viscosidade do solvente e a viscosidade total do fluido. A formulação empregada para resolver as equações governantes e as condições de tensões na superfície livre utilizou a transformação EVSS. Considerando essa abordagem, o fator multiplicativo $\frac{1}{\beta}$ foi removido das condições de contorno na superfície livre, evitando assim, as instabilidades numéricas quando o valor de $\beta$ é pequeno, ou seja, quando o fluido aproxima-se do modelo UCM. 
Um dos principais atributos desse trabalho é a metodologia utilizada para resolver a equação do modelo Oldroyd-B. O tensor tensão extra foi escrito em função do tensor conformação A, que foi aproximado por diferenças finitas implícitas resultando em um sistema linear $(4 \times 4)$, sendo esse sistema resolvido exatamente. Após obter o tensor conformação, o tensor tensão extra foi algebricamente calculado. $\mathrm{O}$ método foi verificado utilizando o escoamento desenvolvido em um tubo e considerando pequenos valores de $\beta$. Para todos os valores de $\beta$ considerados, o refinamento de malha demonstrou a convergência do método numérico. $\mathrm{A}$ capacidade do método numérico em resolver escoamento transientes com superfícies livres foi demonstrada simulando o problema do impacto da gota em uma superfície rígida, e realizando refinamento de malha seguido de uma comparação com resultados obtidos por outras técnicas numéricas. Várias simulações com diferentes valores de $\beta$ foram consideradas, principalmente para razões de viscosidades pequenas. Nesses resultados, observou-se que para $\beta$ próximo de 1 a variação temporal do diâmetro da gota assemelha-se ao conportamento do diâmetro de uma gota newtoniana. Por outro lado, quando $\beta$ é pequeno o diâmetro apresenta movimentos de expansão e contração, e quanto mais próximo de zero (fluido UCM) essas oscilações são mais frequentes. Um estudo utilizando o modelo Oldroyd-B para analisar os efeitos da razão de viscosidades $\beta$ e dos números de Reynolds e Weissenberg na altura do salto de uma gota viscoelástica foi apresentado. Constatou-se que o valor de $\beta$ tem uma influência substancial na altura do salto da gota e na ocorrência desse fenômeno. Os efeitos dos números de Reynolds e de Weissenberg na altura do salto da gota também foram discutidos. Observou-se então, que o problema do salto da gota, simulado numericamente com diferentes valores dos parâmetros $\beta$, Re e considerando valores de $W i$ relativamente altos, demonstrou certa robustez do código axissimétrico desenvolvido. Um estudo quantitativo mostrando as condições para a ocorrência do salto de uma gota viscoelástica foram apresentados.

No Capítulo 3 são apresentados os resultados obtidos na simulação dos fenômenos conhecidos como inchamento do extrudado e inchamento retardado do extrudado. Inicialmente, tratou-se do fenômeno do inchamento do extrudado utilizando o modelo Oldroyd-B. Esse escoamento foi resolvido utilizando refinamento de malha e realizou-se comparações com predições numéricas da literatura. Os resultados mostraram uma boa concordância com resultados da literatura (mais epecificamente com a Lei de Tanner (TANNER, 1970)) e o refinamento de malha demonstrou a convergência do código. Esses resultados verificaram o código nesse tipo de escoamento.

A seguir, considerou-se o fenômeno do inchamento retardado do extrudado o qual foi simulado empregando o modelo Oldroyd-B, com razão de viscosidades $\beta=0.05$ e variando os números de elasáticidade e de Mach viscoelástico. A taxa de inchamento do extrudado e a distância de retardo do jato foram calculadas. Utilizando refinamento de malha e resultados publicados por Delvaux e Crochet (1990), o código axissimétrico foi verificado e a convergência do código nesse tipo de escoamento foi mostrada. 
Na sequência, o fenômeno do inchamento retardado do extrudado foi simulado utilizando vários números de elasticidade e de Mach com ambos os modelos Oldroyd-B e UCM. Conforme foi conjecturado por Joseph, Matta e Chen (1987), a ocorrência desse fenômeno é devido a uma mudança no tipo da equação da vorticidade, de elíptica para hiperbólica. Para verificar esse fato, as regiões subcríticas e supercríticas no escoamento foram determinadas. Os resultados com o modelo UCM mostraram que quando o número de Mach viscoelástico aumenta, as regiões supercríticas no escoamento crescem e para os escoamentos simulados essas regiões podem atingir cerca de $90 \%$ do escoamento. Esses resultados estão de acordo com os obtidos por Delvaux e Crochet (1990) que utilizou o modelo Oldroyd-B. Resultados com valores mais críticos de Mach e E para fluidos do tipo UCM foram obtidos, demonstrando a capacidade do código de obter resultados que podem auxiliar em processos importantes na área de dinâmica de fluidos.

Em resumo, os resultados e discussões apresentadas mostram a eficiência do método numérico desenvolvido e destaca-se que os resultados desse trabalho são de grande interesse científico e tecnológico uma vez que apresentou-se resultados inéditos na área de simulação computacional de fluidos viscoelásticos.

\subsection{Produção científica}

Os resultados desenvolvidos durante o período de doutoramento, foram apresentados em congressos de relevância da área. As apresentações em eventos nacionais e internacionais, originaram trabalhos completos e resumos que foram submetidos para apreciação da comunidade científica. Além disso, um artigo descrevendo os resultados do Capítulo 2 da tese foi submetido para um periódico importante da área. A seguir segue uma relação dos trabalhos originados dessa tese.

- Artigo submetido para periódico.

1. Manuscript Number: JNNFM-D-20-00038

C. Viezel, M. F. Tomé, F. T. Pinho, S. McKee. "An Oldroyd-B solver for vanishingly small values of the viscosity ratio: application to unsteady free surface flows". Journal of Non-Newtonian Fluid Mechanics.

- Trabalhos completos publicados em anais de eventos.

- Congressos internacionais:

1. VIEZEL, Caroline; TOMÉ, Murilo Francisco; PINHO, Fernando T.; MCKEE, Sean. A numerical technique for solving the Oldroyd-B model for the whole range of viscosity ratios. In Proceedings. Barcelona, Spain: International Center For Numerical Methods In Engineerin (CIMNE), 2018. ISBN: 978-84-947311-6-7; Available from: <http://www. 
eccm-ecfd2018.org/frontal/docs/Ebook-Glasgow-2018-ECCM-VI-ECFD-VII.pdf> ;

2. M. F. Tomé, C. Viezel, R. Merejolli, G. S. Paulo, S. McKee. Numerical simulation of die and delayed die swell of Oldroyd-B fluids. Congress on Numerical Methods in Engineering (CMN), 2019. In Proceedings. Universidade do Minho, Departamento de Engenharia Civil, Guimarães. ISBN: 978-989-54496-0-6.; Available from: <www.cmn2019.pt/images/ Congresso/ebook/CMN\%202019_eBook_b.pdf> ;

- Congressos nacionais:

3. Caroline Viezel, Murilo Tomé. Numerical Simulation of Extrudate Swell of Oldroyd-B Fluids. Brazilian Congress of Thermal Sciences and Engineering (ENCIT) 2018. < doi: //10.26678/ABCM.ENCIT2018.CIT18-0820> .

- Resumo submetido para evento internacional.

1. M. F. Tomé, C. Viezel. A numerical study of extrudate swell and delayed extrudate swell of UCM fluids. Iberian Meeting on Rheology (IBEREO), 2019. Porto, Portugal.

- Outros trabalhos.

1. Caroline Viezel, Juliana Bertoco, Murilo Tomé, Michael Vynnycky. Application of the KBKZ-PSM integral model to axisymmetric flows. 24th ABCM International Congress of Mechanical Engineering (COBEM ), 2017. < doi://10.26678/ABCM.COBEM2017.COB17-1490> .

\subsection{Trabalhos futuros}

As próximas etapas do trabalho são:

1. Está em andamento a redação de um artigo que contém os resultados do Capítulo 3 da tese.

2. Uma consequência desse trabalho, é considerar simulações de escoamentos regidos por equações constitutivas integrais, como por exemplo, o modelo integral K-BKZ. Em geral, fluidos modelados por equações integrais são mais realistas e difíceis de resolver numericamente. O processo de implementação do modelo K-BKZ já foi iniciado. A metodologia numérica proposta por Tomé et al. (2016) para escoamentos bidimensionais, foi adaptada e implementada no código axissimétrico. Alguns resultados preliminares para o escoamento do impacto de uma gota de fluido UCM sobre uma superfície rígida plana, possibilitou uma comparação entre os resultados apresentados nesta tese e os resultados iniciais obtidos através da resolução do modelo integral K-BKZ simplificado para fluido UCM. Esses primeiros resultados motiva-nos a prosseguir com o desenvolvimento do código numérico para estudar esse tipo de fluido. 
3. O código numérico pode ser aprimorado considerando efeitos de tensão superficial e a implementação de ângulo de contato. 



\section{REFERÊNCIAS}

AFONSO, A.; OLIVEIRA, P.; PINHO, F.; ALVES, M. Dynamics of high-deborah-number entry flows: a numerical study. Journal of Fluid Mechanics, Cambridge University Press, v. 677, p. 272-304, 2011. Citado na página 30.

AFONSO, A.; OLIVEIRA, P. J.; PINHO, F.; ALVES, M. The log-conformation tensor approach in the finite-volume method framework. Journal of Non-Newtonian Fluid Mechanics, Elsevier, v. 157 , n. 1-2, p. 55-65, 2009. Citado na página 30.

AFONSO, A.; PINHO, F.; ALVES, M. The kernel-conformation constitutive laws. Journal of Non-Newtonian Fluid Mechanics, Elsevier, v. 167, p. 30-37, 2012. Citado na página 30.

AFONSO, A. M.; ALVES, M. A.; PINHO, F. T.; OLIVEIRA, P. J. Application of the logconformation tensor approach to three dimensional viscoelastic flows. 2007. Citado na página 30 .

ALVES, M.; OLIVEIRA, P.; PINHO, F. A convergent and universally bounded interpolation scheme for the treatment of advection. International journal for numerical methods in fluids, Wiley Online Library, v. 41, n. 1, p. 47-75, 2003. Citado nas páginas 45 e 124.

AMOREIRA, L.; OLIVEIRA, P. Comparison of different formulations for the numerical calculation of unsteady incompressible viscoelastic fluid flow. Adv. Appl. Math. Mech, v. 4, p. 483-502, 2010. Citado nas páginas 35 e 39.

AMSDEN, A. A.; HARLOW, F. H. A simplified mac technique for incompressible fluid flow calculations. Journal of computational physics, v. 6, p. 322-325, 1970. Citado na página 41.

BALCI, N.; THOMASES, B.; RENARDY, M.; DOERING, C. R. Symmetric factorization of the conformation tensor in viscoelastic fluid models. Journal of Non-Newtonian Fluid Mechanics, Elsevier, v. 166, n. 11, p. 546-553, 2011. Citado na página 30.

BATCHELOR, G. An Introduction to Fluid Dynamics. [S.1.]: Cambridge University Press, 2000. Citado na página 40.

BERBEROVIC, E. Investigation of free-surface flow associated with drop impact: numerical simulations and theoretical modeling. Tese (Doutorado) — Technische Universität, 2010. Citado na página 31.

BIRD, R. B.; ARMSTRONG, R. C.; HASSAGER, O. Dynamics of polymeric liquids: Fluid mechanics. Wiley, 1987. Citado nas páginas 38 e 71.

BONITO, A.; PICASSO, M.; LASO, M. Numerical simulation of 3d viscoelastic flows with free surfaces. Journal of Computational Physics, Elsevier, v. 215, n. 2, p. 691-716, 2006. Citado nas páginas 29 e 30.

BRASSEUR, E.; FYRILLAS, M. M.; GEORGIOU, G. C.; CROCHET, M. J. The time-dependent extrudate-swell problem of an oldroyd-b fluid with slip along the wall. Journal of Rheology, The Society of Rheology, v. 42, n. 3, p. 549-566, 1998. Citado na página 33. 
BRENSCHEDE, E.; KLEIN, J. Druckverluste und instabiles fließen elastischer flüssigkeiten im hochdruck-kapillarviskosimeter. Rheologica Acta, Springer, v. 9, n. 1, p. 130-136, 1970. Citado nas páginas 32 e 69.

BUSH, M. A numerical study of extrudate swell in very dilute polymer solutions represented by the oldroyd-b model. Journal of non-newtonian fluid mechanics, Elsevier, v. 34, n. 1, p. 15-24, 1990. Citado na página 33.

CASTILLO, E.; BAIGES, J.; CODINA, R. Approximation of the two-fluid flow problem for viscoelastic fluids using the level set method and pressure enriched finite element shape functions. Journal of Non-Newtonian Fluid Mechanics, Elsevier, v. 225, p. 37-53, 2015. Citado nas páginas 29 e 30 .

CHORIN, A. J. Numerical solution of the navier-stokes equations. Mathematics of computation, v. 22, n. 104, p. 745-762, 1968. Citado na página 43.

COMMINAL, R.; HATTEL, J. H.; ALVES, M. A.; SPANGENBERG, J. Vortex behavior of the oldroyd-b fluid in the 4-1 planar contraction simulated with the streamfunction-log-conformation formulation. Journal of Non-Newtonian Fluid Mechanics, Elsevier, v. 237, p. 1-15, 2016. Citado na página 30.

COMMINAL, R.; PIMENTA, F.; HATTEL, J. H.; ALVES, M. A.; SPANGENBERG, J. Numerical simulation of the planar extrudate swell of pseudoplastic and viscoelastic fluids with the streamfunction and the vof methods. Journal of Non-Newtonian Fluid Mechanics, Elsevier, v. 252, p. 1-18, 2018. Citado nas páginas 32, 33, 39, 40, 41 e 71.

COMMINAL, R.; SPANGENBERG, J.; HATTEL, J. H. Robust simulations of viscoelastic flows at high weissenberg numbers with the streamfunction/log-conformation formulation. Journal of Non-Newtonian Fluid Mechanics, Elsevier, v. 223, p. 37-61, 2015. Citado na página 30.

CORONADO, O. M.; ARORA, D.; BEHR, M.; PASQUALI, M. A simple method for simulating general viscoelastic fluid flows with an alternate log-conformation formulation. Journal of Non-Newtonian Fluid Mechanics, Elsevier, v. 147, n. 3, p. 189-199, 2007. Citado na página 30 .

COYAJEE, E.; BOERSMA, B. J. Numerical simulation of drop impact on a liquid-liquid interface with a multiple marker front-capturing method. Journal of Computational Physics, Elsevier, v. 228, n. 12, p. 4444-4467, 2009. Citado na página 31.

CROCHET, M.; KEUNINGS, R. Die swell of a maxwell fluid: numerical prediction. Journal of Non-Newtonian Fluid Mechanics, Elsevier, v. 7, n. 2-3, p. 199-212, 1980. Citado nas páginas 29,33 e 71 .

Finite element analysis of die swell of a highly elastic fluid. Journal of Non-Newtonian Fluid Mechanics, Elsevier, v. 10, n. 3-4, p. 339-356, 1982. Citado nas páginas 29, 33, 39, 40, $41,71,75$ e 88 .

DAMANIK, H.; HRON, J.; OUAZZI, A.; TUREK, S. A monolithic fem approach for the logconformation reformulation (lcr) of viscoelastic flow problems. Journal of Non-Newtonian Fluid Mechanics, Elsevier, v. 165, n. 19-20, p. 1105-1113, 2010. Citado na página 30.

DELVAUX, V.; CROCHET, M. Numerical simulation of delayed die swell. Rheologica acta, Springer, v. 29, n. 1, p. 1-10, 1990. Citado nas páginas 15, 17, 21, 29, 34, 69, 70, 79, 80, 81, 82, $83,84,85,95,108$ e 109 . 
FANG, C.; HIDROVO, C.; WANG, F.-m.; EATON, J.; GOODSON, K. 3-d numerical simulation of contact angle hysteresis for microscale two phase flow. International Journal of Multiphase Flow, Elsevier, v. 34, n. 7, p. 690-705, 2008. Citado na página 31.

FATTAL, R.; KUPFERMAN, R. Constitutive laws for the matrix-logarithm of the conformation tensor. Journal of Non-Newtonian Fluid Mechanics, Elsevier, v. 123, n. 2-3, p. 281-285, 2004. Citado nas páginas 30 e 33 .

Time-dependent simulation of viscoelastic flows at high weissenberg number using the logconformation representation. Journal of Non-Newtonian Fluid Mechanics, Elsevier, v. 126, n. 1, p. 23-37, 2005. Citado na página 30.

FIGUEIREDO, R.; OISHI, C.; CUMINATO, J. A.; ALVES, M. A. Three-dimensional transient complex free surface flows: Numerical simulation of xpp fluid. Journal of Non-Newtonian Fluid Mechanics, Elsevier, v. 195, p. 88-98, 2013. Citado na página 30.

FIGUEIREDO, R. A.; OISHI, C. M.; CUMINATO, J. A.; AZEVEDO, J. C.; AFONSO, A. M.; ALVES, M. A. Numerical investigation of three dimensional viscoelastic free surface flows: impacting drop problem. In: Proceedings of 6th European conference on computational fluid dynamics (ECFD VI). [S.1.: s.n.], 2014. v. 5, p. 5368-5380. Citado nas páginas 29, 31 e 52.

FRANCOIS, M.; SHYY, W. Computations of drop dynamics with the immersed boundary method, part 2: Drop impact and heat transfer. Numerical Heat Transfer: Part B: Fundamentals, Taylor \& Francis, v. 44, n. 2, p. 119-143, 2003. Citado na página 31.

GIESEKUS, H. Verschiedene phänomene in strömungen viskoelastischer flüssigkeiten durch düsen. Rheologica Acta, Springer, v. 8, n. 3, p. 411-421, 1969. Citado nas páginas 16, 32, 69 e 70 .

A simple constitutive equation for polymer fluids based on the concept of deformationdependent tensorial mobility. Journal of Non-Newtonian Fluid Mechanics, Elsevier, v. 11, n. 1-2, p. 69-109, 1982. Citado na página 29.

GOUBLOMME, A.; DRAILY, B.; CROCHET, M. Numerical prediction of extrudate swell of a high-density polyethylene. Journal of Non-Newtonian Fluid Mechanics, v. 44, p. 171195, 1992. ISSN 0377-0257. Disponível em: <//www.sciencedirect.com/science/article/pii/ $0377025792800508>$. Citado na página 71.

GRIEBEL, M.; KLITZ, M. Simulation of micron-scale drop impact. Computers \& Mathematics with Applications, Elsevier, v. 78, n. 9, p. 3027-3043, 2019. Citado na página 31.

GUÉNETTE, R.; FORTIN, M. A new mixed finite element method for computing viscoelastic flows. Journal of non-newtonian fluid mechanics, Elsevier, v. 60, n. 1, p. 27-52, 1995. Citado nas páginas 35 e 39 .

GUNJAL, P. R.; RANADE, V. V.; CHAUDHARI, R. V. Dynamics of drop impact on solid surface: experiments and vof simulations. AIChE Journal, Wiley Online Library, v. 51, n. 1, p. 59-78, 2005. Citado na página 31.

HABLA, F.; MARSCHALL, H.; HINRICHSEN, O.; DIETSCHE, L.; JASAK, H.; FAVERO, J. L. Numerical simulation of viscoelastic two-phase flows using openFOAM $\AA$. Chemical engineering science, Elsevier, v. 66, n. 22, p. 5487-5496, 2011. Citado na página 32. 
HABLA, F.; TAN, M. W.; HASSLBERGER, J.; HINRICHSEN, O. Numerical simulation of the viscoelastic flow in a three-dimensional lid-driven cavity using the log-conformation reformulation in openFOAM $囚$. Journal of Non-Newtonian Fluid Mechanics, Elsevier, v. 212, p. 47-62, 2014. Citado na página 30.

HARLOW, F. H.; WELCH, J. E. Numerical calculation of time-dependent viscous incompressible flow of fluid with free surface. The physics of fluids, AIP, v. 8, n. 12, p. 2182-2189, 1965. Citado na página 33.

HIRT, C. W.; NICHOLS, B. D. Volume of fluid (vof) method for the dynamics of free boundaries. Journal of computational physics, Elsevier, v. 39, n. 1, p. 201-225, 1981. Citado na página 33.

HULSEN, M. A.; FATTAL, R.; KUPFERMAN, R. Flow of viscoelastic fluids past a cylinder at high weissenberg number: stabilized simulations using matrix logarithms. Journal of NonNewtonian Fluid Mechanics, Elsevier, v. 127, n. 1, p. 27-39, 2005. Citado na página 30.

IZBASSAROV, D.; MURADOGLU, M. A front-tracking method for computational modeling of viscoelastic two-phase flow systems. Journal of Non-Newtonian Fluid Mechanics, Elsevier, v. 223, p. 122-140, 2015. Citado na página 29.

Effects of viscoelasticity on drop impact and spreading on a solid surface. Physical Review Fluids, APS, v. 1, n. 2, p. 023302, 2016. Citado nas páginas 29 e 31.

JASAK, H.; JEMCOV, A.; TUKOVIC, Z. et al. Openfoam: A c++ library for complex physics simulations. In: IUC DUBROVNIK CROATIA. International workshop on coupled methods in numerical dynamics. [S.1.], 2007. v. 1000, p. 1-20. Citado nas páginas 29 e 52.

JOSEPH, D. D. Fluid dynamics of viscoelastic liquids. [S.1.]: Springer Science \& Business Media, 2013. v. 84. Citado na página 32.

JOSEPH, D. D.; MATTA, J. E.; CHEN, K. Delayed die swell. Journal of non-newtonian fluid mechanics, Elsevier, v. 24, n. 1, p. 31-65, 1987. Citado nas páginas 15, 19, 32, 34, 35, 69, 70, $84,88,104,105$ e 109.

JUNIOR, I. L. P.; OISHI, C. M.; AFONSO, A. M.; ALVES, M. A.; PINHO, F. T. Numerical study of the square-root conformation tensor formulation for confined and free-surface viscoelastic fluid flows. Advanced Modeling and Simulation in Engineering Sciences, SpringerOpen, v. 3, n. 1, p. 1-23, 2016. Citado na página 31.

KANE, A.; GUÉNETTE, R.; FORTIN, A. A comparison of four implementations of the logconformation formulation for viscoelastic fluid flows. Journal of non-newtonian fluid mechanics, Elsevier, v. 164, n. 1-3, p. 45-50, 2009. Citado na página 30.

KNECHTGES, P.; BEHR, M.; ELGETI, S. Fully-implicit log-conformation formulation of constitutive laws. Journal of Non-Newtonian Fluid Mechanics, Elsevier, v. 214, p. 78-87, 2014. Citado na página 30.

KONAGANTI, V. K.; ANSARI, M.; MITSOULIS, E.; HATZIKIRIAKOS, S. G. The effect of damping function on extrudate swell. Journal of Non-Newtonian Fluid Mechanics, Elsevier, v. 236, p. 73-82, 2016. Citado na página 71. 
LUNKAD, S. F.; BUWA, V. V.; NIGAM, K. Numerical simulations of drop impact and spreading on horizontal and inclined surfaces. Chemical Engineering Science, Elsevier, v. 62, n. 24, p. 7214-7224, 2007. Citado na página 31.

MATALLAH, H.; TOWNSEND, P.; WEBSTER, M. Recovery and stress-splitting schemes for viscoelastic flows. Journal of Non-Newtonian Fluid Mechanics, Elsevier, v. 75, n. 2-3, p. 139-166, 1998. Citado nas páginas 35 e 39.

MCLEISH, T.; LARSON, R. Molecular constitutive equations for a class of branched polymers: The pom-pom polymer. Journal of rheology, SOR, v. 42, n. 1, p. 81-110, 1998. Citado na página 29.

MEREJOLLI, R. Simulação numérica de escoamentos tridimensionais com superfícies livres governados pelo modelo Giesekus. Tese (Doutorado) — Instituto de Ciências Matemáticas e de Computação, Universidade de São Paulo, São Carlos, 2017. Citado nas páginas 18, 35, 88, $89,92,93,94,95$ e 96.

MERRINGTON, A. Flow of visco-elastic materials in capillaries. Nature, Nature Publishing Group, v. 152, n. 3866, p. 663, 1943. Citado nas páginas 32 e 69.

METZNER, A.; WHITE, J.; DENN, M. Behavior of viscoelastic materials in short-time processes. Rubber Chemistry and Technology, v. 40, n. 5, p. 1426-1445, 1967. Citado nas páginas 32 e 69.

MIDDLEMAN, S. The flow of high polymers. John Wiley:New York, v. 13, n. 13, 1968. Citado nas páginas 32 e 69.

MITSOULIS, E. Extrudate swell of boger fluids. Journal of Non-Newtonian Fluid Mechanics, Elsevier, v. 165, n. 13, p. 812-824, 2010. Citado na página 71.

MOMPEAN, G.; THAIS, L.; TOMÉ, M. F.; CASTELO, A. Numerical prediction of threedimensional time-dependent viscoelastic extrudate swell using differential and algebraic models. Computers \& fluids, Elsevier, v. 44, n. 1, p. 68-78, 2011. Citado na página 33.

OISHI, C.; MARTINS, F.; TOMÉ, M.; CUMINATO, J.; MCKEE, S. Numerical solution of the eXtended Pom-Pom model for viscoelastic free surface flows. Journal of Non-Newtonian Fluid Mechanics, v. 166, n. 3-4, p. 165-179, 2011. ISSN 0377-0257. Disponível em: <//www. sciencedirect.com/science/article/pii/S0377025710002818>. Citado nas páginas 31, 43, 71 e 124.

OISHI, C. M.; TOMÉ, M. F.; CUMINATO, J. A.; MCKEE, S. An implicit technique for solving 3D low Reynolds number moving free surface flows. Journal of Computational Physics, v. 227, n. 16, p. 7446-7468, 2008. ISSN 0021-9991. Disponível em: <//www.sciencedirect.com/science/ article/pii/S0021999108002271>. Citado nas páginas 71 e 125.

OLDROYD, J. G. On the formulation of rheological equations of state. Proceedings of the Royal Society of London. Series A. Mathematical and Physical Sciences, The Royal Society London, v. 200, n. 1063, p. 523-541, 1950. Citado na página 29.

OSHER, S.; SETHIAN, J. A. Fronts propagating with curvature-dependent speed: algorithms based on hamilton-jacobi formulations. Journal of computational physics, Elsevier, v. 79, n. 1, p. 12-49, 1988. Citado na página 33. 
OWENS, R. G.; PHILLIPS, T. N. Computational Rheology. PUBLISHED BY IMPERIAL COLLEGE PRESS AND DISTRIBUTED BY WORLD SCIENTIFIC PUBLISHING CO., 2002. Disponível em: <https://www.worldscientific.com/doi/abs/10.1142/p160>. Citado nas páginas 29 e 30.

PAULO, G. D.; TOMÉ, M. F.; MCKEE, S. A marker-and-cell approach to viscoelastic free surface flows using the ptt model. Journal of Non-Newtonian Fluid Mechanics, Elsevier, v. 147, n. 3, p. 149-174, 2007. Citado na página 30.

PENG, J.; ZHU, K.-Q. Instability of the interface in co-extrusion flow of two ucm fluids in the presence of surfactant. Journal of Non-Newtonian Fluid Mechanics, Elsevier, v. 166, n. 1-2, p. 152-163, 2011. Citado na página 29.

QUARTERONI, A.; SACCO, R.; SALERI, F. Numerical mathematics. [S.1.]: Springer, 2000. v. 37. Citado nas páginas 43 e 126.

RAJAGOPAlAN, D.; ARMSTRONG, R. C.; BROWN, R. A. Finite element methdos for calculation of steady, viscoelastic flow using constitutive equations with a newtonian viscosity. Journal of Non-Newtonian Fluid Mechanics, Elsevier, v. 36, p. 159-192, 1990. Citado nas páginas 35 e 39.

RUSSO, G.; PHILLIPS, T. N. Spectral element predictions of die-swell for oldroyd-b fluids. Computers \& fluids, Elsevier, v. 43, n. 1, p. 107-118, 2011. Citado na página 33.

SHIN, S.; CHERGUI, J.; JURIC, D. A solver for massively parallel direct numerical simulation of three-dimensional multiphase flows. Journal of Mechanical Science and Technology, Springer, v. 31, n. 4, p. 1739-1751, 2017. Citado na página 31.

SOUSA, R.; POOLE, R.; AFONSO, A.; PINHO, F.; OLIVEIRA, P.; MOROZOV, A.; ALVES, M. Lid-driven cavity flow of viscoelastic liquids. Journal of Non-Newtonian Fluid Mechanics, Elsevier, v. 234, p. 129-138, 2016. Citado na página 30.

TANNER, R. A theory of die-swell. Journal of Polymer Science Part B: Polymer Physics, Wiley Online Library, v. 8, n. 12, p. 2067-2078, 1970. Citado nas páginas 29, 75, 89 e 108.

TOMÉ, M.; BERTOCO, J.; OISHI, C.; ARAUJO, M.; CRUZ, D.; PINHO, F.; VYNNYCKY, M. A finite difference technique for solving a time strain separable $\mathrm{K}-\mathrm{BKZ}$ constitutive equation for two-dimensional moving free surface flows. Journal of Computational Physics, v. 311, p. 114-141, 2016. ISSN 0021-9991. Disponível em: <//www.sciencedirect.com/science/article/pii/ S0021999116000401>. Citado na página 110.

TOMÉ, M.; CASTELO, A.; FERREIRA, V.; MCKEE, S. A finite difference technique for solving the oldroyd-b model for 3d-unsteady free surface flows. Journal of Non-Newtonian Fluid Mechanics, Elsevier, v. 154, n. 2, p. 179-206, 2008. Citado nas páginas 29, 30, 33 e 47.

TOMÉ, M.; CASTELO, A.; MURAKAMI, J.; CUMINATO, J.; MINGHIM, R.; OLIVEIRA, M.; MANGIAVACCHI, N.; MCKEE, S. Numerical Simulation of Axisymmetric Free Surface Flows. Journal of Computational Physics, v. 157, n. 2, p. 441-472, 2000. ISSN 0021-9991. Disponível em: <//www.sciencedirect.com/science/article/pii/S0021999199963489>. Citado nas páginas 35, 41 e 47. 
TOMÉ, M.; GROSSI, L.; CASTELO, A.; CUMINATO, J.; MCKEE, S.; WALTERS, K. Dieswell, splashing drop and a numerical technique for solving the Oldroyd B model for axisymmetric free surface flows. Journal of Non-Newtonian Fluid Mechanics, v. 141, n. 2-3, p. 148-166, 2007. ISSN 0377-0257. Disponível em: <//www.sciencedirect.com/science/article/pii/ S0377025706002680>. Citado nas páginas 29, 33, 35, 39, 40, 41, 42, 43, 71 e 124.

TOMÉ, M.; PAULO, G.; PINHO, F.; ALVES, M. Numerical solution of the ptt constitutive equation for unsteady three-dimensional free surface flows. Journal of Non-Newtonian Fluid Mechanics, Elsevier, v. 165, n. 5, p. 247-262, 2010. Citado na página 30.

TOMÉ, M. F.; CASTELO, A.; AFONSO, A. M.; ALVES, M. A.; PINHO, F. T. d. Application of the log-conformation tensor to three-dimensional time-dependent free surface flows. Journal of Non-Newtonian Fluid Mechanics, Elsevier, v. 175, p. 44-54, 2012. Citado nas páginas 33 e 88.

TOMÉ, M. F.; MANGIAVACCHI, N.; CUMINATO, J. A.; CASTELO, A.; MCKEE, S. A finite difference technique for simulating unsteady viscoelastic free surface flows. Journal of NonNewtonian Fluid Mechanics, Elsevier, v. 106, n. 2-3, p. 61-106, 2002. Citado nas páginas 29, 31 e 33 .

VERBEETEN, W. M.; PETERS, G. W.; BAAIJENS, F. P. Differential constitutive equations for polymer melts: The extended pom-pom model. Journal of rheology, SOR, v. 45, n. 4, p. 823-843, 2001. Citado na página 29.

WANG, Y.; DO-QUANG, M.; AMBERG, G. Impact of viscoelastic droplets. Journal of NonNewtonian Fluid Mechanics, Elsevier, v. 243, p. 38-46, 2017. Citado na página 31.

XU, X.; DENG, X.-L. An improved weakly compressible sph method for simulating free surface flows of viscous and viscoelastic fluids. Computer Physics Communications, Elsevier, v. 201, p. 43-62, 2016. Citado nas páginas 29, 31, 32 e 57.

XU, X.; OUYANG, J.; JIANG, T.; LI, Q. Numerical simulation of 3d-unsteady viscoelastic free surface flows by improved smoothed particle hydrodynamics method. Journal of NonNewtonian Fluid Mechanics, Elsevier, v. 177, p. 109-120, 2012. Citado nas páginas 29, 31, 32,52 e 57.

$\mathrm{XU}, \mathrm{X}$; YU, P. A technique to remove the tensile instability in weakly compressible sph. Computational Mechanics, Springer, v. 62, n. 5, p. 963-990, 2018. Citado nas páginas 31, 32 e 57. 

APÊNDICE

\section{A}

\section{EQUAÇÕES ADIMENSIONAIS EM COORDENADAS CILÍNDRICAS}

As equações diferenciais em coordenadas cilíndricas na forma adimensional utilizadas no desenvolvimento do método numérico são apresentadas abaixo.

Conservação de massa:

$$
\begin{gathered}
\nabla \cdot \mathbf{v}=0 \\
\frac{1}{r} \frac{\partial(r u)}{\partial r}+\frac{\partial w}{\partial z}=0 .
\end{gathered}
$$

Conservação da quantidade de movimento:

$$
\begin{aligned}
& \frac{\partial \mathbf{v}}{\partial t}+\nabla \cdot(\mathbf{v v})=-\nabla p+\frac{1}{R e} \nabla^{2} \mathbf{v}+\nabla \cdot \mathbf{S}+\frac{1}{F r^{2}} \mathbf{g}, \\
& \frac{\partial u}{\partial t}+\frac{1}{r} \frac{\partial(r u u)}{\partial r}+\frac{\partial(w u)}{\partial z}=-\frac{\partial p}{\partial r}+\frac{1}{R e}\left[\frac{1}{r} \frac{\partial}{\partial r}\left(r \frac{\partial u}{\partial r}\right)+\frac{\partial^{2} u}{\partial z^{2}}-\frac{u}{r^{2}}\right]+\frac{1}{r} \frac{\partial\left(r S^{r r}\right)}{\partial r} \\
& +\frac{\partial S^{r z}}{\partial z}-\frac{S^{\theta \theta}}{r}+\frac{1}{F r^{2}} g_{r} \\
& \frac{\partial w}{\partial t}+\frac{1}{r} \frac{\partial(r u w)}{\partial r}+\frac{\partial(w w)}{\partial z}=-\frac{\partial p}{\partial z}+\frac{1}{R e}\left[\frac{1}{r} \frac{\partial}{\partial r}\left(r \frac{\partial w}{\partial r}\right)+\frac{\partial^{2} w}{\partial z^{2}}\right]+\frac{1}{r} \frac{\partial\left(r S^{r z}\right)}{\partial r} \\
& +\frac{\partial S^{z z}}{\partial z}+\frac{1}{F r^{2}} g_{z}
\end{aligned}
$$




\section{Transformação EVSS:}

$$
\begin{aligned}
& \mathbf{S}=\tau-\frac{2}{R e} \mathbf{D} . \\
& S^{r r}=\tau^{r r}-\frac{2}{R e} \frac{\partial u}{\partial r}, \\
& S^{r z}=\tau^{r z}-\frac{1}{R e}\left[\frac{\partial w}{\partial r}+\frac{\partial u}{\partial z}\right], \\
& S^{\theta \theta}=\tau^{\theta \theta}-\frac{2}{\operatorname{Re}} \frac{u}{r}, \\
& S^{z z}=\tau^{z z}-\frac{2}{R e} \frac{\partial w}{\partial z} .
\end{aligned}
$$

\section{Tensor conformação A:}

$$
\begin{aligned}
& \frac{\partial A^{r r}}{\partial t}+\frac{1}{r} \frac{\partial\left(r u A^{r r}\right)}{\partial r}+\frac{\partial\left(w A^{r r}\right)}{\partial z}=\frac{1}{W i}\left[1-A^{r r}\right]+2\left(\frac{\partial u}{\partial r} A^{r r}+\frac{\partial u}{\partial z} A^{r z}\right) ; \\
& \frac{\partial A^{\theta \theta}}{\partial t}+\frac{1}{r} \frac{\partial\left(r u A^{\theta \theta}\right)}{\partial r}+\frac{\partial\left(w A^{\theta \theta}\right)}{\partial z}=\frac{1}{W i}\left[1-A^{\theta \theta}\right]+2 \frac{u}{r} A^{\theta \theta} ; \\
& \frac{\partial A^{z z}}{\partial t}+\frac{1}{r} \frac{\partial\left(r u A^{z z}\right)}{\partial r}+\frac{\partial\left(w A^{z z}\right)}{\partial z}=\frac{1}{W i}\left[1-A^{z z}\right]+2\left(\frac{\partial w}{\partial r} A^{r z}+\frac{\partial w}{\partial z} A^{z z}\right) ; \\
& \frac{\partial A^{r z}}{\partial t}+\frac{1}{r} \frac{\partial\left(r u A^{r z}\right)}{\partial r}+\frac{\partial\left(w A^{r z}\right)}{\partial z}=\frac{1}{W i}\left[0-A^{r z}\right]+\frac{\partial w}{\partial r} A^{r r}+\left(\frac{\partial w}{\partial z}+\frac{\partial u}{\partial r}\right) A^{r z}+\frac{\partial u}{\partial z} A^{z z}
\end{aligned}
$$

\section{Tensor tensão extra $\tau$ :}

$$
\begin{aligned}
\tau^{r r} & =\frac{1}{\operatorname{Re} W i}(1-\beta)\left[A^{r r}-1\right]+\frac{2}{\operatorname{Re}} \beta \frac{\partial u}{\partial r} \\
\tau^{\theta \theta} & =\frac{1}{\operatorname{Re} W i}(1-\beta)\left[A^{\theta \theta}-1\right]+\frac{2}{\operatorname{Re} \beta \frac{u}{r}} \\
\tau^{z z} & =\frac{1}{\operatorname{Re} W i}(1-\beta)\left[A^{z z}-1\right]+\frac{2}{\operatorname{Re}} \beta \frac{\partial w}{\partial z} \\
\tau^{r z} & =\frac{1}{\operatorname{Re} W i}(1-\beta)\left[A^{r z}-0\right]+\frac{1}{\operatorname{Re}} \beta\left[\frac{\partial w}{\partial r}+\frac{\partial u}{\partial z}\right] .
\end{aligned}
$$

Condições para a superfície livre: considere $\mathbf{n}=\left[\begin{array}{lll}n_{r} & 0 & n_{z}\end{array}\right]^{\top}$ e $\mathbf{m}=\left[\begin{array}{lll}n_{r} & 0 & -n_{z}\end{array}\right]^{\top}$, as condições de contorno para a superfície livre em coordenadas cilíndricas na forma adimensional são,

$$
\begin{gathered}
p=\frac{2}{\operatorname{Re}}\left[\frac{\partial u}{\partial r} n_{r}^{2}+\left(\frac{\partial u}{\partial z}+\frac{\partial w}{\partial r}\right) n_{r} n_{z}+\frac{\partial w}{\partial z} n_{z}^{2}\right]+S^{r r} n_{r}^{2}+2 S^{r z} n_{r} n_{z}+S^{z z} n_{z}^{2} ; \quad \text { (A.13) } \\
\frac{1}{\operatorname{Re}}\left[2\left(\frac{\partial w}{\partial z}-\frac{\partial u}{\partial r}\right) n_{r} n_{z}+\left(\frac{\partial u}{\partial z}+\frac{\partial w}{\partial r}\right)\left(n_{r}^{2}-n_{z}^{2}\right)\right]+\left[S^{z z}-S^{r r}\right] n_{r} n_{z}+S^{r z}\left(n_{r}^{2}-n_{z}^{2}\right)=0 .
\end{gathered}
$$




\section{APÊNDICE}

\section{$\mathrm{B}$}

\section{EQUAÇÕES DISCRETIZADAS}

Cálculo do campo de velocidade $\widetilde{\mathbf{v}}^{n+1}$ : A equação de conservação da quantidade de movimento é integrada no tempo pela equação:

$$
\widetilde{\mathbf{v}}^{n+1}-\frac{\delta t}{R e}\left(\nabla^{2} \widetilde{\mathbf{v}}\right)^{n+1}=\widetilde{\mathbf{v}}^{n}+\delta t\left[-\nabla p-\nabla \cdot(\mathbf{v v})+\nabla \cdot \mathbf{S}+\frac{1}{F r^{2}} \mathbf{g}\right]^{n}
$$

Essa equação em coordenadas cilíndricas é um sistema de duas equações (ver Equações A.4 A.5 no Apêndice A). Assim a equação,

$$
\begin{aligned}
\widetilde{u}^{n+1}-\frac{\delta t}{R e}\left[\frac{1}{r} \frac{\partial}{\partial r}\left(r \frac{\partial \widetilde{u}}{\partial r}\right)+\frac{\partial^{2} \widetilde{u}}{\partial z^{2}}-\frac{\widetilde{u}}{r^{2}}\right]^{n+1}= & \widetilde{u}^{n}+\delta t\left[-\frac{\partial p}{\partial r}-\frac{1}{r} \frac{\partial(r u u)}{\partial r}-\frac{\partial(w u)}{\partial z}\right. \\
& \left.+\frac{1}{r} \frac{\partial\left(r S^{r r}\right)}{\partial r}+\frac{\partial S^{r z}}{\partial z}-\frac{S^{\theta \theta}}{r}+\frac{1}{F r^{2}} g_{r}\right]^{n}
\end{aligned}
$$

tem suas derivadas discretizadas na face correspondente a velocidade $u_{i+\frac{1}{2}, j}=u\left(r_{i+\frac{1}{2}}, z_{j}, t\right)$ na Figura 3 a que aplicada as células $\mathbf{F}$ e $\mathbf{S}$ do domínio resulta em um sistema cuja calculado pela equação

$$
\begin{gathered}
\widetilde{u}_{i+\frac{1}{2}, j}^{n+1}-\frac{\delta t}{R e}\left[\frac{1}{r_{i+\frac{1}{2}}} \frac{r_{i+1} \widetilde{u}_{i+\frac{3}{2}, j}-\left(r_{i+1}+r_{i}\right) \widetilde{u}_{i+\frac{1}{2}, j}+r_{i} \widetilde{u}_{i-\frac{1}{2}, j}}{(\delta r)^{2}}+\frac{\widetilde{u}_{i+\frac{1}{2}, j+1}-2 \widetilde{u}_{i+\frac{1}{2}, j}+\widetilde{u}_{i+\frac{1}{2}, j-1}}{(\delta z)^{2}}\right. \\
\left.-\frac{\widetilde{u}_{i+\frac{1}{2}, j}}{r_{i+\frac{1}{2}}^{2}}\right]^{n+1}=\widetilde{u}_{i+\frac{1}{2}, j}^{n}+\delta t\left[-\frac{p_{i+1, j}-p_{i, j}}{\delta r}-\left.\frac{1}{r_{i+\frac{1}{2}}} \frac{\partial(r u u)}{\partial r}\right|_{i+\frac{1}{2}, j}-\left.\frac{\partial(w u)}{\partial z}\right|_{i+\frac{1}{2}, j}\right. \\
\left.\quad+\frac{1}{r_{i+\frac{1}{2}}} \frac{r_{i+1} S_{i+1, j}^{r r}-r_{i} S_{i, j}^{r r}}{\delta r}+\frac{S_{i+\frac{1}{2}, j+\frac{1}{2}}^{r z}-S_{i+\frac{1}{2}, j-\frac{1}{2}}^{r z}}{\delta z}-\frac{S_{i+\frac{1}{2}, j}^{\theta \theta}}{r_{i+\frac{1}{2}}}+\left.\frac{1}{F r^{2}} g_{r}\right|_{i+\frac{1}{2}, j}\right]^{n} .
\end{gathered}
$$


Os termos $\left.\left.\frac{\partial(r u u)}{\partial r}\right|_{i+\frac{1}{2}, j} \mathrm{e} \frac{\partial(w u)}{\partial z}\right|_{i+\frac{1}{2}, j}$ são aproximados aplicando o método de alta ordem CUBISTA (ALVES; OLIVEIRA; PINHO, 2003) (para mais detalhes ver Tomé et al. (2007)).

Analogamente a equação,

$$
\begin{aligned}
\widetilde{w}^{n+1}-\frac{\delta t}{\operatorname{Re}}\left[\frac{1}{r} \frac{\partial}{\partial r}\left(r \frac{\partial \widetilde{w}}{\partial r}\right)+\frac{\partial^{2} \widetilde{w}}{\partial z^{2}}\right]^{n+1}= & \widetilde{w}^{n}+\delta t\left[-\frac{\partial p}{\partial z}-\frac{1}{r} \frac{\partial(r u w)}{\partial r}+\frac{\partial(w w)}{\partial z}\right. \\
& \left.+\frac{1}{r} \frac{\partial\left(r S^{r z}\right)}{\partial r}+\frac{\partial S^{z z}}{\partial z}+\frac{1}{F r^{2}} g_{z}\right]^{n},
\end{aligned}
$$

aplicada na face correspondente a velocidade escalar $w_{i, j+\frac{1}{2}}=w\left(r_{i}, z_{j+\frac{1}{2}}, t\right)$ da Figura 3a resulta na equação discreta,

$$
\begin{aligned}
& \widetilde{w}_{i, j+\frac{1}{2}}^{n+1}-\frac{\delta t}{\operatorname{Re}}\left[\frac{1}{r_{i}} \frac{r_{i+\frac{1}{2}} \widetilde{w}_{i+1, j+\frac{1}{2}}-\left(r_{i+\frac{1}{2}}+r_{i-\frac{1}{2}}\right) \widetilde{w}_{i, j+\frac{1}{2}}+r_{i-\frac{1}{2}} \widetilde{w}_{i-1, j+\frac{1}{2}}}{(\delta r)^{2}}\right. \\
& +\frac{\widetilde{w}_{i, j+\frac{3}{2}}-2 \widetilde{w}_{i, j+\frac{1}{2}}+\widetilde{w}_{i, j-\frac{1}{2}}}{(\delta z)^{2}}=\widetilde{w}^{n}+\delta t\left[-\frac{p_{i, j+1}-p_{i, j}}{\delta z}-\left.\frac{1}{r_{i}} \frac{\partial(r u w)}{\partial r}\right|_{i, j+\frac{1}{2}}\right. \\
& -\left.\frac{\partial(w w)}{\partial z}\right|_{i, j+\frac{1}{2}}+\frac{1}{r_{i}} \frac{\left.r_{i+\frac{1}{2}} S_{i+\frac{1}{2}, j+\frac{1}{2}}^{r z}-r_{i-\frac{1}{2}} S_{i-\frac{1}{2}, j+\frac{1}{2}}^{r z}+\frac{S_{i, j+1}^{z z}-S_{i, j}^{z z}}{\delta z}+\frac{1}{F r^{2}} g_{z}\right]^{n} .}{\delta r}
\end{aligned}
$$

As Equações B.3 e B.5 aplicadas em cada célula do domínio geram dois sistema lineares. Fazendo algumas adequações algébricas e assumindo que $\delta r=\delta z$ pode-se observar que esses sistemas geram matrizes pentadiagonais simétricas e o método dos gradientes conjugados pode ser aplicado. Note que no termo fonte desses sistemas faz-se necessário conhecer a componente $S^{r z}$ nas quinas das células, isso é contornado utilizando uma extrapolação (média) dos valores de $S^{r z}$ no centro das células vizinhas ao ponto.

\$ Cálculo da pressão auxiliar $\psi^{n+1}$ : Oishi et al. (2011) afirmam que admitir uma formulação implícita como em (2.16) para resolver a equação de conservação da quantidade de movimento requer que a pressão $p^{n+1}=p\left(r, z, t_{n+1}\right)$ seja obtida pela seguinte equação,

$$
p^{n+1}=p^{n}+\frac{\psi^{n+1}}{\delta t}-\frac{1}{R e} \nabla^{2} \psi^{n+1} .
$$

Para esse fim, faz-se necessário obter antecipadamente a pressão auxiliar $\psi^{n+1}=\psi\left(r, z, t_{n+1}\right)$ que é calculada por meio da Equação 2.17 acoplada a equações apropriadas para $\psi$ na superfície livre.

O laplaciano de $\psi$ e o gradiente da velocidade $\widetilde{\mathbf{v}}$ em coordenadas cilíndricas compõe a seguinte equação,

$$
\frac{1}{r} \frac{\partial}{\partial r}\left(r \frac{\partial \psi}{\partial r}\right)+\frac{\partial^{2} \psi}{\partial z^{2}}=\left[\frac{1}{r} \frac{\partial(r \widetilde{u})}{\partial r}+\frac{\partial \widetilde{w}}{\partial z}\right]
$$


que discretizada por diferenças finitas de segunda ordem fornece,

$$
\begin{aligned}
& \frac{1}{r_{i}}\left[\frac{r_{i+\frac{1}{2}} \psi_{i+1, j}-\left(r_{i+\frac{1}{2}}+r_{i-\frac{1}{2}}\right) \psi_{i, j}+r_{i-\frac{1}{2}} \psi_{i-1, j}}{(\delta r)^{2}}\right]+\frac{\psi_{i, j+1}-2 \psi_{i, j}+\psi_{i, j-1}}{(\delta z)^{2}} \\
& =\frac{1}{r_{i}}\left[\frac{r_{i+\frac{1}{2}} \widetilde{u}_{i+\frac{1}{2}, j}-r_{i-\frac{1}{2}} \widetilde{u}_{i-\frac{1}{2}, j}}{\delta r}\right]+\frac{\widetilde{w}_{i, j+\frac{1}{2}}-\widetilde{w}_{i, j-\frac{1}{2}}}{\delta z} .
\end{aligned}
$$

Segundo Oishi et al. (2008) o sistema gerado pela Equação B.8 é acrescido das equações para $\psi$ em células de superfície livre, que são obtidas a depender dos vetores unitários $\mathbf{n}=$ $\left[\begin{array}{lll}n_{r} & 0 & n_{z}\end{array}\right]^{\top}$ e $\mathbf{m}=\left[\begin{array}{lll}n_{r} & 0 & -n_{z}\end{array}\right]^{\top}$ considerados. Para exemplificar como essas equações foram obtidas vamos considerar o caso, $\mathbf{n}=\left[\begin{array}{lll}\frac{\sqrt{2}}{2} & 0 & \frac{\sqrt{2}}{2}\end{array}\right]^{\top}$ e $\mathbf{m}=\left[\begin{array}{lll}\frac{\sqrt{2}}{2} & 0 & -\frac{\sqrt{2}}{2}\end{array}\right]^{\top}$ nas etapas abaixo.

• A condição de superfície livre A.13 é igualada a equação para pressão desenvolvida pelo método numérico (Equação B.6). Ou seja,

$$
\begin{aligned}
p^{n}+\frac{\psi^{n+1}}{\delta t}-\frac{1}{\operatorname{Re}} \nabla^{2} \psi^{n+1}= & \frac{2}{\operatorname{Re}}\left[\frac{\partial u}{\partial r} \frac{1}{2}+\left(\frac{\partial u}{\partial z}+\frac{\partial w}{\partial r}\right) \frac{1}{2}+\frac{\partial w}{\partial z} \frac{1}{2}\right]^{n+1} \\
& +\frac{1}{2}\left[S^{r r}+2 S^{r z}+S^{z z}\right]^{n} .
\end{aligned}
$$

$\checkmark$ As derivadas das componentes de velocidade são reescritas considerando a conservação de massa, e para este caso obtém-se,

$$
\begin{aligned}
& p^{n}+\frac{\psi^{n+1}}{\delta t}-\frac{1}{R e} \nabla^{2} \psi^{n+1}= \frac{1}{\operatorname{Re}}\left[-\frac{u}{r}+\frac{\partial u}{\partial z}+\frac{\partial w}{\partial r}\right]^{n+1} \\
&+\frac{1}{2}\left[S^{r r}+2 S^{r z}+S^{z z}\right]^{n}
\end{aligned}
$$

As velocidades $u$ e $v$ em B.10 são substituídas por $\widetilde{u}, \widetilde{w}$ e $\psi$ utilizando a decomposição 2.18:

$$
\begin{aligned}
\frac{\psi^{n+1}}{\delta t}-\frac{1}{\operatorname{Re}} \nabla^{2} \psi^{n+1}+\frac{2}{\operatorname{Re}} \frac{\partial^{2} \psi^{n+1}}{\partial r \partial z}-\frac{1}{\operatorname{Re}} \frac{1}{r} \frac{\partial \psi^{n+1}}{\partial r} & =\frac{1}{\operatorname{Re}}\left[-\frac{\widetilde{u}}{r}+\frac{\partial \widetilde{u}}{\partial z}+\frac{\partial \widetilde{w}}{\partial r}\right]^{n+1} \\
& +\frac{1}{2}\left[S^{r r}+2 S^{r z}+S^{z z}-2 p\right]^{n}
\end{aligned}
$$

$\checkmark$ A Equação B.11 é discretizada por diferenças finitas, fornecendo a Equação B.12 que é acoplada a Equação de Poisson B.8.

$$
\begin{aligned}
& \frac{\psi^{n+1}}{\delta t}-\frac{1}{\operatorname{Re}}\left\{\frac{1}{r_{i}}\left[\frac{r_{i+\frac{1}{2}} \psi_{i+1, j}-\left(r_{i+\frac{1}{2}}+r_{i-\frac{1}{2}}\right) \psi_{i, j}+r_{i-\frac{1}{2}} \psi_{i-1, j}}{(\delta r)^{2}}\right]\right. \\
& \left.+\frac{\psi_{i, j+1}-2 \psi_{i, j}+\psi_{i, j-1}}{(\delta z)^{2}}\right\}^{n+1}+\frac{2}{\operatorname{Re}}\left[\frac{\psi_{i, j}-\psi_{i-1, j}-\psi_{i, j-1}+\psi_{i-1, j-1}}{\delta r \delta z}\right]^{n+1} \\
& -\frac{1}{\operatorname{Re}} \frac{1}{r_{i}} \frac{\psi_{i+\frac{1}{2}, j}^{n+1}-\psi_{i-\frac{1}{2}, j}^{n+1}}{\delta r} \\
& =\frac{1}{\operatorname{Re}}\left[-\left.\frac{\widetilde{u}}{r_{i}}\right|_{i, j}+\left.\frac{\partial \widetilde{u}}{\partial z}\right|_{i, j-\frac{1}{2}}+\left.\frac{\partial \widetilde{w}}{\partial r}\right|_{i-\frac{1}{2}, j}\right]^{n+1}+\frac{1}{2}\left[S^{r r}+2 S^{r z}+S^{z z}-2 p\right]_{i, j}^{n} .
\end{aligned}
$$


O processo descrito acima é aplicado para todas as células $\mathbf{S}$ do domínio (a depender da posição dos vetores normal e tangencial) de modo que ao final obtém-se um sistema não simétrico que é resolvido através do método dos gradientes biconjugados (QUARTERONI; SACCO; SALERI, 2000).

O sistema gerado para calcular $\psi^{n+1}$ requer condições para $\psi$ em fronteiras como entrada, saída de fluido e paredes rígidas. Adota-se em contornos rígidos e entrada de fluido a condição de Neumann homogênea na direção normal (n) a fronteira,$\frac{\partial \psi}{\partial \mathbf{n}}=0$, na saída de fluidos a condição $\psi=0$ é fixada.

No final desse processo utiliza-se $\psi^{n+1}$ para determinar a pressão $p^{n+1}$ na Equação B.6. 


\section{RESULTADOS COMPLEMENTARES: ESCOAMENTO NO TUBO}

O escoamento de Poiseuille é um exemplo de problema com vastos estudos de solução analítica em particular para os modelos Oldroyd-B e UCM. Trata-se de um escoamento numa tubulação em regime permanente, ou seja, no estado estacionário. Aplicando a hipótese de escoamento totalmente desenvolvido, gradiente de pressão constante e utilizando as condições de contorno é possível obter a solução analítica de forma direta, sem a necessidade de alguma aproximação numérica para fluido do tipo Oldroyd-B.

Adota-se um cilíndro de raio $R=1.0 \mathrm{~m}$ e comprimento $H=10 R \mathrm{~m}$ (ver Figura 5) com domínio computacional axissimétrico $\Omega=[0, R] \times[0,10 R]$ como ilustrado na Figura 5 . Incialmente o cilíndro econtra-se vazio e o fluido é injetado na entrada de fluido (INFLOW) impondo o perfil do escoaemento totalmente desenvolvido no tubo. A expressão 2.36 é solução do escoamento de Poiseuille do fluido Oldroyd-B no regime desenvolvido. Quando a simulação numércia atingir o mesmo regime de escoamento espera-se que o método numérico obtenha solução cada vez mais próxima de 2.36 ao refinar a malha computacional.

Os dados utilizados que caracterizam o escoamento são: $L=R=1 \mathrm{~m}, U=1 \mathrm{~m} \mathrm{~s}^{-1}$, $\rho=1000 \mathrm{~kg} \mathrm{~m}^{-3}, \eta_{0}=4000$ Pa.s, $\lambda_{1}=1.0 \mathrm{~s}, \lambda_{2}=0.2 \mathrm{~s}(\beta=0.2)$. Portanto, $R e=\frac{\rho U L}{\eta_{0}}=0.25$ e $W i=\lambda_{1} \frac{U}{L}=1$. As malhas computacionais utilizadas foram geradas utilizando os dados presente na Tabela 18, e o problema foi simulado até o tempo $t(U / L)=100.0$ observando que neste instante o escoamento já atingiu regime permanente.

A Figura 60 apresenta as soluções obtidas para $w\left(r, z_{m}\right), \tau^{z z}\left(r, z_{m}\right)$ and $\tau^{r z}\left(r, z_{m}\right)$. Estas soluções foram obtidas no meio do cilíndro em $z_{m}=5 R$. Para comparações, a solução exata também foi plotada na Figura 60. Pode-se ver que as soluções numéricas em diferentes malhas concordam bem com a solução analitica 2.36. Além disso, as Tabelas 19 e 20 mostram que os erros calculados com a norma definida pela Equação 2.37 decai quando a malha é refinada e a 
Tabela 18 - Malhas utilizadas para simular o escoamento de Poiseuille do fluido Oldroyd-B.

\begin{tabular}{l||c|c|c|c}
\hline Malha & M10 & M20 & M30 & M40 \\
\hline \hline$\delta=\delta r=\delta z$ & 0.1000 & 0.0500 & 0.0333 & 0.0250 \\
Células na malha & $(10 \times 100)$ & $(20 \times 200)$ & $(30 \times 300)$ & $(40 \times 400)$ \\
$\delta t$ & $6.25000 \mathrm{E}-05$ & $1.56250 \mathrm{E}-05$ & $3.47222 \mathrm{E}-06$ & $1.95312 \mathrm{e}-06$ \\
\hline
\end{tabular}

Fonte: Dados da pesquisa.

ordem de convergência determinada pela Equação 2.38 tende para dois (ver Figura 61). Esses resultados evidênciam que a ordem de convergência da solução numérica está de acordo com as aproximações de diferenças finitas de segunda ordem aplicadas para resolver as equações.

Figura 60 - Comparação de (a) $w(r)$; (b) $\tau^{z z}(r)$ e (c) $\tau^{r z}(r)$ obtidas nas malhas M10, M20, M30 e M40 com a respectiva solução exata obtida para o escoamento de Poiseuille.

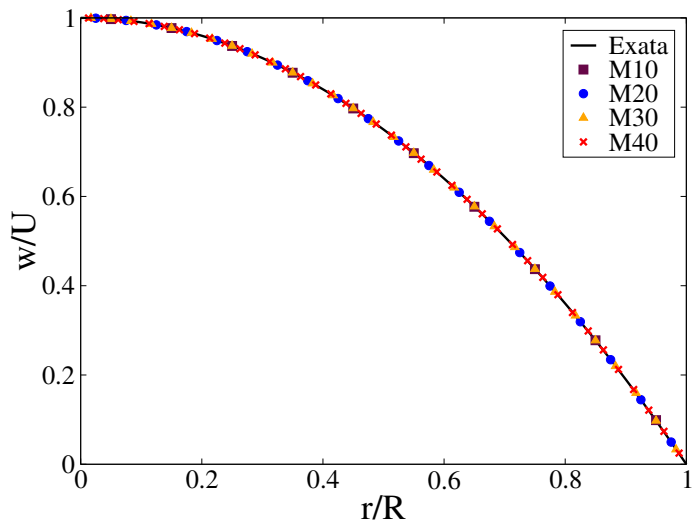

(a)

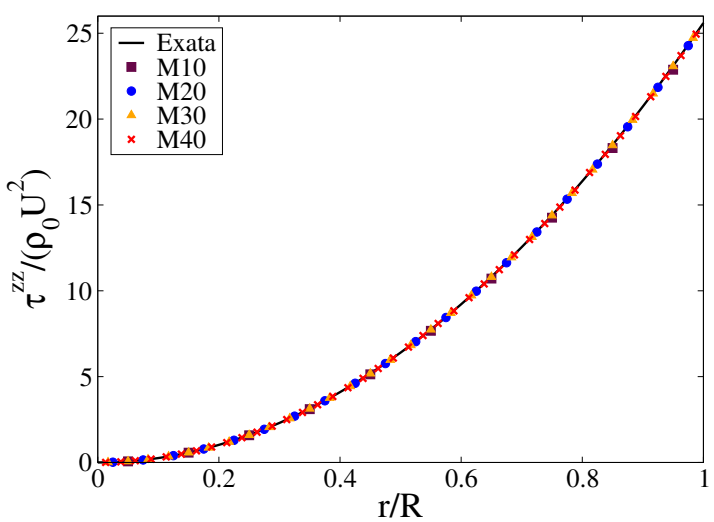

(b)

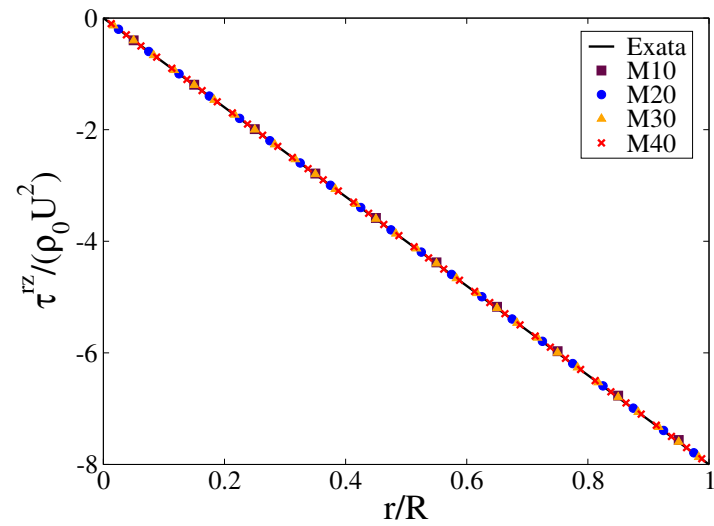

(c)

Fonte: Elaborada pelo autor. 
Tabela 19 - Erros adimensionais entre as soluções exata e numéricas calculadas nas malhas M10, M20, M30 e M40 do escoamento de Poiseuille.

\begin{tabular}{c||c|c|c}
\hline Malha & $E\left(w\left(r, z_{m}\right)\right)$ & $E\left(\tau^{r z}\left(r, z_{m}\right)\right)$ & $E\left(\tau^{z z}\left(r, z_{m}\right)\right)$ \\
\hline \hline M10 & $1.683826 \mathrm{e}-03$ & $2.280432 \mathrm{e}-02$ & $1.124021 \mathrm{e}-01$ \\
M20 & $4.260340 \mathrm{e}-04$ & $5.749979 \mathrm{e}-03$ & $2.845901 \mathrm{e}-02$ \\
M30 & $1.898501 \mathrm{e}-04$ & $2.559584 \mathrm{e}-03$ & $1.267881 \mathrm{e}-02$ \\
M40 & $1.065525 \mathrm{e}-04$ & $1.440446 \mathrm{e}-03$ & $7.137775 \mathrm{e}-03$ \\
\hline
\end{tabular}

Fonte: Dados da pesquisa.

Figura 61 - Decrescimento do erro como função do espaçamento da malha $\delta$ do escoamento de Poiseuille.

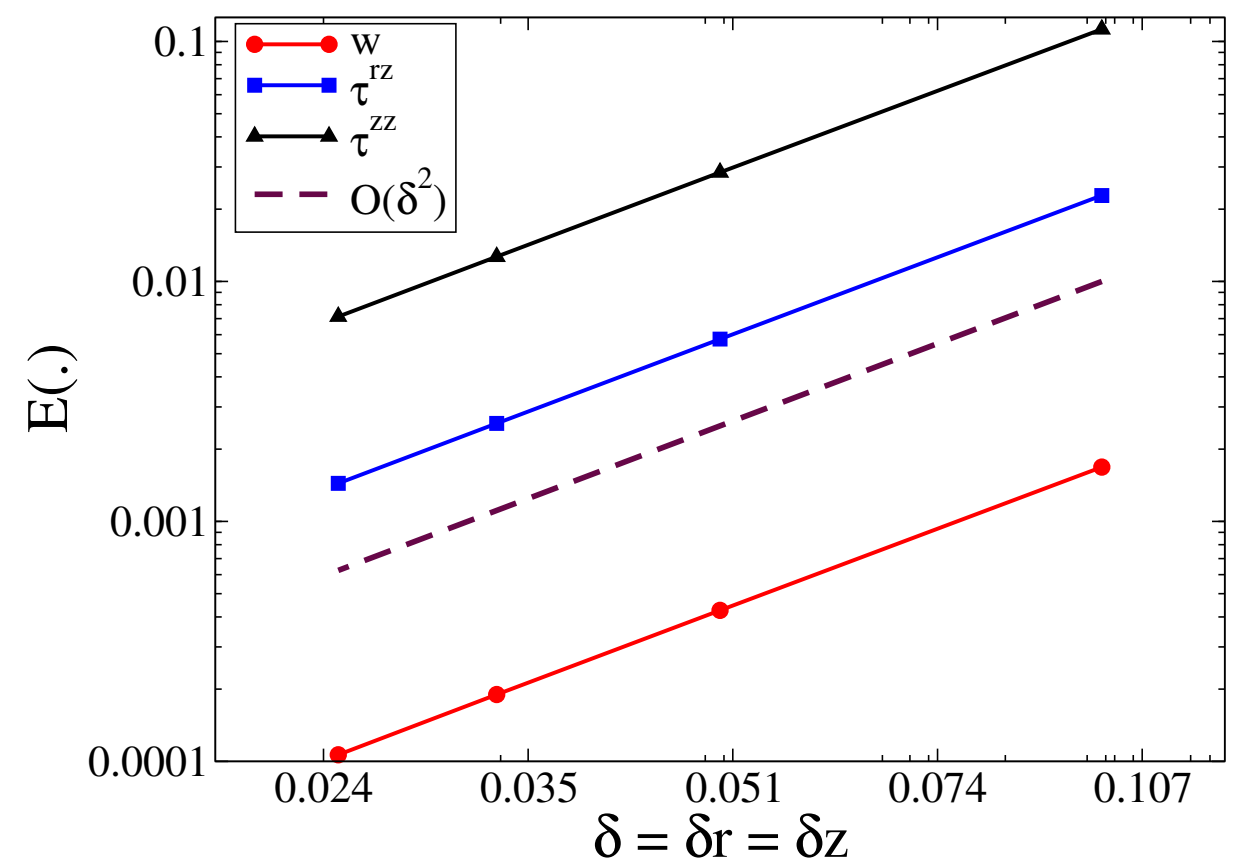

Fonte: Elaborada pelo autor.

Tabela 20 - Ordens de convergência obtidas no escoamento no tubo com $\beta=0.2$.

\begin{tabular}{c||c|c|c}
\hline Ordens & $w\left(r, z_{m}\right)$ & $\tau^{r z}\left(r, z_{m}\right)$ & $\tau^{z z}\left(r, z_{m}\right)$ \\
\hline \hline$O(\mathrm{M} 10, \mathrm{M} 20)$ & $1.983 \mathrm{e}+00$ & $1.988 \mathrm{e}+00$ & $1.982 \mathrm{e}+00$ \\
$O(\mathrm{M} 20, \mathrm{M} 30)$ & $1.993 \mathrm{e}+00$ & $1.996 \mathrm{e}+00$ & $1.994 \mathrm{e}+00$ \\
$O(\mathrm{M} 20, \mathrm{M} 40)$ & $1.999 \mathrm{e}+00$ & $1.997 \mathrm{e}+00$ & $1.995 \mathrm{e}+00$ \\
$O(\mathrm{M} 30, \mathrm{M} 40)$ & $2.007 \mathrm{e}+00$ & $1.998 \mathrm{e}+00$ & $1.997 \mathrm{e}+00$ \\
\hline
\end{tabular}

Fonte: Dados da pesquisa. 


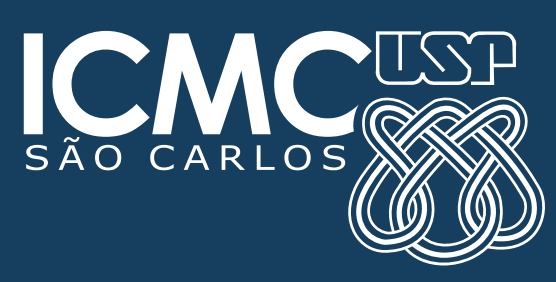

